Copyright: The author, Charlotte Whitby-Coles, 2008 .

\title{
Black Mountain:
}

\section{The politicisation of a pilgrimage site in western India}

Charlotte Whitby-Coles

April 2008

Department of Sociology and Anthropology

School of the Environment and Society

Swansea University

Submitted to Swansea University in fulfilment of the requirements for the Degree of Doctor of Philosophy 


\section{DECLARATION}

This work has not previously been accepted in substance for any degree and is not being concurrently submitted in candidature for any degree.

Signed

(candidate)

Date

\section{STATEMENT 1}

This thesis is the result of my own investigations, except where otherwise stated. Where correction services have been used, the extent and nature of the correction is clearly marked in a footnote(s).

Other sources are acknowledged by footnotes giving explicit references. A bibliography is appended.

Signed (candidate)

Date

\section{STATEMENT 2}

I hereby give consent for my thesis, if accepted, to be available for photocopying and for inter-library loan, and for the title and summary to be made available to outside organisations.

Signed

(candidate)

Date 


\section{Summary}

A once unremarkable site of multi-faith pilgrimage to a Sufi Saint has been transformed and its local history rewritten - this thesis presents a case study of research undertaken around the pilgrimage site of Kalo Dungar or Black Mountain, which is situated in the Rann of Kutch, Gujarat, India. It is based on traditional anthropological participant-observation fieldwork, as well as on library and archival research. The research is presented in the methodological framework of 'ethnography as methodology'; this has enabled the researcher to present a linear journey reflecting the research process. A key element of this presentation, as well as the text of this doctoral thesis, is a film (DVD), Black Mountain. Both text and film suggest that the pilgrimage site of Kalo Dungar provides a micro-example of current issues in India today by highlighting the development of politically motivated religious orthodoxy across India; and that the nature of Kalo Dungar has been altered due to Hindu right-wing religio-political interests and actions, as is vividly demonstrated in the film. It is argued, by using theoretical insights gained by critically examining the cyclical process of syncretism and anti-syncretism, that this trend is aiding the slow break-down of communal harmony and of syncretic and pluralistic practices. 


\section{Contents}

Page Numbers

Declaration and Statements

Summary

Contents

iii

Acknowledgements

vi

List of Figures

ix

Chapter 1 - Introduction

- Background

- Theoretical Position of Research

- The visual element; a linear approach to ethnography

- Chapter outline

$\begin{array}{ll}\text { Chapter 2 - Methodology } & 10\end{array}$

- Epistemology 10

- Reflexivity in the field 13

Reflexivity in Film Making $\quad 18$

Culture Shock 20

- The Research Methods: 21

Participant Observation 21

Participant observation and gaining access to the field 22

Participant observer roles 26

Key Informants $\quad 29$

Interview Methods $\quad 32$

Field Notes $\quad 35$

Visual Methods 38

- Ethics in research 42

- Conclusion 53

Chapter 3 - India's Pledge $\quad 54$

an insight into India's political history and the growth of religious communalism

- Political background 1885 - 1947 (pre-independence) 55

The breakdown of unity and the development of a separate 57

political consciousness

Establishment of separate electorates and the Lucknow pact 58 
The non-cooperation movement and the Khilafat movement 60

Beginnings of communalism 62

The birth of Hindutva, the RSS and Hindu nationalism 64

The battle for Independence $\quad 67$

- 1947 Indian Independence 73

The Nehru era 73

The formation of the Vishwa Hindu Parishad - VHP 79

Indira Gandhi takes the helm - $1966 \quad 81$

- Contemporary Communal Conflict since 1980s 88

1980s revival of Hindu nationalism 88

The Shah Bano affair $\quad 89$

VHP apolitical politics: Ekatmata Yatra -The first of many 90 political pilgrimages

Ayodhya - the end of secular politics 92

- 1990s Ayodhya and the continued success of Hindu 98

nationalism

- Into the $\mathbf{2 1}^{\text {st }}$ century 107

The Gujarat pogrom 107

Post Gujarat to 2007

- Conclusion 115

Chapter 4 - Ethnography Part 1: Kalo Dungar and Dattatreya 116

- Introduction 116

- Kalo Dungar $\quad 118$

- Where is Kalo Dungar? 118

- Experiencing the Great Rann of Kutch 121

- Falling in love with Bhuj 121

- The Pilgrimage to Kalo Dungar 124

- A digression: the border near Kalo Dungar 146

- Leaving Kalo Dungar 147

- Back in Bombay 149

Chapter 5 - Syncretism: traditions of shared faith worship 150 in India

- Anthropology and syncretism 150

- What is meant by syncretism? 151

- Syncretism as opposed to acculturation 154

- Why is the concept of syncretism important for this 155 research?

- History of syncretic traditions in the sub-continent 156

- The Aryans 157

- The Mauryan Dynasty 158

- The Arabs 160

- The Sultanate Period 161

- The Mughal Emperors 161 
Akbar

- The Sufis 164

Universal and Local Saints - Legends of Miracles 169

Syncretic Rituals $\quad 172$

- The Bhakti Movement 176

- The Ismailis 178

- Conclusion 180

Chapter 6 - Ethnography Part 2: Kalo Dungar and Pachmai Pir 183

- On the way to Ahmedabad 184

- Ahmedabad 185

- Back in Bhuj 192

- Drobhana 215

- Back in Bhuj 231

- Back in Drobhana 237

- Back in Bombay 246

- Conclusion 257

Chapter 7 - Anti-syncretism $\quad 262$

- Power as a factor of anti-syncretism 263

- The breakdown of legitimacy and the secular practice $\quad 270$ of the state

- Crisis of secularism 272

- Communal violence \& riots 276

- Fascism 288

- Ritual/pilgrimage, violence/ contestation and the 292 politicising of dargahs

- Conclusion 302

$\begin{array}{ll}\text { Chapter } 8 \text { - Conclusion } & 307\end{array}$

$\begin{array}{lr}\text { Chapter } 9 \text { - Bibliography } & 310\end{array}$ 


\section{Acknowledgments}

First and foremost I want to thank my husband Amin Hajee for his unfaltering devotion and support; for nursing me through numerous illnesses and nursing me through the emotional breakdowns that were far too common over the last couple of years. For co-directing, co-filming and editing Black Mountain, the film that accompanies this thesis; without him the film would not have been possible. His insights into film-making, his experience in the field and his dedication to learn how to edit in order to make the film possible have been un-quantifiable. All this at the same time as fighting a whole Indian village whose residents were unhappy about a home we had bought sitting prettily in their jurisdiction! He has given me the selfassurance over the last few years to believe in myself and my self-ability, by consistently boosting my confidence. Without him and his support I would have neither, undertaken this $\mathrm{PhD}$, nor would I ever have completed it.

I want to thank Prof. Margaret Kenna - my supervisor. Her support and confidence in my ability has never failed to amaze me; if she doubted that I would ever complete this $\mathrm{PhD}$, which I am sure she must, as I did, she never once revealed it. Her patience and endurance while coping with me living most of the last five years in India communicating only by email, she has quietly given me the confidence to believe in myself. And in the final stages of preparing this thesis her inputs and dedication in helping me produce the best piece of work I could, have been remarkable.

I see this thesis as a product of both Amin's and my supervisor Prof. Margaret Kenna’s uncompromising support.

I would also like to thank Dr Felicia Hughes Freeland, my second supervisor, for her advice and support during the last stages of the film-making process and for reading through my chapter drafts.

I want to thank my Mum and Dad for always supporting me whatever my decisions both emotionally and financially and for providing me with a stable and happy 
upbringing that has enabled me to always believe in, and live my dreams. I would also like to thank all of my family in England who have encouraged me and my crazy dreams and supported me throughout my life.

I would like to thank my family in India, especially Shefali, Karim and Kaashif with whom I have lived in India for the past seven years, they have supported me in immeasurable ways and made sure that life for me in India has always been comfortable and happy.

Very Importantly I would like to thank all the people from across the globe who have enabled my research to take place, specifically Reena D’Souza who has couriered books and books from England to India over the past couple of years. Mr Prakash Shukla and Mr Mohammed Khatri my research assistants in Bhuj, Dr Rao for his help with officials in Kutch and Ranju for providing a peaceful haven in Bhuj. I would like to thank too, all the people who agreed to be a part of this research both visually and textually including the Lakhia family in Ahmedabad. As well as all those people who have helped with technical issues during the making of the film including Jamie Whitby-Coles (Final Voice Over), Baloo Saluja (Editing), Saeed Khan (Editing), Nakul Kamte (Sound), Sanjay (Voice Over), Robin (Avid), Vikas (FCP), Anthony (Avid, Bristol) I would also like to thank Vandana Malik from CNN IBN for her assistance in providing the archival footage used in the film.

Thank you too to all those who have painstakingly watched Black Mountain over and over again, and given their reactions to it in its early stages.

I would like to especially thank two dear friends, Kiran Rao and Aamir Khan who have given me their home for the past 16 months, it has provided a beautiful stable environment for me to write and think whilst surrounded by 'feisty' villagers. Without this and their emotional support, I am not sure I would have been able to complete this thesis. On top of this access to their personal library of interesting books was a welcome boon. 
I would also like to thank Howard Lee and Sue Odell in whose flat I have stayed for weeks on end while undertaking archival research in London and I would like to thank Dr Mike Ireland for spurring my first interest in Anthropology all those years ago! And Dr Chris Stray for his help in Latin translations.

I would like to thank too all those people in Panchgani and Wai who have supported me during the last year of this $\mathrm{PhD}$ candidature, it has been a particularly difficult year due to the problems we have faced in buying our house.

And finally I would like to thank the University of Wales, Swansea for providing the financial backing for me to undertake this piece of research. 


\section{List of Figures}

Figure Description

Page Numbers

Figure 1 Map of India 1

Figure 2 Map of Gujarat 3

$\begin{array}{lll}\text { Figure } 3 \quad \text { Map of Kutch } & 118\end{array}$

$\begin{array}{lll}\text { Figure } 4 & \text { Religious composition of Kutch } & 119\end{array}$

$\begin{array}{lll}\text { Figure } 5 & \text { Swami Narayan Temple Bhuj } & 125\end{array}$

$\begin{array}{lll}\text { Figure } 6 & \text { Swami Temple Pujari and pilgrims } & 128\end{array}$

$\begin{array}{lll}\text { Figure } 7 & \text { Pilgrims on the road } & 132\end{array}$

$\begin{array}{lll}\text { Figure } 8 & \text { Boys on cycles } & 132\end{array}$

$\begin{array}{lll}\text { Figure } 9 & \text { Population composition of Khavda } & 136\end{array}$

$\begin{array}{lll}\text { Figure } 10 & 137\end{array}$

$\begin{array}{lll}\text { Figure } 11 \quad \text { Khavda } & 138\end{array}$

$\begin{array}{lll}\text { Figure } 12 \text { The salt plains of the Rann of Kutch } & 140\end{array}$

$\begin{array}{lll}\text { Figure } 13 & \text { Temples at Kalo Dungar } & 140\end{array}$

Figure 14 Lord Dattatreya Temple and Icon of Lord Dattatreya 141

$\begin{array}{lll}\text { Figure } 15 & \text { Sleeping area for pilgrims } & 143\end{array}$

$\begin{array}{lll}\text { Figure } 16 & \text { Local women resting and reciting prayers } & 144\end{array}$

$\begin{array}{lll}\text { Figure } 17 & \text { The legend enacted at Kamar'ali Dervesh. Caretaker prepares } & 172\end{array}$ the area for stone-lifting ritual and the pilgrims gathering.

Placing their fingers under the stone chanting in unison as they lift the stone

$\begin{array}{lll}\text { Figure } 18 & \text { Cloth used to drape over the tomb and avenues of hawkers } & 173\end{array}$

Figure 19 Threads tied on the dargah - tomb structure left behind by 173

$\begin{array}{lll}\text { Figure } 20 \text { Driving to Ahmedabad - trucks and road side hawkers } & 185\end{array}$

$\begin{array}{lll}\text { Figure } 21 \quad \text { Map illustrating area of Pachham } & 196\end{array}$

Figure 22 Maps illustrating the area of Pachham in which Kalo 196

$\begin{array}{lll}\text { Figure } 23 & \text { Khatri Bhai in his home } & 198\end{array}$

Figure 24 Wazir Bhai discussing the meaning of Pir 201

Figure 25 Pragmal Palace and entrance board to Aina Mahal 202 
Figure

Description

$\begin{array}{lll}\text { Figure } 26 & \text { Mr Pramod Jethi and the Aina Mahal }\end{array}$

$\begin{array}{lll}\text { Figure } 27 & \text { Interview with Mr Vaidya } & 206\end{array}$

Figure 28 Population composition of Drobhana 215

Figure 29 Khatri Bhai inquiring for Lakhmeer in Drobhana 215

Figure $30 \quad$ Khatri Bhai with Amar Mehraj Sama 216

$\begin{array}{lll}\text { Figure } 31 \quad \text { Driving to Lakhmeer's house } & 216\end{array}$

$\begin{array}{lll}\text { Figure } 32 & \text { Lakhmeer and Amar Mehraj Sama } & 217\end{array}$

Figure 33 Children in Drobhana 222

Figure 34 Lunch at Lakhmeer's house 223

Figure 35 Hussain Ali with Amar and Lakhmeer in Drobhana 225

Figure $36 \quad$ Footprints on Kalo Dungar 228

Figure 37 Image of footprint from Kalo Dungar brochure 229

$\begin{array}{lll}\text { Figure } 38 & \text { Dharmendra Shah, Bhuj Librarian and bookshop caretaker } & 232\end{array}$

Figure 39 Outside Drobhana shop; inside shop; three local men 239

Figure $40 \quad$ Mohammed Ali Shah - descendant of the Pir, in the local shop 241

Figure $41 \quad$ Local shop in Raterdiya. Myself and Mohammed Ali Shah. 243

Figure 42 Chief Officer of the Local Municipality of Bhuj at Kalo Dungar 248 VHP Rally

Figure 43 Politician speaking at rally on Kalo Dungar 250

Figure $44 \quad$ Pilgrims gathered for the political speeches at Kalo Dungar 251

Figure 45 Argument in salon - Taufeeq and Maulvi 256

$\begin{array}{lll}\text { Figure } 46 & \text { Droogers' table of religious construction } & 267\end{array}$

Figure 47 Table illustrating elements of Schismogenesis 278

Figure $48 \quad$ Power, syncretism, anti-syncretism 305

Figure $49 \quad$ Flow of causation - syncretism $\rightarrow$ anti-syncretism 306 


\section{Chapter 1}

\section{Introduction}

\section{Background}

This thesis is based on research undertaken in India. In essence it highlights the important part played by religion in asserting a sense of identity in a country which 'does not enjoy well-defined borders, lacks internal peace and stability and is yet to attain a cohesive national identity' (Kumaraswamy 2004:14).

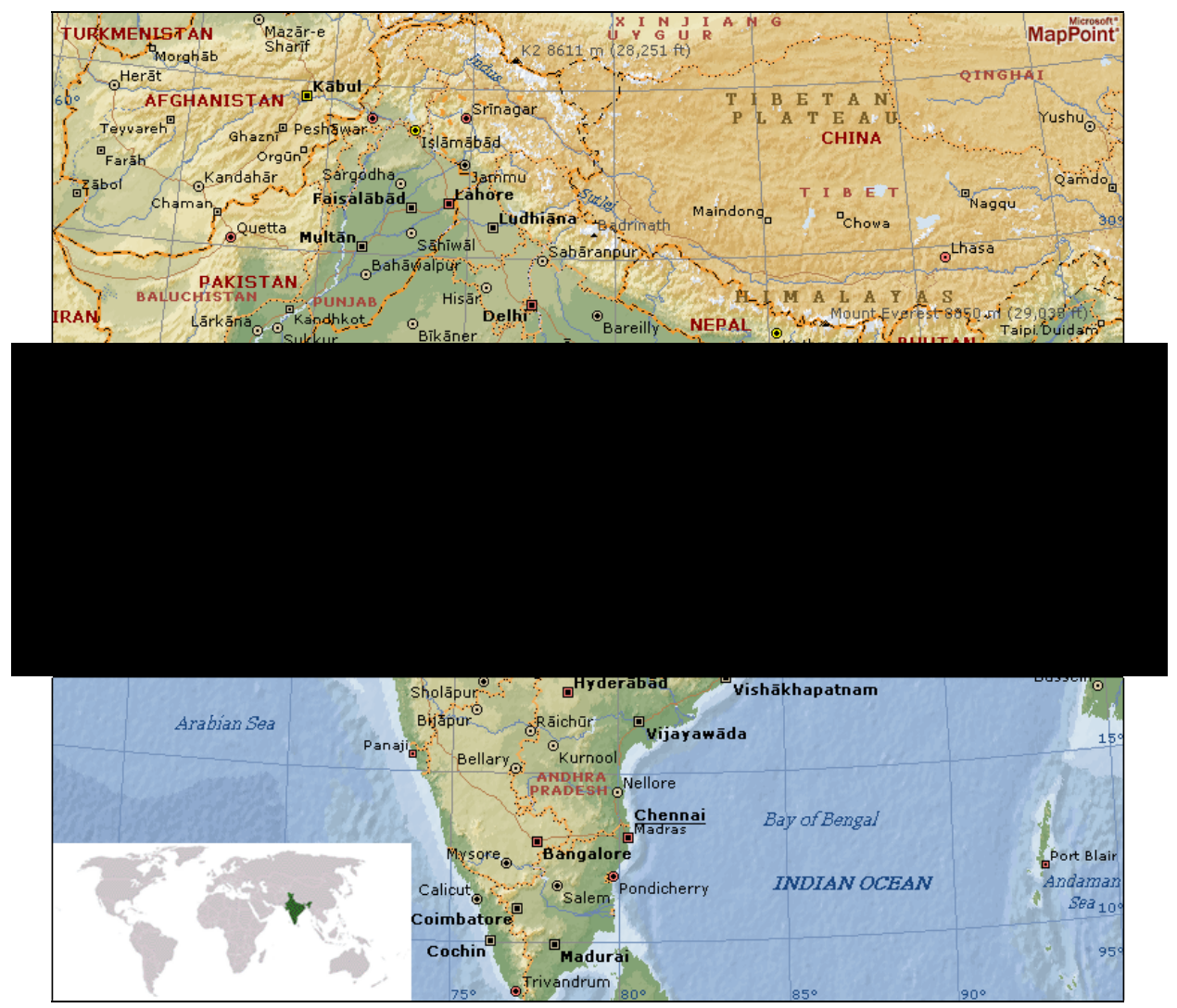

Fig.1.Map of India. Source: Microsoft map point 2006

This statement may come as a surprise to those who have understood India as a country abounding in peaceful non-violent traditions. India is famous, at least in Britain, as a land once colonised and ruled for ninety years by the British Crown ${ }^{1}$; more significantly worldwide for Mahatma Gandhi whose name is synonymous with India's Independence and his non-violent methods of trying to establish India's right to freedom and democracy; of being a developing country struggling to cope with its

\footnotetext{
${ }^{1}$ India was ruled under the British crown from 1857 to 1947 . However, prior to this, India was ruled by a British company, namely the East India Company, for over a hundred years.
} 
increasing population and fight against poverty; and for surviving, since its Independence, as the largest democracy of the modern world which in present times enjoys a growing and thriving economy. It is a country, now sixty-one years into its independent era, that some argue has failed to measure up to the 'potential and promises it held out in 1947' (Kumaraswamy 2004:12). Kumaraswamy asserts that rather than thriving since its Independence in 1947, India has been surviving.

What most people do not always associate with India is the religious-based communal unrest and violence that occur increasingly across the country. Because of this, two Prime Ministers in office, Indira Gandhi and her son Rajiv Gandhi, and the 'Father of the Nation', Mahatma Gandhi himself, have all been assassinated. As the quote that opens this chapter states, India lacks a 'cohesive national identity'. The most obvious example of this lack of cohesion is the existing caste system within the majority Hindu community and the increasing hatred between religious, and in some areas, ethnic communities, of which the most obvious example is the relationship between the Hindu and Muslim population. Much of India's HinduMuslim unrest, although by no means exclusively, can be traced back to political infighting that took place from the early 1920s through to the time of India's Independence in 1947. The 1920s witnessed the growth of Hindu nationalism with the formation of the RSS (Rashtriya Swayamsevak Sangh), established in response to the conflicts that arose in the aftermath of the Non-Cooperation Movement of Mahatma Gandhi. The RSS is considered 'the main driving force of Hindu Rashtra' and is a movement that believes in the creation of a Hindu nation (Basu et al 1993:13). This belief remains the core philosophy that binds the number of Hindu right-wing organisations operating in India today. The 1920s also saw the development of the Muslim League who established themselves as a party that would represent and look after the interests of the minority Muslim population. The establishment of these religious-centric organisations and the subsequent conflict they encouraged between the Hindu-Muslim populations, it can be argued, laid the cornerstone of communal unrest as we witness it today. This unrest culminated in the partition of the subcontinent at the time of India's Independence into India and Pakistan, where two countries were established on the basis of religion. Partition was an event that 'remains the single largest episode of uprooting of people in modern history, as between twelve to fifteen million left their homes to take up 
residence across the border...the consequences [of which] are there to be seen: India and Pakistan continue to be embroiled in conflict' (Lal 2002, Purewal 2003). The border that was created stretches across a vast amount of land 'running nearly $3000 \mathrm{~km}$ ' dividing the regions of Kashmir, the Punjab, Rajasthan, and the desert area of Sindh in Pakistan and Kutch in Gujarat, India, (Purewal 2003:547). The psychological scars of partition are most certainly still evident in the psyche of India and Pakistan today.

The focus of this research is Kalo Dungar or Black Mountain which is a hill in the district of Kutch in the state of Gujarat ${ }^{2}$. From the top of Kalo Dungar one can see for miles across the Great Rann of Kutch, which forms the environmental and physical border that divides India from Pakistan in this region. Kalo Dungar lies $20 \mathrm{~km}$ from the nearest town of Khavda and $80 \mathrm{~km}$ from Bhuj, the largest city in Kutch.

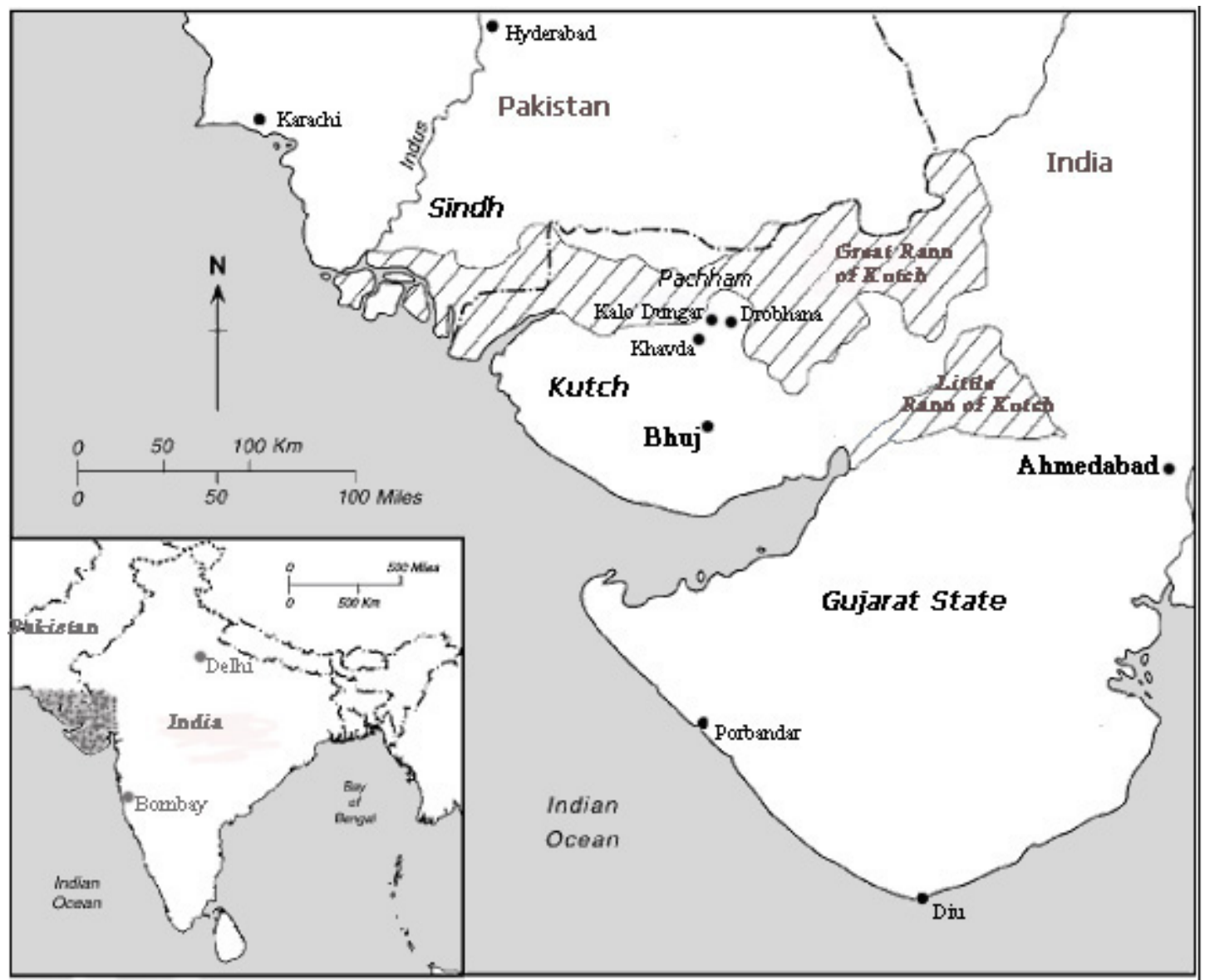

Fig.2.Map of Gujarat depicting the region of Kutch and the significant geographical points of Bhuj, Khavda, Kalo Dungar and Drobhana.

Source: Simpson \& Corbridge (2006) the map has been significantly altered from the source.

${ }^{2}$ Covering an area of 45,612 km², Kutch is the second largest district in India (Jadiya 1997). 
At the top of Kalo Dungar is a pilgrimage site, this has been a holy site, and gathering point for many of the nomadic communities that have roamed the region of Kutch and Sindh for a number of generations, and continues to be regarded as such. I initially embarked upon my $\mathrm{PhD}$ researching religious pilgrimages and festivals across the states of Maharashtra and Gujarat. Whilst in Bhuj, with my then fiancé, now husband, Amin Hajee, we were informed that pilgrims would be embarking upon an 85km journey on foot to the site of Kalo Dungar. Those who wanted to join the pilgrims were to meet at a central point, a temple, in the old market of Bhuj, which we did. It soon became apparent that the pilgrimage was a front for a political rally organised by senior political figures of the RSS and its sister concern the VHP (Vishnu Hindu Parisad). The VHP is one of the most successful and largest of the right-wing organisational bodies in India today. The reason for its involvement was that Kalo Dungar, lying on the border with Pakistan, where a significant majority of the local people are Muslim, was a perfect place to activate political communal activity.

This initiated the discovery that religious sites, which for centuries had been visited by pilgrims of many faiths, especially Hindus and Muslims, were being 'Hinduised' by right-wing political organisations, who were capitalising on the development of orthodox Islamic communities, who in turn were abandoning their worship at such shrines as they were taught the 'true ways' of Islam.

My research into Kalo Dungar drew my attention to India’s turbulent communal history based on its religious-centric beliefs ${ }^{3}$. But I also learned that India had a history in which cultural pluralism and religious syncretism held a strong place, a history where religious cultures and beliefs synthesised and where people have lived in relative communal harmony. It has become evident that this pluralism is currently being slowly broken down by various anti-syncretic elements. Attempts by rightwing Hindu political and apolitical parties to 'Hinduise' shared faith religious sites, like Sufi shrines, are less well documented, and my research attempts to address this gap.

\footnotetext{
${ }^{3}$ A history of the development of communal politics is given in Chapter 3 - India's Pledge. For an in depth insight into India’s political history and communal politics see: Bhatt 2001; Bose \& Jalal 1997; 1998, Chandra et al 2000; Corbridge \& Harris 2000; Jaffrelot 1996; Keay 2000, 2004; Ludden 2005; Metcalf \& Metcalf 2006; Van Der Veer 1994; Wolpert 2004.
} 
The Sufis, sometimes described as the Protestants of Islam, were mystics who followed the more spiritual side of the Islamic faith in their endeavour to become closer to God. They acquired a reputation of being tolerant towards other faiths and as preachers of communal harmony. The regions of Sindh and Kutch are just one example of the existence of syncretic traditions: 'Sindh is known for its deeply rooted Sufi traditions which brought together Sindhi Hindus and Muslims in a shared cultural world characterized by reverence of common saints' (Sikand 2006). This same tradition exists throughout India especially in the Punjab, Bengal, Maharashtra, Karnataka, Rajasthan and Kutch. These syncretic cultural traditions in which places of worship overcame religious divisions, brought communities otherwise defined and divided by regions and religious practice, together in common devotion. The Sufis were also referred to as Pirs, or Saints, who trace their lineage to Prophet Mohammed and are generally known as Saiyeds. There are pilgrimage places to Pirs throughout India and Pakistan many of which, to this day, are frequented by all ethnic groups and faiths, despite the political attempt to convert them into pure Hindu or Muslim places of worship. Sites such as Sai Baba at Shridi, Haji Malang at Kalyan (both in Maharashtra), Pirana in Gujarat, and Baba Budhan in Karnataka, are just a few examples drawn upon in this thesis, as well as the case study of Kalo Dungar. I argue that the history of the Saints worshipped at these specific shrines has been manipulated over the years and on many occasions the Saints, who find their roots in Islam, have had their histories rewritten as reincarnations of Hindu gods. Large sections of the Muslim community too have stopped venerating at Sufi shrines as they are informed by orthodox leaders that true, pure, Islam does not support the veneration of remains at mausoleums and the veneration of Saints, per se. And so these sites and Saints are abandoned by those who had devotedly worshipped them in the past.

India's very survival and existence over the years, even before partition, depended on 'Unity in Diversity'. Though its unity has been constantly challenged, it has survived. The strength of secularism in India has been in the deep-rooted pluralistic and syncretic traits mentioned above that have created a unity within the country. This case study of Kalo Dungar provides what I believe to be microcosm of what India faces today on a national scale: 
...the anthropologist is inclined to turn...[to] the microscopic. We are the miniaturists of the social sciences, painting on Lilliputian canvases with what we take to be delicate strokes. We hope to find in the little what eludes us in the large, to stumble upon general truths while sorting through special cases (Geertz 1968:4).

\section{Theoretical Position of Research}

A detailed account of the theoretical argument of the thesis is given in Chapter Seven, but before proceeding with the main ethnographic aspects of the research, I will briefly sketch how the concepts of 'syncretism' and 'anti-syncretism', have provided the theoretical framework on which this thesis is grounded.

The thesis draws on diverse theoretical perspectives in an attempt to analyse the different behaviours that were revealed during the fieldwork process. These perspectives are outlined in detail in Fig.49 (page 301) of the thesis and explained in detail in the same chapter. The framework stems out of the idea of a cycle of development from syncretism to anti-syncretism and back again - a cycle conceived of as a spiral rather than a closed circle. There are three main theoretical ideas that are applied to illuminate the progression of this spiral cycle from syncretism into anti-syncretism. First, it is suggested that through varying stages in history there have been active periods where syncretism has ignited anti-syncretic behaviour due to the battle of power and purity that has arisen. Second, it is also put forward that anti-syncretism has developed out of a complex series of activities including struggles between power and politics, and the breakdown of political legitimacy and secular practices which have produced communal conflict. This is understood in the thesis through the process of schismogenic reactions that develop when there is a change in the norms of individual behaviour resulting from ongoing interaction between different groups, ultimately ending in conflict when two different communities, such as Hindu and Muslim, are pitted against, or confront, each other. The conflicts that occur are not necessarily due to natural schismogenic reactions but are instigated through what Brass (2001) describes as 'institutionalised riot systems'. This kind of riot system supports the basis of fascist politics as seen to be practised by the Hindu right. Third, it is further suggested that pilgrimage has been, and is often used as, a ritual in helping to execute the types of organised conflict and contestation that have been witnessed in India. Kalo Dungar is an example of this 
kind of contestation. The research indicates that a possible cause of the factors mentioned above is the challenge presented to the long-term development of syncretism that has been the result of centuries of cultural and religious amalgamation in the sub-continent. Syncretism is ambiguous as a term and presents ambiguous religious practice, it does not provide clear boundaries that communities

prefer to be able to define for themselves. This anomaly is then dealt with in varying ways; one way is its eradication or clarification. Kalo Dungar is just one example of how this eradication and clarification is being achieved by both the Hindu and Muslim communities across the sub-continent.

The spiralling cycle that sees syncretism producing anti-syncretic behaviour is one that experiences different levels of progression and effect, there are periods of less activity followed by an intense increase in activity, ensuring that communal relations are damaged almost irrevocably as they degenerate following each outbreak of communally motivated anti-syncretic behaviour.

\section{The visual element; a linear approach to ethnography}

An important aspect of this thesis is the ethnographic film that accompanies it. During fieldwork, as explained in the following Methodology chapter, a film camera was used to record events and interviews. The resulting footage was then edited into the film Black Mountain. This film is an integral part of the thesis; it is a visual version of the text which provides the reader with images, insights, and interpretations of the events at Kalo Dungar. However, the film, it is hoped, can also stand alone as an introduction to these events.

The film depicts the journey of the research process and its findings as it progressed and the written ethnography does the same. It was important that the written ethnography followed the same linear pattern primarily in order to present the two genres of ethnography as one entity, but also because I wanted to present the written thesis as a journey of the research process. 
For a reader of this research who is not familiar with Indian religio-political history it is important that each aspect of the research is understood in the context of Indian religio-political history, hence the layout of the thesis chapters:

\section{Chapter outline}

Chapter 2: Methodology: gives a clear account of the research methods used to gather material for this thesis and the reasons for the specific methods chosen, including the use of film.

Chapter 3: India's Pledge: gives some background to the political history of India since 1885 through to the last sixty-one years of Independence, with specific reference to the growing trend of right-wing religious orthodoxy in politics and society.

Chapter 4: Ethnography Part 1: describes the pilgrimage site of Kalo Dungar, and the researchers pilgrimage to the site in December 2003.

Chapter 5: Syncretism: Traditions of shared faith worship in India: introduces and reviews the disputed term 'syncretic', which is used to describe multi-faith religious practices, with specific reference to the Indian sub-continent.

Chapter 6: Ethnography Part 2: describes the journey of discovery undertaken to find out why there was such communal interest in the pilgrimage site of Kalo Dungar.

Chapter 7: Anti-syncretism: the development of anti-syncretic behaviour is discussed as an inevitable reaction to syncretism by those in support of 'purity' as well as in the context of the breakdown of political legitimacy and the subsequent crisis of secularism which has lead to an increase in communal violence. It is suggested that communal violence can best be understood as a product of Schismogenic practices. The discussion of these issues leads on to a consideration of communal violence and fascism. The chapter culminates in a discussion of approaches to pilgrimage. 
Chapter 8: Conclusion: attempts to briefly summarise and evaluate my own approaches to the research, including the attempt to use both a visual and a written presentation of the fieldwork and research findings.

In order to make sense of the references made to it in the following chapters, the reader should now watch the accompanying film Black Mountain. 


\section{Chapter 2}

\section{$\sim$ Methodology}

Methodology, according to Brewer, is the 'broad theoretical and philosophical framework' (2000:3) within which a piece of research is carried out. And the research methods or procedural rules are the techniques that are used in order to obtain knowledge. In most cases the methodological framework that guides research provides a context within which certain research methods fit. Brewer states that 'the flow of causation' is thus:

methodology $\rightarrow$ procedural rules $=$ research methods $\rightarrow$ knowledge (op.cit.5)

This research used an array of qualitative ethnographic research methods, including: participant observation, interview methods, key informants, digital video, photography, as well as: library, media and locally based archival research.

\section{Epistemology}

Ethnography is the methodological framework within which the research was undertaken. An ethnographic piece of research usually involves 'the immersion of the anthropologist in the everyday life and activities of the people [and] the culture being studied’ (Clammer 1984:68, Hammersley \& Atkinson 1995). Davies describes ethnography as 'a research process based on fieldwork using a variety of...research techniques' (2008:5, Seale C, 1998:221), which is produced through the 'interpersonal, cross-cultural encounter[s]' of the researcher (Clifford 1983, cited by Hastrup 1992:118). In contrast to those who describe ethnography as just another method within a methodological framework, Sarah Pink chooses to 'define ethnography as methodology’ and as

an approach to experiencing, interpreting and representing culture and society that informs and is informed by sets of different disciplinary agendas and theoretical principles. Rather than being a method for the collection of 'data' ethnography is a process of creating and representing knowledge...that is based on ethnographers' own experiences (2001:18). 
Burgess (1984) talks of strategies when describing the various processes of qualitative research. Assuming that a methodology (among other things) represents the series of strategies or methods employed in undertaking research, Pink's conclusion that ethnography is methodology makes sense. Seen in this light, ethnography rather than being just one method is a complete approach to creating, representing and acquiring knowledge based on first hand experiences (Pink 2001).

Ethnography is also a term which refers to 'a particular form of research [described above] and its eventual written product' (Davies 2008:4/5 my interpolation). The ethnography for this thesis is presented not only in the traditional written format but also in a visual format, a film. One of the aims of my methodology was, that as far as my informants agreed and as far as my participant observation allowed, I would use a video camera to record events that transpired in order to create a film that told the journey of my research. The ethnographic methods incorporated in the fieldwork, that is, participant observation and interviews, were undertaken (as far as was possible) under the observant eye of the camera. This process has resulted in the accompanying film Black Mountain.

It is 'the politics of the researcher and the context in which interpretation takes place, that defines what sort of ethnography' results (Skeggs 2001:426). This outlook has its roots in feminist ethnography, and although this thesis is not claiming a feminist approach, it certainly draws on aspects of feminist methodology in that it recognises that the 'emotional and the personal cannot be separated from intellectual endeavour' (Okely 1992:9). Rather the personal becomes political and theoretical (ibid). A large part of the methodology for this research is based on the acknowledgement that the main instrument in data collection is the researcher whose personal and political viewpoint affects it (Burgess 1984,1984a). Acknowledgement of these influencing factors produces research undertaken from a 'dialogical epistemology', wherein the 'self' is placed 'within the field of investigation' creating 'an inter-subjective matrix for knowledge' and understanding (Callaway 1992:44). Throughout this thesis there is constant self-reflection on how I was affected by, and affected, the research process. 
This research involves other epistemologies too. In creating what is essentially a linear journey of discovery in both the written and visual ethnographies presented, there is a 'mirroring of reality' normally evident in a realist epistemology (op.cit.33). The written research and the film are both examples of how the journey of the research process progressed, and how my understanding of the subject and of the research paralleled that process. A prime example of this, as indicated in the Introductory chapter, is the fact that the theoretical developments that have emerged from this thesis are not discussed until the final two chapters, reflecting the reality of how they developed through the fieldwork process and ultimately during the writing up of the thesis.

Aspects of this research have also been undertaken within a phenomenological epistemology. Phenomenology is a philosophical movement led by Edmund Husserl (1859-1938) which is concerned with the study of the states of consciousness implied by the description and analysis of everyday life - or as Husserl termed it lebenswelt or lifeworld, the world of immediate and overriding reality of experience (Abercrombie et al 1984: 238,313, Seymour-Smith 1986:222). As a scientific study of experience it attempts to describe the nature of human consciousness in its 'lived immediacy’ (Jackson 1996:2), as it is centred in the 'experiencing' of one’s surroundings - what Heidegger refers to as 'being-in-the-world' (Jackson 1996:16). According to Laing, the task of social phenomenology is to 'relate my experience of the other's behaviour to the other's experience of my behaviour... social phenomenology is the science of my own and of other's experience' (Laing 1967, cited in Jackson 1996:27 emphasis in original). Phenomenology as a method is therefore highly significant to reflexive ethnographic anthropological investigation with its emphasis on the lived experiences of everyday life or life worlds. Maso refers to phenomenological ethnographies as ones that assume 'that there are individual differences as well as [individually] different ways of looking between each other and within a group’ leading to different constructions of reality (Maso 2001:144). I think it becomes evident in my research that my informants, depending on whether they were Hindus or Muslims, right-wing or not, each had different ways of looking at the pilgrimage site of Kalo Dungar as well as at each another. These differing views certainly contributed to their construction of what they perceived as the 'truth' or 'reality' of the current situation of the site. Maso also expresses the 
view that phenomenological ethnographers try to 'get close to the subjects in order to capitalize upon their familiarity with the topic of study' (Gubrium \& Holstein 1997:42). I, as the researcher, most certainly became close to informants in order to 'capitalize on their familiarity' (although the use of the verb 'capitalize' implies a more exploitative motive than I think I had), in order to understand and gain historical knowledge of the pilgrimage site.

With these epistemological approaches in mind it is important to recognise, as Mason does, that qualitative research has an 'exploratory character', hence 'an allencompassing research design cannot necessarily be completed before research is begun' (1996:9). Because of this there should be flexibility on the part of the researcher when undertaking any type of ethnographic research. I follow Wax when she suggests that 'strict and rigid adherence to any method, technique or doctrinaire position may, for the fieldworker, become like confinement in a cage' (1971:10). The approach to this research was certainly flexible and followed Kane's analogy that 'research techniques are a bit like fishing flies: you choose the right one for the fish you want to catch' (1985:51). Given the highly experimental and complex nature of the process of ethnography, not only is it imperative to maintain a balance of research methods, but the researcher must also be aware of the feedback that the fieldwork, sometimes indirectly, constantly provides for him or her regarding which particular research method may be appropriate at a specific time. This leads on to the notion of reflexivity in the research process.

\section{Reflexivity in the field}

Being reflexive prior, during and after fieldwork is important in order for the researcher to understand the research process more completely; it gives the research findings the context in which they should be considered, and therefore validated. As Hastrup expresses by citing Tedlock (1983) fieldwork 'is not the unmediated world of the "others", but the world between ourselves and the others' (1992:117), as the essence of it (i.e. ethnography) lies in the social interaction and social relationships founded between the researcher and their subjects (Cohen 1984).

Pink suggests that 'a reflexive approach recognizes the centrality of the subjectivity of the researcher to the production and representation of ethnographic knowledge' 
(2001:19). So making the subjectivity of the researcher apparent in the written or visual document that represents the research findings, inevitably suggests the subjectivity of one's research, which subsequently allows for acknowledgment of both its strengths and its shortcomings.

After all, what an anthropologist finds out is 'inherently connected with how she finds it out' (Emerson et al, 1995:11 emphasis in original). How an anthropologist makes discoveries in the field is influenced greatly by the many elements that make up their identity which, first and foremost, will affect the way the researcher is received, the relationships they make, as well as the subsequent roles they take on, which in turn will affect what the researcher sees, how they see it, and what they choose to record (Pink 2001, 2004, Woodthorpe 2007). Sen, although not directly in the context of research methodology, refers to this as 'positionality' in her discussion on nationalist interpretations of India's past, in which she states the importance of 'positional perspectives’ (1997:12). A person’s positionality can ‘influence both (i) observation of events seen from a particular position, and (ii) the overall assessment of an event, from a particular perspective' (ibid). In other words, 'the nature of observations and the conclusions drawn are inescapably influenced by the position of the observations' (op.cit.13) and the observer. Watson brings to our attention the point that we 'rarely step outside ourselves in order to reflect on how our own lifehistories are contributing to the perspectives we are accumulating' (1999:4), perhaps if we did we would then be emulating Coffey's suggestion that 'the qualitative researcher or ethnographer is simultaneously involved in auto/biographical work of their own' (2002:314), as well as becoming a 'biographer of Others' (op.cit.313 emphasis in original). Even though, as Okely (1996) acknowledged, due to the developments of feminist anthropology, we have come to realise the significance of autobiography in research, I think as Davies recognises, it is important that the ethnographic writing and findings do not become too 'self absorbed' where 'boundaries between subject and object disappear, the one becomes the other... [which] effectively denies the possibility of social research' (2008:5). Coffey states too, that the self should not become the 'key focus of the fieldwork' as to do so 'would render much ethnographic work meaningless' (1999:37); she goes on to suggest that 
we should not lose sight of the ethnographic imperative that we are seeking to understand and make sense of the social worlds of others, albeit using ourselves as key research instruments (ibid).

An 'ethnographic encounter' is influenced by many factors, not just our own perception of the person or society we might be attempting to interact with, but also by the way in which those that we are working with, perceive us. Max Weber acknowledged that we live in a world of 'irreconcilable values' (cited in Seale 1998:19) in which it is difficult to 'discard values' (op.cit.19). In this context these values might be the way in which people perceive each other, for example most of us carry pre-set notions of another culture or people. India is no exception to this. Preset notions are extremely prevalent in Indian society and no matter how much one tries to maintain an objective point of view about people and their communities one cannot but be affected by what one hears. For example, even amongst family and friends, certain communities ${ }^{1}$ are talked about or referred to in certain ways and many communities have certain characteristics that over time have for others, developed into stereotypes. A name, for example, tells a person all the primary notions that they might like to find out about you before even embarking upon a conversation, revealing both a person's religious background and ancestry and even the region of the country from which he comes. The combination of these different elements provides a slot for that person to fit you in to, like the universal stereotypes that are associated with whichever community he or she may belong to. As Sikand so rightly observes,

resisting the tyranny of labels is a constant struggle, a daily battle. No sooner does a child come into the world than it is branded, for no fault of his or hers, with a label that generally stays until the grave that boxes it into a specific caste or religion (2003:1/2).

Everyone in India would understand by my and Amin's names that I was a Christian and he was a Muslim², so, more often that not, despite protest, these would be the categories into which we would be slotted. Never before had I become as aware of

\footnotetext{
1 "Communities" is used here within an Indian context, in which the use of the phrase "a community" usually describes a group of people who belong to a certain religious group or a certain area of the country and they carry with them certain stereotypes. For example people from Gujarat are referred to as Guajaratis, and a stereotype associated with them is their taste for sweet flavouring in food dishes. Another example would be of Parsees, who are often referred to as eccentric, or Sadarjis, people from the Sikh community, about whom jokes are often made; they have a reputation of being a bit "silly". ${ }^{2}$ Amin is an Ismaili Muslim by birth, and now leads his life as an agnostic.
} 
my religious background as a Protestant Christian, even Catholics would turn suspicious upon discovering my Protestant heritage. As for Amin, being a Muslim, the constant negative association that being a Muslim created was at times psychologically exhausting, ‘Amin...oh so you're a Mohammedan', the words would ring in our ears. Brewer acknowledges that 'features of identity can affect research practice', religion being one of them (2001:99) and skin colour another. Both Amin and I share a humanistic outlook on life, sometimes agnostic and more often than not completely atheist attitudes towards religion, but this position does not count for much in India. The account below from Sikand expresses this most succinctly.

You must be something...your name sounds Hindu, so Hindu you must be' said the exasperated census-wala ${ }^{3}$. 'It is meant to sound Sikh' I said, clenching my teeth in barely suppressed fury. 'You must be Sikh then,' he declared like an imperious judge. 'No, no,' I protested. 'Just write "Humanism” in the box.' 'There is no such religion in the census form...If you are not anything then you must be Hindu,' he decided for me. 'Your parents must follow some religion and that should be yours too.' 'I'd rather be an atheist than be called a Hindu or any such thing,' I insisted. There was no religion called 'Atheism' in the list either. He reluctantly placed me in the box meant for sundry 'Others' (2003:1).

I encountered this kind of interaction on numerous occasions during fieldwork where forms to be filled in order to enter certain temples, undoubtedly caused confusion when caste or religious belief was raised.

The influence of my perceived identity by the local people as a Western white Christian woman and that of my partner (who later became my husband) as an Indian Muslim man, was immeasurable. Not only on the data that could be and was generated but also to the access I was able to gain and not gain. At times during fieldwork I was not completely aware of the effect our identities were having on the data generated, however in contrast there were instances when it was glaringly obvious. It is important too, to be aware that it is not just the perceived identity I acquired that affected the data generation process but also my own personal baggage and that of my partner that certainly influenced the research process. These factors revealed themselves increasingly as I started to analyse my research data. A most

\footnotetext{
${ }^{3}$ Wala - Hindu term normally used at the end of a noun in order to describe the profession of someone. For example someone who drives a rickshaw would be called a rickshaw-wala.
} 
obvious example of this was the cynicism I discovered I had developed towards religious institutions.

Important aspects to consider when using reflexivity are the acknowledgement of social attributes such as gender, age, class, ethnic background, personality, as well as religious and political views. Despite being one of the few countries in the world in which a woman has governed the country as early as the 1960's, India is a place where a woman's status is not equal to a man's. Women are revered as goddesses in the Hindu religion, however this practice often reveals itself in a way that the women, especially in rural India, are heard less rather than more. They are the keepers of the home and their role is very much one within a domestic sphere, as bearer of children and carer of spouses. There are times when, due to the uncomfortable feeling felt by men, even an acknowledgment of a woman's presence in a social situation is not offered. For fear of upsetting any cultural custom or person, in the past I have stood quietly behind Amin while he has initiated conversations and discussions, while I have been completely ignored. I can say now however, that I often take the initiative to greet the man concerned and this is never met with hostility but with due respect if at times a little awkwardness. Negotiating gender status and relationships has been a constant learning experience in the field, and probably due to the combination of my own personal lack of confidence during fieldwork, lack of language skills and being accompanied by male research assistants, has meant that representation in this research is male-centric. My research assistants (Amin and Khatri Bhai) being both male and Muslim, meant that there were many constraints posed on this research with regard to the inclusion of women. It was not appropriate for either of them to approach the women in the Muslim dominated village of Drobhana and it is likely that the women themselves would not have been comfortable had they been asked to talk to us. In this situation my lack of language skills at this stage prevented me from approaching the women myself.

On the pilgrimage to Kalo Dungar there were more opportunities to talk to women participants, but the presence of my male assistant hampered this to a degree, once again. There were English-speaking women in Bhuj to whom I talked to regarding the site of Kalo Dungar but they did not have any information regarding the site. However, perhaps if I was to meet them again now there are questions I might ask 
them with regard to the role of women within the right-wing political movement in the region of Kutch. It is important to highlight here the difficulties in approaching and discussing the sensitive issue of the political nature of Kalo Dungar with Hindus, both women and men; this is even more evident when trying to question and establish the direct personal involvement of a person, male or female, in the rightwing movement, especially considering that Amin, my primary research assistant, was a Muslim and I am perceived as a Christian. Given my now personal establishment in India, improved language skills and personal comfort levels, it would be interesting to further my research from a more female-centric perspective in order to gain a more holistic picture.

\section{Reflexivity in Film Making}

A final element of reflexivity to discuss is its position in the process of film-making. According to Ruby (2000), reflexivity has not yet permeated into visual anthropology. However as Pink (2004:4) suggests Ruby recognises its importance in film-making, believing that the maker should reveal 'the assumptions that guided her or his work, [because it] is essential to an ethical approach in visual anthropological practice' (Ruby 2000:167). Revealing more of the film-making process would enable the audience to understand the ethical issues that surfaced, and were resolved, during the research (Ruby 2000). Film is a medium in which, through use of editing techniques, research can be manipulated and fiction can be presented as fact, and it is through reflection on the film-making process that the maker can reveal their ethical approach and give transparency to the research. Ethics in research and film-making are issues discussed in more depth later in the chapter. It is not only the ethical issues of film-making which should be considered here, rather all aspects of the filmmaking process, including, for example, the process of editing. Decisions made during the process of editing film footage have an immeasurable effect on how research is presented, which warrants an element of reflection on how and why the film is presented in a certain way, either within the film itself or in written documents that might accompany it. I have attempted to do this in Black Mountain, using voice-overs, and in this thesis, in a reflexive commentary. I hope that the film, along with this thesis, make a contribution to advancing the development of reflexive, autobiographical, ethnographic film-making. 
According to MacDougall, films are as 'inherently reflexive’ as photographic images, in that 'corporeal images are not just the images of other bodies; they are also images of the body behind the camera, and its relations with the world' (2006:3). So ‘images’ provide a reflexive way of understanding the subject, in that they provide isolated observations, revealing 'commonalities and connections...these may be the characteristic mannerisms of a person, or how a particular cultural theme emerges repeatedly in different contexts'(op.cit.4). However, they also provide an insight into the film-makers' ways of seeing, 'before filmmakers can compose images [by editing] ...they have had to film them...Thus, before films are a form of representing or communicating, they are a form of seeing' (op.cit.6). MacDougall believes that when we are 'seeing' we are prepared for a different kind of knowledge. Eventually, as we reflect on what we have seen, we project our ideas upon it, which in turn, 'turns us back on ourselves' (op.cit.7). Ultimately, 'each successive scene [in a film] locates the author in relation to the subjects' (ibid), making knowledge possible on multiple levels.

Another important aspect of reflexivity in film-making is the awareness of the effect having a camera in the field can have both on the subject and the researcher. A camera of any kind can be extremely intrusive and at times inappropriate, especially in a conservative society, and in any society depending on the sensitiveness of the research topic. Those being researched may or may not be comfortable being in front of the camera, in which case the camera can often have a negative impact on research, with people not opening up in its presence. These problems can often be overcome, although not always, by the researcher using techniques to ensure a comfortable environment. This is normally best attained in ethnographic research by spending long periods of time in the field getting to know and understand the subjects of the research. Sometimes the researcher can be uncomfortable, especially if they are unsure as to when it may be appropriate/polite or inappropriate/impolite to put a camera in another person's space. During this research I experienced both sides of this issue of the camera, in the latter case, there were many occasions when in actual fact, those under the photographic eye minded much less than I did. I quickly discovered that in India, where the Hindi film industry reaches every corner of the country, the dream of becoming an actor on the big screen exists in everyone so people were eager to be interviewed on camera. I was also aware that with my 
video camera and photography equipment I was putting myself in a certain economic context, which gave the opportunity for people to make judgements about me and my financial or social background, that in turn might affect their perception of me and their involvement in my research. It is not that photography or film is not present in India, it is a large part of middle class Indian culture to take photos, however in the rural setting of some of my research, this is not necessarily the case. Cameras are still a novelty for many people in these areas, most especially for children (see Chapter 6, Fig.33).

\section{Culture Shock}

An often forgotten element in reflexivity is that of emotions. Considering that 'emotions [are] the central features of human life’ (Parrott \& Harré 1996:1) it would seem appropriate that the 'emotionality of the research process needs to be incorporated into discussions of methodology' (Woodthorpe 2007:1), something I will endeavour to include as I go on to describe the research process, beginning with the effects of culture shock ${ }^{4}$.

Culture shock (see Oberg 1960:178) ${ }^{5}$, unlike reflexivity, cannot claim to contribute to a way of understanding or knowing of the research subject or subjects. However, understanding the phenomenon of culture shock has enabled a reflexive personal understanding of some of the emotional baggage I carried as a researcher in the beginning of the fieldwork process. Despite my personal relationship with my husband, Amin, I still experienced periods of what I now recognise as severe culture shock, in which one can feel a number of things including revulsion and associated guilt, as well as depression, anxiety and homesickness. These symptoms provided me with a building anxiety as to whether or not I would be able to be a good researcher, and whether or not my peers faced the same kinds of problems. I was aware too, that the personal relationship I shared with Amin sometimes affected my long term vision of this environment, that at times I despised so much, and was going

\footnotetext{
${ }^{4}$ Even though 'many anthropologists experience culture shock whilst in the field, [it] is a subject that is rarely discussed in the academic setting' (Irwin 2007:1). In fact as Irwin points out, there resides a certain amount of 'academic bravado' in anthropology where a researcher would not necessarily feel able to admit to these feelings, it is assumed that as 'anthropologists [we] are 'naturally' better at negotiating unfamiliar situations than other sojourners' (op.cit.5).

${ }^{5}$ The founder of the term 'culture shock', Kalervo Oberg, describes feelings that I have often felt while living in India; that is, a 'terrible longing to be back home, to be able to have a good cup of coffee and a piece of apple pie, to visit one's relative, and, in general, to talk to people who really make sense' (1960:178).
} 
to be a major part of my life, something that I think at times terrified me and subsequently affected my ability to think clearly about my research.

\section{The Research Methods: Participant Observation}

When I set out to begin my research, participant observation was one of my primary research techniques. Wolcott suggests that participant observation is the 'cornerstone' of ethnographic research methods, and together with interviewing, these two methods are described as 'the dynamic duo of field research' (Wolcott 1995:160). Participant observation, as advocated by Malinowski (1922), involves

extended periods of fieldwork in which the anthropologist should attempt to immerse him or herself in the daily life of the people studied, thus minimizing the interfering effect of his or her presence and permitting a full appreciation of the cultural meanings and the social structure of the group (Seymour-Smith 1986:216).

Participant observation is generally unrestricted in time scale and allows for movement and flexibility within the sometimes, uncertain ways of the field. As my research developed, the kind of participant observation described by Seymour-Smith was not necessarily possible or appropriate to my study. For considerable periods of time when I was in India, I was living in Bombay and not always directly in the region of my field of study ${ }^{6}$. I do not think that this meant that I was not carrying out participant observation; rather my participation was on different levels and in different contexts. Firstly I was participating in one sense by living an Indian life, not perhaps the same kind of life of every informant in my research, however I established a deep understanding of the lives of many Indians such as my informants. Secondly I participated directly in the pilgrimage that became the focus of my study (as well as many others), and even though I did not live for long periods in Kutch, I re-visited and lived for short periods in the area of study on numerous occasions and I had past experiences of living in the same area through previous trips to India. What is significant about spending extended periods in the field is being able to establish trust and friendship so as to be able to gain the fullest insight possible into the area of study. For me, despite my relatively short but frequent trips into the specific field area in Kutch, I was able, due to reasons of access discussed below, to

\footnotetext{
${ }^{6}$ Amin was born in Bombay and has lived there all his life. Bombay is now also referred to as Mumbai and the two names are inter-changed throughout this thesis.
} 
meet with, and establish friendships with as many people as I could, gaining much information about the pilgrimage site of Kalo Dungar. This familiarity with Kutch also meant that much of the ground work that a researcher has to undertake while staying in the field area for long periods, had, for the most part, already been established. That is not to say that I might not have benefited more by staying permanently in the area, but I did the best I could in juggling personal and professional aspects of my life.

There were many positive factors with regard to my staying outside of the direct field area, (although by remaining in India for large sections of the research period I was arguably still immersed in the field), one being that it enabled reflection on the fieldwork experiences I had had. For example, being in Bombay, I interacted regularly with friends in talking about India, its politics and history and gained a great insight into how the Indians I was surrounded by felt about India; this enhanced my subsequent trips into the fieldwork area. I learned a great deal in this process, and together with reading the daily newspaper, political India became familiar to me during these periods, and I was able to understand, in some depth, India's syncretic and religio-political history. All these factors ensured that my participation in the field was indeed extensive.

\section{Participant observation and gaining access to the field}

Seale states that 'the observer is the primary research instrument, accessing the field, establishing field relations, conducting and structuring observation...' (Seale 1998:221). Accessing the field is an extremely important element in participant observation; without the right access any kind of observation is difficult (Seale 1998, Brewer 2000). So one of 'the participant observer's first problems is that of entry' in that

[he] gets his data on the basis of his ability to be admitted to the situations he wants to study and, once there, to persuade people to let him stay. Whether entry becomes a problem depends partly on what the researcher has chosen to study and what research role he has decided to take (Gans 1994:57).

Whereas Burgess (1984a) states that the access that can be obtained will depend on the researcher, Gans (1994) acknowledges that entry or access into the field can be 
made more difficult depending on the subject of study. There were times in Kutch that entry into certain areas of my study was difficult. For example (as we discover in the following ethnography chapters), attending the pilgrimage more than once was not possible because of fears for our safety and attending the political rally that took place on the final day of the pilgrimage, which I did attend (see Chapter 4), was also not possible for the same reasons. However I was able to overcome these difficulties mainly due to my relationship with my husband in the field.

It seemed obvious from the beginning that Amin would accompany me on my research journeys, in fact, looking back there was never even a question of who would travel as my translator or research assistant, this was a journey that we had assumed we would travel together. Amin was my guide, translator, assistant and support throughout my fieldwork trips ${ }^{7}$. Access into Bhuj, and the region of Kutch where the pilgrimage to Kalo Dungar takes place, was made relatively easy due to our past associations with the area. Bhuj was where we lived while we were filming for Lagaan during which time we met many interesting people, including museum curators, local tailors and local NGOs, as well as the local Maharaja, policemen, local business men, local actors (that were used as extras and played character roles in the film), as well as the surrounding village chiefs and villagers. Some years later I even started a business exporting the textile handicrafts of Kutch to England; so not only did my contacts in the region stem from my association with the film Lagaan and with our long term relations with the local people, but also with the new business venture that I had undertaken. These connections meant frequent trips to Bhuj and frequent trips into the villages that are scattered around the desert areas. But it was serendipity that brought us to Kalo Dungar when we were invited back to Bhuj in 2003 to take part in a function organised by old friends from Lagaan; it was during this trip that we were informed about the pilgrimage to Kalo Dungar.

Much of the access I gained in the field came about circumstantially. The film Lagaan was a blockbuster hit in India, taking India to the Oscars in 2001. Everywhere we went our association with the film Lagaan, and Amin being one of the leading characters, gained us access into people's homes and hearts without

\footnotetext{
${ }^{7}$ His role and subsequent influence over the research data generated will be discussed in detail later in this and subsequent chapters.
} 
which undertaking this research would have been extremely difficult, given its sensitive nature. I did not set out to research anything that might be politically sensitive to any particular community or person, however, as the research developed and the political nature of the pilgrimage to Kalo Dungar emerged, it quickly became obvious that I was treading precarious ground. Religion is probably the single most important element of Indian culture to be respected and followed. Because of this, politics and religion are intertwined too. One cannot be separated from the other and one has to be extremely careful not to make what might be interpreted as politically sensitive statements, or make public one's opinions so as to intentionally or unintentionally upset any particular person's political or religious beliefs. Constant negotiation and skill was required in the field in order to gain the difficult access that Gans (1994) recognises when dealing with difficult subjects.

Another important element of access I would like to address is that of acceptance which overlaps with the issue of gender (discussed earlier).

in cultures where the institutions of marriage are pervasive, the childless, single women in the field can find it difficult to establish entrée and a field role...This is why in some anthropological research women work in husband and wife teams (Brewer 2000:99).

Amin and I were not officially married during my initial fieldwork but to the outside world we were researching, we were. I was introduced as Amin’s fiancée or wife. 'Living with someone' or 'living in' as it is referred to in India, is not a local custom, and it was important that I was associated with Amin as more than his girlfriend in order to command respect. I am extremely aware of how I am perceived everywhere I go. Westerners in India, not obviously on business, are generally categorised into the 'hippy' traveller community that roams the sub-continent, as well as belonging to the colonial country that ruled over India for so long. It was essential from the beginning that I was not slotted into the stereotype of 'easy woman, dope smoking hippy' and 'colonial tyrant'. I would not say that this was the sole reason that Amin and I embarked upon a husband and wife partnership, however, there was certainly, from Amin's point of view, an awareness of my vulnerability in the field was I to be alone, and a need to protect me from what was for him a knowing gaze. There were other advantages with at first appearing to be married, and subsequently really being 
married to Amin, and that was, that the idea of a foreigner marrying an Indian and settling down in India, ensured that I was given another type of acceptance and respect, as someone who appreciated and understood the beauty of India and who was in fact not that different from an Indian. I was accepted with love and open arms, often like a sister or daughter-in law, which enabled me access on a much deeper level than I expected. These are experiences mirrored by Pertierra (2007) in her account of falling in love and marrying in the field in Cuba, where gradually her partner, native to Cuba, became 'an attentive and at times protective partner' who would accompany her to interviews and 'impatiently [hold] the video camera' (Pertierra 2007:5). She also shares the experience of added acceptance, as she felt that her relationship and subsequent marriage with a Cuban man was interpreted as a 'gesture to people I was working with of the good faith I had in committing myself to experiencing life in Cuba' (ibid). In contrast to Pertierra’s comments about her husband 'impatiently' holding the video camera, there was certainly a conscious decision, due to Amin's involvement in film, that his participation in my research would greatly assist the film-making process which I eagerly wanted to pursue, making it a degree easier because we could act as a camera-man/researcher team able to exchange roles when required.

Through my fieldwork experiences I can categorically agree with Davies in her concession that 'a very close personal friendship neither guarantees nor precludes a good ethnography’ (2008:93). The close proximity with India I enjoyed through my own personal relationship at times as well as assisting the research process also produced problems. Conflicts of interest, and emotional baggage, certainly caused husband and wife tensions. This was also enhanced by the subject of the research and its emotional effect on both Amin and me. When we discovered the political nature of Kalo Dungar, the reason it raised so much interest for me was probably due to my own religio-political interests and beliefs, and it certainly affected Amin, due to his status as a Muslim, and his experiences growing up in an India, where Hindu and Muslims have slaughtered each another in communal clashes. Davies points out that it is important that 'ethnographers be prepared to examine as honestly and carefully as possible their personal reasons for undertaking the research and their feelings...towards those they research’ (Davies 2008:95), and this I have tried to do. 


\section{Participant observer roles}

Burgess (1984) refers to Gold's (1958) four 'ideal typical field roles: the complete participant, the participant-as-observer, the observer-as-participant and the complete observer' (1984:80 emphasis in original). Each of the four roles suggests varying degrees of participation in the field and its varying dimensions, including whether participation is open or closed and whether the role of the participant is, therefore, known or unknown. Sometimes the research itself controls these varying elements of participant observation, but usually the participant observer must choose the type of role best suited to their research. The ethical position of the researcher will probably affect these decisions.

To take Gold's (1958) first role, the complete participant normally conceals their role as participant in the field, resulting in covert observation (Burgess 1984:80; Sen 1997:13). These days, covert observation is mostly considered unethical, often being likened to the role of an undercover investigative journalist. However, choices regarding this type of observation are largely dependent on the research subject and the 'gatekeepers', who are the ones with the

power to grant or block access to and within a setting. Sometimes, the ethnographer is faced with situations in which relevant gatekeepers are unlikely to permit access, so that covert or secret research is the only way of studying them. This has been done, for example, in studies of...religious sects....and right wing political movements...Here the observer seeks to present himself or herself as an ordinary, legitimate member of the group (Seale 1998:221).

When I first embarked upon the pilgrimage to Kalo Dungar I was not aware of its political nature; this was discovered shortly after the pilgrimage began. At this point I did not then admit to all the people who had welcomed Amin and me onto the pilgrimage that my research might be controversial, and that its orientation, almost certainly construed by them as anti-Hindu, might incriminate them; doing this would surely have meant that we would have been asked to leave much earlier than we eventually were.

After the initial experience of the pilgrimage to Kalo Dungar, when we realised that the gatekeepers were the politicians, I did not feel able to tell them the developing 
central theme of my research, as then they would make the rest of my research difficult to undertake. As research developed and different reactions to our research arose, it was difficult to know which party to tell what to, mainly for fear of offending anyone's sensibilities. It soon became clear that, generally within a Hindu environment, unless I could understand the exact political position of a particular Hindu friend (which is not always easy to gain), being completely open about the research was not possible. Instead I explained the topic in very general terms. In contrast to this, in a Muslim environment, I explained the research in the same way as described above, but would also reveal a little more about my interest in the syncretic nature of pilgrimage, and the political angle that became evident at Kalo Dungar. In this sense my observation was never really completely covert, rather it was semi-covert.

The second role categorised by Gold is the participant-as-observer. It is in this role that most of the participant-observation for this research was undertaken. This is when 'the researcher participates as well as observes by developing relationships with informants' (Burgess 1984:81). In this role the participant makes known to his informants that the principal reason for participation and observation is the research. The issue of how far the researcher should participate in this role is dependant on the research, those being observed, and the researcher’s judgements.

Another aspect regarding the role of the participant-observer is the issue of what is sometimes referred to as 'going native', where over-familiarity for the participant observer can lead to difficulties in data generation. This is an issue often associated with the first two roles discussed above. A participant-as-observer role can sometimes develop into a complete participant role in circumstances where the researcher becomes over-familiar with the research setting to the point that the researcher is no longer able to 'record the observations that are made' (op.cit.81). Living at such close quarters within a large extended Indian family enabled me to gain an insight into Indian culture in a more familiar way than might have been achieved otherwise. However, at the same time, over-familiarity has often meant, in my personal case, a much reduced sense of objectivity and at times I have felt an observational numbness and a loss of ability to observe due to the 'near complete participation’ (Davies 2008:86) that I was experiencing, in which everything I 
experienced began to feel 'normal' to me. And I quote Dubisch (1995), who comments that

fieldwork poses a variety of challenges to identity... at such times the line between observer and observed grows thin, blurs and occasionally disappears... although I do not become Greek when I am in Greece, perhaps I have a "Greek Self” manifesting itself more strongly when I am in a context in which that self has been shaped and where it is reinforced $(1995: 115)$.

It has been a challenge for me personally throughout my research to maintain a balance between my role as researcher and as a member of society and family. I often become anxious that I have lost perspective and might now take for granted much of the behaviour that surrounds me. However I feel that I am becoming more and more aware of my 'Indian self' so as to be able to develop an amount of reflexivity to my surroundings.

Becoming a complete participant and developing an Indian self, has perhaps enabled a considerable understanding of the makeup of India and its social complexities; however, it has most definitely caused much internal conflict. This internal conflict is also noted by Kondo who, whilst working in Japan, experienced a transformation of self that induced feelings of a 'fragmentation of the self' producing a 'collapse of identity', culminating in her leaving the field at one point 'in order to reconstitute [herself] as an American researcher' (1990:16). The idea of becoming a 'complete participant' is, according to the definition by Junker (1960, cited in Seale 1998:222 and Burgess 1984) associated with the role of a covert researcher, where the observer abandons the position of analyst for identification with the people under study' (Seale 1998:222) and as described above, at times, rather than generating a complete knowledge, one can perhaps lose perspective. In my case my research was certainly overt both in the field and out of the field, in the personal family and friend space I inhabited, where the focus and subject of my research was known by everyone. I therefore became what Seale terms a 'marginal native' (op.cit.226 emphasis in original). The syndrome of 'going native' perhaps reinforces the opinion of those who argue that participant observation is overly subjective; after all it is fundamentally 'goal-directed behaviour' in the sense that 'we do not observe 
"everything that is there to be seen". An observation is made; it is the product of an active choice, not of a passive exposure' (Kaplan, 1964, cited in Ellen 1984:18).

In Gold's last two roles: the observer-as-participant is described by Burgess as one in which contact with informants is minimal, the only time this role was undertaken during this research was during fieldwork to large pilgrimage sites where interaction with pilgrims was minimal and short lived. The final category of complete observer is similar to the previous role in that observer/participant-informant contact is minimal to the point that the observer may indulge in such acts as eavesdropping (1984:82).

\section{Research methods: Key Informants}

Most of the people with whom I engaged in unstructured interviews automatically became key informants. Tremblay (1984) defines the use of key informants in two ways: the traditional use of key informants, interviewed at length over a period of time to provide the ethnographic data on 'kinship and family organisation, economic system, political structure and religious beliefs and practices' (op.cit.98); and secondly, the 'focused key informant technique' used to gain insight into 'specific aspects of a cultural setting rather than the cultural whole' (op.cit.99). Tremblay's second type resembles my use of key informants. Once Kalo Dungar and its political implications became the focus of the research, I began to target people who would be able to give insight into its history and present state. There were instances when, in the course of conversation, other cultural factors of the area were discussed; however, the use of the informant from the outset was very much goal-directed and focused.

Another important aspect of fieldwork is that informants often lead you to other informants; this is known as 'snowballing'. This can happen with researchers who might already be present in your field, as well as through your first field encounters. In the case of this research my first research encounter of Kalo Dungar led me to a new subject and a whole set of people involved in the pilgrimage. When I came out of the field for retrospection and re-entered with a new focus, I encountered many informants who led me to current researchers in the field. Their research, even though it differed from my own, due to the nature of the small town and relatively 
close-knit area of Kutch, overlapped in areas. Their knowledge from their own research and encounters with different people led me to more and more informants. A prime of example of this was when I met a student from the University of California, Berkeley, who had just completed her $\mathrm{PhD}$ research; she led me to a man who had become her assistant in the field, Mohammed Hussain Khatri ${ }^{8}$. He became, due to his non-professional anthropological interests, involved in my research too and became an assistant in the field, leading us to the Sama community, who in turn enabled us to gain a completely different perspective on the pilgrimage site of Kalo Dungar, than we had previously experienced. Despite Khatri Bhai refusing to let us remunerate him for his services as an assistant, this fortunately, did not affect the amount of control we were able to exercise over him. Khatri Bhai seemed to understand the nature of the research, and with instruction and guidance from me, we were able to work together in order to gain the maximum amount of ethnographic detail from the village to which he took us (see Chapter 6). And his reflections on his life as a Muslim in Kutch, and on the changing political landscape of the area, were enormously insightful (see further discussion regarding assistants below). MacDougall suggests that,

anthropologists often select their informants from those who stand out in the crowd, but this is perhaps even more the case in visual anthropology, where one looks for people who are particularly eloquent in their relations with others, either in speech or manner (2006:113).

This was not completely the case in my situation; informants were selected on the basis of whether they had any knowledge or information regarding the pilgrimage site in question, and I found that I was extremely lucky as I stumbled upon, and was led to, eloquent and articulate informants, each with their own character representing the cultural nuances of the area that they were from.

It is important to acknowledge, although I do not wish to undermine the key informants chosen during the research process, that, as there were difficulties in revealing the political issues that the research was raising with informants from Hindu and Muslim communities (an issue discussed in more detail later in the

\footnotetext{
${ }^{8}$ Mohammed Hussain Khatri will be referred to in the rest of the thesis as Khatri Bhai. Bhai means brother and is often fixed after a person's name as a mark of respect.
} 
chapter), accessing and choosing informants presented another set of obstacles. It is evident through the thesis that representation from the social strata of Hindu and Muslim communities in Bhuj and the surrounding area of Kalo Dungar varies. Specifically the reader will discover that on the Hindu side most of the informants, who were interviewed after the pilgrimage had been made to Kalo Dungar, were historians or museum curators, the exception being the two young men in the bookshop. These two presented an example of a younger educated generation's point of view, however it was not possible to back this up by further such interviews, due to the rarity of finding interested participants willing to talk freely about their political and religious points of view regarding the site of Kalo Dungar. It was also difficult to discuss or interview Hindus from different pockets of the social demography due to the political issues surrounding Kalo Dungar and the status of Lord Dattatreya at the site, which most did not want challenged. It was, for obvious reasons, also impossible for us to approach members of the right-wing political network regarding the topic of Kalo Dungar due to the sensitiveness of the issue and the fact that we were a Christian and a Muslim (from their perspective) undertaking politically sensitive research; this put us in a vulnerable position. Hence we were only able to understand the point of view of the political bodies from the pilgrimage we undertook and the DVD footage we obtained later in the research.

From the Muslim community it is mainly local villagers living around Kalo Dungar that were interviewed. This is where the majority of the local Muslim population reside and have been directly affected by the activities at Kalo Dungar over the years. We did not interview many Muslims residing in Bhuj itself which, in hindsight, may have brought up further issues regarding the changing status of Muslims in the region and the threats they face from increased Hindu right-wing political behaviour.

It can be argued that the demographic representation of the key informants affected the kind of information the research produced, and this is a valid point. However through this research I have realised that the biases, subjectivity and sometimes unbalanced representation of communities within research of this kind depends highly on: the researcher; the assistants; the subject matter; and the local social and political situations one finds oneself in; all of which will simultaneously restrict and open up research in a number of different ways. Depending on the ways in which 
these factors affect the research, the results will also be affected. However that is not to say any different combination of factors will produce better or more valid research, rather it will produce different pieces of research from which different kinds of conclusions can be drawn.

\section{Research Methods: Interview Methods}

As Whyte states 'the anthropologist or sociologist gathers a large part of his research data through field interviews’ (1994:111), sometimes interviews are focused, sometimes they are not. For this research, interviews were generally unstructured conversations, 'conversation is a crucial element of field research' (Burgess 1984:108). Rapport (1997) advocates the use of 'conversation as anthropological focus...because of the "naturally occurring” importance of conversation: it goes to the heart of social exchange and culture process' (1997:180). Conversational interviews, in my experience, allow the interviewee the space to be themselves which permits their character to stand out, contributing richly to ethnographic detail. It is common that as a conversation begins, informants are perhaps shy or uneasy, mostly due to the unusual situation in which they may find themselves. Despite interviews being casual and conversational in nature, interviewees are still often conscious that the content of the conversation is contributing to a specific research process, most of them are familiar with television interviews, and understand them as occasions during which information is elicited. In my case, even though prior to the interview we had spent some time with the interviewee, the presence of the camera ${ }^{9}$ may still have contributed to an initial uneasiness. When an interview is undertaken in the form of a conversation however, the informant has the space to relax and slowly their characters emerge. For film the emerging of a character through the interview is an interesting visual process to watch, as an informant slowly 'warms' on the screen.

For ethnography in general, it is also valuable for the researcher to be able to put the context of what an informant is saying in to socio-cultural terms, this is possible

\footnotetext{
${ }^{9}$ Ninety percent of the interviews undertaken in my research have either been recorded audibly or on video camera, with the majority on camera. At times, whilst watching Black Mountain, I have felt that some interviews look more structured than they actually were, this impression results, I feel, due to editing and the use of a particular question and a particular time in the interview during what was probably a much longer conversation than is shown in the film. Researchers are aware that interviews can go on for hours, and part of film-making is to choose appropriate sections of footage in order to give the film a rhythm.
} 
when the actual character of a person is allowed to emerge, which is then, in the case of film, visually evident for the audience. It also enables the researcher to reflect on why the informant might have said things in the way they did. This leads to another aspect of interviewing, that of the development of narrative. In a conversational interview, as an informant's character develops and they relax, he or she may engage in a type of narration, perhaps of a life history or even local history. Ricoeur (1991, cited in Lawler 2002) considered 'narrative as a category by which people make an identity'. This was certainly true of some of my informants, especially those from the Sama community in Drobhana, Kutch, and of one of my younger Hindu informants who began to reflect on his life history associated with Kalo Dungar during his interview. As Riessman (1993) acknowledges, 'if research participants are given sufficient space within research based on interviews, it is likely that they will produce narrative if asked about their lives’ (cited in Lawler 2002:243), these same narratives then 'tell us a great deal about the social world he or she inhabits' (ibid), as 'people use narratives to interpret the social world and their place within it, and, further, to constitute an identity’ (op.cit.251).

The interviews undertaken for this research were generally completely unstructured and conversational, apart from the first question asked. As Davies points out 'ethnographers retain a degree of control over the interview interaction in that they introduce both the general area of discussion and more specific topics' (2008:112). The interview process, and my control over it, was hindered by two main elements;

a) lack of language skills on the part of the researcher.

b) use of research assistants to carry out the interview process.

A lack of language skills on my part meant that Amin, as my research assistant, undertook the majority of interviews. Despite setting an agenda prior to the interview, with different interview questions noted on paper in order to gain some direction and control over the interview, many of the interviews, specifically in the style that questions were asked, were sometimes inappropriate according to anthropological methods. This happened for two reasons, the most obvious being that Amin is not a trained anthropologist, and secondly due to the fragile social exchanges that sometimes occurred in our questioning regarding the pilgrimage site and its complex past. Davies points out that 
a good interviewer needs to be open to the possibility that respondents [may] not be able [or want] to discuss the subject in terms that they suggest...they may, for example, openly reject a line of questioning as nonsensical and perhaps try to redefine what is being discussed (2008:112).

There were many such examples of this type of behaviour during this research. One particular example is the interview with a local historian and museum curator in Bhuj - Mr Vadiya (see chapter 15 in Black Mountain, and Chapter 6 of this thesis). When watching the film the questions and intonation of Amin - the interviewer seem aggressive and inappropriate, which may well be true, however what is not obvious, as it was not recorded on camera, is that there had been an uneasy social exchange prior to the first particular question heard in the film. It has not been easy to give context to this encounter, specifically, having only a voice-over to do so, however it is a good example of how it was not easy for me as researcher to maintain complete control over the interview process. This interview is also a good example of how easy it is to become frustrated in the field, something that Rabinow (1977:43-49) addresses quite beautifully in his well-known monograph on research in Morocco. His frustrations emerge in a confrontation with his assistant, but at times informant, Ali. These confrontations can easily manifest between researcher and assistant in the field and between researcher and informants too. As Davies affirms 'virtually all interviewers will form opinions about interviewees as individuals, what sort of people they are... and so forth, it is also important to try to develop an idea of how you, the interviewer, are being perceived' (2008:114). There were also added complications in this research of interpersonal problems, a husband and wife team, as discussed above, can sometimes experience tensions. The pressured situation of this research and the political threat that we felt, went some way to creating quite tense situations which sometimes emerged through specifically difficult interviews.

In interviews where informants sometimes mixed their language between English and Hindi, a common phenomenon in India, it is important to note that I understood the use of the English language in these situations, Indian English often uses terms with different meanings and in different contexts than they would be used in England, however, long enough immersion in India ensured that these nuances were completely understood by me, however there was sometimes difficulty if an 
informant resorted back to Hindi, or in some cases Gujarati, if their English failed them, in which case I relied on Amin's translation in order to be able to follow the conversation again.

A final aspect of interview methods that I wish to address is that of how the relationship of researcher to research assistant affects the research process. 'The remarkable contribution of...assistants...is not widely enough appreciated or understood' (Sanjek 1993:13). Amin, as an assistant and interviewer, as well as Khatri Bhai, (the assistant who helped us in Drobhana), were two people who made an extremely rich contribution to this research. As an interviewer Amin was able, in his ability to break down social barriers and his ability to explain the research we were undertaking in an understandable and sensitive manner, to ensure that we could conduct the interviews we wanted. As De Neve comments on his assistant Kumar, who assisted him with research in Tamil Nadu, 'this is a real skill that for some...comes naturally, while others like myself, have to learn it through time and experience' (2006:83). Amin took on this role in a way I am not sure I could have done, even with the best of language skills. My informants were able to relate to Amin in a way that may never have been possible with me. Similarly when Khatri Bhai took us into the rural villages of Kutch, his local language skills and cultural positioning meant that he was able to take us to informants who provided me with rich ethnographic information. Both Amin and Khatri Bhai (with whom in comparison I spent little time) provided the research with another dimension too, in their willingness to reflect on some of the uncomfortable aspects of their own society that the research was uncovering. As De Neve puts it, 'it is the reflections of our "informants" and "“assistants" about their own society that are crucial to the ways in which "we come to know them”' (op.cit.68) and 'it is this rare quality which may well make for a perceptive assistant, capable of sharing, and indeed enriching the ethnographer’s own imagination’ (op.cit.81).

\section{Research Methods: Field Notes}

Both participant observation and key informants and interviews, along with the fieldwork process in general, rely on the discipline of note-taking to record the 'events which occur during fieldwork [which] become transformed...Through the process of recording - the note, the diary, the tape transcript - a moment is taken out 
of time and space' (James 1999:117) to reveal the 'subtle nuances of social life' (Ibid).

Before embarking on this fieldwork, despite having a good idea about the techniques I would use to generate data, I was still unsure of the best way to document these findings. I was concerned that I might not be able to consistently write good detailed field notes of my observations. One of the main concerns in ethnographic research is when to write notes, Mason advises that 'you...need to make decisions about whether to make notes while you are observing, [or] to write up "field notes" at some point following your observations' (1996:69). Having now had the experience of quite diverse fieldwork situations, I feel that making notes at the time may not always be practical or possible and depends on whether the field setting is appropriate and conducive to this. Research, after all, 'depends upon the researcher, those who are researched, and the setting in which the researcher works' (Burgess 1984:32, 1984a:2). Sanger (1996) observes that sometimes note taking can be a distraction, especially when interviewing, not just for the researcher but also for the participant. He also suggests that, due to the fact that not everything can be written word for word, note taking is selective and there is 'inevitable reductionism' (op.cit.72). It was important for me that there was a reflexive element in my fieldnotes.

There are ethnographies that are rich in reflexive content which offer templates for reflexive note-taking. Rabinow's account of his research in Morocco is an excellent example as is $A$ Different Place by Jill Dubisch, in which she reflects upon her fieldwork experiences in Greece. In reading Dubisch's work one begins to understand how different aspects of personality and experiences affect research. A famous if controversial example of reflexivity in the field is that of Bronislaw Malinowski whose private daily jottings, A Diary in the Strict Sense of the Term (1967) were published after his death. More recently, Margaret Kenna published personal letters sent home from the field and diary entries during fieldwork (2001). One may consider both these works, although Kenna's came much later, as forerunners to reflexive note-taking. Webb (1994) affirms the use of note-taking as a ‘instrument of discovery' enabling the 
scientific worker to break up his subject matter, so as to isolate and examine at his leisure its various component parts, and to recombine them in new and experimental groupings in order to discover which sequences of events have a causal significance (1994:195).

Burgess suggests three categories of note-taking 'substantive field notes, methodological field notes and analytic field notes' (1984a:292). All three represent different aspects of the research process, substantive notes will include the 'main observations, conversations and interviews which the researcher makes’ (ibid), methodological notes will include the 'circumstances under which the field researcher gathered the data' (ibid) and finally analytical notes will include an analysis of the data gathered. A diary, on the other hand, if not included in the main field notes, will most likely, as was the case with Malinowski, provide a self reflection of the field experience and emotional aspects. It is much more common in the present day to include the emotional and personal aspects of research in the discussion of the methodology of data collection and within the analysis of data, although it still may not be included directly in the research notes.

My personal experience in taking field notes has often been confused. Prior to entering the field in the beginning of my research I had decided that,

... in the evening I would keep a daily diary of events. It would be as detailed as possible with reference to my emotions along with my observations... (Extract from research diary Sept: 2003)

This I endeavoured to do, however, in another extract from my diary after returning from the field (the field trip I refer to was fairly short, i.e. participation in the Kumbh Mela which ran for five days), I reflect with what feels like a certain amount of stress of not being able to write consistently during my fieldwork, and finally whether the notes I would eventually make would do the experiences justice.

...In the first two days that I was in Nashik there was no time in which I could begin writing my diary... The day after we arrived back in Bombay I spent recuperating and sleeping. It was not until the next day that I felt in a frame of mind to write... When it did come to writing my diary, I was slightly worried, as to whether I would be 
able to remember what I had seen and observed...I am not entirely sure that I can ever do justice to this pilgrimage in words and I quite often find myself at a loss of how to describe it (Extract from research diary Sept:2003).

During the early stages of my fieldwork, no matter how much reasoning I had done with myself, I constantly felt that I was making a compromise, or even excuses, for not making field notes 'on the job'. On reflection I felt that these doubts were misplaced, and as fieldwork continued I feel I matured in my thinking and I was able to resolve things in my mind and come up with solutions. I realised too that, as I mention in the section on visual methods, my camera and the footage I gathered were an important contribution to my field notes and I realised that in recording my experiences on tape, some detail I might have missed in my notes would be recorded.

I also embarked upon analytical field notes, in two ways. Firstly, during fieldwork when Amin and I would reflect on the day's events, for example, I felt it important to make notes of these reflections. It has been fascinating, as the reader will discover in the following chapter, to reflect on the disparity between Amin's and my own personal experiences. When we were in the field he felt, as a Muslim, constantly threatened and at times quite scared, emotions that I was not always aware of, much to his dismay. For the most part I did not feel the same way. The camera cannot record what the researcher is feeling unless the researcher is undertaking a video diary, which I did not, however it is something I think may prove interesting to explore in the future.

\section{Research Methods: Visual Methods}

I had decided before entering the field that the research I was undertaking could feasibly include and possibly benefit from the use of film (video) as a data generating and observational tool.

It is not my intention here to provide a history of the development of Visual Anthropology from its inception by makers such as Mead, Bateson and Flaherty 
among others, and more specifically to its growth over the last twenty years ${ }^{10}$. Rather, it is my intention to discuss the use of visual research methods and their contribution to this research. David MacDougall, a leading filmmaker (and writer) in visual anthropology, says that film provides a visual experience of 'the unique individuality of human beings through their faces, gestures, postures, speech and interaction with others' (MacDougall 2006:272). This enables a very different kind of knowledge from that gained from a written text, which is why I wanted the reader, as viewer of Black Mountain, to be able to 'experience' the social world of that pilgrimage, in a different way from what is described in this text.

Despite visual anthropology being a fast growing subject in its own right, it is presently uncommon to find visual based postdoctoral anthropological degrees in which a film or a work of art, for example, can represent a percentage of the final assessment. In most cases, as with my own doctoral work, even though it is permissible to incorporate the visual into the research, it is the written text that makes up the evaluation. The visual becomes an added part of the research process, not necessarily contributing directly to the final evaluation. In this case producing a film and a full-length thesis can be an overwhelming task, and it has certainly been extremely difficult dividing time between attending to the needs of the film and of the written thesis.

Since I began this doctoral candidature there has been a notable increase in short courses available to students interested in undertaking visual based research, to the extent that it is relatively easy now to take a short course in understanding the basics of ethnographic and documentary film-making without having to enrol on a degree course to do so. However at the time I was going into the field these courses were few and far between and very costly. I did manage to take a weekend course in the basics of digital film-making, however this was not based on ethnographic filmmaking, but short fictional films.

\footnotetext{
${ }^{10}$ Please see, among others, Banks \& Morphy 1997, Banks 2001, Crawford \& Turton 1992, Devereux \& Hilman 1995, Grimshaw 2001, Guindi 2004, Heider 1971, 1997, Hockings 1995, Loizos 1993, MacDougall 1998, 2006, Pink 2001, 2004, Ruby 2000.
} 
My objective going in to the field was relatively simple, I wanted to record my research process as it proceeded. So, just as David MacDougall (2006) expresses in his discussion about his film project with the Doon school in his book The Corporeal Image, I entered the field without a script, but with a camera, along with myself, as an instrument for observation and recording experience. I had more or less no experience of using a video camera, I did have an assistant (Amin) who has worked in film, the fictional kind, but in most ways both of us were learning on the job. My association with still photography meant I quickly understood the basic technical aspects of the camera, however it was not really until watching the first set of footage, that I realised, the way you shoot, and frame an image is very important so as not to produce a type of amateur home movie. As the fieldwork developed, so did our understanding of using the camera. We also understood quite quickly that in order to be able to record the research process completely it was much easier if there were two people present, this meant that either Amin or I operated the camera when necessary. Without this support, it became increasingly obvious that at times when one is in conversation with an informant or active in participant research it is almost impossible to do it completely with a camera in hand. During these times you become extremely aware of what is pictorialised through the camera lens and at times miss out on surrounding activities, which may be important to the research. This is one of the issues that using a camera in the field raises, other issues include the subjective nature of film-making, much like the subjectivity discussed in the section on participant observation above. But as Clifford states 'ethnographies cannot reveal or report on complete or whole accounts of reality...they only ever tell part of the story’ (Clifford 1986:6, cited in Pink 2001:8).

Another issue debated between anthropologists is whether the camera can become more important than the research and intrude into the generation of data, for example, those under study may be affected by the presence of a camera, therefore failing to ensure a 'true' representation of the situation. In order to allay this criticism of film, some anthropologists have argued for purely observational film in which the camera captures 'un-tampered events' (Nicholls 1984:259). In this kind of film-making 'long takes should be employed in order to preserve the integrity of events in the wholeness in which they spontaneously occur' and 'stylistically the camerawork should be low-key’ (Henley 2004:114). Secondly, the film-maker 
should be absent in the film, a viewer of an observational film should not be aware that there is a film-maker or camera in between the image and them. This is a factor that in the past MacDougall, among others, has taken objection to, stating that it dehumanises film-making, a process that, as discussed above, he believes is intrinsically reflexive. He argues that 'by revealing his role, the filmmaker enhances the value of this material as evidence. By entering actively into the world of his subjects, he can provoke a greater flow of information about them' as well as recording 'one culture encountering another' (MacDougall 1998:283). Participatory film does exactly this, in that the film-maker and the events which occur play an active role in the story telling, even giving the subjects of the film the opportunity to film themselves as well as viewing and reacting to the film. The intention is that their reflections and insights, including comments about whether the film has turned out how they had envisaged, can be incorporated before the final edit; this ensures a truly participatory process in that the film-maker shares with the subjects of the film the final aspect of the story-telling process.

There are issues posed in being able to fulfil this kind of participation completely, especially when a film-maker stumbles, as I did, on a sensitive subject and the film then evolves into something that it did not set out to be. This is an issue discussed further below when considering the ethical dilemmas of research. Self-reflexive films, as discussed by Nicholls (1985) 'mix[es] observational passages with interviews, the voice-over of the film-maker with inter-titles' (1985:260). In Black Mountain I hoped to be able to produce a film that involved a certain amount of observational cinema along with participatory elements, and self-reflection of an autobiographical nature that allowed for a transparent understanding of the research process. I had not set out to make the self-reflexive type of film described by Nicholls, having in the past taken a dislike to the 'voice of God' style of narration over an otherwise meaningless visual.

It was through the editing process of the film that changes in the style of film that I could make began to emerge. It is common for documentary and ethnographic films to be constructed on the editing table, due to their unscripted nature. It quickly became obvious whilst editing Black Mountain that, due to the sensitive and complex turns that the research was taking, much of the footage and interviews would need to be given context in order for a viewer, to understand the narrative. It was important 
for me as researcher and film-maker, that the film reached as wide an audience as possible. Knowing relatively little about the process of film-making prior to embarking upon this process, I did not foresee the type of film that this would mean, i.e. one that would have to have an authoritative, but not anonymous, voice-over, in order to communicate its point. Through the editing process, when I realised that the complexities of the background to the issues of politics and religion in India were not coming across clearly, I had little choice, some kind of commentary would definitely be required. Rather than using an interview with a religio-political historian or such like, in order to stage the information required to fill in the gaps, I decided to use my own voice. As MacDougall expresses 'ideas do not develop in an orderly fashion: they begin with a notion that gathers authority until it is altered by experience or some new understanding' (2006:141).

One of the most positive aspects of the film-making process was the edit during which it dawned on me that the edit was becoming an analytic process; the footage I had was in fact my data, whilst editing the film I was analysing the data constantly, and my understanding of it evolved as the film edit evolved. Making and editing the film has given me a much deeper insight into my research than I might have gained otherwise.

\section{Ethics in research}

Ethics refers to that complex of ideals showing how individuals should relate to one another in particular situations, to principles of conduct guiding those relationships, and to the kind of reasoning one engages in when thinking about such ideals and principles (Smith 1990:141).

The Ethical Guidelines of the Association of Social Anthropologists (ASA) state that 'as professionals and as citizens' anthropologists 'need to consider the effects of their involvement with, and consequences of their work for; the individuals and groups among whom they do their fieldwork (their research participants or "subjects”)' (ASA 2008). It is our duty, as social researchers, and as ethnographers, to acknowledge the ethical dilemmas we face in undertaking social research, after all the 'conduct of social research has effects upon all participants... and its outcomes have implications at social and political levels' (Homan 1991:160). It is vital then, 
as Pink insists, that 'a consideration of the ethical implications of ethnographic research and representation should underpin any research project' (2001:36). Punch mirrors this attitude when she describes fieldwork as a 'craft that involves both coping with negotiations and continually dealing with ethical dilemmas’ (1998:159). May states that 'ethical decisions are concerned with what is right or just' (1993:42). However what one thinks is right or just will depend on a personal moral judgement, often reached in a particular situation - my own decisions on these issues are discussed at the end of this section, and in various sections of the thesis.

Invariably in a discussion concerning ethics in anthropological research there will be debate around the appropriateness of a 'code of conduct'; there exists considerable conflict within the anthropological profession as to whether an ethical code of conduct is conducive to good research. However, I do not think that any researcher would disagree with the idea of guidelines to aid research during fieldwork, but there are fears that a code of conduct should not become a set of strict rules by which researchers must abide. Punch, for example, discusses the issue of codes at length, acknowledging that 'codification presents a number of dilemmas, particularly for researchers who engage in [anthropological] fieldwork' (1998:168), she makes an interesting point stating that,

The generality of codes often does not help us to make the fine distinctions that arise at the interactional level in participant observation studies, where the reality of field settings may feel far removed from the refinements of scholarly debate and ethical niceties (ibid. emphasis in original).

Her comments highlight the fact that ethical codes may not be easy to put into practice in the field, if only for the obvious reason that fieldwork varies so widely from one piece of research to another. And 'a strict application of codes [may] restrain and restrict a great deal of informal innocuous research' (op.cit.171). The issue of ethical codes provides increasing dilemmas for funded research. Often funded social research depends on researchers adhering to a set of ethical guidelines either fixed by the professional body of the subject concerned, or most commonly, by the funding bodies themselves. In certain instances funding may be stalled if there appears to be a breach of ethical conduct. In ethnographic and visual research, it is not unusual for researchers to keep a flexible code of ethics they feel best suits their 
research which allows for 'the methods to serve the aims of the research, not the research [to] serve the aims of the method' (McGuigan 1997:2, cited in Pink 2001:3/4). However by installing ethical boundaries via ethical codes the freedom of research should not be lost.

It is suggested that a reflexive approach to research will encourage greater ethical behaviour; 'with increasing reflexivity in the conduct of social research...comes greater awareness of ethical questions...' (Davies 2008:53). This is a point echoed by Burgess, who suggests that,

it is only by constant self-evaluation and reflection on our research experiences that we are most likely to understand moral dilemmas and the compromises that we are required to make in the conduct of field research (1984:207).

Pink develops this further by pointing out that ethnographers must develop an 'understanding of the ethical context(s) in which they work' which will then enable a more 'reflexive approach to their own ethical beliefs' (2001:37). The acknowledgment of the context of ethical dilemmas is extremely important, as the cultural context of a piece of research will obviously affect decisions in the field, be they ethical or methodological. Methods and ethics are 'embedded in the specific research contexts' (ibid) therefore, to confine research to a set of strict ethical codes before research has begun, can sometimes be unrealistic.

Ethical issues have always been a topic for debate in social research; however, with respect to area of ethnographic film, they are an increasing area for concern. Technology has advanced enormously and digital video has made film-making economically more viable for researchers and has therefore made film-making a more accessible research method. As MacDougall points out 'it has now become possible to make a professional-looking film largely on your own, shooting it yourself and editing it in your home or office’ (2001:15). These technological advancements have increased awareness within the profession of visual anthropology of the importance of paying more attention to ethical issues, 'ethical considerations in anthropology are nowhere more important than in filmmaking’ (Asch 1992:95). 
Murphy and Dingwall (2001) in their discussion on the ethics of ethnography cite Beauchamp (1982) in setting out four main principles associated with ethical practice: Non-maleficence; beneficence; autonomy or self-determination; and justice (2001:239). However ethical issues can range across the whole sphere of the research system including concern for: the participants and subjects; fellow researchers and the discipline in general; sponsors, funders and employers (if applicable) and even the researcher's own or host government (ASA 2008) ${ }^{11}$. The first category, i.e. concern for the research participants and subjects, is the main focus of this discussion. In general the issues involved in this category are associated with: harm; consent; privacy; confidentiality; anonymity; trust; protection; rights.

In all anthropological research what is of prime importance, is that anthropologists acknowledge and realise the fundamental responsibility they have to the participants, subjects and cultures they study. This begins with ensuring that 'the anticipated benefits of a study outweigh its potential risks', in the way of harm that the research may have on the people and society in which it is concerned (op.cit.340). A second part of that responsibility is being sensitive and understanding towards the subjects, both during fieldwork and in how the researcher writes about his/her subjects afterwards, or presents them in a film. Researchers should 'endeavour to protect the physical, social and psychological well-being of those whom they study as well as their rights, interests, sensitivities and privacy' (ASA 2008). In film-making it is important that the maker is aware of the possible effect of the presence of the camera and that it may not always be an appropriate research tool; this concern should involve developing 'an ethnographic appreciation of how visual knowledge is interpreted in a cross-cultural context’' (Pink 2001:33).

The next major concern for the anthropologist is that of consent. The principle of informed consent is that the human subjects of research should be allowed to agree or refuse to participate in the light of comprehensive information concerning the nature and purpose of the research (Homan 1991:69).

\footnotetext{
${ }^{11}$ Neither the ASA (2008) or Murphy and Dingwall (2001) claim the only ethical concerns within social research are limited to these, as it is widely acknowledged that whilst in the field further issues can always develop. One example of this concerned with ethnographic film is that of distribution of the finished film and its interpretation by different audiences which can range from professional academic environments to the general public.
} 
Issues of consent are paramount both for anthropologists and film-makers, 'negotiating consent entails communicating information likely to be material to a person's willingness to participate' in the research, 'such as the purpose(s) of the study, and the anticipated consequences of the research' (ASA 2008). This should be in a style and language that will enable those concerned to understand the aim of the research (Davies 2008, Homan 1991, Pink 2001, Schaeffer 1995:256). Depending on the context of the research 'people may be less competent to comprehend the explanation of the research and to make an informed decision' (Davies 2008:58), as ‘they may have no concept of social research’ (Homan 1991:74). In these circumstances consent may well be given, but how many people give their consent with full knowledge of what may be involved in taking part in research, the political or social implications it could have, and if a film is produced, to whom it will be shown. Winston (1995) discusses the issue of consent in documentary film-making at length and with specific reference to films that involve people with mental illness.

One aspect of research that can affect the issue of consent is that it may be difficult for the researcher to predict completely the consequences of research. For example, informed consent might have been taken at the beginning of the research, but the research goals could change during the process. In this case, according to the ASA guidelines, consent should be re-negotiated if required. The idea of re-negotiation however is ambiguous too depending on the situation of the research. Prior to beginning my research, whether through participant observation or interviewing, informed consent, where possible was obtained from the participants, this also included consent to the use of a camera to record events. As has been already discussed and is illustrated throughout the following chapters, the context of this research changed from participation in a local pilgrimage to discovering a right-wing political agenda in the guise of a pilgrimage. At the outset, informed consent to take part in the pilgrimage, as a participating pilgrim, was given; however, when the political nature of the pilgrimage was realised, it was not re-negotiated. This was due mainly to the fact that if it had been re-negotiated, most probably informed consent would have been refused. After participation in the pilgrimage and on returning into the field, in order to discover a further history of the pilgrimage site, the issue of informed consent arose again. It remained difficult, even at this stage, to openly reveal the now political nature of the research subject to local informants, 
because, had some of the informants known, they may not have been too willing to talk to Amin or me about the site. In these cases, consent to participate was not completely informed. Rather, consent was given on the general description of the research as being an 'interest in the site of Kalo Dungar'. It is important to note here specifically, the different ways in which Hindu informants and Muslim informants were approached and informed about the research. The reasons for these different approaches are discussed in the ethnography Chapters 4 \& 6; however, it is necessary to mention the ethical consequences of these decisions at this point. It is made clear in the ethnography chapters that, on my realising the political nature of the pilgrimage and related activities at Kalo Dungar, Hindu informants were not informed in complete detail about the reason for our enquiries, i.e. to discover previous histories related to the site. We did not inform them of our political experiences at the site as this would have meant that a) our line of enquiry would most probably have been closed by them and b) it would have put us in a position where we might have been looked upon in a negative manner by them, and other sections of the same community. Bhuj is a small town and it is difficult to stay anonymous especially considering our history with the city, this meant that we could not completely reveal my research purpose without putting ourselves at possible risk from the right-wing community. On the other hand, our experiences with the Muslim community were different, especially those who lived around the site of Kalo Dungar. The fact that Amin was a Muslim ensured a certain amount of trust from other Muslims who were willing to talk openly about the history of the site and their connection to it, including the political nature of the activities that currently surround it. It was possible to be more honest with this community regarding the nature of our enquiries because we were not associated with the political bodies involved and they did not feel threatened by our research or us; they no longer had interest in the site, unlike the Hindu community to whom our research, at times, might have seemed disrespectful to Lord Dattatreya and their dedication to him. In this situation it is very difficult to reconcile professional ethical judgements. If I had been asked prior to this research if I would conduct semi-informed research I would have categorically said no, for the reason that it goes against my ethical viewpoint, however I had to reconcile this dilemma, and I did so by carrying out semi-covert research with the idea that 'social inquiry is predicated on the belief that greater access to well-founded information will serve rather than threaten the interests of 
society' (ASA 2008). I had to make a moral judgement at this stage in the research process and I did so, by continuing with the research, in the hope that if I completed it, I would be able to illustrate the changing nature of India's shared faith traditions which would perhaps 'serve, rather than threaten, the interests of society' in the longterm. Some film-makers 'produce images to inform audiences of injustices, corruption, and other societal ills, often to persuade people to act against these evils' (Ruby 2000:147). Even though I did not originally intend to make a film with this motivation, to some degree parts of Black Mountain do present a relatively negative aspect of Indian society, that of right-wing Hinduism. Ruby (2000) expresses a great doubt in the ethical procedures of research being upheld in a film of this kind, and it has been argued that 'some measure of deception is acceptable in some areas where the benefits of knowledge outweigh the harms' (Punch 1998:172). Deception, like informed consent, is a complex issue. However, as in all genres of research and film-making, one can only hope that as anthropologists we endeavour to uphold a moral commitment to ethical behaviour and research.

Another issue of consent arises in the context of crowd research. It may not always be completely physically possible for the researcher to inform the participants about the research in order to gain their consent. In certain situations trying to do this can be highly disruptive to the research process (Davies 2008, Hammersley \& Atkinson 1985). It is often the case that 'ethnographers...do not have the power to ensure that all participants are fully informed and freely consent to be involved' (Hammersley \& Atkinson 1995:226). And in most cases, as Murphy and Dingwall point out, 'research lies on a continuum between overtness and covertness' (2001:342). Many of the pilgrimage sites and religious festivals that were initially the focus of my research attracted crowds of over fifty thousand people on a daily basis. With such vast numbers it would not have been physically possible to gain consent from each individual. This issue becomes even more complicated when one is making a film. In most circumstances, during filming, as in still photography, one would seek the permission of the 'subjects of the images' (Pink 2001:43). In ethnographic film, however, there is often continual activity in the background of a scene or image and it may not be possible to trace these individuals, and in both visual and text-based ethnography 'the observation of crowd behaviour... would be rendered impossible if individual consent were required from each of those observed' (Homan 1991:75). 
In crowd behaviour observation the researcher may only be able to seek consent from a gatekeeper, just as Winston (1995) explains in making a film on the mentally sick, the gatekeeper might be the hospital rather than the persons themselves. There are different kinds of gatekeepers; there are those who control the access to a research site who have a legal responsibility to monitor entry or access to an area, and those who are acting on behalf of the research subjects, such as hospital governors. Gatekeepers can even be in the form of senior officials such as politicians and highranking police officers. It was this kind of gatekeeper that I was required to approach in order to gain access, and subsequently consent, to film at both at the Kumbh Mela and at Kalo Dungar. There, at the outset of the pilgrimage, I asked various people involved in the organisation of the pilgrimage for consent to research and film and I gained consent from those with whom I engaged in conversation and interviewed. Some ethnographers insist on signed consent forms at the start of filming which are then used as 'blanket permission' for the rest of the shoot, this may be effective if an intense and detailed discussion has taken place prior to filming (Banks 2001:132), however, in an ethnographic context, such as the one illustrated above, I am not convinced this is the solution to this ethical problem. Rather it just provides an easy exit clause for some less well-intentioned researchers. Gaining consent is, as we have discovered, an extremely complex issue and it raises many dilemmas. It might be that, as Winston states, 'an appeal for responsible behaviour... is the best we can do'; it is finally the 'the attitude and sensitivity of the film-maker to the subject and the relationship they establish [that] is the clue to ethical film-making' and research in general (1995:240).

Other issues raised in association with consent are: anonymity; trust; protection; rights; privacy; and confidentiality. Asch (1992a) affirms that trust between the ethnographer and the people they are studying is essential, as without trust, consent and/or co-operation to carry out research and filming will be far more difficult to achieve. He points out that trust comes in the form of an unwritten 'social contract' in which we take on the responsibility of not allowing any harm or disgrace to come to those people whom we are studying (1992b:110). An anthropologist should assess key issues; they should be aware of 'political, social, and economic implications of the use of [research] data' (Schaeffer 1995:257) and consider if a piece of written 
research or film footage could be used politically or socially against the participants. During the initial editing process and analysis of this research, it did seem that the film footage and ethnography could potentially be seen in a negative light against some of the participants, and perhaps, due to the political nature of the material, used in a potentially harmful way against them. There was a possibility that Hindu sentiment might be offended, and perhaps the social actors in the film associated with the right-wing politics of Kutch might oppose it. Some, of a group of close friends in Bombay, shown an early cut of the film, found it very difficult to watch to the end. Despite being aware of, and opposing, the sentiment of the right-wing Hindu organisations, watching events unfold on screen proved uncomfortable for them. Because of the Hindu right-wing being so powerful, and the Muslim population being vulnerable to them, I had worried about the social actors in the film from the Muslim side who had presented their version of the history of the pilgrimage site on camera. During the research process however, they themselves had not expressed any anxiety as to playing a part in the research, being recorded on film or telling their story. In fact I was able to be completely honest with the Muslim informants in the film as to the intention of the research, in that it was trying to understand the political Hindu interest in the pilgrimage site. On re-analysis of the film footage at a later date, I realised that, none of them had said anything negative regarding the Hindu right-wing parties and their interest in the site; they had just stated the facts as they perceived them, not even voicing any resentment towards the Hindu community. I, on the other hand, in the editing process and through my initial voice-over, had seen the research and therefore presented the film with what I see now as a slightly anti-Hindu bias. And I had begun to fear for the safety of some of the participants, especially the Muslims, should the film be screened in India. In retrospect, most of this anxiety had probably come from my own experience in the field, which, as discussed in Chapter 4 and 6, was at times extremely tense. Amin felt scared and frightened at what the research was revealing and very vulnerable as a Muslim making inquiries that potentially incriminated the Hindu right-wing, who often declare publicly their distaste for Muslims. More than my participants, Khatri Bhai, also shared some anxieties, and whilst in the field discussed with me issues regarding the sensitive nature of the material and the wish that the film should not present the local Muslim population in any bad light, so as to not increase their already vulnerable state. At this stage we had assured Khatri Bhai that their 
sentiments would surely be respected and that we had no intention of projecting anyone negatively so as to put them in danger. It is my intention to show the complete film to Khatri Bhai, who will then advise me as to whether or not he thinks the Muslim informants might like to see the film themselves and give his opinion as to whether he feels that they would be in any danger because of it.

There is footage in the film that presents right-wing Hinduism in a negative light due to the statements made by the politicians. However, this exposure is less worrying; it is no secret that these are their sentiments, these opinions are aired nationally on a regular basis and even though uncomfortable for people to watch (as discussed earlier), they do not present a harmful situation for them as participants. As for the Hindu informants in the film, the situation is different again. The fact that they are Hindu renders them less vulnerable than Muslim informants, and there was a sense during the research that the reluctance of some of them to talk about the different religious histories associated with the pilgrimage site, other than the Hindu version, implied that they were more aware of the history than they revealed. So even though I did not tell them directly of my political interest in the history of the site, they were most probably aware of it. The information that is given by them is relatively simple, in that no community is being incriminated through their information. And on a recent screening of the final cut of the film, the same people who had found it uncomfortable to watch previously, now felt that the film had a better balance. It is a film now that, I feel, presents a journey with the story of a pilgrimage site mirroring some of the social and political issues that face India today.

Privacy, confidentiality and anonymity are further ethical issues that need to be addressed, and from these three issues a series of questions around the issue of ownership arises. 'Researchers must be cautious about the degree of confidentiality they promise and realistic about their own abilities to protect their informants' anonymity' (Davies 2008:59/60). The use of pseudonyms has generally been the way that researchers have protected the identity and therefore privacy of their research subjects, but as Murphy and Dongwill (2001) point out, they are not always effective; with regard to film, as Banks (2001) points out 'I have never seen the 'fuzzy face' effect adopted by television makers to disguise identity in any ethnographic or sociological documentary film' (2001:131). I am not sure this is still 
the case, but perhaps Black Mountain, if it is considered to put the participants at risk, and is ever screened in India will be the first of its kind. Or, as the ASA guidelines point out, 'in certain political contexts, some groups, for example, religious or ethnic minorities, may be particularly vulnerable and it may be necessary to withhold data from publication' (2008).

The promise of privacy and confidentiality will depend very much on the purpose of the film, especially in terms of its audience, 'I must know on whose behalf and to what end I write' (Strathern 1987, cited in MacDougall 1998:91). It is almost impossible to know exactly the end to which one writes, and 'neither a researcher's own preparation, nor other ethnographers' accounts can predict how a 'visual method' will develop’ (Pink 2001:35).

In the case of this research there are a number of dilemmas concerning the protection of informants' identity and ensuring confidentiality, especially due to the extensive use of visual materials, both photographically within this thesis and through Black Mountain. I decided to include photographs within the written text in order to give visual context to the material in the knowledge that a thesis is not a published document for public reading. However if future articles were to be published from the research then pseudonyms would be used and photographs avoided. However, with regard to Black Mountain, these dilemmas are more complex. It is hoped that the film can be submitted to ethnographic film festivals. Despite their specific audience these are public events that anyone can attend. In this case, it is intended that permission be obtained from the informants in the film, so that the film can be screened at public events of this kind, should it be accepted. However, if permission is refused it would be unfortunate that the film, which offers a unique autobiographical account of the research process as well as making political comments, may not reach out to the audiences for whom it was intended. This is an ongoing dilemma which the researcher hopes will reach a positive outcome. One of the potential solutions would be to re-cut the film and edit the informants who may refuse permission or 'fuzz out' their faces in order to protect their identity.

A final issue to be discussed, especially with regard to film, is that of ownership, distribution and interpretation. Who owns the image? Who decides where an image 
should or should not be screened and how does one control how the film will be interpreted? Most important is that the element of trust that has built up between the ethnographer and the participants should be honoured. The most common way of offering something back to those who have put their trust in you for your research is, in the case of film, to take it back into the field for the subjects to see (Banks 2001, Pink 2001, Asch 1992b). Screening the film to your subjects can provide you with vital feedback as to how the film might be improved, and as to whether the film has communicated to the audience what was intended? Many of these suggestions are extremely dependant on the context of different research situations like the instances I have described throughout this chapter; however they provide food for thought for the ethnographer who is conscious of carrying out ethically sound research. One way of resolving this issue is getting signed release forms from the people who participated in the film, something that can only really be done once they have viewed the finished product and can make a judgement about it. Some film-makers endeavour to get signed release forms from the outset, however, just as with the issue of consent, unless one can know the outcome of the research before it begins, it may not be appropriate to take signed forms from people when you as the maker do not yet know what the film will say.

In conclusion to this section on ethical practice, it is important to remember that 'social research is an engagement not an exercise' (Banks 2001:179), involving people not objects who have allowed us into their lives, reciprocating this trust and respecting the individuals involved should be of paramount importance to the ethnographer. However what cannot be avoided is that 'the personal dimension of ethnographic research, the moral and philosophical beliefs of the researcher and his or her view of reality impinges greatly on the ethical practices that he or she applies in research’ (Pink 2001:37).

\section{Conclusion}

The intention of this chapter has been to provide a comprehensive overview of the methodological framework through which this research has been undertaken, and into the issues facing ethnographers and ethnographic film-makers in carrying out research. The following chapter provides an insight into the development of communal politics in India. 


\section{Chapter 3}

\section{India's Pledge}

\section{an insight into India's political history and the growth of religious communalism.}

India is my country and all Indians are my brothers and sisters, I love my country and I am proud of its rich and varied heritage. I shall always strive to be worthy of it. I shall give respect to my parents, teachers and elders, and treat everyone with courtesy. To my country and my people I pledge my devotion. In their wellbeing and prosperity alone, lies my happiness. (India's National Pledge).

Black Mountain, the film which accompanies this thesis and forms an integral part of it, opens with a young boy ${ }^{1}$ reading India’s Pledge ${ }^{2}$. India’s Pledge was formulated at the time of India's independence as an oath of allegiance to the Republic of India. A promise that every member of the population would make, to respect their historical heritage, and each other as people, to realise what freedom and independence meant for India and to remind them to abide by the moral guidance that the pledge suggests in order to achieve India's dream of peace, happiness and prosperity $^{3}$. Similarities of this pledge can be drawn with the USA 'pledge of allegiance' and other oaths of allegiance made to countries, monarchs, constitutions and even national flags ${ }^{4}$.

The Pledge makes a relevant starting point for this chapter ${ }^{5}$. My intention is to summarise the troubled legacy that is India's history from the end of the $19^{\text {th }}$ Century

\footnotetext{
${ }^{1}$ The boy is my husband's nephew Kaashif.

${ }^{2}$ See Black Mountain - chapter 2.

${ }^{3}$ I was drawn to this pledge at a point in my research where the realisations of the lost dreams of a nation were beginning to impact on me emotionally. Perhaps the idea of marrying into this rich, varied and, as I was discovering, quite troubled heritage was drawing me even closer to my subject than I evidently was already.

${ }^{4}$ It is not apparent who the author of the Pledge was or in which language it was originally written, but I think it is a fairly safe assumption that it was written in English, that being the language of the government at this time.

${ }^{5}$ The Pledge appeared a poignant notion to include in the beginning of the accompanying ethnographic film too, and one I felt complemented the reflexive nature of the film. It is my intention that this pledge should place the dream that was Independent India at the beginning of the journey. As the viewer learns through the film about certain aspects of India today, there is a sense of irony in considering the words of the Pledge, then confronting the current situation that separates the reality, from the dream that was so paramount to the founding fathers of India's Independence.
} 
to the present day, providing a basic chronology of events. This chronology includes the growth of communal politics during and after India's struggle for Independence ${ }^{6}$.

\section{Political background 1885 - 1947 (pre-independence)}

The roots of India's dream of political sovereignty can be found in the formation of the National Congress in 1885. The Congress was India’s first nationally unified political association through which various issues were debated ${ }^{7}$. The membership of the Congress from the outset was predominantly Hindu with very little representation of other minority communities (perhaps with the exception of the Parsees).

Initially the members of Congress faced difficulties in framing their political policies, because of the need to maintain inter-community unity; they did not want to be seen as appeasing the (Hindu) majority and upsetting the (Muslim) minority. But certain members in the Congress relied on 'Hindu symbols and traditions' to rally support, and even though as an organisation the Congress avoided religious association, these rebellious members believed that the

Hindu masses could only be aroused through the use of religious predisposition, the popularization of national historical myths, and the celebration of Hindu festivals and [these members] decided to blend Hinduism with nationalism (Hasan 1994:22/3).

Specific members like Bal Gangadhar Tilak, Aurobindo Ghose and Lajpat Rai actively used Hindu religious symbols and traditions to rally the support of the mass populations ${ }^{8}$ within their local states of Maharashtra and Bengal. Bal Gangadhar Tilak (1856-1920) became extremely well known for reviving an old religious festival in Maharashtra called Ganpati in which processions are held in honour of the

\footnotetext{
${ }^{6}$ This is so the reader can put into context the material presented in this thesis and in the accompanying film.

${ }^{7}$ The National Congress became 'the organizational vehicle for India's first great nationalist movement, embodying the dreams and aspirations of "New India"” (Wolpert 2004:255). Prior to its formation there were many localised groups, which had been unified on a regional scale, and many smaller groups as well, most of which were 'quasi religious' in nature rather than politically secular (Seal 1971:249); such as the Arya Samaj in Bombay and the Brahmo Samaj in Calcutta.

8 'Mass population' is a term often used in India to describe the majority population of the country who are Hindu, live in rural towns, villages or slum dwellings of metropolises and are poor, with little or no education.
} 
Elephant God Ganesh ${ }^{9}$. He also revived another Maharashtrian festival in tribute to Shivaji on his birth date ${ }^{10}$. Both festivals alienated the Muslim population of India ${ }^{11}$. These revivals introduced a completely novel form of political campaigning introducing extremely important and effective tools which were later used to the advantage of Hindu nationalist politics and the nationalist cause ${ }^{12}$; they began a new kind of politics of 'mass Hindu political activism' in the form of 'public, urban Hindu devotionalism' combined with the 'formation of politicised regional folk genealogies’ (Bhatt 2001:32).

Tilak believed that the Vedic Aryan period ${ }^{13}$ in India's history was a period of unity in which a great Hindu nation existed, and he wanted to re-establish this unity amongst the Hindu population in order to build a strong Hindu nation. Similarly in Bengal, Aurobindo Ghose (1872-1950) was ‘adamant about the relation between nationalism and Hinduism' ${ }^{14}$ (Bhatt 2001:38). Another Congress member who aligned himself with the extremist section of the Congress was Lajpat Rai (18651928) a previous sympathiser with the Brahmo Samaj and Arya Samaj ${ }^{15}$, Lajpat Rai believed that "Hindus are a nation in themselves, because they represent a civilization all of their own” (Mathur 1996:1 quoted by Bhatt 2001:50). Many of Lajpat Rai's ideas can be found quite unchanged in Savarkar's Hindutva ${ }^{16}$. The idea

\footnotetext{
${ }^{9}$ Ganesh is one of India's most popular Hindu Gods, and was used as a tool to bring together the mass population in processions; on many occasions processions culminated in violent conflicts between Hindus and Muslims as they deliberately passed by Muslim mosques, see Raminder Kaur (2003). ${ }^{10}$ Shivaji is used as 'the pre-eminent symbol of Hindu militancy [and]... as a symbol for Indian nationalism' (Bhatt 2001:34), who saved the Hindu Maratha population from the onslaught of the Mughals (Bhatt 2001:34).

${ }^{11}$ These political tactics continue to inspire the Hindu nationalist movements, as we discover later in the chapter.

12 These campaigning methods became evident in this research and are extremely well visualised in Black Mountain.

13 The Vedic Aryan Period existed from 1500BCE to 600BCE, a period in which the four Vedas were written. The Vedas became the literary and religious foundation for what is now known as Hinduism. ${ }^{14}$ Ghose was an extremely important figure in the 'revolutionary and terroristic nationalist movements' (Bhatt 2001:28) that were flourishing in Bengal at the same time, that is during the end of the nineteenth century.

${ }^{15}$ The Bhramo Saraj and the Arya Samaj were political parties founded in the second half of the nineteenth century that supported and promulgated the idea of a 'Hindu supremacy' over other religions (Bose \& Jalal 1998:111) and the purification of Hinduism in general.

${ }^{16}$ This is an ideology that will be discussed later in the chapter, as well as the ideologies of the RSS, or Rashtriya Swayamsevak Sangh; the most powerful and successful Hindu nationalist organisation in India.
} 
that religion represents true nationalism is mirrored in many other European histories, for example Northern Ireland and Greece ${ }^{17}$.

The activities of these extremist members of the Congress ensured a growing feeling of antipathy among the Muslim community towards the Congress's visions of nationalism. And there was an increase in both Hindu and Muslim consciousness, highlighted in the formation of essentially Hindu organisations such as the Bhramo Samaj and Arya Samaj and a separate Muslim political conference ${ }^{18}$. This development simultaneously began to undermine syncretic traditions and practises and 'inter-religious peace and understanding' (Hasan 1994:47).

\section{The breakdown of unity and the development of a separate political consciousness}

The breakdown of unity came in two forms: first the introduction of the decennial census which made very public the social status and religious identity of the people of India. The British Crown then used these statistics to establish majority and minority communities. Despite internal differences within the Hindu and Muslim communities, this was the first time that these communities were now officially defined as either Hindu or Muslim (Bose \& Jalal 1998). These new administrative data did not allow for the ambiguity that existed within the religious traditions of the communities they categorised. The roots of partition are found in the minority (Muslim) communities' fears that their political rights might not have been protected under what was perceived as a majority (Hindu) community government. 'Aggressive imperialism' of the Viceroy of 1899-1905, Lord Curzon (Bose \& Jalal 1998:117) was the second factor that contributed to the breakdown of communal ${ }^{19}$ unity, with the decision to partition Bengal in 1905, vehemently opposed by the

\footnotetext{
${ }^{17}$ In Northern Ireland, for example, ‘a Roman Catholic... is a person who believes he is "Irish”, to be a Protestant on the other hand is to support the Imperial rulers' (Hickey 1984:57). In Greece 'to be Greek and to be Orthodox [Christian] are very nearly synonymous...Nationalism and religion are thus closely intertwined' (Dubisch 1995:131).

${ }^{18}$ The Muslims of Bengal, the state in which the largest community of Muslims resided, had begun to create their own associations such as the National Mahommedan Associations (Seal 1971).

${ }^{19}$ A term used throughout this research and much of the literature on India's political history to describe the relationship between religious communities, usually between Hindus and Muslims, in the same way as 'communal politics' describes the political policy that uses religion as its main driving force.
} 
majority of the country's population ${ }^{20}$. A violent rebellion ensued, terrorist activities increased, as well as radical nationalist action all over the country. It was at this time that Congress began its demands of self-rule.

In 1906, India witnessed the development of the Muslim League, a period referred to as the Muslim breakaway. They wanted 'to safeguard the separate interests of Muslims within any proposed constitutional reforms' (Bhatt 2001:45) ${ }^{21}$. Someone who gave his complete support to the League was Lord Minto, he made promises to the Muslim community that, in any 'administrative re-organisation' he was involved in, their interests and their rights would be protected (Wolpert 2004:277). And in 1909 Viceroy Lord Minto and Secretary of State John Morley put forward the Morely-Minto constitutional reforms bill ${ }^{22}$. The bill, aimed at providing a limited elective membership to the Indian Legislative Council so as to protect the government from being dictated to by any majority community, introduced guaranteed separate electorates for Muslims (Bhatt 2001, Kulke \& Rothermund 1998) ${ }^{23}$. The bill remains a bone of contention in Hindu-Muslim relations. 1909 also saw the formation of the Hindu Sabha or society, formed, according to Jaffrelot, in response to the already 'pro-Muslim bias of the British administration' (1996:18). Its intention was to uphold Hindu interests in much the same way as the League intended to uphold Muslim interests ${ }^{24}$.

\section{Establishment of separate electorates and the Lucknow pact}

The separate electorates for Muslims were finally established in 1917 in the Montague-Chelmsford proposals, and finally came into effect in 1919. For most of this period the Congress and the Muslim League were at loggerheads regarding the separate electorates, this was until 1916, when a bid was made to take advantage of Britain and its allies fighting $\mathrm{WWI}^{25}$ who said they were 'fighting for the cause of

\footnotetext{
${ }^{20}$ The Swadeshi movement was formed as a resistance body to the partition. The movement brought moderates and extremists together in their bid to reverse the partition, and to boycott colonial rule, including foreign institutions and goods. Bengal was reunified in 1911.

${ }^{21}$ It is important to note here that the Muslim League was not supported by the whole Muslim community, rather a section of it (Puniyani 2003).

${ }^{22}$ This was influenced greatly by the Home Secretary Herbert Hope Risley (1851-1911).

23 This was a precedent that had already been set by the British in other colonial countries such as Cyprus (Pandey 1979:33).

${ }^{24}$ By 1915 it was renamed the Hindu Mahasabha, which worked towards providing 'a collective defence of the socio-political interests of Hindus’ countrywide (Jaffrelot 1996:19).

${ }^{25}$ World War one.
} 
freedom and would themselves advance the cause of self government' (Hasan 1994:82). The Congress and League realised that it was time to make peace with each other if they were going to fight for constitutional reforms and self-governance. Mohammed Ali Jinnah, one of the main leaders of the Muslim League, through his tireless negotiations to try to bring unity between the two parties, held a meeting in Lucknow in December 1916. The Lucknow Pact ${ }^{26}$ was made, when Congress finally 'accepted the principle of separate electorates for Muslims in the larger interest of forging a united Hindu-Muslim front against colonial rule’ (Bose \& Jalal 1998:129). Finally, in 1919, the Montague-Chelmsford reforms, in accordance with the Lucknow Pact, set about creating 'Hindu and Muslim mass constituencies...based on the meticulously collected census data of the colonial state' (Blom Hansen 1999:37) ${ }^{27}$.

Despite this newly created Congress-League unity there was still uneasiness amongst the extremist Hindus. Those in the Hindu Mahasabha felt that the Muslims were being given too much. Some in the Muslim camp too, were extremely unhappy about the newfound unity established with 'non-Muslims' (Hasan 1994). Not all Hindus and Muslims agreed with these extremist attitudes, however the newfound unity between the Congress and League did create a climate of inter-community peace. During this period

it was common for leaders of different religious persuasions to visit temples and mosques and to exhort on the virtues of communal unity...there were dramatic scenes of Hindus and Muslims joining in each other's festivals and removing the irritants in their otherwise harmonious relationship (op.cit.99).

The Lucknow Pact, however, did not work completely in Congress' favour; they made hasty decisions and agreements for immediate political benefit based on separatist ideas. It has been argued that this lost the Congress moral ground and put at risk the secular politics it was trying to build (ibid).

\footnotetext{
${ }^{26}$ Otherwise known as the Congress-League Reform Scheme.

${ }^{27}$ It was ironic that the census system of data collection which facilitated the divide and rule politics of the British Crown, ultimately enabled the nationalist movement to establish mass Hindu-Muslim constituencies united against their colonists.
} 


\section{The non-cooperation movement and the Khilafat movement}

The 1920s have been described as the most turbulent time in Indian politics in which 'India-experienced unprecedented political upheaval' (op.cit.104, Bhatt 2001). The beginning of this has its roots in the Khilafat movement in 1919, described as the most violent anti-imperialist movement since 1857. The social and economic consequences of WWI were immense ${ }^{28}$ and the people were ready to rid India of the British Raj and to create a new unity between the Hindus, Muslims and Sikhs. During WWI, Britain's offensive on Turkey ${ }^{29}$ was seen by the Muslim community as British India at war with a Muslim power. This was the beginnings of the 'South Asian Khilafat movement' (Bhatt 2001:46); part of the 'pan-Islamic' ${ }^{30}$ machinery which ensured many changes took place in Islam worldwide, so as to oppose colonial powers. What brought the Khilafat movement and Indian nationalism together was their common goal of removing foreign power. It was with this ideology that the Khilafat movement, though at times causing communal conflict in India, activated large sections of the population against colonial rule and forged many intercommunal relationships. This was especially so when it was taken up by Mahatma Gandhi as part of his 'satyagraha' ${ }^{31}$ political agenda in $1920^{32}$, when he became leader of the Congress.

By merging the Khilafat movement in 1920 with his non-cooperation movement, Gandhi 'created an unprecedented level of political activity, mass mobilization, and unrest in the entire subcontinent from 1919 to 1922' (Blom Hansen 1999:242). Gandhi's hope was that in helping the Muslims 'in the hour of their peril' he would 'cement the bonds of communal unity' (Hasan 1994:128). During a speech on the Khilafat movement on $24^{\text {th }}$ November and in a letter to the press on $10^{\text {th }}$ October 1919, Gandhi went so far as to say,

\footnotetext{
${ }^{28}$ Britain had drained India’s economy in order to finance their increased military costs.

${ }^{29}$ When Turkey allied with Germany, Britain mobilized its Indian troops against Turkey. At this time, Turkey was still part of the Ottoman Empire, under the Sultan. The Sultan was considered by Sunni Muslims as the 'Amir-al-Mumineen (Commander of the Faithful) or the Khilafat-al-Mumineen. The Khilafat was the viceroyalty of the Prophet of Islam... [and] the Khalifa was the defender of the Holy Places of Islam’ (Hasan 1994:112).

30 'Pan-Islamism - a multifaceted often opaque search for an Islamic meaning in the modern world was the vehicle through which radical and nationalist ideas were conveyed....it signified the unity and solidarity of all Muslims against the common threat of western empires which had penetrated into the heartlands of the Muslim World' (Hasan 1994:107).

31 'Satyagraha' was the non-violent, non-cooperation political resistance movement initiated by Gandhi to fight colonial rule.

${ }^{32}$ August $1^{\text {st }} 1920$ was coincidently also the day that Tilak died.
} 
it is impossible...that one of the four limbs of the nation be wounded and the rest of the nation remains unconcerned...you are my neighbours and my countrymen. It is my duty to share your sorrows. I cannot talk about Hindu-Muslim unity and fail in giving effect to the idea when the test comes (Gandhi 1919, in Hasan 1994:128/129).

However this communal harmony did not last long. During the 1920s the Hindus and Muslims were once again conflicting and competing entities, and extremist views began to predominate. This time, however, they concerned 'which community the Indian nation was going to belong too’ (Blom Hansen 1999:45). On the Muslim side, the Khilafat movement became more Islam-centric; mainly due to the increased involvement of the Ulama ${ }^{33}$, who were not happy with the inclusion of Hindus in what they saw as an Islamic battle that the Muslim community needed to fight. The Ulama were 'a body of men developed to perform specialised religious functions...literally those who possessed knowledge (ilm)’ (Hasan 1981:3, 1994:146). They become known for flying the flag of a pure traditional Islam, 'fossilising' its scriptures, and insisting on a static religion, as opposed to the reformists' more flexible view of Islam, which they believed should evolve with the socio-political situation. As the Khilifat movement became more religio-centric, 'certain Hindu ideologues felt threatened by the mobilisation of Muslims' (Jaffrelot 1996:11). In 1921 Gandhi fell out with the Ulama over differences concerning the nationalist movement, a rupture that was to prove instrumental in the complete breakdown of Hindu-Muslim unity. The Khilafat movement died in 1924 with ‘Ataturk’s abolition of his own [country’s] Caliphate, unleashing pan-Islamic frustrations inside India for what would thereafter be the worst decade of communal rioting' (Wolpert 2004:301) ${ }^{34}$.

As these events unfolded, other sources of Hindu-Muslim conflict developed. These included the 'Moplah Rebellion' ${ }^{35}$ (Bhatt 2001:47), where forced conversions of a number of Hindus to Islam were performed, sparking off violent inter-communal

\footnotetext{
${ }^{33}$ Ulama are the self-proclaimed priesthood of Islam.

${ }^{34}$ The Muslim population of India, along with Islamic communities worldwide, viewed Turkey as the last Islamic power yet to be colonised by growing Christian world dominance, they saw its downfall as another Christian colonial victory, and fighting for its survival had provided a reason for the Islamic communities to unite against foreign powers.

${ }^{35}$ A rebellion which saw Hindu peasants revolt against landlords who were the descendants of Arab merchants.
} 
riots across the country and a campaign of 'reconversion and purification' (Wolpert 2004:306) that forcibly converted Muslims to Hindus using a 'form of Hindu Baptism’ (Keay 2000:480, Wolpert 2004:306). The mid-twenties witnessed unprecedented Hindu-Muslim violence 'so bloody, so gruesome, and so widespread' (Hailey May 1927, in Hasan 1994:211), that Gandhi called off the non-violent noncooperation movement describing the problem as 'an insoluble puzzle' that he would 'keep out of' (op.cit.212).

\section{Beginnings of communalism}

During this extended period of violence the term 'communalism' developed. It was introduced to describe behaviour that was anti-nationalist, which used religion as a political tool and believed it to be the basis on which the nation state should be built. If someone was seen to be supporting the Muslim cause, i.e. being partisan, their behaviour was seen as 'communal' (Bose \& Jalal 1998:143, Bhatt 2001). It was during this period that, rather than a return to religious unity, there was a 'departure from the acknowledgement and accommodation of religious difference' (Bose \& Jalal 1998:143).

Another source of communal tension was the issue of cow protection. The Hindus of India made a plea to ban cow slaughter, the cow being a sacred symbol. Gandhi hoped that the Muslim population would support the Hindus in the cow protection movement, stating in 1925: 'I gave all the help that I could for the Khilafat movement, because I wanted to enlist their sympathy in the matter of cow protection' (Hasan 1994:220), however this did not happen ${ }^{36}$. In supporting the Khilafat movement, Gandhi was accused of bringing religion into the political forum and to some degree held guilty for fanning communal tension (ibid). Jinnah had criticised Gandhi as 'buying Hindu-Muslim unity on the cheap, for which the nation "Hindus and Muslims alike” would have to pay dearly in later years’ (Ahmad 2005: 34).

During this period, too, the Hindu Mahasabha obtained its completely Hindu nationalist direction, using a new framework of ‘Hindu Sangathan' (Hindu

\footnotetext{
${ }^{36}$ The support of the Congress towards cow protection seemed contradictory to their wish for HinduMuslim unity considering the violence that ensued around this sensitive subject; this was just one example of the elements of communal Hinduism within the party.
} 
Organisation or Unity). 'Sangathan...became the foremost rallying-cry of those Hindus who believed themselves to be lagging behind Muslims in mobilization and militancy’ (Thursby 1975:158). The Hindu nationalists used what Jaffrelot describes as their 'stigmatisation and emulation' strategy (1996:20), reinventing a Hindu identity inspired by emulating Western values and cultural traits and yet emulating and stigmatising the threatening other, i.e. Muslims (ibid). In the aftermath of the Khilafat movement, the Hindu nationalists defended themselves against what they saw as the external Muslim threat, by borrowing the traits which they perceived as their (Muslim) strength. According to Balkrishna Shivram Moonje (leader of the Hindu Sabha and later a great influence in the Hindu Mahasabha), this was two-fold. First; the Muslim community was 'religiously well organised and disciplined' ${ }^{37}$ (Moonje 1923, cited in Jaffrelot 1996:20), and he (i.e. Moonje) encouraged the Hindu community to lose its water-tight divisions of caste in order to create a unified community. This behaviour can also be compared to the process of complementary opposition of segmentary politics, which Evans-Pritchard used to explain the political unity that was created by the Nuer tribes who were made up of many differently segmented groups. It was important that when necessary, these segments, who at times feuded between themselves, united, in order to fight against other groups who came to attack them (Evans-Pritchard 1940, Lewellen 2003). Similarly the division of segments that make up what we refer to as Hinduism, need, according to Hindu nationalist politics, to unify in order to fight the Muslim "other”. Further comparisons can also be made regarding this concept of the segmentary political system. The Nuer, Evans-Pritchard states, were more likely to engage in conflict with people who had a culture similar to their own, not against those with a culture very different from theirs, who, because of their difference, were perhaps viewed as less of a threat. In the Indian context, considering the people are all largely from the same ethnic makeup, their differences culturally are minimal, however, religiously they are fundamentally different. But, despite this, the Hindu nationalists felt they needed to build similarities with their opposition (the Muslims) in order to combat them successfully, even though culturally they already shared so many similarities. As will be argued in a later discussion regarding Schismogenesis, the Hindu nationalists can be said to want to move out of a perceived submissive,

\footnotetext{
${ }^{37}$ This was an exaggeration of the cohesiveness of the Muslim community, in which there was very little unity, actually made up of many different and conflicting sects.
} 
complementary relationship with the Muslim community, towards a more symmetrical relationship. In order to do this they thought it necessary to increase the similarities in their behavioural patterns so as to be able to combat them on equal terms.

This imitation of 'the other' also surfaced in Moonje’s second concern, which was the lack of a place for all Hindus to gather in order to create a feeling of 'oneness'. He suggested that Hindu temples be made to 'serve the purpose which the Masjid does for the Mahommedan' (Moonje 1923, cited in Jaffrelot 1996:22). The new framework for the Hindu Mahasabha, the Hindu Sangathan - saviour of the dying race, written in 1926, developed this proposal by Moonje ${ }^{38}$. Building new temples became the policy of the Hindu Mahasabha, and it was conveyed to the mass population through various means of propaganda used in political campaigning. A sense of fear was slowly instilled into the Hindu community that their 'race' was under threat, and vulnerable - a policy still used today by Hindu nationalist parties. This is most evident in Gujarat, a state, that is actively still working towards a Hindu Rashtra, with a policy to build as many Hindu temples as possible, using donations made to the VHP (Vishwa Hindu Parishad) by emigrant nationalists.

\section{The birth of Hindutva, the RSS and Hindu nationalism}

As feelings of inferiority in the Hindu community grew, so did Hindu nationalism. The 1920s can 'be seen as the product of the consolidation of Hindu nationalist ideology' (Bhatt 2001:63). In 1926 the Hindu Mahasabha, through their 'Hindu Sangathan' movement, worked towards producing organisations through which Hindu society would be able to fight and fend off further foreign invaders (Bhatt 2001, Bidwai 2003). In 1923 Vinayak Damodar Savarkar ${ }^{39}$ published Hindutva Who is a Hindu? This is recognised as the 'basic text' for Hindu nationalist ideology (Jaffrelot 1996:25, Van Der Veer 1999:429) ${ }^{40}$, providing the political platform necessary to mobilise the Hindu population. Giving the Hindu community 'a pan-

\footnotetext{
38 The writer of the Hindu Sangathan, Swami Shraddhananda, wrote 'the first step I propose is to build one Hindu Rashtra Mandir (temple of the Hindu nation) in every city and important town, with a compound which could contain an audience of 25,000' (Shraddhananda 1926, cited in Jaffrelot 1996:22).

${ }^{39}$ Vinayak Damodar Savarkar went on to become president of the Hindu Mahasabha 1937-1942.

${ }^{40}$ Hindutva, however, was not a new term. Its roots can be found in Bengal in 1892 when Chandranath Basu published Hindutva - an Authentic Indian History in which he highlighted the superiority of Hinduism to Christianity (Bhatt 2001:25).
} 
communal identity', Hindutva enables the political agenda of creating a Hindu Nation to be fulfilled (Ram-Prasad 1993:294). Savarkar described the Hindu as a 'person who regards this land of Bharat Varsha, from the Indus to the Seas, as his Fatherland as well as his Holy-Land, that is, the cradle of his religion' (Van Der Veer 1999:429). Through his writings Savarkar consolidated the 'various strands of Hindu Nationalism into a political force' (Bhatt 2001:84). His teachings were based on the notion that 'Hindus constituted... a nation', that Hinduism was under siege or threat of 'extermination' in India, and that Muslims were the treacherous 'fifth column' in the nation who had 'extra-territorial designs' (Bhatt, 2001:77/78). Savarkar believed Muslims should be forced out of India; this could be achieved through the 'mass political mobilisation' of the Hindu population (Ram-Prasad 2003:175) ${ }^{41}$. The core doctrine of Hindutva states that:

Hindu, and Hindus alone, constitute the Indian nation, since they are the original inhabitants and sole creators of its society and culture. Hinduism is uniquely...tolerant...but its tolerance has often been mistaken for weakness. The Hindu nation has been repeatedly conquered by aliens particularly Muslims and then the Christian British...The subsequent entry and takeover by foreigners created the illusion that India was a land of many different and equal cultures. In truth, however, all cultural traditions survived by Hinduizing themselves - otherwise they remained alien, distanced, oppressive (Basu et al 1993:37).

Savarkar stated in his writings that 'Hindutva was not a word but a history' (Savarkar 1923, cited in Bhatt 2001:86). What lies at the heart of Hindutva is 'the myth of a continuous thousand-year-old struggle of Hindus against Muslims as the structuring principle of Indian History' ${ }^{42}$ (Basu et al 1993:2), alongside the important fact that the inhabitants of Hindustan believed it to be their Holy Land. Initially Savarkar believed Hindutva to represent a group of people, of the same territory, sharing racial and cultural characteristics who would make up the nation. The development of religion as a criterion to explain the ideology of Hindutva came later in his thinking. In 1989 he went as far to say that 'racial inheritance of Hindu blood was the most

\footnotetext{
${ }^{41}$ It has been suggested that these Hindutva ideologies gave rise to [the notion of ] a two nation theory and there can be no doubt that it contributed to the partition of India in 1947 (discussed later in the chapter).

${ }^{42}$ Myths of this kind and others comprise much of how Kalo Dungar and other sites like it are viewed by the local population. Through oral history and folklore 'myths' becomes 'facts' in the minds of the local people who feel some sort of ownership over these religious sites.
} 
important characteristic of Hindutva' (Savarkar 1989, in Bhatt 2001:95). This was the final component that prevented any other faith than Hinduism from being a part of his envisaged nation ${ }^{43}$. Savarkar's thinking was hugely influenced by Giuseppe Mazzini (1805-1872), 'in Mazzini, Savarkar found an ideological framework and a political philosophy that combined cultural pride and national self assertion’ (Blom Hansen 1999:77). Jaffrelot suggests that 'Savarkar learnt nationalism from the Western experiments and then tried to apply this imported concept to his own country’ (1996:26).

Founded by Dr Keshav Baliram Hedgewar in Nagpur Maharashtra during 19241926, the RSS went on to establish itself as 'the most important and politically successful Hindu Nationalist Organisation' and the main driving force behind militant nationalism (Bhatt 2001:113). Its political ideology came from Savarkar's Hindutva, and soon Western fascism, such as that developed by Mussolini and later the Nazism of Hitler, began to influence its nationalist thinking: 'the RSS draws a deep inspiration from Hitlerism’ (Moazziz 2003:36).

Hedgewar's guide and mentor was Balkrishna Shivram Moonje ${ }^{44}$. Both of them believed that many of India's problems were based on her 'inability to defend herself' because of the 'lack of coherent social organization and a sense of national consciousness' (Beckerlegge 2004:109). It was these beliefs that led Hedgewar to develop the training grounds and programmes the RSS cultivated, aimed at 'character building' (Beckerlegge 2004:109) ${ }^{45}$, that mirrored the 'fascist [Italian] youth organisations that had been set up in order to discipline and instil in them [the youth] a respect for traditional values’ (Casolari 2003:109). These institutions had been visited by Moonje in 1931 during a trip to Italy when he met the Fascist leader

\footnotetext{
${ }^{43}$ One can only assume that it must have dawned on him that if one talked of Hindutva representing a culture and territory, then that very culture and territory was shared by other faiths too, most probably converts from Hinduism itself. Ironically then, even those converts would have some inheritance of Hindu blood.

${ }^{44}$ It was Moonje who moulded Hedgewar during his revolutionary training in Kolkata while he was studying to become a doctor (Beckerlegge 2004:106).

45 These training grounds were set up by revolutionising the traditional village akhara or gymnasium which instituted 'a daily routine of exercise, military drills and marches, weapons training, ideological inculcation, and Hindu nationalist prayers to "the Motherland and Holyland” and to the RSS's new saffron flag' (Bhatt 2001:119). By 1926 members of the RSS, who were now known as Swayamsevaks, were given uniforms and those fully trained were sent to other provinces of India to set up more branches, known as Shakhas.
} 
Mussolini. According to Casolari, these youth organisations were the 'keystone of the fascist system of indoctrination - rather than education - of the youths' (2003:112). After this visit to Italy Moonje wrote:

The idea of fascism vividly brings out the conception of unity amongst people...India and particularly Hindu India need some such institution for the military regeneration of the Hindus...Our institution of Rashtriya Swayamsewak Sangh...is of this kind, though quite independently conceived. I will spend the rest of my life in developing and extending the institution of Dr Hedgewar throughout Maharashtra and other provinces. (Moonje Papers 1931, cited in ibid).

In 1939 (a year before he became President of the RSS) Golwalkar wrote a book, We, or our nationhood defined, in which he supports the Nazi notion that 'a "nation" should comprise a pure “Race” having no contaminants' (Bhatt 2001:133), and he praised Germany for purging the country of the Jewish race.

From the outset the emphasis of the RSS has been on 'its role as a cultural organization rather than as a political party' (Beckerlegge 2004:110); on character building and educating the Hindu population in the importance of their cultural heritage, and of being prepared to defend it against foreign rule and infiltration. However, since Independence, it has been an ally of a political system of right-wing parties that have engaged in nationalist political acts.

\section{The battle for Independence}

Throughout this period of Hindu nationalist growth there was a continuing battle for Independence on a supposedly secular level by the National Congress Party led by Gandhi and his non-cooperation movement, which had revived itself despite ongoing Hindu-Muslim conflict at the end of the 1920s. Through Gandhi's leadership, the Congress had 'transformed itself from an elite, moderate club to a mass national party...capable of mobilizing millions in its revolutionary non-cooperation campaigns' (Wolpert 2004:301) ${ }^{46}$. However not everyone agreed with his politics.

\footnotetext{
${ }^{46}$ Gandhi represented the simplicity of the peasant workers of rural India, he was a Mahatma for the Hindus who viewed him as the quintessential Hindu, and he was a friend for the Muslims because of his support for the Khilafat movement.
} 
In 1927 Hindu-Muslim conflict reached a climax when the Simon Commission ${ }^{47}$ was set up in order to draw up an improved Indian Constitution. The fact that there was not one Indian included as a member of the Commission caused outrage and when the commission arrived in India they were met with boycotts and protests demanding their return to Britain. Ironically it was this incident that created some hope for unity across India. The Congress, under Motilal Nehru (the father of India's first Prime Minister Jawaharlal Nehru), set up its own committee and called for an All Parties Conference to 'formulate the elements of a future constitution' (Bose \& Jalal 1998:142) that would be 'acceptable to Indians', in which they proposed a “"commonwealth of India" with all powers to be derived "from the people", (Wolpert 2004:311). However unity was not to last long. The Muslim League, under Mohammed Ali Jinnah, agreed to co-operate with the Congress if there was to be 'a reasonable charter of safeguards for the Muslim minority' (Bose \& Jalal 1998:142). The Muslim league demanded that at least one-third of seats should be reserved for Muslims, their proposal was rejected and Jinnah walked out of the conference claiming that 'without these safeguards...there would be revolution and civil war' (Keay 2000: 483). Hereinafter a 'unanimous commitment to separate Muslim electorates' was made and 'Hindu-Muslim unity...was never to be revived' (Wolpert 2004:312).

The constitutional reforms India awaited did not come quickly enough, and a frustrated Congress, now under Jawaharlal Nehru, set a new political demand of complete Independence and complete self rule: “purna swaraj”. December 1929 witnessed the unfurling of the Congress flag of saffron, white and green, which was to become the Indian tricolor, to shouts of “Long Live the Revolution” (Keay 2000, Wolpert 2004). And January 26th 1930 was asserted to be Independence Day, a day that officially came seventeen years later ${ }^{48}$.

The 1930s saw a revival of the non-cooperation movement mostly due to the huge impact of the Depression. It was most famously resurrected by the Salt March in 1930, in protest against the Salt Tax, which resulted in the imprisonment of Nehru

\footnotetext{
${ }^{47}$ Led by Sir John Simon (Stern 1993).

${ }^{48} 26^{\text {th }}$ January is now celebrated as Republic Day, the day when India's constitution came into force in 1950 .
} 
and Gandhi and other Congress leaders. By 1931 Jinnah had exiled himself to England, and it was not until 1936 that he returned to India for the 1937 legislative elections through an invitation by Liaqat Ali Khan requesting him 'to put life into the Muslim League and save it' (Singh 1987:3). Prior to this in 1930 Muhammad Iqbal, whilst presiding over the Muslim League annual meeting, proposed 'the formation of a consolidated North-West Indian-Muslim State’ (Wolpert 2004:317). In 1933 leaflets were distributed in Cambridge, England, by an Indian Muslim student, Chaudhri Rahmat Ali, called 'Now or Never' in which the name 'Pakistan' was used for the Islamic "father-land” in India. It is interesting to note here that Pakistan was viewed as a 'fatherland' as opposed to India as the 'motherland'. 'Pakistan' is an Urdu word derived from Persian, meaning “'Land of the pure”' (Wolpert 2004:318), to denote a country or territory in which a purist type of Islamic practice could be followed. The word Pakistan contains the first letters of the Muslim majority states across the subcontinent, Punjab, Afghania, Kashmir \& Sindh (Wolpert 2004, Bose \& Jalal 1988, Keay 2000). These separate but important incidents can be described as the initial stages of a separate Muslim state, from which there was no turning back.

In 1935 the Government of India Act was introduced. This was the last Constitution to be formulated by the British Raj. Its focal point was the increased autonomy given to the provinces of British India. It was in 1937 that the first legislative elections took place under the 1935 Act. Congress emerged with a total of 716 legislative members; the Muslim League on the other hand won just 109 seats, not even a majority of the 482 separate Muslim seats that were reserved (Wolpert 2004:324). Congress' success was far-reaching, with 70\% of the total popular vote supporting Nehru's claim in 1937 that 'there were “only two parties” in India, the government and the Congress' (ibid). Jinnah disagreed, and after the defeat of the Muslim League in these elections began to devote his life to realising the League's potential. The success of Congress in the elections of 1937 gave them an opportunity to prove themselves, however, they failed, when the much-awaited power obtained by those sitting in office was misused and abused. Jinnah himself had already realised that in order to gain Muslim support for the League he needed to deter the Muslim community from supporting the Congress. Only by attacking the Congress could he achieve this. The Pipur Report was published in 1938 to legitimise the attacks made by the League against the Congress, including claims that Congress 
were deliberately engaging in Hindu acts such as the singing of the Bande Mataram ${ }^{49}$ anthem in schools and raising the Congress flag on all public buildings as well as the suppression of the Urdu language - all acts which Jinnah and the League felt proved the Hindu bias of the Congress (Singh 1987, Wolpert 2004). The tricolor flag was criticised and described as ‘purely a party flag and nothing more’ (Singh 1987:33). It was argued that the national flag 'should represent the "true feelings and sentiments of the Muslim community” [and that mere] showing of the Muslim colour [green] was not of much significance' (ibid).

1939 saw the beginning of WWII with Britain declaring war on Germany. India was aggrieved as it learned that the Indian people were at war with Germany too. Congress's morale was shattered, despite believing in Britain's fight against Nazi and Fascist dictatorships, they were unwilling to lend their support. The British had not consulted them prior to the declaration of war and in protest Congress ordered all of its 'provincial ministries' to resign (Kulke \& Rothermund 1998, Wolpert 2004). With the Congress no longer in ministry Jinnah was able to concentrate on formulating the goal manifesto of his Party. In March 1940 he announced during a League session in Lahore:

If the British Government is really in earnest and sincere to secure peace and happiness of the people of the subcontinent, the only course open to us all is to allow the major nations separate homelands by dividing India into autonomous national states (Wolpert 2004:331/332).

This Lahore Resolution became known as the 'Pakistan Resolution' (even though Pakistan had not been mentioned directly) and it 'called for a constitution whereby the areas in which Muslims are numerically in a majority, should be grouped to constitute “"Independent States”' (Keay 2000:496, Stern 1993:177/178). This was the start of what became known as the 'two nation theory'.

The Lahore Resolution was condemned by Mahatma Gandhi, as 'a call for the “vivisection of India”. He appealed to Muslims" "good sense” and "self interest” to desist from “the obvious suicide” that partition would mean’ (Wolpert 2004:332).

\footnotetext{
${ }^{49}$ Bande Mataram is an anthem that sings praise to the Motherland, an anthem objected to by a section of the Muslim Community who perceives it as having essentially Hindu connotations.
} 
Jinnah's attitude towards India differed completely, either because of his opinions regarding India's multi-religious society or because of his own political motivations. He was adamant that 'Hindus and Muslims could never evolve as "a common nationality” and he labelled the "misconception of one Indian nation” the root cause of most of India's troubles' (ibid). He proclaimed that the Indian nation and the central government that everyone talked about, was just an impression given by the British, but it did not in fact exist (op.cit 332/333). He believed that 'the Hindus and Muslims belong[ed] to two different religious philosophies, social customs, and literatures. They neither intermarry nor inter-dine together and, indeed, they belong to two different civilisations' (ibid). On the other hand, Gandhi claimed that the Muslims of India were recent converts or descendants of converts. 'They did not become a separate nation as soon as they became converts'; he tried to establish that despite the conversions of some of the Indian population to Islam, there remained unchanging similarities between the people, their language and their customs (op.cit.333).

Just the threat of partition, even before its actuality, had already encouraged the development of Muslim separatists and paramilitary groups which led too, to a growing fear in a section of the Hindu community of India and a growth in Hindu nationalism (Jaffrelot 1996, Bidwai 2003). This was the beginning of the end of Gandhi's dream of a free and independent India, and the culmination of an ongoing religio-political battle that had begun many centuries before. It was the start of a long and deep divide between Hindus and Muslims in the sub-continent. The battle for Independence continued, divided, one for an Independent India and one for the birth of a new Independent country - Pakistan.

1942 was the birth of the Quit India Movement, which came about thus; in battling WWII, Britain needed to get India on her side and this gave rise to many negotiations, one of which, known as the Cripps mission, made an offer to India, that once the war was over it would receive Dominion Status. This offer was deeply disappointing for India, expecting full-fledged freedom. Gandhi proclaimed that the British should 'leave India to God. If that is too much, then leave her to anarchy' (Wolpert 2004:336). It had started out as a non-violent protest movement which turned extremely violent when Gandhi was arrested in a pre-emptive attempt to 
prevent trouble, however this action caused a backlash in which bombs were exploded and strikes and boycotts were held; the government machinery was brought to a standstill. Britain had no choice, and realising their defeat, began negotiations towards the transfer of power (Keay 2001).

No one had taken very seriously Jinnah's claim that India needed a separate state for the majority Muslim areas, but as no one had dismissed it either, the idea was given some weight. Throughout the negotiations for Independence, Jinnah and Gandhi remained at loggerheads, with a continuous battle between Gandhi's secularism and Jinnah's separatism. Jinnah would not agree to an Independent India if there were no proper separate electorates to protect the Muslim population; however Congress and Gandhi were adamant that to give in to these demands would go against their party's secularist beliefs and intentions. The 1945-46 elections were held to decide who should be handed power. Jinnah and the League polled 'seventy-five per cent of the total Muslim vote cast', a quite remarkable feat considering the defeat ten years earlier in 1937 (Bose \& Jalal 1998:180), and Congress ninety percent of the general electorate seats (Wolpert 2004:342). Successive Shimla conferences witnessed continual Congress-League deadlock, as the League’s demand for separate states was rejected. A new Congress government was inaugurated in September 1946 but Jinnah refused to be a part of any constituted assembly led by Nehru; 'by the dawn of 1947 all progress toward affecting any sort of peaceful transfer of power ceased' (op.cit.347). By April 1947 Nehru declared publicly that if Pakistan was what the League wanted then they could have it. This sudden declaration meant that the country had to be split in a matter of weeks, by people who had never visited India before, with outdated maps for reference. It was attention to geography that was important now, for example where rivers flowed, not ethnic regions. Jinnah was caught off guard, he did not expect the British to be in such a hurry to hand over power, and he never believed that Congress would permit partition, but instead give in to his demands for separate states, rather than see the country divided.

The birth of Pakistan in August 1947 was neither imminent nor historically inevitable. It was more an aberration, a historical accident...the birth of Pakistan symbolised more than anything else, Jinnah's personal triumph, his answer to the obdurate Congress leadership which had persistently refused to treat him on equal terms (Hasan 1994:283). 
After the era of Mughal rule in India which is used as a milestone and even referred to as a pretext for communal violence, the partition of India in 1947 was the epitome of the politicisation of religion in the politics of the sub-continent and it has been described as 'a nightmare from which the Sub-continent has never really recovered' (Bose \& Jalal 1998:198).

What my mind could not resolve was the question: what country did we belong to now, India or Pakistan? And whose blood was it that was being mercilessly shed every day? And the bones of the dead, stripped of the flesh of religion, were they being burnt or buried?...When I sat down to write, I found my thoughts scattered. Though I tried hard, I could not separate India from Pakistan and Pakistan from India (Saadat Hasan Manto (post 1947), cited in Hasan 1994:1)

Encapsulating the personal conflict so many people faced at the time of Partition, this passage reflects the confusion of belonging, felt to this day, which still proves to be a source of conflict and anger. Metcalf \& Metcalf (2006) affirm that after Partition there was a fear that safety could be found only in the religious community to which one belonged, and this generated state-specific loyalties, either to India or Pakistan. These feelings of loyalty and confusion are used by the Hindu nationalists to mobilise their supporters, who, after Partition, viewed Muslims with 'intense suspicion' (op.cit.222). The feeling of loyalty which a section of the Muslim community holds towards Pakistan, is seen as an extremely contentious issue and used continually to incite hatred in Hindu nationalist political campaigns.

\section{Indian Independence}

\section{The Nehru era}

Independence represented two things: i) Partition of the sub-continent into two countries; which 'remains the single largest episode of the uprooting of people in modern history, as twelve to fourteen million left their homes to take up residence across the border' (Lal 2002); ii) free and independent India. Independence, despite the catastrophes that Partition gave rise to, was to be celebrated; it was after all, fought for so tirelessly by the nationalist movement leaders and the people of India. Independent India began its freedom with Jawaharlal Nehru at the helm and he began his speech on the eve of Independence with the words: 
Long years ago, we made a tryst with destiny, and now the time comes when we shall redeem our pledge...At the stroke of the midnight hour, when the world sleeps, India will wake to life and freedom (Jawaharlal Nehru, August $14^{\text {th }} 1947$, in Chandra et al 2000:68).

Of course 'when India finally rose to keep its "tryst with destiny” [it was] a deeply demoralising moment of sheer catastrophe’ (Ahmed 2005:29). Partition was an event from which communal harmony would not blossom instantaneously; as long as 'distrust and suspicion' filled the minds of the common man, communal disharmony would plague India's initial years of freedom (Graham 1990:2). But, if we recollect India's Pledge at the opening of this chapter, the people of India had made a pledge of devotion to their country and each other, in whose well-being and prosperity lay their happiness; it had to recover. An atheist at heart, Nehru 'was a product of the Enlightenment with his commitment to rationality, humanity, respect for the individual, independence of spirit and secularism' (Chandra et al 2000:173). And he would fulfil his goal by creating a democratic secular political system of governance in which there would be room for all the religions that made up India's varied heritage, an act he and his supporters believed would ensure prosperity. A secular political system is one that separates religion from politics and the state: 'it also requires that the state should not discriminate against a citizen on grounds of his or her religion or caste' (Chandra et al 2000:433). India’s secularism, however, could not and would not be so black and white; it had to acknowledge the importance of religion in Indian culture. '...$[T]$ he different communities that populate the nation [had] to be represented in the state' (Van Der Veer 1994:23), therefore, a pluralistic secular system developed, in which India's religious minorities and lower castes were supported, and India's Muslims were allowed to follow the Sharia in their personal law. Nehru was most anxious that the minorities of India, especially the Muslims, should feel that they were citizens of India and therefore acquire all the rights of an Indian citizen (Chandra et al 2000, Jaffrelot 1996). This is something the Hindu Nationalist movement has always taken objection to, with the RSS describing Nehru’s secular government as 'pseudo-secular' (see Chapter 7 - Antisyncretism). There was indeed an ambiguity to Nehru's secularism, as Gould points out: 
there had been much ambivalence in the Congress party itself on the issue of what secularism should mean especially with regard to what policies should be adopted toward the country's 'mega-minority' the Muslims (1998:520).

This very ambivalence may well have 'paved the way' for certain communal activities that plagued the country after Nehru's political era. Van der Veer goes as far to say that the Indian state is an example of the 'institutionalisation of difference' by 'projecting a secular "multiculturalism", allowing for the possibility of the peaceful coexistence of different ethnic and religious communities' (1994b:200), and through the reservation of seats for the minorities. Some have argued that this in fact was just a continuation of the legacy of divide and rule politics left behind by colonialism and bred more awareness of difference and subsequent divisions.

A further discussion regarding Indian secularism is undertaken in Chapter 7 which looks in more detail at the ambiguity of India's secular governance. However, for now suffice to say that the Congress did not tire, they maintained their belief in an Indian nationality based on a 'composite notion of culture' (Jaffrelot 1996:83). And it was Hindu Nationalism that was to experience the first setback to their goals rather than Nehru’s secularism when Mahatma Gandhi was assassinated in January 1948. His assassinator was Nathuram Godse, a former RSS member who, like many high caste Hindus, considered Gandhi's support for the Muslim cause a real threat to the social hierarchy of Indian society, especially in his insistence that the Indian government pay 'compensation to Pakistan for the losses it incurred during partition' (op.cit.87). In his support for lower castes and minority groups, Gandhi was making what the higher caste considered to be the 'cultural periphery' of society, the 'centre' (Nandy 1980, cited in op.cit.46). In fact Gandhi was just too much of a "pluralist” for the Hindu nationalist organisations which lead to 'considerable antipathy against Gandhi in these circles' and ultimately to his violent death (Van Der Veer 1994:73). Nehru summed up the country's grief, when in his response to Gandhi's death, he said 'the light has gone out of our lives and there is darkness everywhere' (Nehru Speeches 1948). The RSS was banned and many of its leaders and workers imprisoned. The ban was lifted eighteen months later on condition that the RSS would not 'meddle' in politics, that it would 'renounce violence and secrecy' and 
'profess loyalty to India’s flag and constitution' (Chandra et al 2000:79); most of these conditions were not met.

By 1951 India was celebrating the inauguration of its constitution, $26^{\text {th }}$ January Republic Day. This constitution is the 'set of principles and institutions' that governs the country (Metcalf \& Metcalf 2006:232). The constitution needed to encompass the demands of unity and diversity. Nehru was conscious that India was diverse in culture, language and every other aspect that made up the communities living within its national boundary. He was also anxious that India remained a democratic state. He was concerned that the minorities, whom he felt were consistently discriminated against, were recognised in the new constitution, and in order to ensure this he introduced new legislation banning untouchability and providing for the reservation of seats for untouchables and other castes and tribes in the legislatures. They became known as the 'scheduled castes' and later 'scheduled tribes'. The Congress under Nehru continued to maintain their secular stance, but unlike other secular states, Indian secularism sought to encourage a dialogue between religious orders and the state, in order to 'sustain all of India's various religions’ (Metcalf \& Metcalf 2006:233). It was Nehru’s aspiration that India could celebrate the diversities it housed and use them as a 'source of strength to [an] emerging nationhood' (Chandra et al 2000:84).

The year 1951 also gave birth to the Bharatiya Jana Sangh (BJS) otherwise known as the Jana Sangh. This was an independent party presided over by Shyama Prasad Mookerjee, but it soon became obvious that the RSS was at its forefront. Banished from public activity and convinced of their right to exist, the RSS sought a new political party that could represent what the RSS stood for; the Jana Sangh became just that, a political front organisation which worked within the framework of the RSS and its other affiliates who by now had become collectively known as the Sangh Parivar - the RSS 'family of organisations'. Graham (1990) states that the Jana Sangh brought the vision of a Hindu nation back into the political playing field despite its rather lacklustre beginnings. But it was not until the 1970s that the Jana Sangh fulfilled its objective of becoming a genuine opposition and political force to the dominant party politics of the Congress. The Jana Sangh's political policy was that India was ‘one nation, one culture, one people’ and not the composite nation 
envisaged by the Congress (Bhatt 2001:154). However it could not afford to show an outward affiliation to Hindu Nationalism and kept a distance from linking politics with religion because it had to work as an electoral party within the democratic secular political constitution. Since the death of Gandhi, communal affiliation did not win votes and it was vital that the Jana Sangh tried to gain supporters from across the ethnic divide.

During Nehru's political reign he managed to make sure that communalist politics, after the death of Gandhi, did not regain too much credibility, of course communal violence did break out ${ }^{50}$, however he was quite successful in achieving his goal. From the inauguration of the new constitution in 1951 through the 1950s and '60s he had a different rebellion to deal with, in the agitators for the formation of linguistic states, as opposed to the regional zoning that had been established on Independence and reaffirmed in the new constitution ${ }^{51}$. There had always been agitators, Gandhi being one of them, who believed that India's provinces should be divided according to linguistic and ethnic criteria. Nehru felt that re-mapping India according to its linguistic states would weaken its composite strength. However he had no option but to go back on his stance when the agitations in 1952 developed into angry protests. December 1952 saw the formation of the first linguistic state - Andhra Pradesh; by 1953 Nehru accepted a resolution for the formation of linguistic states across the country. The use of language as a means to reorganise India's map soon became replaced by tribe, caste and religion, and since the 1960s India has continually divided itself up into large and small states accommodating various ethnic identities. But, to the surprise of Nehru,

it did not lead to the disintegration of the country. On the contrary, it enabled the Centre to accommodate regional identities with the required flexibility... In a way the redrawing of the administrative map reflected India's ability to maintain unity and diversity' (Jaffrelot 2004:206).

\footnotetext{
${ }^{50}$ For a thorough account of communal violence in the different political eras since Independence Asghar Ali Engineer's (2003a) book on communal riots is a good source of reference.

51 This zoning did not take into consideration ethnic diversity, something Nehru supported; he felt the existing zoning allowed India to live out its unity in diversity. After Independence, India's provinces were segregated according to three classes, consisting of the regions that were previously ruled by the British Crown, those that were previously princely states, and the provinces that were governed from New Delhi.
} 
The Hindu nationalists vehemently opposed the idea of linguistic states; in their eyes it further divided their sacred territory. India's land for them was not a set of administrative provinces but a sacred earth, the Bharat, a sacred land, to be worshipped not divided. For the Hindu nationalists, the Bharat is 'defined by Hindu ritual places; rivers, lakes, lingams, mountains’ (Jaffrelot 2004:214), all potential places of worship and pilgrimage. These features of the natural landscape, as places of pilgrimage, and pilgrimage in general, were then, and continue to be, used in political ways by the Hindu nationalists to motivate the masses.

There are few criticisms of Nehru's governance of India as he led them through their first years of Independence; however Chandra et al (2000) make some insightful points. They suggest that Nehru, despite his dislike for communal forces in politics, which he once described as 'India's form of fascism', could have done more to bring 'his own brilliant understanding of communalism to the people' (2000:181). He believed instead that development of the economy, planning, science and education 'would automatically weaken communal thinking and help form a secular consciousness, he ignored the need for struggle against communalism as an ideology’ (ibid). Nehru relied very much on his speeches to motivate the masses, he failed to 'create any institutions or structures or agents through which people or even lower-level cadres of his own party could be mobilized and activized and politically educated' (op.cit.182). There was a lack of organisational infrastructure for his own party people which eventually led to a 'general weakness in execution of his policies and ideas' (op.cit.183). Bose describes Nehru’s political era as a time in which the regime was 'producing traditional patterns of domination, and creating new ones' and failing to address issues such as the growing gap between rich and poor and communalism (1997:115). There was also a ‘degeneration of the Congress party' as a hegemonic ideological force, as party workers became more concerned with the best way to make money rather than with the political social cause 'worthy of sacrifice' (Rudolph \& Rudolph, cited in ibid). All these factors culminated in the split of the Congress in 1969 between Nehru's 'old guard' and his daughter Indira Gandhi’s ‘populist progressive’ politics. 
Despite these criticisms of aspects of his leadership, Nehru impressed upon the Indian people the precious value of democracy as well as the importance of using an adapted form of secularism as a tool to keep the plural nature of India alive and at peace. His ‘achievements were of gigantic proportions’ (Chandra et al 2000:184) and he left behind a legacy admired by the Indian nation today. The Nehru era ended with his death in 1964.

\section{The formation of the Vishwa Hindu Parishad - VHP}

1964 saw the foundation of the VHP, 'which sprang from the ranks of the RSS "family"...specifically to overcome sectarian divisions within Hinduism and to encourage the “re-conversions” of Indian Muslims and Christians’ (Lessinger 2003:162). As well as to 'establish and strengthen contacts with... all Hindus living abroad' Bhatt 2001:180), who would eventually become the financers of the VHP cause $^{52}$. The VHP was founded on Lord Krishna's birthday, a day undoubtedly chosen for its religiously symbolic reasons, considering the important role religious leaders and Gurus subsequently played in the organisation. The VHP has been extremely successful, even more so than its sister concerns the RSS or Jana Sangh ${ }^{53}$. It has achieved its objectives with 'direct action' using religious rituals and doctrines as a tool to mobilise the masses and generate support, much the same as Tilak did in the 1920s. In contrast to the VHP who have worked extremely closely with 'leaders of Hindu religious movements' (Van Der Veer 1994:131), the RSS has attempted to keep 'ritual and doctrine' in the wings. The main reason for the VHP's success has been the significant distance it has kept from politics, by doing this they have been able to rekindle the Hindu cause, and its connections within Hindu religious establishments, enabling it to 'engage in ethno-religious mobilising campaigns' (Jaffrelot 1996:193) ${ }^{54}$. As Van Der Veer explains, VHP nationalism embraced 'religion as the defining characteristic of the nation' (Van Der Veer 1994:132), rejecting the secular state and believing that the "“majority community” should rule the country', otherwise referred to as “majority rule” (op.cit.133). What was also essential to the VHP campaign was that India and Hinduism were under threat from

\footnotetext{
52 There is much literature dedicated to the VHP organisation, Basu et al (1993), Blom Hansen (1999), Jaffrelot (1996), Van Der Veer (1994) are prime examples of comprehensive analyses of Hindu nationalism that dedicate pages to the VHP and its involvement in the Hindu Nationalist movement.

53 This, during the 50s and 60s, lost much of its Hindu Identity in order to work within the confines of secular politics and the anti-communal policies of Nehru (Jaffrelot 1996:193).

54 The first of these was in 1966 to bring an end to the slaughtering of cows.
} 
the foreign religions of Islam and Christianity and from the lack of unity of the existing Hindu population (ibid), reigniting the ideologies of previous Hindu nationalist advocates such as Moonje. The VHP sought to increase this unity not just within India, but worldwide, and has become one of the 'strongest transnational movement[s] among Hindus all over the world' (op.cit.134). They have succeeded in unifying the world Hindu population by developing in them a sense of fear that their religion is under threat.

This transnational nature of the VHP brings to the fore the fairly recent political ideology of 'long-distance nationalism’ (Glick Schiller \& Fouron 2002:356), which is the result of a new form of state that 'extends its reach across borders, claiming that its emigrants and their descendants remain an integral and intimate part of their ancestral homeland, even if they are legal citizens of another state’ (op.cit.357). This is in contrast to previous views of nationalism in which 'to accept permanent settlement elsewhere was generally defined as national betrayal' ${ }^{55}$ (ibid).

Lastly, the VHP were perhaps the first Hindu nationalist organisation who used pilgrimage as a direct political tool to address their potential supporters. In the past only localised processions in celebration of religious festivals were used as instigators of conflict, for example, the revival of the Ganpati festival by Tilak as mentioned earlier. The VHP, from their very onset, have used the most important pilgrimage gathering on the Hindu calendar, the Kumbh Mela, not only to announce the formation of the organisation but also to hold their World Hindu Conventions, something that they continue to do.

\footnotetext{
${ }^{55}$ This view that emigrants are betraying their nation has been prevalent in Indian nationalism until fairly recently. The 1990s saw an extensive drive against what became known as "brain drain". Indian nationals residing in India felt that Indians who had moved abroad to complete their education should have returned home and brought their skills back to their homeland, instead of remaining abroad. Of course as India's economy has grown, opportunities, once only perceived as available in the West, are now available in India and this has encouraged the return of many emigrants. Glick Schiller \& Fouron make us aware too of Mussolini's efforts to reach out to Italian citizens in America, so it may be no coincidence considering the inspiration and influence Mussolini had on the Hindu nationalist cause that these same tactics were adopted. Of course in the days of Mussolini the call to long-distance nationalists overseas was to return home and help fight the nationalist cause, longdistance nationalism for the VHP has been to maximise their financial support and widen their support base.
} 
The final sections of this chapter include a discussion of the resurgence of Hindu nationalism in the 1980s and a look at the various tools adopted by Hindu nationalism to achieve its goal of a Hindu nation, culminating in the destruction of the Babri Masjid at Ayodhya and later the Gujarat pogrom, as well as the resurgence of Muslim communalism. However before moving on to this section, I will look at the crux of this aggressive revival - the politics practised from 1966-1975 when Nehru's daughter, Indira Gandhi, took the helm of the Congress party. This is a view reflected by Sumatra Bose (1997), who goes further to suggest that the reason for the success of Hindutva and the Hindu nationalist regime can be traced back to the politics adopted by Nehru and the declining Congress political regime at the time of his death in 1964. This would imply that Mrs Gandhi inherited a broken regime, rather than being the cause of its breakdown. Bose (1997) provides an excellent critique of the Indian state and the Congress and its role in creating the political climate that enabled the rise of Hindu nationalism, a reality that, Bose argues, writers on India’s history and Hindutva do little to acknowledge.

\section{Indira Gandhi takes the helm - 1966}

The period of Indian politics from 1966-1977 is often acknowledged as a period where the Indian state witnessed the beginning of a breakdown: a breakdown of democracy; of the Congress; and the one party dominant system. This period was the beginning of what, following Gramsci, Bose terms the 'organic crisis' ${ }^{\text {'56 }}$ of the Indian state in the late 1980s which gave rise to an 'atmosphere especially conducive to "Hindu nationalist” mobilisation’ (1997:114). According to Bose, the crisis was due to a series of factors, caused by a crisis of 'legitimacy' ${ }^{57}$ (op.cit.109). This crisis of legitimacy begins with a 'deficient regime', namely the Congress which in turn begins to lose its supremacy and generates a lack of faith and a political environment filled with 'instability [and] unpredictability’, providing a window of opportunity needed by the Hindu nationalist movement to 'mount a serious bid to capture state power'(ibid). This they did through the BJP in 1996 (ibid). We will return to this

\footnotetext{
${ }^{56}$ When referring to the term 'organic crisis' Bose is adapting 'concepts and analytical tools' developed by the political writer Antonio Gramsci, see David Forgacs (ed) An Antonio Gramsci Reader (1988).

Bates states that, according to Gramsci, an 'organic crisis is manifested as a crisis of hegemony, in which the people cease to believe the words of the national leaders, and begin to abandon the traditional parties' (Bates 1975:364).

${ }^{57}$ Here Bose adapts 'concepts and analytical tools' developed by the political scientist Juan Linz (1978) in his work The Breakdown of Democratic Regimes: Crisis, Breakdown and Re-equilibration.
} 
'organic crisis' later, as during the late 70s and early 80s the Hindu nationalist movement really gains momentum.

First we return to the moment when Indira Gandhi took the helm of the Congress in 1966 at a time when, it is suggested, the Congress was already in turbulent waters. It is in this period, that I believe the actual 'organic crisis' began. Mrs Gandhi became Prime Minister at a time of economic crisis, as a result of which the rupee was devalued in order to secure aid ${ }^{58}$. At the same time the VHP and Jana Sangh were agitating for the ban on cow slaughter which aroused volatile attention across the Hindu traditionalist sector of Congress and the Hindu population, culminating in riots in the Northern states. Mrs Gandhi was yet to establish herself at this time but it would soon become clear that she would be no push-over. In 1967 after Mrs Gandhi had been in office just one year, a general election was held in which the Congress did not fare well, just about holding onto their seats in the Lok Sabha (Indian Parliament) but losing their majority in many states across the country. These elections gave birth to a new form of coalition politics, practised by Congress and the opposition parties individually, which was to change the face of Indian political practice. The Jana Sangh allied with the opposition leftist parties and formed coalitions in the states where they had gained a majority. The Congress never recovered from this election catastrophe, and Mrs Gandhi broke away from the old guard to form and lead the new Congress (I) party. Forming various alliances, she managed to stay in office and immediately began to devise policies that would regain her popularity with both rich and poor and landless labourers that had defected from Congress. She began by nationalising the major banks and called for a general election in 1971, hoping to regain power and shake off the frustrating limitations of being a minority government. She faced opposition from a new 'Grand Alliance' of opposition parties, but unfazed, began a campaign running into the general elections called 'garibi hatao' or 'end poverty' which successfully regained her popularity as she swept the polls gaining a 'two-thirds majority' and restoring 'the Congress party to its dominant position' (Chandra et al 2000:238). The elections of 1971 opened up

\footnotetext{
${ }^{58}$ There was hostility with China, followed by hostility with Pakistan, and an economic downturn caused by failed monsoons in 1965 . The consequence of this was a drought in 1966 which ensured a loss in India's grain production, a famine was prevented, but recovery from this point meant devaluation of the rupee to secure aid and a 'green revolution' to increase agriculture production (Metcalf \& Metcalf 2006).
} 
a new style of politics in which it was realised that 'building a coalition of the poor and disadvantaged around a national programme could be a viable political option' (ibid). This was the beginnings of Mrs Gandhi's populist politics. The promises made to the rural poor were left unfulfilled as crisis broke out in East Pakistan which became known as the Bangladesh War ${ }^{59}$, after which Bangladesh was formed in 1972. Mrs Gandhi’s popularity soared after the war as Indians admired her 'toughness and determination and the superb leadership qualities she had displayed throughout the crisis' (op.cit.242). But the wave of success did not last long as people’s expectations of Mrs Gandhi's promises were not met; evidence of corruption surfaced and her politics became increasing dictatorial and authoritarian. By now she had completely de-institutionalised the Congress party, abandoning the democratic process of electing local party workers depending on their popularity, in favour of selecting party workers according to her favour (Metcalf \& Metcalf 2006). She transformed the party into 'an instrument of personal power to ensure that it nurtured no one who might challenge her position as prime minister or endanger the succession of her son - first Sanjay, then Rajiv’ (Hardgrave \& Kochanek 1993:258). Mrs Gandhi had most certainly developed a political style of 'populist authoritarianism...in which the figure of Indira Gandhi alone mattered. The slogan “Indira is India and India is Indira” reflected this’ (Metcalf \& Metcalf 2006:254). Her popularity waned in 1973, amplified by the formation of JP (Jayaprakash Narayan) movement in 1974, lead by Jayaprakash Narayan ${ }^{60}$. The movement was formed in protest against Mrs Gandhi's authoritarian politics and a 'system that has compelled almost everyone to go corrupt'. The members of this new party called on the Prime Minister to step down, given the decision against her by the Allahabad High Court, finding her guilty of indulging in 'corrupt campaign practices' in previous elections and subsequently declaring that her 'election [was] invalid' (Chandra et al 2000:248/49). After an appeal was made to the High Court, Mrs Gandhi was allowed to stay in office until it was heard. This enraged the opposition and the JP movement who once again called for her resignation and a national

\footnotetext{
${ }^{59}$ In this war India supported East Pakistan and its fight to become an independent country. This fight for independence had given rise to a West Pakistan onslaught on the people of East Pakistan. India defeated West Pakistan, with ease after a thorough nine month military plan that Mrs Gandhi had master-minded and executed with extreme precision.

${ }^{60}$ Jayaprakash Narayan was an old Socialist and Gandhian who came out of political retirement in order to lead the JP Movement with another veteran Congressman Moraji Desai against the politics of Indira Gandhi.
} 
campaign to enforce it. Mrs Gandhi responded by declaring a State of Emergency in June 1975.

The JP movement accused Mrs Gandhi of destroying the democratic institutions of the country in her hunger for power. The State of Emergency lasted for eighteen months during which time many feared that India had lost its democratic regime forever. During the Emergency public feeling towards Mrs Gandhi deteriorated as people felt a 'denial of their civil liberties’ (ibid). Also during this time, Mrs Gandhi took the opportunity to introduce her son Sanjay into the political arena, giving him parallel powers to her own in 1976 which enraged everyone further. The Emergency did not end until Mrs Gandhi called for free and open elections in January $1977^{61}$. The elections of 1977, contrary to what Mrs Gandhi had hoped, were a washout for Congress, and thirty years of Congress rule came to an end. A new united coalition, dominated by the Jana Sangh, called the Janata Party, took over, with Moraji Desai, an old Congress veteran, as its leader (Metcalf \& Metcalf 2006:258). The Janata Party in their short term rekindled certain Hindu nationalist policies under Desai, which went on to become successful policies of Hindu nationalist politics in the 1980s and 1990s under the new Hindu nationalist party the BJP ${ }^{62}$, led by L.K. Advani and Atal Behari Vajpayee. The most significant being the 'textbook controversy' in 1977, when a number of historical textbooks were withdrawn that did not 'condemn forcefully enough certain Muslim invaders in the medieval period and because they emphasised the responsibility of leaders like Tilak and Aurobindo for antagonism between Hindus and Muslims' (op.cit.288) ${ }^{63}$.

\footnotetext{
${ }^{61}$ For me it is this period of political actions carried out by Indira Gandhi that challenged Indian politics and the Congress, paving the way for the eventual 'organic crisis' described earlier. In endeavouring to corrupt and weaken the democratic institutions laid down by her father, Indira Gandhi aroused potent opposition. However the opposition her actions aroused were not particularly pure in their motivations; the opposition in this sense did not stand for anything much better than perhaps Indira Gandhi had to offer. On the contrary, the JP movement allied itself with the Hindu nationalist movement parties such as the Jana Sangh and RSS. Much of the aggressive agitations developed by the JP movement were the brainchild of these parties who eventually took over the JP movement. Indira Gandhi, then, in her power hungry politics, did in fact reopen the door of opportunity to the Hindu nationalist political movement that her father had tried so hard to close after the assassination of Mahatma Gandhi in 1948. Emergency was not the only political act that reopened these doors, there was much more to come.

${ }^{62}$ BJP full form - Bharatiya Janata Party, founded in 1980.

${ }^{63}$ The manipulation of text books during the BJP rule in the 1990s has been an extremely potent and significant issue that the BJP and its allies have used to ensure the complete victimisation of the Muslim population, in which the myth of the brutal Muslim invader has been created in order to incite hatred between the Hindu and Muslim communities.
} 
Emergency had even brought Hindu nationalists and Muslim political leaders closer together 'since members of the Jamaat-e-Islami ${ }^{64}$ and the RSS had been imprisoned together' (Jaffrelot 1996:285). This was the first time since partition, and the last time (up to the present day) that Hindu nationalists and Muslims shared any political ground. This broad nexus of allied parties suffered from 'internal contradictions between electoral and party-building strategies' (op.cit.311) ${ }^{65}$ which led to its collapse in 1979. General elections followed in 1980 which brought Congress back into power under Indira Gandhi once again.

The return of the Congress brought with it a more cautious and hesitant Indira Gandhi, reluctant to trust anyone but the few party workers around her, including her son Sanjay, who died in a plane accident in 1980, leaving her 'shaken and further weakened' (Chandra et al 2000:266). The Congress was not the party it once was, flawed by a lack of organisation and structure or any political instruments to implement policies. After Sanjay’s death, Mrs Gandhi introduced her second son Rajiv into the policy arena to continue the family dynasty; he entered politics with new energy and began to reorganise the Congress party, now in complete disarray. He was elected as an MP in 1983. Indira Gandhi's return to power ended with her assassination by two of her Sikh bodyguards in 1984 .

The assassination of Indira Gandhi was the culmination of a number of events. A flagging Congress in the polls, poor state elections and a reunification of the opposition parties in the form of the new $\mathrm{BJP}^{66}$, who entered the political arena with a new 'anti-Congress' campaign opening up new counter-offensive politics in 1983. This had caused Mrs Gandhi to turn to communal politics and the communal Hindu

\footnotetext{
64 The Jamaat-e-Islami has been the Muslim political party that has represented what is termed by Hardgrave \& Kochanek (1993) as 'Muslim communalism, along with Jamiat-ul-Ulema'. Both groups represent Muslim orthodoxy, the demands of which 'embrace a wide range of measures for the protection of the Muslim community’ (op.cit.185).

${ }^{65}$ There were disputes between the Hindu nationalist ex-Jana Sangh activists and their alliance with the RSS and the more moderate Gandhian Hindu traditionalists' parties within the coalition. In fact under Moraji Desai, the 1980s and '90s Hindu nationalist stars, L.K. Advani and Atal Behari Vajpayee, both ex-Jana Sanghi allies, held influential roles, soon to be removed by the more secular Charan Singh, Moraji Desai’s successor.

${ }^{66}$ The BJP, reluctant to join forces with previous coalitions that had failed, launched itself as an independent party made up of ex-Jana Sangh and presided over by AB Vajpayee standing for 'Gandhian socialism' and 'positive secularism' (Jaffrelot 1996:316). In fact the BJP would go on to become the only true opposition to the Congress and to an extremely successful right-wing Hindu nationalist organisation.
} 
vote by appealing 'explicitly to communal sentiments’ (Bose 1997:121); 'courting voters on the basis of ethnic and religious affiliation...embedding in India for the first time since the 1940s a decisive communal politics’ (Metcalf \& Metcalf 2006:259). She increased her public visits to Hindu temples and in 1983 inaugurated a temple (Jaffrelot 1996). However the crux of her communal politics was with the Sikh community in Punjab. The Punjab was on the brink of civil war as the Sikh community demanded a capital for their new Punjabi-speaking state. At this time there was also an international movement by a section of the Sikh community for an 'autonomous, even independent, Sikh state, or Khalistan' ${ }^{67}$. Creating a Sikh state on such a sensitive border region with Pakistan was unthinkable so Mrs Gandhi launched an attack on Bhinranwale and his men - Operation Bluestar. An army was sent into to attack the Golden Temple in Amritsar - the most sacred Sikh temple (also known as a Gurudwara) in the world. Inevitably this led to massive communal backlash and another Amritsar massacre. Through meddling in communal politics, Indira Gandhi lost the support of the Sikh population and enraged the whole community. Her two Sikh bodyguards shot her as she walked in her garden on $31^{\text {st }}$ October 1984.

After her death, communal violence raged through the streets of Punjab and Delhi and an orchestrated pogrom - instigated by her successor and son Rajiv Gandhi against the Sikh community was launched, killing thousands of Sikhs in Delhi and Punjab. It would prove a difficult start to his political leadership but a successful one too, as he gained the largest victory the Congress had ever achieved in the general elections held two months after his mother’s death. The Gandhi family dynasty continued with Rajiv Gandhi in charge, enjoying the success of 'majoritarian nationalism’ politics adopted from his Mother.

Majoritarian nationalism is described by Bose as a

\footnotetext{
${ }^{67}$ On top of this there were rumblings within the Sikh community regarding 'Sikh religious practice, together with opposition to the moderate leadership of...Akali Dal’ (Metcalf \& Metcalf 2006:259). These events culminated in a fundamentalist teacher, Sant Jarnail Singh Bhindranwale, taking up the Khalistan cause. He was supported by Indira Gandhi purely because she herself wanted to oust the Akali Dal from leadership due to their support in the past of the Janata regime. Of course this support for Bhindranwale encouraged his radicalism and he and his armed followers 'blockaded themselves in the holiest Sikh shrine, the Golden Temple in Amritsar' threatening not to leave until the Sikh state they were fighting for was created (ibid). Indira Gandhi had given weight to this cause and now she found herself having to fight it.
} 
political philosophy and programme...that seeks to build electoral success on the basis of, a solidary 'majority' community defined...by factors such as race, language or religion...the outstanding feature of majoritarian nationalisms is that their ideology and concrete strategy...are always defined in negative terms, in opposition to an 'Other' (which frequently turns out to be a minority group within the boundaries of the state in question) (1997:114).

The Congress had adopted the political philosophy associated with the right-wing Hindu nationalist parties. Corbridge \& Harriss assert that the Congress under Indira Gandhi 'produced a fragile system of authority' as it relied on a single leader 'to sustain its political support', and as the legitimate regime began to break-down, it experienced a fundamental transformation (2000:94). This was brought on when a 'catastrophe' occurred which happened in the 1980s. '[A]ll systems are flexible, but within certain limits, when the limits are stretched a "catastrophe” may occur and the system undergoes a fundamental transformation as a result' (2000:93). This can be compared to Bose’s (1997) 'organic crisis' and 'crisis of legitimacy', and Young's (1993) work on the 'crisis of legitimation' ${ }^{68}$. This fundamental transformation came about in part, in my mind, for two reasons...

i) the change in direction of Congress politics, away from the genuine secular socialist objectives it once believed in, to a 'majoritarian nationalist' vote bank politics in order to regain and maintain what at times was a considerably diminishing popularity and respect.

ii) the increasing criminalization of the political system as new members with criminal records were elected mostly because of their personal alliance with the Gandhi family rather than anything else; this was aided by the deinstitutionalisation of the party started by Indira Gandhi and continued by her son Rajiv.

'Congress had...become the captive of a single family...no party elections had been held at any level since 1972' (Bose 1997:126), the family dynasty continued, and in many ways still does today as Sonia Gandhi, Rajiv Gandhi’s Italian born wife, presides over the party and is currently grooming, for similar dynasty-defined roles, her son and daughter, who in the last few years have taken active roles in the Party. Increased corruption in the civil service and the police force triggered further

\footnotetext{
${ }^{68}$ Young (1993) describes the crisis of Indian politics as a 'crisis of legitimation' beginning in the late 1980s.
} 
communal violence, and dwindling democratic practices meant the Indian state system began to malfunction (Corbridge \& Harriss 2000).

\section{Contemporary Communal Conflict since 1980s 1980s revival of Hindu nationalism}

This government malfunction gave rise to an increase in communal activity which was compounded by the Congress' undemocratic nature and majoritarian nationalist politics. Rajiv Gandhi soon learned that populist communal politics effectively mobilised the people. His first dabble in this strategy would be what became known as the "Shah Bano" affair (described below).

The newly founded BJP, the party that was expected to stand for communal politics, fared particularly badly under the president-ship of Vajpayee in the 1980 general election. With communal politics on the rise, perhaps an increase in their seats at the general election would have been expected. But Vajpayee was a moderate communalist and had adopted a more moderate political strategy to win back the public. The unexpected communal politics of the Congress and perhaps the death of Indira Gandhi swept them indisputably into power. Communal politics had, then, rerevealed itself, but under another party. And as Chandra et al (2000) and Bhatt (2001) acknowledge, it was this '...political opportunism towards communalism practised by secular parties, groups and individuals' that contributed immensely towards the growth of communal politics (Chandra et al 2000:438). Of course, as Jaffrelot explains, Indira Gandhi 'saw the move towards the communalist right...as a means of undermining the parties that stood to the right of Congress (I)'; she felt that by becoming 'the mouthpiece for communalism, she was protecting India from the dangers of it' (1996:332), unfortunately the reality was quite the opposite. And as Engineer writes, it was the realisation by the Hindu right that they were being beaten at their own game that 'changed the very nature and intensity of communalism in India’ (2003b:10).

The more communally aggressive L.K. Advani took over leadership of the BJP from Vajpayee due to the failure of his moderate policies. Convinced of the need to adopt the Hindutva nationalism strategy once again, Advani began to address issues in a way not seen before by Hindu nationalist parties. He began with an attack against 
the 'Nehruvian concept of secularism' renaming it 'pseudo-secularism' and calling it a 'sham...meant only to create a Muslim vote bank' (Engineer 2003b:10). From the Congress, the BJP had learned that 'electoral strategy based on majority communalism could be highly successful', a factor they had not yet truly exploited (Bhatt 2001:169).

Congress communal politics continued through the 1980s with Rajiv Gandhi in power who made three political decisions which, in retrospect, facilitated the continued growth of communalised politics that have become more associated with Indian politics than the secularism its constitution stands for. Two of the decisions he made affected communal relations between the Hindu-Muslim communities immeasurably. And the third decision created enough hatred for him to be assassinated in 1991. He would be the third Indian political figure to be assassinated, due to the stoking of smouldering fires that constituted communal politics ${ }^{69}$. The three decisions included his involvement in the Shah Bano affair, the Ayodhya and Babri Masjid (mosque) issue and finally his involvement in the guerrilla warfare experienced by Sri Lanka from the Tamil Tigers, one of whom was his eventual assassin.

\section{The Shah Bano affair}

In 1985 Rajiv Gandhi decided to intervene in a court case that involved a Muslim woman (Shah Bano), who, divorced by her husband after a forty-five year marriage, had put a case against her husband demanding he pay her maintenance. Under Sharia law if a man divorces a woman she is not entitled to any monetary compensation or maintenance. The Indian Supreme Court passed a judgement in 1985 that Shah Bano should be paid maintenance, because in this case Muslim personal law did not apply as it was commonplace for all citizens to apply for maintenance; they also quoted extracts from the Quran which supported their claim. The Muslim leaders were extremely offended by this decision and appealed against the Supreme Court Judgement claiming that they had no right to 'interpret the holy scripture' and the 'controversy snowballed in to a major political problem as

\footnotetext{
${ }^{69}$ I include the assassination of Mahatma Gandhi, here I am not suggesting in any way that he was a communalist, or believed in communal politics; however that said, he most definitely brought and used religion into the core of his political beliefs and practices.
} 
thousands of Muslims took to the street and demonstrated’ (Engineer 2003b:198) ${ }^{70}$. It was the largest protest by Muslims since partition (Engineer, cited in Jaffrelot 1996:335). Rajiv Gandhi intervened in the issue by reversing the Supreme Court decision. According to Engineer (2003b) he 'bowed down to the pressure'. However Metcalf \& Metcalf suggest the decision was a conscious one, in which 'Rajiv Gandhi cared little about the Shah Bano case... [but] saw an opportunity to draw conservative Muslim voters to the Congress cause’ (2006:262). The Hindu nationalists perceived this decision as one that appeased the Muslim minority and the BJP tried to re-introduce to the political spectrum the issue of a common civil code that did not make exceptions for personal religious laws ${ }^{71}$. This was a strategy, no doubt motivated by the turn of events in the Shah Bano case but also directed towards another factor of Muslim personal law, that a Muslim man was allowed more than one wife - hence an 'over-production' of children - whereas the Hindus could only have one.

Rajiv Gandhi's reversal of a Supreme Court order in the Shah Bano affair set a new benchmark for the intervention of the state on judicial issues as well as upsetting a large section of the Hindu population who saw him as yet another politician indulging in minority appeasement. This time however he would need to settle the score, which he did with his second decision as he moved his focus from the Shah Bano affair to another extremely populist issue, that of the Babri Masjid or Mosque in the small town of Ayodhya.

\section{VHP apolitical politics: Ekatmata Yatra-The first of many political pilgrimages}

The beginning of the 1980s was a decade of extreme activity for communal agitations but they took place outside the political sphere, revolving around the socalled non-political communal organisation, the VHP, which inevitably became more and more political, during this same decade (Juergensmayer 1993: 239). The VHP rallied more and more religious leaders and began a reconversion campaign in 1981 in response to the Meenakshipuram conversions, in which thousands of low caste

\footnotetext{
${ }^{70}$ Muslims took to the streets for the 'Shariat protection week' in which the Muslim population was encouraged by agitations to believe that their personal law was in danger.

${ }^{71}$ A common civil code was something that Nehru himself was cautious of introducing for fear of antagonising the Muslim population. A common civil code has, as yet, still not been introduced into Indian politics.
} 
Hindus in South India converted to Islam. In returning to the strategy of 'strategic emulation of the threatening other', the VHP responded with a reconversion campaign of Muslims to Hinduism across a number of states nationwide. A part of this campaign was also to change the nature of the Hindu temple to a place for 'Hindu socialisation' in order to replicate the 'character of Muslim worship in the mosque’, discussed earlier (Jaffrelot 1996:359, Blom Hansen 1999). Further 'propaganda' (Corbridge \& Harriss 1999:112) regarding the threat of Islam led to the next step in the VHP campaign trail in 1983 with the launch of the first 'pilgrimage or Yatra' style campaign - the Ekatmata Yatra (literally, One Mother Pilgrimage). Ekatmata was initiated to attract communal attention and it was the first real example of the use of pilgrimage for the political means of mass mobilisation ${ }^{72}$. It was a 'politico-cum-religious pilgrimage' (ibid), in which the VHP introduced the worship of 'Bharat Mata' or Mother Goddess. Mother India and her geographical landmass became the divine entity to be worshipped by Hindus, as it was part of what they held sacred and a symbol of their national unity (Blom Hansen 1999, Jaffrelot 1996). The RSS vision of the 'Bharat' is one where:

...the rivers figure as the first markers of identity of the Indian space, probably because water has a particular purificatory value in Hinduism and many of the water courses are regular objects of pilgrimage. Next comes, for similar reasons, the lakes, which...'have inspired all the people of Bharat to rise above the differences of caste and of region and create a strong nation'. Then it is the turn of the mountains which concludes the 'natural' set. The set of 'cultural' signs opens with the four Dhams (lit. the places of residence, in this case of the Hindu gods) situated in Badrinath in the Himalaya, Rameshwaram in the extreme south, Dwarka in the west, and Puri in the east that correspond expediently to the cardinal points. In this account, the places of pilgrimage are presented as the anchoring points of the unity of the Bharat since time immemorial (Jaffrelot 2004:210, cites Sharma 1993).

Ekatmata Yatra used these very symbols that made up the Hindu earth in mobilising their supporters, reproducing 'the modus operandi of a pilgrimage' (Jaffrelot 2004:212) in which processions began from all corners of the country and converged

\footnotetext{
72 The VHP had used pilgrimage in a political manner previously when they were first founded in 1964 and in subsequent years when they held world Hindu conventions at the most famous Indian pilgrimage, the Kumbh Mela. However the Ekatmata was the first campaign organised in the style of a pilgrimage in which pilgrimage sites were visited as part of the campaign.
} 
in Nagpur, Maharashtra ${ }^{73}$. Distributing water from the Ganges as they travelled, it was an extremely clever campaign, the 'Ganges is one of those rare symbols venerated by all Hindus'; through the campaign the river became a symbol of Mother India and therefore a ‘symbol of national unity’ (Jaffrelot 1996:361). The Yatra had an extremely anti-Muslim and anti-minority feel as these communities were ‘depicted as encroaching upon Hindu culture through conversion' (Blom Hansen 1999:155). The presence of the RSS in this campaign revealed that it was much more than just an apolitical communal activity but an effort to gain a Hindu vote bank. The processions were most successful in the areas where there was a history of communal tension, which according to Jaffrelot (1996) revealed the insecurity of the Hindu population.

The use of pilgrimage and processions of this kind to mobilise the masses is highlighted through the pilgrimage to Kalo Dungar which centres on a VHP political rally. In this case, the local majority Muslim community is targeted specifically because the pilgrimage site lies on the border with Pakistan, a threat in itself and, therefore, a majority Muslim area. This pilgrimage, beginning on the $6^{\text {th }}$ December 2003, was also proclaimed as a celebration of the demolition of the Babri Masjid, an event to which we turn next.

\section{Ayodhya - the end of secular politics}

It is argued that the success of the Ekatmata campaign encouraged the VHP to launch the Ram Janambhoomi movement which demanded the demolition of the Babri Mosque in 'North India pilgrimage centre' of Ayodhya, in the state of Uttar Pradesh and its replacement by a Ram temple (Van Der Veer 1994:2). The importance of understanding the historical background of the 'Babri Masjid' or 'Ayodhya' as it is commonly referred to, cannot be underestimated, being the single most significant issue that changed the face of Indian politics ${ }^{74}$.

There are many disputed histories that are associated with Ayodhya and the Babri mosque. Disputes over history; reinvented history; myth and fact; oral history and

\footnotetext{
${ }^{73}$ Nagpur was also where the founding fathers of Hindutva had lived and is now where the head offices of the RSS are situated.

${ }^{74}$ This is reflected in the mountain of literature dedicated to the subject, only some of which I can refer to in the brief account given here.
} 
folklore affect many religious sites of pilgrimage and worship in India. These disputes are often the reason for the politically motivated manufacturing of misunderstanding, which usually culminates in communal tensions and ultimately violence.

The blurred divide between history and myth, and the ways in which archaeological evidence can be interpreted and distorted are integral to understanding the Ayodhya issue. The Hindu Nationalists argue that the Babri Mosque was built during the Mughal period by the first Mughal Emperor, Babur, in 1528. According to local history, the mosque was built at the birthplace of Lord Ram, one of the most important gods in Hinduism and the 'god-hero' of the great mythological epic the Ramayana (Van der Veer 1987, 1994:2). Van der Veer (1987) provides a local history of the site prior to the construction of the mosque where, it is claimed, a temple once stood. Local folklore suggests that Babur ordered his general to demolish the existing temple and build a mosque which was the wish of two Pirs ${ }^{75}$ whom he had met in Ayodhya and had been impressed by the power of Ram's temple (ibid). It is also said that, after the demolition, the carved pillars of the temple were then used in the rebuilding of the mosque.

There have been many landmark moments in the history of Ayodhya. The first goes back to the end of the East Indian Company era of India's history in 1855/ 1886, when there was an appeal by a section of the Hindu community to build a temple on the site. This increased tensions about ownership of the site and forced the British to put railings around the mosque. Previously Hindus and Muslims had both worshipped in the mosque, Muslims offering Namaaz and Hindus performing Pujas, convinced that there was a sacred temple within the shell of the mosque. However, after the outbreak of tensions, only Muslims were allowed to pray inside the mosque and the Hindus were relegated to singing bhajaans ${ }^{76}$ on the platform erected for them outside (Gould 1998, Van der Veer 1987, 1994). Since this time there have been a number of communal conflicts in Ayodhya, the most serious one erupting in violence in 1934.

\footnotetext{
${ }^{75}$ A Pir is an Islamic holy man, normally from the Sufi sect, who is revered by people from all castes and creeds for the miracles he has performed. A history of Sufis and Pirs is found in Chapter 5 Syncretism and Shared Faith traditions.

${ }^{76}$ Bhajaan - A type of devotional song.
} 
The second landmark is one that is associated with the divine intervention of Lord Rama in December 1949 (Pandey 2006). After Independence, for fear of more communal tension, the mosque had been closed to both Hindus and Muslims, and guarded. But when images 'miraculously' appeared of Lord Rama in the mosque, it became extremely important that Hindus should be allowed to pray in the mosque, otherwise Ram would be offended, and Hindus flocked in large numbers to pay their respects; Muslims, fearful of a Hindu attack on the mosque, gathered too; riots followed (Gould 1998, Van der Veer 1994) ${ }^{77}$. However the appearance of the images, rather than a miraculous act by Lord Ram, were rumoured to have been the work of the local constabulary, until it transpired that the Deputy Commissioner and a local magistrate, both members of the RSS, had orchestrated the whole incident. Neither was ever tried for their part in this illegal act. After this 'break-in' or 'miracle' at the mosque, the Supreme Court ordered the mosque to be padlocked to both Hindus and Muslims in order to prevent the escalation of communal violence that was predicted. During the next thirty-five years the dispute over the mosque certainly lost its fire, but the embers smouldered as the images were never removed. The embers were reignited in 1984 when the VHP brought Ayodhya back into the public arena, through one of their apolitical campaigns for which they had become famous during the start of the 1980s. The Ram Janambhoomi campaign demanded that the Babri mosque be demolished and a temple of Ram rebuilt on the site, replacing the one that was desecrated by Emperor Barbar and his generals (Chandra et al 2000). The campaign created a public stir and Rajiv Gandhi decided to take advantage of it.

In 1986 the District Judge at the court of Faizabad passed an order that the padlocks to the mosque should be removed; some sources claim that Rajiv Gandhi made it known that he would have 'no objection' if the District Judge did this ${ }^{78}$. Rajiv is claimed to have done this in order to try to counteract the backlash he experienced from the Hindu community over the Shah Bano fiasco. An advisor to Rajiv Gandhi, Arun Nehru, said ‘in early 1986 the Muslim Women’s bill was passed to play the

\footnotetext{
${ }^{77}$ There is some confusion as to whether it was statues or images of Ram and Sita (his wife) that appeared in the mosque, either way rumours began concerning how they arrived.

${ }^{78}$ The direct involvement of Rajiv Gandhi in this incident is left out of some history books, describing the district court decision as coming out of the blue, but it is most certainly true that it was Rajiv himself who ordered the court to take this action.
} 
Muslim card; and then came the decision on Ayodhya to play the Hindu card. It was supposed to be [a] package deal' (cited in Jaffrelot 1996:371). The mosque was reopened; this was seen by the BJP, RSS, VHP and their allies as a victory for the Hindu nationalist cause. However, there were riots across the country, Hindus demanding that the mosque be demolished and a temple built, and the Muslims demanding that the mosque be returned to them. The BJP saw this episode as a huge step towards achieving their goal, of what Gould calls, the 'ethno-religious state' (1998:522), and they fully exploited the situation, beginning their mass mobilisation campaigns. The media were key figures in abetting their cause, especially the television and written media channels, that supported the Hindu movement. A major example of this was the televised drama series of the Ramayana that was launched on Doordarshan, the vernacular Hindi television channel. Never before had this mythological epic been presented in this way and there are reports that watching the weekly episode, over the eighteen month period that the series ran, was like an act of devotion for many Hindu viewers who actually 'respond[ed] to the image of Ram on screen as if they were receiving darshan ${ }^{79}$ from the God, greeted him by performing puja [prayers] before the television set' (Jaffrelot 1996:389). The success of the Ramayana promoted the production of the next mythological epic, the Mahabharata, and the 'country became transfixed'. The BJP made sure that the images of their mass mobilisation campaigns connected with the images on the television screens all over the country. Engineer (2003a) comments that throughout this time, and during the Shah Bano affair, the media engaged in a lot of 'Muslim bashing' especially the Hindi media. He explains that the

language press particularly gave an impression that it [was] a settled fact that Babar had demolished a Ram Temple in Ayodhya and now it [was] time the Hindus vindicated their honour by constructing a Ram temple by removing the mosque' (Engineer 2003a:125).

The so called 'archaeological fact' that the Ram temple ever existed at the site was debatable.

\footnotetext{
${ }^{79}$ Darshan literally means seeing, 'in the Hindu ritual tradition it refers especially to religious seeing or the visual perception of the sacred'; when going to the temple for darshan, one goes to 'see the image of the deity’ (Eck 1998:3).
} 
During this campaign the VHP succeeded in making Ram the most important God for all Hindus. Hinduism is full of divisions, the core divisions of Hinduism place Ram, Vishnu or Shiva as their most important deity, and these three divisions are normally in conflict. However, the VHP had managed to unify Hinduism with their campaign for Ram. This was the second time they had achieved this, the first being the worship of 'Bharat Mata' during the Ekatmata Yatra campaign mentioned above. This unification continued and became an important aspect of communal politics, for the first time it enabled the mobilisation of the masses on unified grounds (Jaffrelot 1996), this is mirrored in the recent use of Lord Dattatreya at various sites, Kalo Dungar being one example (see Chapter 7).

The mosque was eventually demolished in 1992. It was the culmination of a seven year aggressive campaign generated by the VHP but politically supported by both the RSS and BJP. Prior to the demolition however, the religious network of the VHP increased in strength as 'the pro Hindu position, previously marginalised by the politics of secularism, now enjoyed a new legitimacy’ (op.cit.371). It was time for the next VHP campaign. Launched in 1989, the 'Ram Shila Pujan'... consisted of honouring in a devotional manner, bricks (shila) inscribed with the name of Ram' (Jaffrelot 2004:212) ${ }^{80}$. Pujas or prayer meetings were held all over the country in at least '297,795 different places’ (Bonney 2002). Bricks were worshipped all over the country and across the world. These sanctified bricks were then sent to Ayodhya with 'Ram' inscribed on them, along with the name of the village, town or country from which they had been sent, to be used to build the new Ram temple. It was a campaign that unified the Hindu community as bricks were sent from all over the world; the VHP had proved their commitment to unifying Hindus the world over. This campaign culminated in the laying of the first brick at the temple site, a ceremony that, according to Gould, had been agreed between the Congress and BJP when the mosque had been opened, a 'symbolic legitimation' that the mosque would one day be replaced by the temple (1998:522). On 9th November 1989 all Hindus were 'called upon to turn towards Ayodhya and make an offering of flowers' (Jaffrelot 2004:212), another example of 'emulation of the strategic other' strategy, as this act 'seemed [to be] inspired more or less consciously by the Muslim prayers

\footnotetext{
${ }^{80}$ Blom Hansen (1999) gives an excellent overview of the Ram Shila Puja campaign in his book The Saffron Wave: Democracy and Hindu Nationalism in Modern India.
} 
to Mecca' (ibid). The Ram Shila Pujas caused violent communal conflict across the country, including massacres of Muslims not seen since Partition (Blom Hansen 1999). The creation of 'partial truths' had managed to build 'a mountain of hatred' (Puniyani 2003:26).

Whilst the VHP and its allies built their cause for the demolition of the Babri mosque, popularity for Rajiv Gandhi slowly diminished as he regressed further into a style of politics more 'Indira than Indira’s' (Corbridge \& Harriss 2000:102). Loyal cadres began to fall away, the most dangerous being V.P. Singh who was finance minister under Rajiv Gandhi. He was sacked from his post and immediately formed a new coalition front. In 1988 he joined forces with seven other parties and became the Janata Dal. They even set aside their secularist beliefs in order to 'benefit from or at least not be harmed by - the strength of the BJP' (Jaffrelot 1996:381). There was disagreement regarding the issue of Ayodhya, a campaign that V.P. Singh was adamant he would not support, but both sides needed each other in order to create a legitimate opposition, and readied themselves for the general elections in 1989 where they made a pact that they would not contest seats against each other. The electoral campaigns went ahead amongst the communal violence that had spread through the country, ignited by the Ram Shila Pujas. Rajiv Gandhi was insistent that the Congress be seen to support the VHP in its campaign and inaugurated his election campaign in Ayodhya. By this time the RSS too re-entered the fold by aiding the BJP election campaign. By now the RSS had increased its centres enormously which provided a large vote bank of supporters, the BJP used the ensuing violence around the Ram Shila Pujas in their favour by relating their candidates to religious figures in the Pujas; it was 'the climax of the strategy of ethno-religious mobilisation' where 'the Hindu vote was pursued' through 'strengthening the Hindu collective consciousness, irrespective of whether [it] provoked violence' (op.cit.398).

Despite endeavouring to follow what had been a successful use of 'majoritarian nationalism' politics, this time it was the turn of the BJP to benefit from this strategy, increasing their parliamentary seats at the elections from 2 to 85 (Bose 1997:124). With the economy at its lowest ebb and increased corruption in the Congress party and a loss of faith that the Congress would uphold India's secular constitution, Congress did not fare well in the general elections. And for the first time no single 
party had secured a majority, there was a hung parliament (op.cit.125). There had been what Bose (following Gramsci) describes as an 'organic crisis of authority' (ibid). Rajiv Gandhi showed no interest in forming a coalition government, so despite the poor results for the National Front under V.P. Singh with the increased seats of the BJP and other left parties, a coalition was formed and V.P. Singh became Prime Minister. But the coalition was fragile and did not stick to its commitments to each other for long.

\section{0s Ayodhya and the continued success of Hindu nationalism}

The 1990s was yet another decade of extraordinary events in Indian politics filled with communal tensions which, scholars argue, took hold due to the vacuum created by the 'deinstitutionalisation of the Indian state', the break down of bureaucracy and of the secular, socialist and democratic institutions set up post-independence (Metcalf \& Metcalf 2006:272). The first year alone set the precedent. There was yet another assassination, more caste backlash and another aggressive political pilgrimage campaign for the Ayodhya cause. It took just four months for the new coalition parliament to breakdown, and there were two major reasons. Firstly, Prime Minster V.P. Singh, without agreement from this coalition, implemented the 'recommendations of the 1980 Mandal Commission report' that would provide reservation of seats in 'central administration and public corporations' for 'other backward castes’ (OBCs) (Jaffrelot 1996:414), which, combined with the scheduled castes and tribes, would make up 'roughly half of the society as a whole' (Metcalf \& Metcalf 2006:274). He felt that in implementing this reform he would secure the vote bank of the low caste groups, however, instead he experienced a caste backlash from the higher caste groups; one Brahmin student actually immolated himself in protest $^{81}$ (Bhatt 2001:171, Gould 1998:519, Van der Veer 1994:5). Secondly the BJP, now presided over by L.K. Advani, despite objection by the other coalition groups who did not support the Ayodhya cause, launched the Rath Yatra or Chariot Procession. Some commentators suggest that the Rath Yatra was launched by the BJP in order to try to gain back their Hindu vote bank damaged by the implementation of the Mandal Commission reforms. However more than anything,

\footnotetext{
${ }^{81}$ Self-immolation became a new protest strategy in village India after this point, where to secure attention villagers immolated themselves for their cause. This is a strategy that I have personally witnessed during my time in India.
} 
it was launched as a 'national procession and demonstration of strength' through which the BJP moved towards a complete strategy of 'ethno-religious mobilisation' (Jaffrelot 1996:416). It would be the third political pilgrimage for Ayodhya, designed to build on the already growing Hindu unity and solidarity that the Ekatmata Yatra and Ram Shila Pujans had created (op.cit.417).

Jaffrelot (1996) uses Turner's concept of 'communitas' in order to examine the phenomenon of using pilgrimage processions as a tool for ethno-religious mass mobilisation. Turner defined communitas as “"a relationship between concrete, historical, idiosyncratic individuals"', which 'emerges where social structure is not' (Morris 1998:254), it “embraces an “ill-assorted bunch of social phenomena,”, (op.cit.258). Communitas emerges in an experience which is outside the social structure of everyday, and therefore in the Indian context, enables a gathering of people that 'transcend[s] caste differences'. Organised processions or pilgrimages are 'one of the few circumstances in which different castes are involved in a common activity’ (Jaffrelot 1996:394). The processions organised as religious pilgrimages, in this case however, were to fulfil the political ideology of Hindutva, to present a cohesive Hindu population in order to intimidate what was perceived as the threatening Muslim minority, and they (i.e the pilgrimage processions) were of an aggressive kind. As Jaffrelot rightly states 'religious processions have always created circumstances in which communal riots are likely to occur', and in the case of Ekatmata, Ram Shila Pujas and the Rath Yatra, an 'aggressive communitas' was created in order to directly instigate communal violence for political means (op.cit.395). But the Rath Yatra had even more sinister undertones than the previous two campaigns, this time, for the first time, we witnessed a political leader actively use 'propaganda of an overtly Hindu nationalist character' (op.cit.418). Riding in a Toyota jeep decorated 'like the chariot used by warrior Arjuna....in the...televised serial Mahabharata', along with the saffron flag of the RSS and the lotus symbol of the BJP, L.K. Advani posed as Lord Rama as he began his journey from Somnath in Gujarat. The procession crossed ten northern states to reach the final destination of Ayodhya (Blom Hansen 1999:164, Davis 2005, Van Der Veer 1994). Throughout the journey the success of the television serialisation of the Ramayana was exploited as music from the serial was played through loudspeakers interspersed with antiMuslim slogans such as 'the only place for Muslims is the graveyard (qabarstan) or 
Pakistan’ (Metcalf \& Metcalf 2006: 276), along with slogans in support of the building of a Ram temple in Ayodhya (Blom Hansen 1999). The Rath Yatra was a national scale event, given immense media coverage. Villages and towns through which the chariot passed were decorated with saffron flags and emotions ran wild as activists stirred up ‘communal propaganda’ (Blom Hansen 1999:165, Davis 2005). Communal rioting broke out across the country, especially along the path of the chariot. Engineer states that according to The Times of India daily newspaper the Rath Yatra turned into a 'blood yatra', as about '300 riots took place throughout the country' (2003b:13). And in states where Congress was in power through which the Rath Yatra travelled, they did not intervene, frightened of opposing the 'Hindu wave', too cowardly, in the opinion of some critics, to practise their preaching of communal harmony (Jaffrelot 1996).

During the Rath Yatra the VHP too launched another campaign, the Ram Jyoti Yatra, a procession carrying the light of Ram. A flame from Ayodhya was used to light torches in important religious centres around the country and as the campaign coincided with Diwali ${ }^{82}$, people were encouraged to light 'diyas' or candles in their homes 'symbolising the awakening of the devotees of Lord Ram' (op.cit.19). Many processions were banned to prevent violence, but despite this, communal violence did escalate. The Rath Yatra continued too, but before it reached Ayodhya, Advani was arrested in Bihar under the orders of the Prime Minister. The arrest of Advani, rather than preventing violence, spurred it further, as kar sevaks ${ }^{83}$ continued on their march to Ayodhya. They broke through the heavy barriers around the mosque (most would argue with help from supportive members of the police force), scaled the $7^{\text {th }}$ Century structure and draped a saffron flag around one of the domes. The Prime Minister had deployed army troops there who subsequently opened fire on the kar sevaks, many of whom were killed. Anger erupted around the country as the kar sevaks were described as martyrs of the Ram temple cause and their remains paraded (Blom Hansen 1999, Jaffrelot 1996, Van Der Veer 1994). The BJP withdrew their support from the coalition government and it fell.

\footnotetext{
${ }^{82}$ Diwali - The Indian festival of light that celebrates the victory of good over evil, when traditionally candles are lit in every home.

${ }^{83}$ Kar sevak is the term given to the supporters of the demolition of the Babri mosque and the building of a new Ram temple on its site.
} 
During the renewed electoral campaigns in 1991 Rajiv Gandhi was killed, the result of his third unwise decision during his tenure as Prime Minister. Unrest began in 1983 when a previously communally peaceful Sri Lanka witnessed communal fighting ${ }^{84}$. Rajiv Gandhi decided to covertly support the Tamil rebellion in Sri Lanka, understanding the sympathy the cause was receiving from Indian Tamils. However, after a plea from the Sri Lankan government that India send in a peacekeeping force to try to control the violence, Rajiv Gandhi obliged (Metcalf \& Metcalf 2006). The Tamil Tigers refused to give up their arms and eventually India withdrew its troops in 1990, the Tamil Tigers however did not forgive India and ultimately assassinated Rajiv Gandhi using 'a new and powerful tool [they had devised], that of suicide bombing' (op.cit.263). The Nehru family era ended when Rajiv's Italian-born widow Sonia refused the offer to lead the party. It seemed that the Congress felt that, without a descendant of Nehru at their helm, they could not function.

The BJP election campaign in 1991, greatly supported by the VHP, was to be the 'most violent, and the most brutal election campaign in the history of independent India' (Blom Hansen 1999:166). The election campaign began a new phase in Indian politics with the introduction of vast amounts of propaganda produced through audio cassettes, video tapes and promotional leaflets all carrying Ayodhya as the most important issue. BJP and VHP continued campaigning for the demolition of the mosque, with the help of all the above media.

Narasimha Rao eventually took Congress to the elections in 1991, and, with the wave of sympathy for the loss of Rajiv Gandhi, Congress once again regained power. They began their tenure first as a minority government that grew quickly into a parliamentary majority and survived a five-year term. The BJP too had success in the election, gaining power in the state of Uttar Pradesh (the state in which Ayodhya lies), as well as emerging as the leading opposition to the Congress. Commentators state that the BJP, on gaining this political footing, looked to distance itself somewhat from their communal ideologies so to be seen as 'a responsible party of

\footnotetext{
${ }^{84}$ The Sinhalese Buddhists, wanting to rid the island of the Hindu Tamil speaking population who had ties with Indian Tamils across the water, launched an attack on them. The Tamil residents resisted and fought for Independence for themselves using guerrilla warfare under the Tamil Tigers.
} 
government', a party that was also aware that should they, to use the language of Brass (2003), tend to the fires of communalism too much, then there was the possibility that the government would remove them from state power (Corbridge \& Harriss 2000, Van der Veer 1994). However this soon changed, the VHP, still set on a swift demolition of the Babri mosque, was keen to build on the momentum of the elections and the Ayodhya movement. The BJP and VHP decided to announce and organise a rally in Ayodhya of two hundred thousand members on the $6^{\text {th }}$ of December at the site of the Babri mosque to resume the temple construction. Leaders from the BJP and VHP were present and a promise was made to the Supreme Court, members of which were worried about the safety of the mosque, by both parties, assuring that the mosque would not be damaged (Chandra et al 2000:422). But 'thousands of paramilitary troops were sent to the area to prevent kar savaks from physically attacking the Babri Masjid’ (Blom Hansen 1999:183). Sadly, however, neither Narasimha Rao and his Congress government nor the country's army could prevent what many considered the worst event in Indian politics since partition - the demolition of the Babri Masjid, which, according to Gould, marked the end of an era when 'secularism as an unchallenged, or at least "unchallengeable" basis for the Indian state disintegrated along with Babar's almost five centuries old mosque' (1998:523, emphasis in original). The BJP leader, L.K.Advani, who was present at the rally, conveniently disappeared as the demolition of the mosque began, along with other party leaders, and they later denied their involvement. There seems 'little doubt that the entire event had been well planned in advance' (Van Der Veer 1994:6), given the swift and more or less unhindered execution of the demolition plus the added fact that the kar sevaks had arrived armed with 'ropes, pick-axes, shovels and hammers’ (Corbridge \& Harriss 2000:130). Van der Veer (1994) argues that government took powerful action after the demolition, dismissing the BJP state governments and ordering president's rule in Uttar Pradesh, suggesting that the mosque would be rebuilt and banning many Hindu organisations such as the VHP and RSS. Scholars such as Engineer claim that 'Narasimha Rao the then Prime Minister, remained a silent spectator' taking 'no action whatsoever. Even the Central Reserve Police Force stationed 11 kilometres away from the site of the Masjid was never deployed' (2003b:14). Despite these opposing views the consensus seems to be that the Congress government did not act quickly or forcefully enough, maintaining what has been their sometimes obvious, but at other times ambiguous, 
stance on communal majoritarian politics throughout the 1980s and 1990s. The government, realising the amount of support for the Hindu nationalist movement at this time, were reluctant to oppose it too strongly so as not to lose its vote bank. There had been much talk about restoring the secular constitution but little action was taken by the government to ensure this. There is also a consensus that, given the lack of police and armed forces resistance to the demolition, many of the forces' members deployed actually supported it and were happy to assist, rather than to fight the kar sevaks. The same can be said for the communal violence that flared up in the aftermath of the demolition. The worst hit city was Bombay, where Hindu mobs ${ }^{85}$ organised by the Shiv Sena ${ }^{86}$ attacked Muslim populated areas of the city, instigating a killing spree in which the police participated. The same kinds of scenes were witnessed in Gujarat's capital Ahmedabad and in other major cities. Black Mountain contains a scene of Amin talking about the blood baths of violence in the streets of Bombay after the mosque fell. He describes his fear of being lynched by the mobs through the long period of violence during December 1992 and January 1993 and the bomb blasts in March 1993, which were an act of retaliation by the Muslim community. Amin's final remark in his commentary, as he witnesses the politicians in Bhuj celebrating the demolition of the Babri Masjid, is "had they not learnt anything?" 87 An exasperated question filled with frustration that the death, destruction and violent scenes witnessed by him and the rest of the Indian population during 1991, 1992 and 1993 were not enough to deter the Hindu nationalist parties from continuing their political goals in 2003, through the spread of hatred and stirring anti-Muslim feelings in their supporters. As Jaffrelot observes, there could be no responsible Indian citizen who was not 'disturbed by the way in which the Ramjanmabhoomi movement had brought about communal violence’ (1996:477).

\footnotetext{
${ }^{85}$ Mobs is a term used frequently in the Indian context to refer to an unruly manufactured group of young men who are used to carry out violent communal acts.

${ }^{86}$ The Shiv Sena (Shivaji’s Army) are one of the most powerful Hindu right organisations in India. They are the elected party who govern the state of Maharashtra. Founded in Maharashtra, the Shiv Sena liken themselves to the warrior Shivaji Marharaja's army. Shivaji was a famous $18^{\text {th }}$ Century Maratha warrior king whose armies fought off the Mughal invasion of the surrounding region. Many of Shiva's forts can still be seen dotted over the mountain range. He is a symbol of victory over the Muslim invaders. For an excellent insight into the Shiv Sena and their politics in Maharashtra and Bombay especially see Blom Hansen (2001).

${ }^{87}$ See Black Mountain - chapter 7.
} 
The violence after the demolition, according to Brass (1996), was organised violence of ““institutionalised riot system[s]” carried out by specialists’ (Lessinger 2003:153), which meant that the violent mobs moved systematically from town to town across India, afflicting atrocities on Muslim communities in the characteristic manner of Hindutva violence, spreading terror. In the words of Bidwai it is 'impossible to understand the pusillanimity of the Rao government of Congress Party in the face of the Hindutva assault' (2003), the only explanation that any commentator seems to be able to give for this apathy on the part of the Congress, is the breakdown of the Nehruvian 'ethno-accommodative' institutionalised politics that was once the cornerstone of Indian politics (Gould 1998:523). Using Ayodhya as an example, Gould suggests that in the past, issues that flared up around Ayodhya were dealt with carefully and neutrally. However things changed when in 1986 Congress Prime Minister Rajiv Gandhi opened the locked gates of the mosque to Hindu worshipers, and later in 1992 the Rao government looked on as the mosque tumbled down; the 'secular government [had] compromised its unambiguous affirmation of secular (i.e. ethno-accommodative) principles and colluded with proponents of the ethnoreligious state’ (ibid). These actions assisted the communal reworking of politics, removing the 'moral ground' from beneath the feet of Congress, which gave the BJP the opportunity to gain power and grow into a ‘national political party’ (op.cit.524/5).

The 'relationships between Muslims and Hindus throughout India have been quite fundamentally changed' by the events of 1992 (Corbridge \& Harriss 2000:131) ${ }^{88}$. For the BJP the fact that the mosque was no longer there meant that they lost an important element in the iconography of anti-Muslim mobilisation, and support waned as the 'object of their [Hindu] hatred had disappeared...for many Hindus the Babri Masjid embodied the stigma of an historical Muslim domination' which had to be removed, it was easy to rally support for this cause (Jaffrelot 1996:489). However its destruction removed the stigma, and for many that was enough, building the temple on its remains, according to Jaffrelot, was not really a concern. The BJP soon realised that it would now require a slightly more moderate stance in order to consolidate its growth and support. Ayodhya could no longer be the focus of their

\footnotetext{
${ }^{88}$ On India's 60 years of Independence celebrations in 2007, the demolition of the Babri mosque was voted by the public in one of the leading newspapers as the worst day since India's Independence, surpassing then, the terrible events of Partition in the memory of the present generation.
} 
politics; the drama was over, it was now important that they regained their credibility as a political party rather than as a communal troublemaker. Their political campaign in 1993 did not focus on communal issues, aware that if it did the BJP faced losing much of their middle-class support structure who had financially lost out in the aftermath of Ayodhya due to financial loses in business (Jaffrelot 1996).

The response of the Muslim community to the growing Hindu nationalist political cause that had gained such strength and momentum, was, in comparison to the actions of the Hindu right, somewhat passive until the events of the Babri Mosque in 1992 and the subsequent riots. A helpless Muslim community retaliated in March 1993 to the massacre that had been inflicted upon them, aided as most of them believed, by government machinery, especially the police force. Seven bombs were detonated in seven different places around Bombay. Masterminded by the Muslim underworld, the bombs ensured an end to what had become a pogrom, nobody had expected this reaction and it shocked and frightened the whole country, putting an end to violence. In Blom Hansen’s (2000) account of Muslim politics in Bombay he states that there were two 'distinct responses', apart from the bomb blasts, to the antiMuslim violence after the Babri mosque, 'one was a largely conservative quest for internal purification and unity of the Muslim community', the other was a call to regain an assertiveness in politics, this time not through the Congress but through the ‘Samajwadi Party, a North Indian lower-case political formation’ (op.cit.261). The request for a return to conservatism came from the Tabligh-i-Jammat, an organisation that calls upon the Muslim community around the world to follow their religious duties (Van der Veer 1994). Apart from the Tabligh there have been two main Muslim organisations during the twentieth century: the Jammat-i-Islami and the Jammat-ul-Ulema, who represent and seek to protect the orthodox Muslim community and they were most prominent during the 1920s up until Partition (Hardgrave \& Kochanek 1993). There are separatist Kashmiri groups too, the Jammat-i-Islami being one of them, who on most occasions since the bomb blasts of 1993, have been held responsible for subsequent bomb attacks. However, 'it is striking that no national party emerged in post-independence India to represent Muslims as an interest group’ (Metcalf \& Metcalf 2006:280). The Muslim community had in the past relied solely on Congress for their protection, however since 1992 faith in the Congress weakened, only to be restored in this present decade. 
Despite the lack of Muslim political movements since independence, it is through that one action in 1993 that the Muslim community became, in the media and politically, a highly dangerous terrorist community and fears escalated that the whole Muslim minority community would turn to these guerrilla tactics in order to make the country understand that it should not underestimate them (Jaffrelot 1996). Somehow this one act, as opposed to the multiple atrocities carried out by Hindus on Muslims across the country, created a new reason to fear the terrorist Muslim minority. Subsequent world events did nothing to change this; they just confirmed to the average Indian citizen that all Muslims were terrorists ${ }^{89}$.

What this research highlights, following Blom Hansen (2000) is the return to purity and conservatism among the Muslim population since the increase in Hindu nationalism in India. Kalo Dungar provides an example of this through the local Islamic communities, who, even if it has meant a change to their own historic cultural practices, now practise what they consider a purer form of Islam than they did previously. Has this change come about through the threat of Hindu nationalism or through the worldwide threat the Muslim community have felt over the last two or three decades? There might be elements of both, but, in the context of Kalo Dungar, it could be argued, that the Hindu nationalists have taken advantage of this change in the local Islamic practice of their faith.

After the Babri Mosque affair and subsequent bombings in 1993, elections followed and for the first time since 1989 communal rioting did not follow the political campaigning (Jaffrelot 1996). An economic crisis and more corruption allegations saw the popularity of the Congress decline. In 1996 the BJP became the largest parliamentary party, but by now Indian politics was fragile. Unstable coalition governments plagued politics for the next few years, and after successive elections the BJP finally came into power in 1998. By 1999 they were at the head of a 24

\footnotetext{
${ }^{89}$ A film was recently made in India called "Black Friday”, based on a novel, which centred around the bomb blasts in 1993, the catalyst however to these bombs - the demolition of the mosque - was given just a few minutes' attention in the film. Although I have not read the novel, the film treatment confirms in my opinion that what the Hindu nationalists would like us all to believe is that the Muslim community are the victimisers not the victims, and that it is the poor Hindu majority that are most under threat from the radical ways of the Muslims. This is an opinion that I think has echoes worldwide. It is what the Muslims are doing, not what they are reacting to, that fills so much of media and political debate.
} 
party National Democratic Alliance (NDA) (Bidwai 2003, Ludden 2005), and the 'Sangh Parivar took center-stage in national life' (Ludden 2005:vii). The future for India’s Muslims and other religious minorities looked bleak. By 1999 the BJP coalition was strong enough to last a full five-year term, in which time, more moderate politics were practised but communal behaviour was given freedom through their political allies such as the VHP and RSS who 'had moved from margins to mainstream by occupying the Prime Minister's office and all national ministries' (Ludden 2005:vii). During the second half of the 1990s, even though the BJP began to take a more moderate stand publicly, their communal campaign did not end. But their focus seemed to be directed to small scale issues, and even though there was not a return to communal rioting on the scale witnessed in the first half of the decade, communal conflict did still occur for a number of different small and often petty reasons (Engineer 2004). There was certainly an increase in offences towards the Christian community in India, which culminated in the burning to death of a pastor and his children in their car in Orissa (Engineer 2003b, Metcalf \& Metcalf 2006). In order to be able to capitalise on their power the BJP 'modified its extremism as a part of a short-term strategy to gain electoral access to state power' (Zavos et al 2004:5), and an example of this was that they did not work towards building the new temple of Ram in Ayodhya. The moderation of BJP political strategies was also due to the 'political constraints of coalition' (Bhatt 2001:176, Ram-Prasad 2003).

The late '90s witnessed the beginning of the BJP slander towards the Congress and their new leader Sonia Gandhi, the widow of Rajiv Gandhi, who by now had agreed to join Congress. Her Italian-born status gave the BJP an excuse to prove that the Congress were not a party fit to govern Hindu India.

\section{Into the $21^{\text {st }}$ century}

\section{The Gujarat Pogrom}

The next milestone for Indian politics was in February 2002, when the country witnessed the worst outbreak of communal violence since Ayodhya in 1992. On February $27^{\text {th }} 2002$ there was a train burning incident at the Godhra train station. It 
was reported that a group of Muslims had set alight a carriage of the Sabarmati Express train in which kar sevaks were travelling back from Ayodhya, where they had been helping the campaign for the building of the Ram temple. It later transpired that the train had been set alight following a spontaneous incident at the platform between Muslim tea vendors and the kar sevaks. The creation of confusion around the incident was indeed necessary in order to make sure that the communal violence ensued. A 'bandh' or closure of the city was called the following day, when violence broke out; at the end of the first day a hundred people had been killed (Engineer 2003b). According to Engineer, it was not simply a reaction to the train burning incident that started the rioting, rather it was a build up of anger created by the relentless spreading of the 'hate-ideology' of the BJP government and the Sangh Parivar against the Christian and Muslim minorities of Gujarat. The carnage of Gujarat coincided with a downturn for the BJP, who were losing elections nationwide, including in Gujarat, where their governance, or lack of it, was under question, accentuated by rumours of corruption which were rife after the earthquake in Kutch, Gujarat, in 2001 (more of which can be understood in Chapters 4 and 6). There is an adage in Indian politics that if you want to win an election start a riot, because of 'the proven formula - riot, polarization and thereby electoral success for communal forces' (Puniyani 2002b:153). That is exactly what the BJP did in Gujarat. The Gujarat pogrom was a classic example of the type of institutionalised riot systems discussed by Brass $(1996,2003)$ in which, as discussed further in Chapter 7, there are specific roles occupied by persons and groups in order to keep alive the embers of communal unrest. These include the creation of rumours and the role of 'firetenders' in stoking the embers of communal unrest, such as instigating incidents like the train burning incident at Godhra. There is evidence that Narendra Modi undertook a survey during the pogrom which suggested that the BJP might win elections after the violence, and they did; one might assume that planned violence of this kind would ensure the downfall of a government; rather it can secure their power (Puniyani 2002b). There have been commentators, such as Imtiaz Ahmad (2003) and Robinson \& Parthasarathy (2005), who have suggested that the violence in Gujarat was different from previous communal violence. Rather than 'a phenomenon that essentially belonged to civil society and the state sought to control it,' the 'state abandoned the time-honoured principle of even-handedness and sided with one community’ (Ahmad, I. 2003:288). 
The violence in Gujarat was planned methodically and preparations for it made far more in advance than any previous communal violence witnessed in India, which is perhaps what made it so much more frightening. This is evident from the organised way in which the Hindu mobs attacked Muslim quarters in the city. According to Momin (2002), Krishna (2003) and others, Gujarat is a society of ghettoes, an 'industrialised state' which has suffered from 'deindustrialisation in the era of globalisation', this has generated a 'globalisation-bred pauperisation of the working class'. Not only has this made it a picking ground for Hindutva politics which empower the people through violence, it has also encouraged a 'complete ghettoisation of the state' in which 'communal identity has become a prominent divide among the state’s industrial workforce’ (Krishna 2003:15). This ghettoisation has also been due to the 'continuing cycles of violence' in Ahmedabad (Spodek 2004:88). The ghettoisation of the Muslim community made its members a very easy target for the Hindu mobs. These mobs had been given detailed lists of Muslim organisations, businesses, and homes, by the state, enabling them to target Muslims specifically building by building, despite the fact that many of the businesses were running under Hindu names to protect themselves, because of the history of communal violence in the state. Through their research Robinson \& Parthasarathy (2005) discovered from victims, that this time the violence took a different form, much more brutal and sinister than before. Previously, if Muslims stayed at home during riots they were safe, but this time the mobs went to people’s homes to burn and loot them. Rioters were armed too, with mobile phones, LPG gas cylinders used for explosions, and metal cutters. There were even trucks of looters waiting in the wings, with police officers standing by, and even state ministers sometimes leading the violent mobs. Women and children were targeted; gang rapes, sexual mutilation and even extraction of foetuses, were just some of the violent acts carried out (Bonney \& Hawkes 2004, Chenoy et al 2003, Noorani 2003, Tehelka 2007). Official estimates of casualties were far from accurate; it was more like two thousand casualties killed in the riots than the eight hundred suggested by officials (Engineer 2003b, Spodek 2004). Most casualties were Muslims, as were those who occupied the refugee camps once the violence had subsided. It has been suggested that the complicity of the state can even be found in these camps, where, it seems, 'the 
government is deliberately pushing this enormous number of Muslim population to the margins of survival' (Chenoy et al 2003:211).

It soon transpired that it was the state's Chief Minister, Narendra Modi and his party the BJP, along with their political allies, who had orchestrated the pogrom. The state government were accused of apathy towards the rioting and even 'having planned its strategy' by calling the 'bandh' after the train attack. Narendra Modi deliberately ensured that law and order was not upheld, and it is claimed that the armed forces were not called to intervene for three days, in order for the killing to continue unabated (Bonney \& Hawkes 2004, Chenoy et al 2003, Dixit 2003). Modi has been criticised by a number of international human rights organisations for his aggression towards religious minorities. He also embarked upon a mass cover-up of the state's role in the riots, as well as exerting control over the judiciary process that victims sought in the aftermath. '[T]he same police force that was accused of colluding with the attackers was put in charge of the investigations into the massacres' (Bonney \& Hawkes 2004:17). The official report from the judiciary commission set up by Modi and the state government is still awaited ${ }^{90}$. Noorani describes the commission in any case as ‘a cruel joke’ (2003:279), a view mirrored by Setalva (2003), who draws our attention to the 'pathetic' record of the judicial system concerning justice for survivors (2003). Despite various other reports made by independent human rights commissions such as the National Human Rights Commission and the Citizens for Justice and Peace, implicating Modi as a key player in the outbreak of the violence, no charges have been brought against him. According to Krishna Iyer et al (2003) it is not just the 'criminal justice system [but] the entire Administration that has failed' in Gujarat (2003:247) ${ }^{91}$.

This 'state complicity', as described above, according to Krishna, has to be seen in the context of the 'total crisis sweeping through the political system that has made the state give up all pretensions of democracy, rule of law and human rights' (2003:18), that points directly to the ‘authoritarian’ nature of the Gujarat state (ibid).

\footnotetext{
90 This is according to the 2007 report by Amnesty International concerning India.

${ }^{91}$ Most recently in 2007 Modi was indicated once again as being responsible through an exposé of the course of events in 2002 by Tehelka magazine who recorded interviews with those involved in the violence.
} 
This authoritarianism also implicates, according to Krishna (2003), Chenoy et al (2003) and many others, the BJP and the Sangh Parivar as fascist organisations. What happened in Gujarat is described by these commentators as 'ethnic cleansing' (op.cit.202) not communal rioting, a type of violence inextricably linked with fascist groups. 'There is a constitutional breakdown in Gujarat' (Noorani 2003:280) where the state in its duty, as stated in the Indian Constitution, has failed to protect its citizens from external and internal disorder. Neither was the state government or its leaders answerable to the central government for this failure, rather, and most disturbingly, it continues to govern. Even more chilling are the words of the Prime Minister at the time, Atal Behari Vajpayee, who, rather than condemning the ongoing violence, stated 'wherever there are Muslims in the world there is strife. Islam has come to mean forcing their opinion through terror and fear' (in Puniyani 2002b:152).

There have been times that the Congress, during its control of the state, has turned a blind eye and been involved in violent communal activity. As Arundhati Roy iterates 'the Congress sowed the seed and the BJP...swept in to reap the hideous harvest...the Congress...has done by night what the BJP does by day’ (2003:35).

\section{Post Gujarat to 2007}

Perhaps the most distressing conclusion to this discussion of the Gujarat Pogrom is that in the state elections that took place in Gujarat at the end of 2002, Narendra Modi and the BJP were voted back into power with a two-thirds majority over Congress; this happened again in 2007, despite the atrocities they had organised in the state. Krishna suggest that this is ‘a telling commentary on the limits of [India's] parliamentary democracy’ (2003:218) and continues to be so four years later. Gujarat had now officially signed up to 'a newly vicious form of Hindu nationalism' (Metcalf \& Metcalf 2006:299). More election victories in other states in 2003 spurred the BJP to hold early national elections in the spring of 2004. Convinced that it would regain power with its "India Shining” campaign, elections were held and the BJP were voted out of office in favour of Congress who regained power, with the Gandhis at its helm once again, under Rajiv Gandhi’s widow, Italian-born Sonia Gandhi president of the Congress party. The campaign succeeded despite attempts by the BJP to convince the population that with a 'foreigner' at their helm, voting for Congress was like a vote for the minorities of India, further diminishing 
the rights of the majority Hindu population. But this India was tired of the empty promises from the BJP and they lost their majority Hindu vote bank overnight. It was a surprising turn of events and one that many Indians had doubted would come about. Sonia Gandhi turned down appeals for her to become Prime Minister of India and the post was given to her chief advisor, Dr. Manmohan Singh, a Sikh economist, finance minister during the early ' 90 ’s.

Congress did not come back into power on their singular strength, the days of a single party majority were over (Bonney 2004). The Congress, who once swore never to share power, now 'forge[d] alliances' without which it could not have won, creating the United Progressive Alliance (UPA). 'The alliance partners have come together due to their shared dislike of the BJP and ostensible desire to strengthen secularism and democracy' (Pant 2004). Secularism and democracy at this time, according to Pant, is reduced to the direct opposition to communalism and what is viewed as the fascist regime of the BJP.

Zavos et al (2004) draw our attention to the 'issues of culture and identity [that] have always presented themselves as salient features of Indian politics', no more so than over the last two decades (2004:1). They state that 'the collapse of one-party dominance... has fragmented the nation and brought regionalised and localised politics to Delhi' (op.cit.2). It is perhaps the rise in regional politics that has given credence to the rise in 'cultural incursions [and] the political mobilisation of people around cultural symbolism and language' (ibid), therefore 'national politics is... shaped by local politics' (op.cit.5). In the past, through the legacy of colonial politics within which the National Congress began its political career, when society was divided and strict socio-cultural boundaries allocated, politics too had strict boundaries, the voice of the people was not and did not want to be heard. This legacy stayed with Nehru's political ideals despite his post-colonial dream of including those socio-cultural diversities into politics, and the lower classes of India's masses were not effectively incorporated into independent Indian nationalism (ibid), 'cultural identity was largely pre-packaged and actively depoliticised' (op.cit.11). It was not let out of its box until the Congress regime began to break down in the 1970s and identity politics entered the political practice (ibid). This is 
the time when, other political writers suggest, India's legitimate political institutions began to collapse.

It is also important to recognise, in concluding this discussion, although it may come as a surprise after the information detailed in this chapter, that despite popular belief and despite the extensive literature on Indian politics, Indian politics is in fact not only a contest between BJP and Congress ${ }^{92}$. But it is clear that collectively the Congress and BJP have perhaps affected Indian politics more than any other parties and for the purposes of this research are the most important components.

It is not possible to say that communal politics, now that BJP are out of power, has disappeared. However, since the violence in Gujarat in 2002 there has not been a repeat of that scale or kind of violence. Engineer (2006 \& 2007) gives an account of communal riots in 2005 and 2006 and in both papers he states that communal violence has decreased after Gujarat, he likens this pattern to a similar kind of 'watershed' that was witnessed after the riots instigated by the demolition of the Babri Mosque (Engineer 2007:100), this cyclical pattern is reflected in the cycles of syncretism and anti-syncretism described in Chapter 5. He also describes communal incidents between Hindus and Muslims, stating that riots and conflict are still caused by religious processions and disputes over dargahs/mosques and temples. The other major cause of conflict continues to be the build up of 'hate propaganda by communal forces’ (Engineer 2006:42). This propaganda often surfaces in the production of rumours, which often instigate communal violence, as we learn from Brass (2003) in Chapter 7.

Ram-Prasad suggests that the fact that the Gujarat violence did not spread into other equally communally sensitive states indicates that 'the Hindutva movement, as a whole, would appear to be at a cross-roads', and even though the BJP regained power in Gujarat, it lost power in other states (2003:193/4). But in Gujarat the scars from the 2002 pogrom are still not healed, just as nationally, the scars of the Babri Mosque demolition remain raw, adding to the scars left behind from the horrendous

\footnotetext{
${ }^{92}$ They make up just a small percentage of political support. As mentioned above, it is the development of regional parties and politics that take centre stage, $49 \%$ of India is governed by other political parties (Ludden 2005).
} 
events of Partition. The BJP and Hindu nationalist parties govern other states in India too, and the RSS and VHP are very active in chipping away at the communal fragility of the country; the case study of this research is just one example of this. There has also been an increase in Islamic extremism, stemming mostly from militant groups associated with the unresolved issue of Jammu Kashmir. Recent bombings in Bombay (as depicted in Black Mountain), Delhi and Hyderabad and Malegaon (Maharashtra) have been attributed to Jammu and Kashmiri militant groups. A general movement away from culturally colourful Indian Islam to what is considered a more pure form of Islam, is the most endemic feature of these militant groups. Indian Islam has always been considered by purist Islamists as adulterated, incorporating too many aspects of other cultural traditions that have influenced it over the centuries as it slowly sought to conquer Hindustan ${ }^{93}$. Ludden (2005) exemplifies this point when he recognises that 'Indian Islam is older than American Christianity and European Protestantism'; it would seem obvious that it has been influenced by the varying Indian cultures surrounding it, contributing enormously to what some describe as the composite, even plural and syncretic, religious traditions that exist in India today. To Ludden, Indian Islam 'represents the characteristic capacity of Islam everywhere to be adaptable to the environment' (2005:5), this adaptable and changing aspect of Islam is not something supported by the purists, just as the adaptable and changing aspect of which makes up most of the Hindu way of life, is not supported by the Hindu nationalists. This drive towards purity, whether it is the purity of a nation, i.e. Hindu Rashtra, or religion specifically, is a driving force behind the breaking down of syncretic traditions in India and a development towards ‘anti-syncretism’94 . '[E]xclusive Hindu Nationalism’ (Pant 2004) may seemed to have waned for now, enabling this composite culture of India's heritage with its diverse traditions to thrive to a degree. However as the following chapters illustrate, the changing nature of these composite traditions is real and present. It is a shame that, as Misra suggests, 'those who seek a...divided identity and interpret...[Hinduism and Islam as]...irreconcilable opposites deny the opportunity of the state to function properly', due to the fact that syncretism, or at least the view of India as a composite nation, 'has been the primer on which has been etched "the idea of India”’ (2004:235).

\footnotetext{
${ }^{93}$ See Chapter 5 - Shared Faith Traditions.

${ }^{94}$ This is a concept discussed and developed in a later chapter.
} 


\section{Conclusion}

This chapter attempts to provide an understanding of India's political history as a background to the pilgrimage to Kalo Dungar, a description of which follows. Suggestions were made to account for the type of political hatred and politically violent rhetoric witnessed at that site. The plural composite culture of India, its syncretic nature, has been radically affected by the events summarised here, which, I contend, have aided the growth of 'anti-syncretic' attitudes and behaviour. 


\section{Chapter 4}

\section{Ethnography - Part 1}

\section{Introduction}

The main section of this chapter provides an ethnographic account of the first visit to Kalo Dungar.

[A] "well written" ethnography, [is] one that holds our interest and conveys a vivid sense of another culture, is a creative endeavour, as is any ethnography. For fieldwork never presents us with a coherent account but rather with information and images that we must select and arrange and present and write about whether poorly or well, whether vividly or dully, using our own creative skills (Dubisch 1995:17).

I present here two ethnographies, one in a visual format and one in a written format. Both have the title Black Mountain. Whilst the visual ethnography provides moving images and sound to amplify written description, the text goes further by providing an in-depth discussion of issues which could not be raised in the film.

Both the visual and written ethnographies incorporate equally, a) the research findings b) the journey and c) the feelings and experiences of the researcher into the ethnographic description.

Such details as our own reactions to what we observe, who we were with when we observed it (spouses, friends, lovers), how we have been included in or frightened or embarrassed or angered by what was unfolding around us are usually suppressed in the final written narrative that we present professionally (op.cit.57).

Ethnography of this style has previously been described as the 'Impressionist Tale'. The impressionist tale is a part of what Okely terms the 'autobiography of fieldwork' (cited in Dubisch 1995:56), which enables an insight into 'the doing of fieldwork rather than simply the doer or the done', and enables the reader to have a more 'immediate, sensual contact with the field' (ibid). In a Different Place is an attempt by Jill Dubisch to write an ethnographic account of her research in a manner that moves away from the traditional realms of the 'realist account(s) of objective facts recorded by an omniscient and invisible observer', to a style that attempts to break- 
down the 'distance between the observer and the observed', which she states as an important aim of 'experimental ethnography' (op.cit.6). It is these experiments in ethnographic writing that enables the

I of the anthropologist...to wander freely throughout the ethnographic narrative, blurring [that] boundary between "personal" and "objective" reflecting a greater self-consciousness about the anthropologist's own position' within the culture that he/she is studying (op.cit.5).

Dubisch aims to use both her own and others' emotions in the narrative so as not to isolate personal reactions or experiences from other parts of the data, choosing rather to integrate them, as opposed to generic anthropological writing which is often 'constrained by a shared set of professional standards and conventionally agreed upon modes of presenting “facts” in appropriate language’ (op.cit.17/18).

Translating experience into words is, as I have found, one of the most difficult aspects of ethnography. Film, by its very nature, provides a naturally 'thick description' of the visual colours of research, however it can prove just as difficult a medium as words, to translate experience. I hope that the combination of these two media will ensure that each one can make up for the short-comings of the other and provide a 'thick description' rich with the colours of research, a reflection on the research process and a thought provoking insight into specific issues affecting India today in respect to its religio-political dimension. 


\section{Kalo Dungar}

To protect one's country is to protect one's religion. This is the fundamental aim of this pilgrimage (Dilip Bhai, Bhuj 2003 - as seen in the accompanying film 'Black Mountain')

The pilgrimage site of Kalo Dungar ${ }^{1}$ or Black Mountain (as it translates in English) is situated in Kutch, Gujarat, on the edge of the Great Rann of Kutch (a salt desert which becomes a salt marsh during the monsoon season).

\section{Where is Kalo Dungar?}

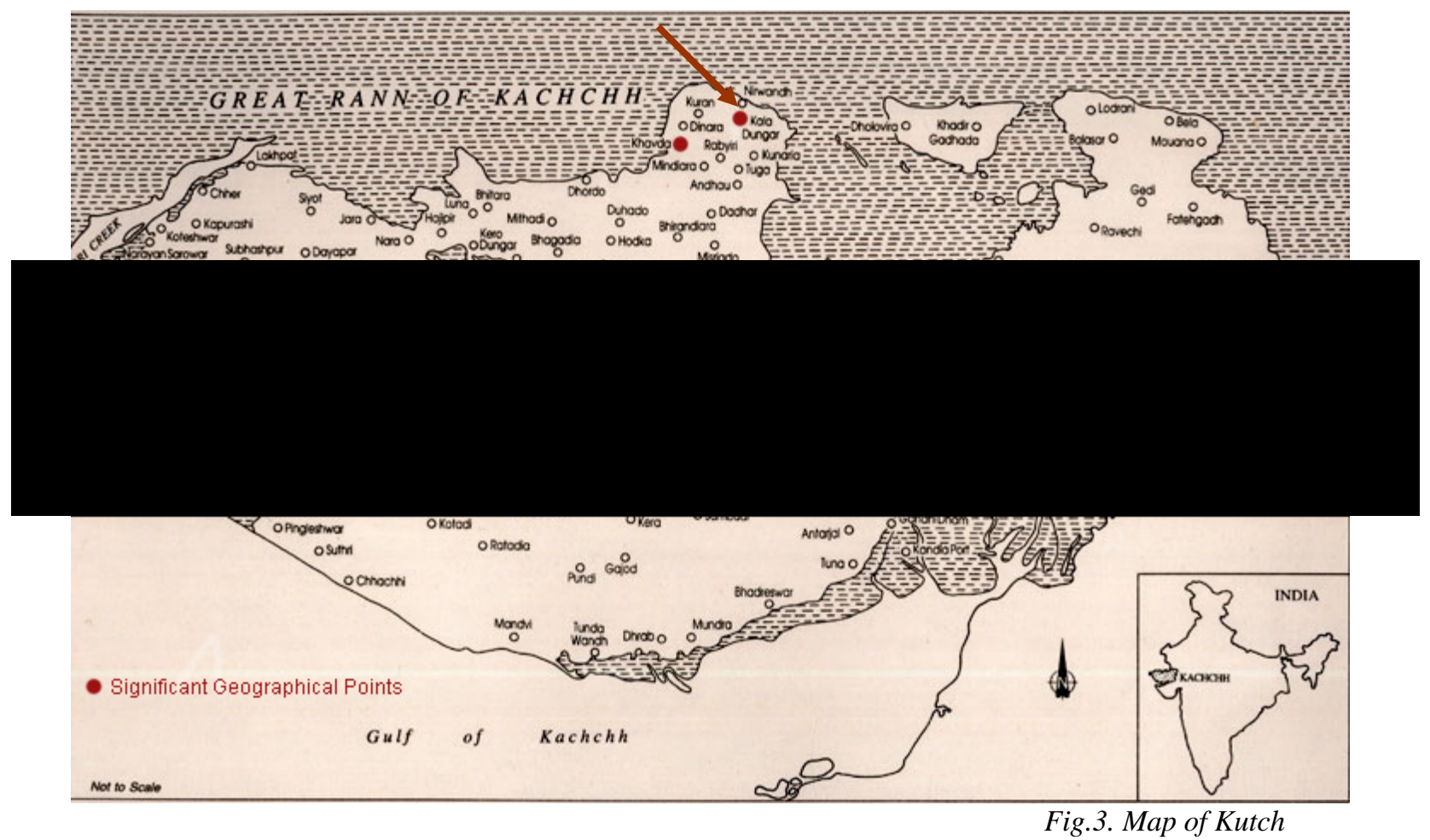

Kalo Dungar is a rocky hill (or small mountain) of black stone in the district of Kutch $^{2}$ in the state of Gujarat. The range of hills cuts through Pachham Bet or Island. Pachham, which means 'west', is one of four 'islands' in the Great Rann of Kutch $^{3}$ (Campbell 1880, Rushbrook Williams 1999). During a heavy monsoon the

\footnotetext{
${ }^{1}$ Kalo Dungar is sometimes spelt Kala Dungar. Kala in Hindi translates into English as Black and Dungar into Mountain.

${ }^{2}$ Kutch is also spelled "Cutch" and "Kachchh". It is said that the geographical shape of Kutch resembles that of a tortoise, hence the name "Kutch", a word derived from the Kutchi word Kaachbo meaning tortoise, (Jethi, no date, Wikipedia 2006).

${ }^{3}$ The islands beginning from the east are known as Charad, Bela, Khadir, and Pachham which is the most Western of the four.
} 
islands rise up out of the water that immerses the Rann. Extending over an area of $45,612 \mathrm{~km}^{2}$, Kutch is the second largest district in India (Jadiya 1997). The district of Kutch is bounded in the south by the Gulf of Kutch, in the west by the Arabian Sea, in the north and north east by the Great Rann of Kutch and the Sindh ${ }^{4}$ region of Pakistan and in the east and south east by the Little Rann of Kutch, all representing the physical extremes for which the region is famous. Kutch has a total population of nearly 1.6 million (Census of India 2001), of which approximately 78\% is Hindu. Fig.4 shows the religious composition of the district set against that of the entire state of Gujarat and the country as a whole.

\begin{tabular}{|l|c|c|c|}
\hline Religious Communities & Kutch District & Gujarat State & India \\
\hline All Religions & $1,583,225$ & $50,671,017$ & $1,028,610,328$ \\
\hline Hindus & $1,223,254$ & $45,143,074$ & $827,578,868$ \\
\hline Muslims & 329,254 & $4,592,854$ & $138,188,240$ \\
\hline Jains & 23,894 & 525,305 & $4,225,1053$ \\
\hline Sikhs & 3,341 & 45,587 & $19,215,730$ \\
\hline Christians & 2,834 & 284,092 & $24,080,016$ \\
\hline Buddhists & 101 & 17,829 & $7,955,207$ \\
\hline Others & 58 & 28,698 & $6,639,626$ \\
\hline
\end{tabular}

Fig.4. Table of Religious Composition of Kutch, Gujarat \& India Source: Census of India 2001: accessed 9/12/2007

The political history of Kutch and its neighbour Sindh is complex and not one to be attempted here ${ }^{5}$, however it is important to elucidate the significant junctures in this history in order to understand the perspective of the informants and material gathered in this research. There have been two instances of Sama rule in Sindh and Kutch. The first was in the $8^{\text {th }}$ Century CE during the Arab invasion of Sindh when the Sama Rajputs enjoyed some independence allowed to them by the Arab leaders. During this time many of the Hindu Samas converted to Islam and a mixed heritage of Hindu Islamic practices developed. The second Sama Dynasty began in the $12^{\text {th }}$ or $13^{\text {th }}$ Century CE. Around this period many Samas from Sindh migrated, or it is argued,

\footnotetext{
${ }^{4}$ Sindh, once an adjoining part of Kutch, is now a part of Pakistan that borders the Great Rann of Kutch. Sindh and Kutch are extremely similar both in physical geographical terms as well as sociologically.

${ }^{5}$ A comprehensive history of this political history can be gained from Campbell 1880, Burnes 18271828, Panhwar 1979, Randhawa 1998, Rushbrook Williams 1999, and Wikipedia 2006.
} 
were ousted from Sindh to Kutch. At this time they began a new era of independent rule under Lakha or Lakho, who was the adopted son of a Sama Chief named Jada, and took on the clan name of Jadeja. During this period the Sama Rajputs became known as the Jadejas and they ruled Kutch for around 700 years, 130 years of which was during the British Empire (Panhwar 1979). It is to this Jadeja period that most of Kutch relates its ancestral heritage; in the film Black Mountain we encounter a village, called Drobhana, at the foot of Kalo Dungar, where a local Muslim population of Samas reside. They give us an account of their history, of Kalo Dungar and of their ancestral heritage. They state that they were Jadejas before they converted to Islam, when they became Samas (Black Mountain - Chapter 19).

Their conversion took place possibly during the Arab invasion of Sindh in the $8^{\text {th }}$ century, but possibly later when Jadeja Hindus began to live in Kutch. Panhwar states that the 'Jareja Samma religious practices are a mixture of Hindu and Muslim rituals and Cutchis pay equal respect to Muslim Saints and Pirs and Hindu Deities' (1979:16). Kutch has changed since 1979; there is no evidence that there are now any Sama communities who pay respect to both Pirs and Hindu deities ${ }^{6}$.

Kutch has always been a melting pot of nomadic, semi-nomadic and artisan tribal communities including Ahirs, Meghwals, Rabaris, Jatts, Mutwas, Lohanas, Harijans and Samas ${ }^{7}$. These tribal communities find their ancestral heritage all over the subcontinent but most commonly towards the West in Afghanistan, Iran and even Syria, where it is believed the Jatts of Kutch and possibly some of the Samas originated ${ }^{8}$. The accounts of the Jatts, according to Ibrahim, 'locate their origins at "Halab" in modern Syria, from where they came to Sindh as "warriors of Islam" in the campaign that finally brought Islam to Sindh in the eighth century AD’ (2004:175). The immigrants were camel herders who settled in the area and took up farming, relying primarily on their herds.

\footnotetext{
${ }^{6}$ Although there is evidence that this practice exists between Hindus and Muslims in this area and through Gujarat and Rajasthan, some examples of which are given in the following chapter otherwise, see Sila Khan 2003, Roy 2005.

${ }^{7}$ For further reading on the tribes and handicrafts of Kutch see D’orazi Flavoni, F, 2002, Jethi 2000, Randhawa 1998, Rushbrook Williams 1999.

${ }^{8}$ I refer here to the Samas whose heritage dates back to the Arab invasion of Sindh when many marriages of alliance took place between Hindus and Muslims.
} 


\section{Experiencing the Great Rann of Kutch}

From the top of Kalo Dungar one can see for miles across the Great Rann of Kutch, which forms the environmental and physical border that, in this region, divides India from Pakistan. The Rann of Kutch stretches approximately 10,000 square miles between the Gulf of Kutch and the mouth of the Indus River in southern Pakistan (Jadiya 1997, Wikipedia 2006). 'To the north stretch the Sind and Thar deserts of Pakistan, and across the Gulf of Kachchh to the south are the farm lands of the Saurastra region of Gujarat' (Jadiya 1997:1). It has been described vividly by past government officers in the region, both during and post Independence, Randhawa (1998) being the latest. As early as in 1828, Lieutenant Sir Alexander Burnes gave his impression of the Great Rann:-

In length the Runn extends from the Indus to the Western confines of Guzerat...the whole tract may be truly said to be a 'terra hospitiis ferox' [a land fierce to travellers/visitors]...it is I believe a space without a counterpart in the globe differing as widely from what is termed the sandy desert, as it differs from the cultivated plain, neither does it resemble the steppes of Russia but may justly be considered of a nature peculiar to itself. (Alexander Burnes 1827-28:58/59)

This description is as fitting 181 years later in 2008 as it was then: the Great Rann is a region of salt plains, often referred to as the salt desert, and was once originally a part of the shallows of the Arabian Sea. The salt plains spread into a vast clay bottomed desert, unlike that of a sandy desert. The cracked clay bottom gives an image of a fossilised land which in the dry arid heat creates a mirage like a shimmering blanket of water running freely as far as the eye can see. As Alexander Burnes wrote 'nowhere is that singular phenomenon the mirage or surab of the desert or as the natives most aptly term it dhoo-an (smoke or vapour) seen with greater advantage than on the Runn' (1827-28:59). During the wet season parts of the Rann form a marshland which remains wet during the dry season and provides a grassy breeding ground for pink flamingoes, cranes and a host of migratory Siberian birds that can often be seen gliding like pre-historic giants across the desert.

\section{Falling in love with Bhuj}

Kalo Dungar is located 100kms north of Bhuj, the district capital of Kutch.

According to the Census of India 2001, Bhuj has a population of 98,528. The city is 
demarcated by a city wall built in 1723 as a defensive barrier against suspected invaders (Rushbrook Williams 1999). The population of Bhuj now sprawls out beyond the old city walls as over the years every square inch of the old city has been used and occupied.

In very recent years the makeup of Bhuj has changed considerably. After my first visit to Bhuj in 2000 to be part of a Hindi film called Lagaan, an earthquake, hit Kutch on January $26^{\text {th }} 2001$ - India’s Republic Day. The effects of the earthquake politically and socially, will be addressed later in the chapter but the physical effects were there for all to see. The earthquake affected the city of Bhuj as the epicentre was just a twenty kilometres away. It was the largest earthquake to hit Kutch since 1819 reaching 7.8 on the Richter scale. We returned in June to Bhuj to screen the film (Lagaan) for the people who had played a part in making the film possible. As we touched down into the new airport building and made our way into Bhuj, our surroundings were almost unrecognisable. We passed buildings half collapsed, mounds of rubble lined the streets, and huge cracks left behind by the earthquake. Friends in the old market re-told stories of how they survived the earthquake, of how they reacted to the terrifying noise of the tremors, the sound of cracking and falling buildings and the feeling of helplessness as the city crumbled around them and they were blinded by the dust that engulfed them. Visiting Bhuj during this time left all of us feeling numb, a numbness none of us can forget. But our abiding memory will be of the people waiting at the local theatre for the film to begin, the joy and relief on their faces to be doing something other than thinking of the misery of the earthquake; the resilient faces of all those whose lives had been turned upside down since we last met.

It may not be clear why these feelings and experiences regarding the earthquake are relevant to this ethnography as they took place a couple of years before my research even began; however, the fact is that the earthquake altered the psyche of the people of Bhuj. The earthquake is considered a starting point for many of the changes that one witnesses across Kutch today, physically, aesthetically, socially and politically, of which the events I witnessed at Kalo Dungar may be considered a part. Ed Simpson (see Simpson 2005, 2006, 2006b, 2007, Simpson \& Corbridge 2005) has 
written extensively on the effects of the earthquake on the political and social make up of Bhuj. His work will be considered later in the chapter.

In the past, apart from studies of the textile traditions of the tribal communities of Kutch, there has been little research in the area. However, since the earthquake, Kutch has become a hub of post-earthquake related activities as charities, developers and researchers have flocked to the region, involved in research and work covering the re-development of the area and the psychological effects of the quake. During my own fieldwork I came across several researchers, including Ed Simpson and Farhana Ibrahim, who had been undertaking individual doctoral research in Kutch. Their experiences in the field pulled them unwittingly into the socio-political changes since the earthquake, even though their researches focused on very different issues.

Much of the re-development of Bhuj has taken place outside the limits of the city wall, and a suburban Bhuj has been created, quite different from the old city. Many of the residents of the old city, according to Simpson (2005), moved into the redevelopment area of Bhuj as they received new homes in compensation for their fallen ones. Most of them, at least at the time of his research, tended to avoid visiting the old city so as not to re-visit their traumatic experiences. Prior to, and even more so after these changes, Bhuj has been and is a city that is home to many of the ethnic communities that make up Kutch’s rich heritage.

It often seems that significant moments in anthropological fieldwork are relegated to the margins of the eventual texts in which ethnographies appear. In prefaces, epilogues and acknowledgments pages, friendships are made, grants are awarded, and babies are born all of which for many anthropologists were perhaps as crucial in enabling an ethnography to take the direction that it did as any theoretical disposition or discovery (Pertierra 2007:1).

My research is based on a chain of serendipitous events occurring over the last seven years, beginning with my first encounter in Bhuj when I arrived to be part of the film Lagaan, where I met my now husband, Amin Hajee, who was a character actor in the same film. For the past seven years I have been living in Bombay, exploring India, and visiting Bhuj and the surrounding areas of Kutch. 
It was our previous association with Bhuj that brought Amin and me back there in 2003, two years after the earthquake, primarily for another function associated with Lagaan. At this point my doctoral research had just begun, I was looking into the commercialisation of pilgrimage in India, and my initial research involved visiting numerous pilgrimage sites. Aware that we were returning to Bhuj, as a part of my research I explored Kutch once again, as well as visiting many of the famous pilgrimage sites that dot the district and the state of Gujarat, including Dwarka and Somnath $^{9}$. During our visit to Bhuj, we met up with an old friend and co-actor, Prakash Shukla. I had told him about my research; a few days later he told us that he had seen an announcement in a newspaper for a pilgrimage that was taking place to Kalo Dungar, a hill situated about $100 \mathrm{~km}$ away north of Bhuj near the Great Rann of Kutch on which a holy shrine existed. It would begin on the $6^{\text {th }}$ December, many of the pilgrims walked many miles from around the district to reach the site. He offered us his motorbike and Amin and I were excited about the prospect of joining the pilgrims and began making plans for the trip.

\section{The pilgrimage to Kalo Dungar}

It was 5am when we wound our way around the dusty, rubble filled, desolate streets of Bhuj; the holes and cracks still left behind by the devastating earthquake of 2001 filled us once again with emotion. I was sitting pillion on the motorbike, filming as we passed through familiar streets, and our conversation was filled with nostalgic memories. It was hard to believe that two years after the earthquake some buildings were still left half collapsed. Amidst the littered reminders of past events, we arrived at the starting point of the pilgrimage, a large temple in the heart of the old walled market area. There were but a few people milling around outside the temple, mostly men huddled up in their traditional Kutchi woollen shawls guarding themselves against the cold pre-dawn snap in the air ${ }^{10}$.

\footnotetext{
${ }^{9}$ See Black Mountain - chapter 4 - for visuals on the pilgrimages I embarked upon.

${ }^{10}$ See Black Mountain - chapter 5 - for this and visuals of the temple as the pilgrims gathered (described below).
} 

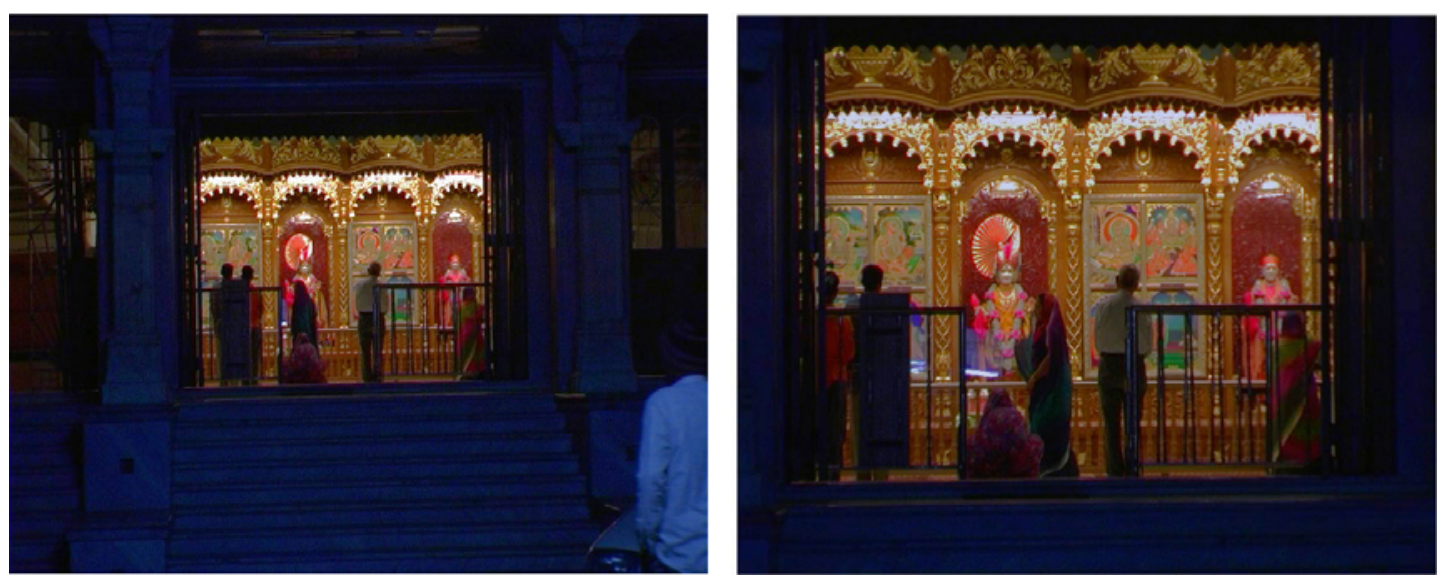

Fig.5. Swami Narayan Temple illustrating the marble steps, pillars and alcoves in which the statues are displayed. Note the ornate gold leaf that adorns the frames and pillars inside the temple.

As time passed more people gathered around outside the temple, and a group of young boys entered. They arranged themselves at the side of the 'idols' ${ }^{11}$ and began singing a bhajaan ${ }^{12}$ and clapping their hands. I called Amin to watch and, taking the camera from me, he entered the temple and filmed the boys. They did not seem to mind him filming, and in fact began to sing louder and clearer when they saw his camera. We then went back outside where pilgrims were standing. Many pilgrims were still arriving, some on foot, some by bicycle and others by motorbike, many sitting "threes up" (three passengers). Some of them were carrying saffron coloured flags, which is the colour associated with Hinduism. At this stage in my research I was aware of the use of the saffron flag by right-wing political organisations, however I had also witnessed the saffron flag used in neutral situations, and so I continued filming and observing without taking much notice of its presence ${ }^{13}$. It was not until later that I understood the reason for the increasing presence of saffron flags and their implication.

At this stage there were very few women in the gathering which was not unusual considering the hour. It is generally not expected that a woman would be out on the streets at this time, however, as time went on quite a number of women pilgrims joined. Amin began to recognise some faces, people we had met through Lagaan

\footnotetext{
${ }^{11}$ This Anglo-Indian term is not used pejoratively, but is used to refer to statues which are believed to contain the essence of a deity.

${ }^{12}$ Bhajaan, pronounced budgen, is a prayer that is sung, similar to a hymn in Christianity.

${ }^{13}$ Saffron has always been the colour associated with Hinduism, however it has been adopted over the years by Hindu right-wing political organisations. A show of saffron flags is now not just a symbol of religious affiliation but also of a political one too.
} 
and whom we had met on our initial arrival in Bhuj. It became obvious that they were members of the organising body of the pilgrimage and on seeing Amin and me at the meeting point a number of them became very excited. They welcomed us and asked us why we had come; we explained to them briefly that we were making a film about pilgrimage and had been informed about this particular one. There were a few more inquisitive questions directed to Amin. It quickly became obvious that there was some confusion as to why someone called 'Amin', a Muslim name, would be participating in the pilgrimage. This sparked a series of questions from some of the other pilgrims around us.

Pilgrim: Who are you? Haven't I seen you somewhere before?

Amin: I'm Amin, I was Bagha in "Lagaan!”

Pilgrim: $\quad$ Oh Yes! Now I got it. But why are you here?

Amin: $\quad$ Because I want to experience this pilgrimage with you all, I want to understand and film you as pilgrims at different points through the pilgrimage.

Pilgrim: What's your full name?

Amin: $\quad$ Amin Hajee.

Pilgrim: What are you? What is your identity [i.e.caste]?

Amin: $\quad$ I am a human being.

Pilgrim: No you cannot be that, what is your religion, your identity? You are a Muslim, aren't you? Tell us!

Amin: Well I was born to Muslim parents, but I'm a humanist!

Pilgrim: $\quad$ Humanist? How can you be that? You can either be a Hindu or a Muslim.

(Conversation between Amin and a Pilgrim, Bhuj 2003, not shown in 'Black Mountain').

There was some disappointment amongst the pilgrims as it transpired that Amin was, in fact, not the Hindu drummer he enacted in Lagaan. During this conversation, which almost became a confrontation, none of our friends from Lagaan intervened, they watched from afar. We were a bit confused but not deterred as we knew we were amongst acquaintances and there remained an unspoken bond that we shared as a result of the film. In fact when we had met them earlier upon our arrival in Bhuj during a lunch get-together we had learned, to our surprise, that they were supporters of the RSS ${ }^{14}$. This association with the RSS had not yet dawned on me, however talking to Amin later that day, I realised that at this point he was already beginning to

\footnotetext{
${ }^{14}$ RSS - The Rashtriya Swayamsevak Sangh - is the most powerful and successful right-wing Hindu nationalist organisation in India; see Chapter 3 - India's Pledge.
} 
put certain pieces together but at this early stage, he too, was not sure what to make of the events around us.

Eventually even though some of the pilgrims still did not fully understand why we were there, our presence was supported in part and the group around us dispersed as we continued to film the subsequent proceedings ${ }^{15}$. About an hour had passed when a crowd of around 100-150 people had gathered and the pilgrims started to congregate around the bottom of the temple steps. At this point Amin quickly took the camera from me and I continued observing the proceedings. From the temple steps a pundit, the chief pujari ${ }^{16}$ (see Fig.6) stepped out with a group of people around him ${ }^{17}$. Local media had gathered around the fringes as the opening ceremony or initiation of the pilgrimage began. A man standing just behind the Pujari began the ceremony with calls of "Jai Shri Ram - Salutations Lord Ram" ${ }^{18}$ followed by further calls of “Dattatreya Bhagwan Ki Jai-Salutations Lord Dattatreya” and "Shri Swami Narayan Bhagwan Ki Jai - Salutations Lord Swami Narayan”, then finally "Bharat Mata Ki Jai - Hail Mother Land". Each time a chant was made the gathered pilgrims repeated it in chorus. The same man then began a speech, which translates:

We are celebrating Lord Dutt's Birthday by embarking upon this pilgrimage with the blessing of the revered Saints. In dedication to Lord Swami Narayan this year's auspicious journey will commence with the blessings of our revered head priest. Our first stop will be after the railway crossing. In the afternoon we will stop to rest and eat at Loriyaar village, then after lunch at 2pm we will resume our journey.

He paused as if stopping but then suddenly continued with more passion in his voice:

We must remember that today is the day that the entire Hindu community is proud of. After many decades on $6^{\text {th }}$ December 1992 the stigma at Lord Ram's Birthplace was finally removed because of the united strength of our Hindu community. Therefore today is a symbolic and special day for our journey. I now request our revered

\footnotetext{
${ }^{15}$ Later as the pilgrimage proceeded, we met various groups of pilgrims who took to Amin with pleasure on finding out his involvement in Lagaan. Some of these encounters can be seen in Black Mountain.

${ }^{16}$ Pujari, pronounced Poojarie, is a Hindu priest.

17 See Black Mountain - Chapter 6

${ }^{18}$ Jai Shri Ram can also be interpreted as 'Lord Ram is the greatest'.
} 
head priest, Swamiji, to hand over the orange flag to the pilgrims and mark the auspicious beginning of this pilgrimage.

(Pilgrimage Organiser and RSS Worker, Bhuj, 2003) ${ }^{19}$.

Although at this point I did not understand all of it, I realised that towards the end of the speech the man spoke with a lot of aggression. After the speech ended the Pujari began to wave the large saffron flag that he now held in his hand and there were more chants from the congregation of “Jai Shri Ram - Salutations Lord Ram”, as well as repeats of previous chants, all repeated again in chorus by the pilgrims. The Pujari handed over the blessed flag to a pilgrim standing in front of him and then began to address the gathering.

Our Swami Bappa (spiritual father), who is currently on tour in Nairobi, and our head priest who is in Ahmedabad have both been informed about this journey that you are embarking upon. They are very happy that you are making this journey and they believe it is a good thing that we are doing. They all send everyone their blessings and best wishes that the journey goes safely and uneventfully.

(Chief Pujari-Swami Narayan Temple, Bhuj, 2003).
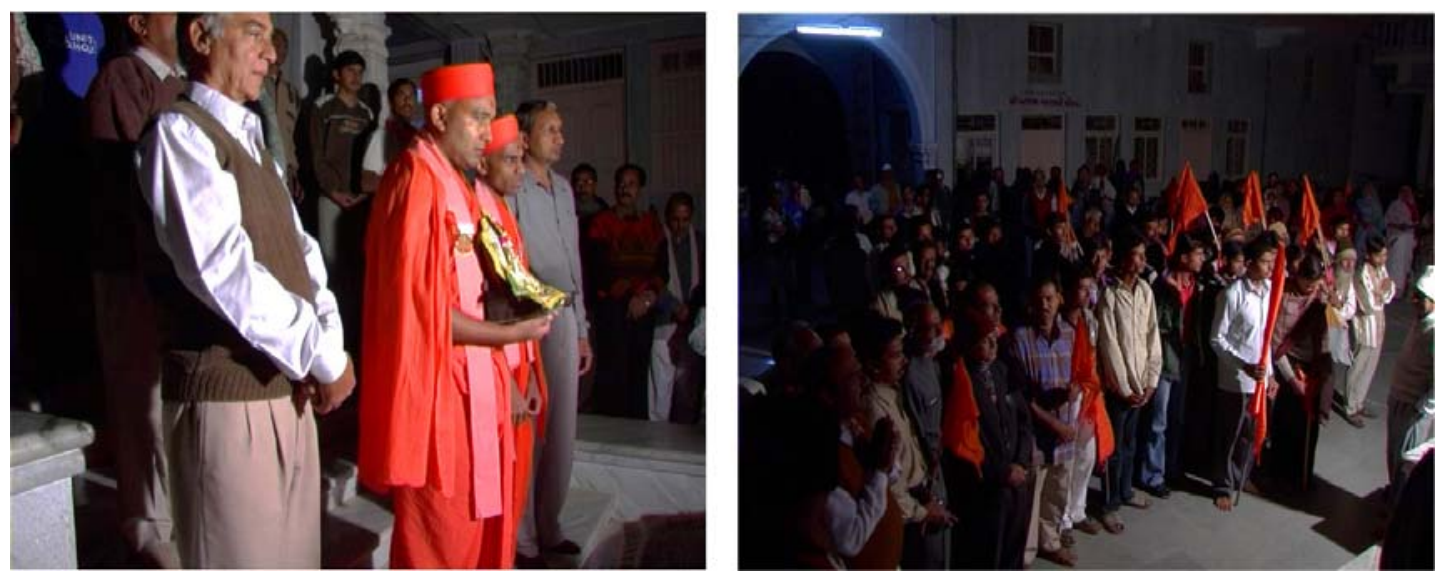

Fig.6. Pujari addressing the Pilgrims.

After his speech the Pujari handed out Prasad ${ }^{20}$ to the pilgrims and they departed in high spirits amidst chants of "Jai Shri Ram”. Some walked while others left by the transport on which they had arrived. Once the pilgrims had dispersed, I spotted

\footnotetext{
${ }^{19}$ This speech can be viewed in Black Mountain - Chapter 6 along with the inauguration ceremony and following speeches by the Chief pujari.

${ }^{20}$ Prasad is a term used to describe a blessed offering. It is normally something sweet that has been blessed and is distributed after a prayer or pilgrimage as part of the holy ritual.
} 
Amin who was filming a television interview that was being given by one of the organisers, Dilip Bhai ${ }^{21}$. I stood next to Amin as the interview took place. When it finished I began collecting our belongings, and asked Amin to hurry up so that we could follow the pilgrims. He seemed pre-occupied and I asked him if he was alright. He replied in a short, agitated manner "do you have any idea what these people just said?” I replied “well, not exactly but they seemed pretty passionate”. Amin explained to me the nature of the speeches beginning with the first speech where Dilip Bhai referred to the $6^{\text {th }}$ December 1992 as a day of victory and celebration, "...he was referring to the demolition of the Masjid in Ayodhya and the massacre of Muslims that took place”. I was shocked and quickly realised why Amin was feeling so uncomfortable. I knew about the demolition of the Babri Masjid in Ayodhya, and the repercussions felt across the country, especially in Bombay ${ }^{22}$.

Dilip Bhai expressed the view that to protect India it was important to protect its religion which, in this context, is assumed to be Hinduism. It suddenly dawned on us that perhaps the reason for the political undertone of the pilgrimage was the fact that the site was situated close to the Pakistan border, an area populated by a Muslim majority, as are most Indian borders with Pakistan. These are deemed a threat to India by the Hindu extremists and presented as such to their supporters and the Indian population at large.

It also became apparent to us that the intention of this pilgrimage was more than a religious journey, rather it had political implications. I began to feel a sense of inadequacy and frustration at my limited language skills and rudimentary knowledge of the significant political and religious events that have shaped India over the last ten years ${ }^{23}$. Had Amin not been there to translate both the content and the subtext of these speeches to me, it is quite possible that I would have continued on the journey quite oblivious, at this stage, of much of its political manipulation.

${ }^{21}$ See Black Mountain - Chapter 6.

${ }^{22}$ Amin's reflection on this can be heard in Black Mountain - Chapter 7.

${ }^{23}$ It was much later in my research that I began to realise that PhDs are a learning process for all researchers, not just within their chosen subject but with the emotional and mental development one goes through as a researcher. 
This is perhaps the first example of one of the ways my fieldwork experience has been affected by travelling with Amin. If I had embarked upon this pilgrimage with a another research assistant, and had they been Muslim, it is more than likely that as soon as it was discovered that they were Muslim we would have been asked to leave. If I embarked upon this pilgrimage with a Hindu assistant, depending on their political and religious viewpoint, I may well have gained a completely different understanding of the proceedings, depending on their translation of the events, which would in turn have depended on their political and religious sentiments. Being with Amin gave me a perspective perhaps not possible otherwise. As a Muslim he was only tolerated because he had played a part in the film Lagaan (a Hindu drummer), and I was only tolerated because I was perceived to be his wife. As a Muslim and therefore a member of a minority in India, Amin has an in-depth perspective of what it is like to be on the receiving end of the Hindu right-wing political actions, and it is very unusual for a Muslim to be allowed to attend this type of private function. The Hindu extremists want the Muslim population to be aware of their actions in order to intimidate them, but they do not necessarily want them at such close quarters. I was beginning to understand from being with Amin, what it was like to feel persecuted for being a Muslim in India.

On realising the political angle of the pilgrimage Amin and I were contemplative and silent. We mounted our motorbike and began riding slowly back through the streets of Bhuj. I felt intrigued and to some extent excited by the opportunity and the prospects that this pilgrimage presented for my research, it seemed to me far more interesting than my previous subject. But Amin was worried for our safety as he has witnessed how 'Hindu mobs' can turn on Muslims, even their neighbours, once psyched up by political bodies. He was concerned that we should not get involved in something that we could not handle if things went wrong. After much deliberation we decided to continue on the pilgrimage; we turned around, still silent, in the direction of the walking pilgrims, slightly nervous of what lay ahead ${ }^{24}$. The sun was

\footnotetext{
24 The possibility of risk or personal danger was not part of discussions with my supervisor about researching the original topic for my doctorate (which might not have involved the kind of risk which we were now facing). 'Risk assessment' has only recently become an established aspect of fieldwork preparation at undergraduate or postgraduate level at Swansea University. However when 'risk' became an evident element of the research I did discuss the range of possible risks involved in it and we outlined the ways in which I could reduce them.
} 
rising as we rode out of the city, giving the crumbling city walls a golden glow. The streets were alive now with morning life, trading for the day was just beginning as the vegetable carts lined the roads. Slowly Amin and I began to reflect as we rode through the streets and I remember Amin's words clearly as he joked about the confrontation he had with the pilgrim at the temple, he laughed and said "yes, you must beat me because I believe in Humanity! " his tone was sarcastic and he continued by impersonating the same man who had asked him "you believe in humanity?" as if it was some kind of strange disease. Amin felt disappointed at the unwillingness of this particular group of pilgrims to see him as another human being and not a Muslim, and this haunted him throughout the rest of our journey as people kept questioning him about his religion.

We came upon our first pilgrims at the outskirts of the city; they were in very joyous spirits. It was the main group of pilgrims that we had seen leave from the temple; they were walking, which is considered the ultimate sacrifice, carrying the huge saffron flag given to them at the temple, which fluttered in the wind as they walked in front of a white jeep on which more flags were on display, and behind which more pilgrims followed. As far as I could tell the jeep was a kind of backup transport and we later discovered that one of its passengers was a doctor and he was carrying medical supplies and water for the pilgrims. We continued past these pilgrims and encountered three men walking alone. Amin recognised one of them as a man who had been prostrating in the temple. We stopped to talk with them and when they asked Amin who he was, they were extremely excited to hear that he was a character in Lagaan. One of the three pilgrims proudly explained to us that he was one of the Promooks ${ }^{25}$ of the RSS in the district of Bhuj. They were jovial and informed us that the pilgrims would rest for the night at Bhirandya and then the next day they would reach Kalo Dungar. We passed many tribal men and women, young and old, as they walked wearing flip-flops and some barefooted along the hot flat tarmac road while the desert stretched out around them.

${ }^{25}$ Promook means leader. 

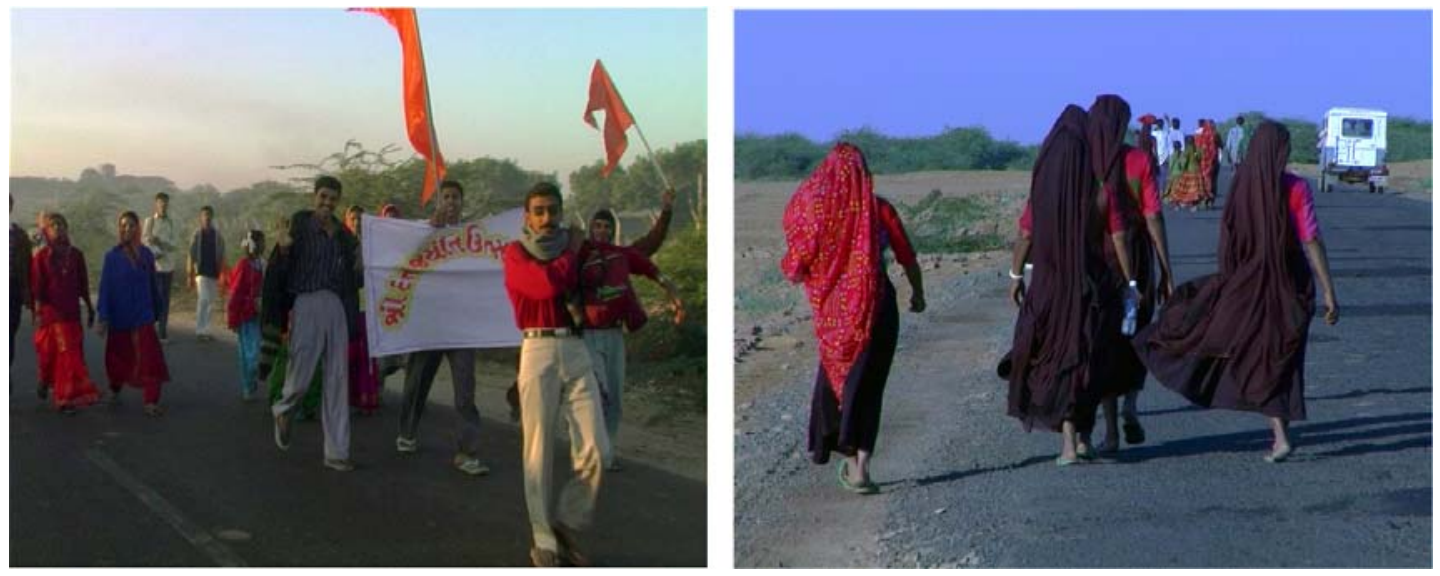

Fig.7. Pilgrims on the road flying the saffron flag; and tribal women.

The desert heat began to scorch as they walked in clusters, some with their families, children and grandchildren. Pilgrims passed on motorbikes, in cars, and jeeps, jubilant with excitement. On seeing the camera they would shout excitedly "Jai Shri Ram" this is, as mentioned earlier, a chant that expresses your devotion and allegiance as a Hindu to Lord Ram. We passed one group of six schoolboys on bicycles, their bikes were adorned with colourful tinsel, they had made cardboard signs to put on the front, and saffron flags fluttered from their handlebars. We stopped to talk to them; we could now see their handmade cardboard signs clearly, they had drawings of a mountain with a flag on the top and in Gujarati it was written Kalo Dungar.

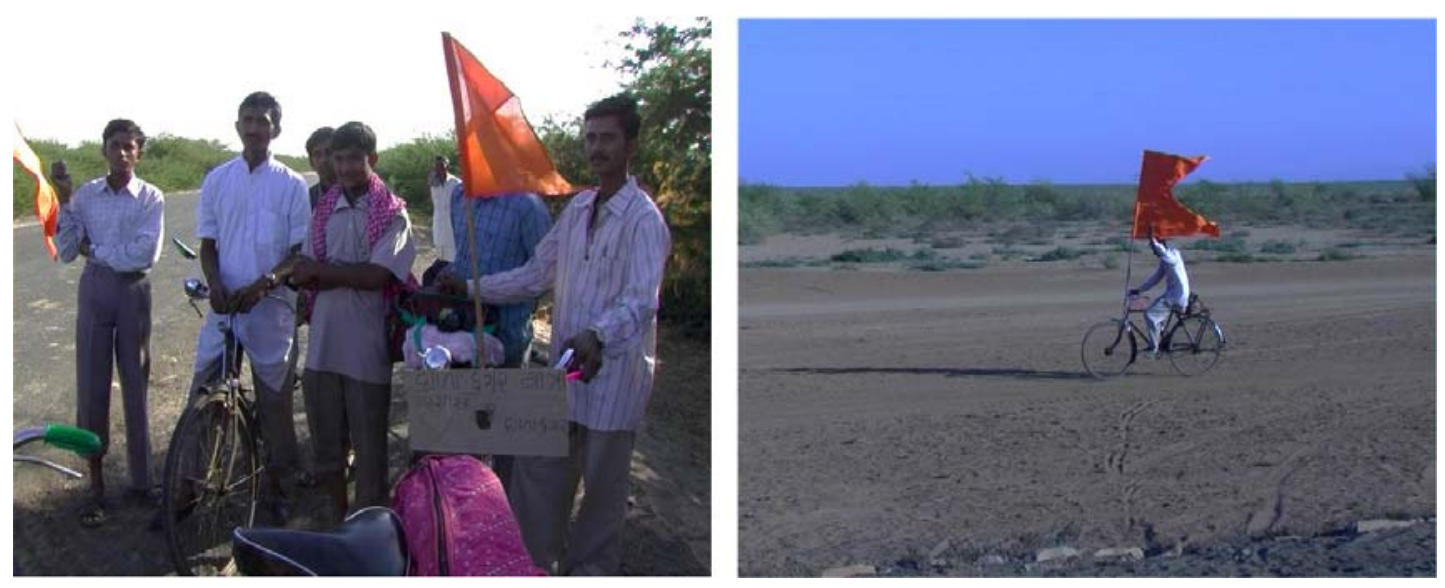

Fig.8. Boys on cycles showing their handmade cardboard signs and flags. 
The boys were extremely jovial and enthusiastic, and happy to talk us about what it was that made them decide to cycle all the way to Kalo Dungar ${ }^{26}$.

$\begin{array}{ll}\text { Amin: } & \text { Where have you all come from? } \\ \text { Boys: } & \text { Ghatsheesa, and we are all voluntary members of the } \\ & \text { RSS National Volunteer Service Group. On the } 8^{\text {th }} \\ & \text { there will be eight busloads of people from our village } \\ & \text { who will join us at Kalo Dungar. } \\ \text { Amin: } & \text { How do you feel when you do all this, what do you do } \\ \text { Boys: } & \text { it for? } \\ & \text { It is our responsibility, this area has a minority of } \\ & \text { Hindus and so our presence here has been scarce. } \\ & \text { pilgrimage to Kalo Dungar and a fair for Lord Dattas } \\ & \text { birthday's celebrations. For the last couple years we } \\ & \text { have been trying to make this trip and go to Kalo } \\ & \text { Dungar because: what is it that we can contribute to } \\ & \text { sustain our religious centre there? }\end{array}$

The boys then told us a legend of Guru Dattatreya living at Kalo Dungar.

Boys: $\quad$ Our Lord Guru Datt had stayed there [Kalo Dungar] for 12 years performing penance; during his twelve years of penance there he used to feed the wild animals and birds. One day when he ran out of food he cut of one of his own limbs and fed it to the hungry animals, as he did this he repeated 'Lay Ung - Take my Limbs'. Now even today the priests repeat these words as they distribute the blessed food and 40 to 50 foxes come to eat the offerings.

Amin: $\quad$ So will we be able to see this ritual?

Boys: $\quad Y e s$, if you get there in the evening or early in the morning you will get to see it

Amin: $\quad$ So we will meet you again at Bhirandya?

Boys: $\quad$ Yes!

Amin: $\quad$ Jai Shri Ram

Boys: $\quad$ Jai Shri Ram

The boys left and Amin translated their conversation for me. These RSS volunteers had been told that the reason it was important for them to attend the pilgrimage was to build up the Hindu presence in the surrounding area. This encounter left us feeling dispirited.

\footnotetext{
${ }^{26}$ See Black Mountain - Chapter 8.
} 
We had spent a long time on the bike by now, driving up and down trying to film different groups so as to have enough footage for our film. We reached a place where many pilgrims were resting at the side of the road under a couple of trees providing respite from the sun. This part of the Rann is known as the Banni region; its only grassy area. On either side of the road there were herds of camels grazing. The white jeep that we had seen earlier was parked on the side of the road. The pilgrims were being given packets of water and there was chai ${ }^{27}$ and biscuits for everyone. Word had spread around some of the pilgrims that we were on their trail, and even if they had not been told about us they had seen us on the motorbike filming. They were intrigued by what we were doing there. Because we now realised the political as well as religious nature of the pilgrimage we chose simply to explain to the pilgrims that we were making a film about pilgrimage ${ }^{28}$. The organisers whom we already knew were pleased to see us; they insisted that we stop and have chai and biscuits with them. We were hesitant, but so as to not look rude, we dismounted, quite relieved to take a break. The doctor was sitting on a ground sheet with a Tupperware box beside him full of painkillers and band-aids. Pilgrims were getting their feet treated for the blisters they had already gained and some were repairing their rubber flip-flops that had broken whilst walking. We spoke to some of the pilgrims about why they were undertaking the pilgrimage and what it meant for them. There were a group of quite elderly men and women, who had walked from Nakatrana, which is $52 \mathrm{~km}$ further away from Bhuj. There was an elderly pilgrim whom we had passed many times on the journey, he looked frail and thin, with wrinkled skin scorched by the sun and a long white beard; he walked alone bare footed and with a wooden staff. We tried to talk to him, but he couldn't answer, he pointed to his mouth and shook his hand, he was mute and pointed to his identity badge, which stated he was from Anjar which is $46 \mathrm{~km}$ from Bhuj. He was the first one up and back on his feet after his tea break! ${ }^{29}$

We were not sure at this point whether all the pilgrims were aware of and involved directly in the political aspect of the pilgrimage or whether they regarded themselves

\footnotetext{
${ }^{27}$ Chai is Indian tea. It is a brewed mixture of tea leaves, milk and sugar, sometimes ginger and cinnamon is added.

${ }^{28}$ The ethics of this account of the research are discussed in Chapter 2 - Methodology.

${ }^{29}$ For these interactions see Black Mountain - Chapter 10.
} 
as making a purely spiritual journey, as none of them had so far explicitly mentioned any political aspect to their pilgrimage. When one man approached me to ask us why we were there I explained to him that I was undertaking research on religious pilgrimage in India, and began to ask him some questions about this particular pilgrimage. He explained that this was a pilgrimage to Kalo Dungar where a temple of Lord Guru Datta or Dattatreya stood, and that he carried out vocational religious service for the organising body of the pilgrimage on these occasions. He said that Kalo Dungar was first and foremost a very popular picnic spot which is at the highest point in Kutch and overlooks the Rann, and up there people can pray at the temple and enjoy the surroundings. The pilgrimage is in celebration of Guru Datt's birthday which falls on Poornima ${ }^{30}$ when it occurs during Margashirsha (NovemberDecember) of the Hindu calendar. This day is referred to as Datta Jayanti. This year (2003) it happened to be $8^{\text {th }}$ December, but every year it changes by a few days. The pilgrimage starts two days prior to the full moon so that all those who wish to go by foot have enough time to reach the top for the celebrations. He explained that Dattatreya is believed to be a reincarnation of the trinity of Bhrama, Vishnu and Mahadeva/Mahesh (Shiva) and he represents all three gods. This can be seen in his icon, where he is 'depicted with three heads representing the trinity of the Hindu pantheon - Brahma, Vishnu and Shiva’ (www.ShreeSwami.org, accessed 18-01-08). In brief, Dattareya is the son of Anusuya, who was the wife of a great sage Atri Maharishi. One legend asserts that the wives of the holy trinity (Bhrama Vishnu and Mahesh/Shiva), Saraswathi, Lakshmi and Parvati (respectively) sent their husbands to Anusuya to test her. After passing the test she bore a child, which is believed to be a reincarnation of the holy trinity, hence, the appearance of Lord Dattatreya with three heads ${ }^{31}$.

\footnotetext{
${ }^{30}$ Poornima is the Full Moon.

${ }^{31}$ For more details on the birth and history of Lord Dattatreya please see the following sources from which most of the above information was verified. http://www.s-a-i.info/assoc_change/poornima_10.html http://www.astrojyoti.com/DattatreyaJayanti.htm http://www.dattapeetham.com/india/datta/DattaLarg.html http://www.avatara.org/dattatreya/story.html http://www.ShreeSwami.org http://en.wikipedia.org/wiki/Dattatreya
} 
The pilgrim then narrated the same legend of Lord Dattatreya already told to us by the boys on bicycles. He ended the conversation by telling me that people "undertake this pilgrimage because they want blessings from God, that's all." Some of the pilgrims began to get up and resume their journey, others continued to rest whilst more pilgrims kept arriving. We too resumed our journey and continued along the road that split the desert in two, passing herds of camels along the way under the bright clear blue skies of the afternoon. We travelled at a slow pace filming everything we passed. But our enthusiasm for finding the night stop of the pilgrims in Bhirandya lessened and we decided it would be better for us to travel straight on to Khavda where we had arranged our own accommodation.

Khavda is one of the last inhabited towns before one reaches the Border Security Forces in the Rann of Kutch. It is the nearest town to Kalo Dungar where local people in surrounding villages find industry and employment.

\begin{tabular}{|l|l|r|r|r|}
\hline State: Gujarat & District: Kachchh & & & \\
\hline Sub-district: Bhuj & Village: Khavda & & Males & Females \\
\hline Area of village (in hectares) & $1,061.37$ & & \\
\hline Total population & 3,203 & 1,702 & 1,501 \\
\hline Scheduled castes population & 484 & 258 & 226 \\
\hline Scheduled tribes population & 967 & 517 & 450 \\
\hline
\end{tabular}
Source: Census of India 2001: accessed 9/12/2007

We arrived in Khavda at around 5pm. We had been on the bike following the pilgrims all day and we were exhausted physically and emotionally, our morale wavering as we kept facing the political nature of the pilgrimage. We did not spend any time looking around the small town but just inquired as to where we could find our accommodation. In a short time we found Kutch Mahila Vikas Sangathan (KMVS). This was our night stop. KMVS is a charitable organisation that works towards the betterment of tribal communities. We were already associated with the organisation as we had bought handicrafts from them. We parked our motorbike and entered the beautifully carved gates, inside there was a traditional Kutchi courtyard and there was a round seating area in the middle. There were a group of tribal women in full tribal attire with another group of young girls dressed in western outfits. One of them was on a placement from her University in America. Her 
family was originally from Kutch so she knew the local language, and she was working towards the development of midwifery and general health care. We discovered that the place was a new centre providing healthcare, especially midwifery, for Kutchi women. The centre was known as PMVS Pachham Mahila Vikas Sangathan (Pachcham is the area of this small district of Kutch).
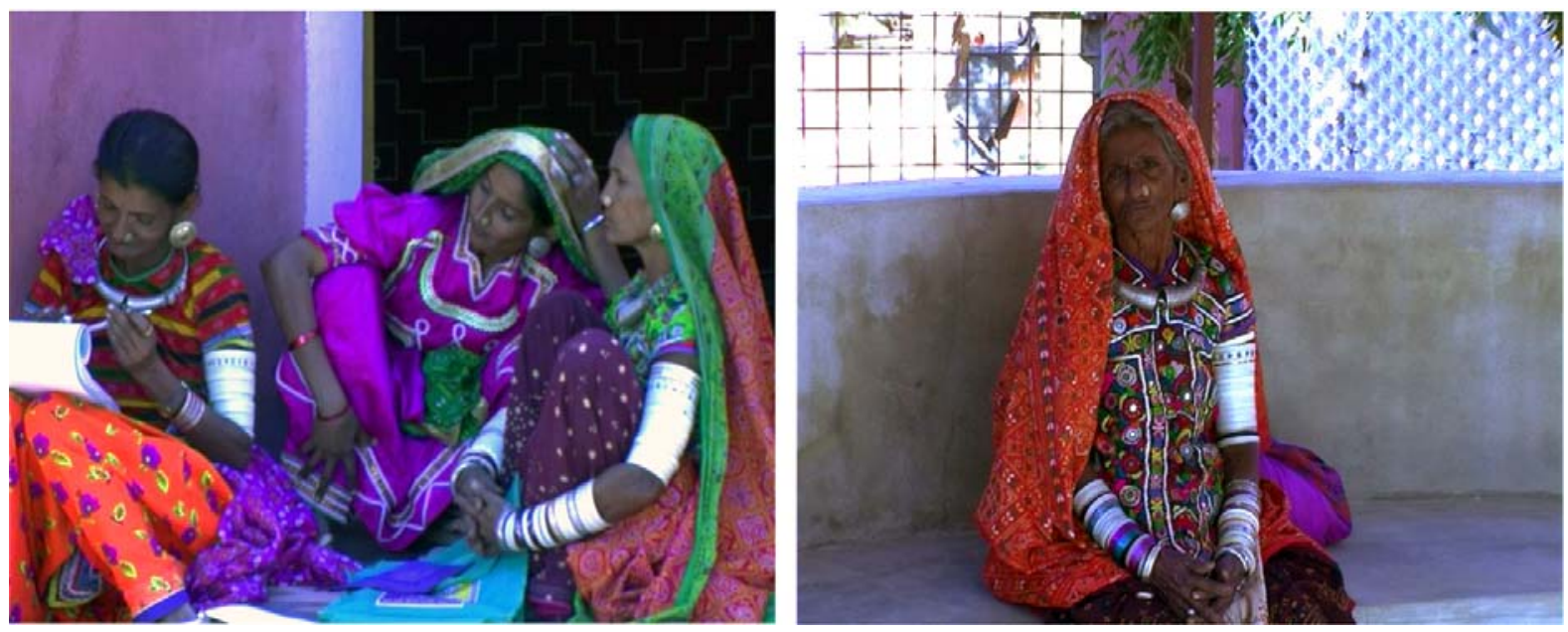

Fig.10. KMVS Staff

Most of the group were sitting outside waiting for jeeps to take them back to their various homes as it was a Friday and they normally go home for the weekend. They left and the caretaker showed us to our room.

The next morning we had an early breakfast and left to catch up with the pilgrims. We first headed off the main road to explore Khavda. Apart from the teashops that line the main road, there was another small road running through the main market area where there were repair shops for the motorbike rickshaws of the town (see Fig.11 below). 

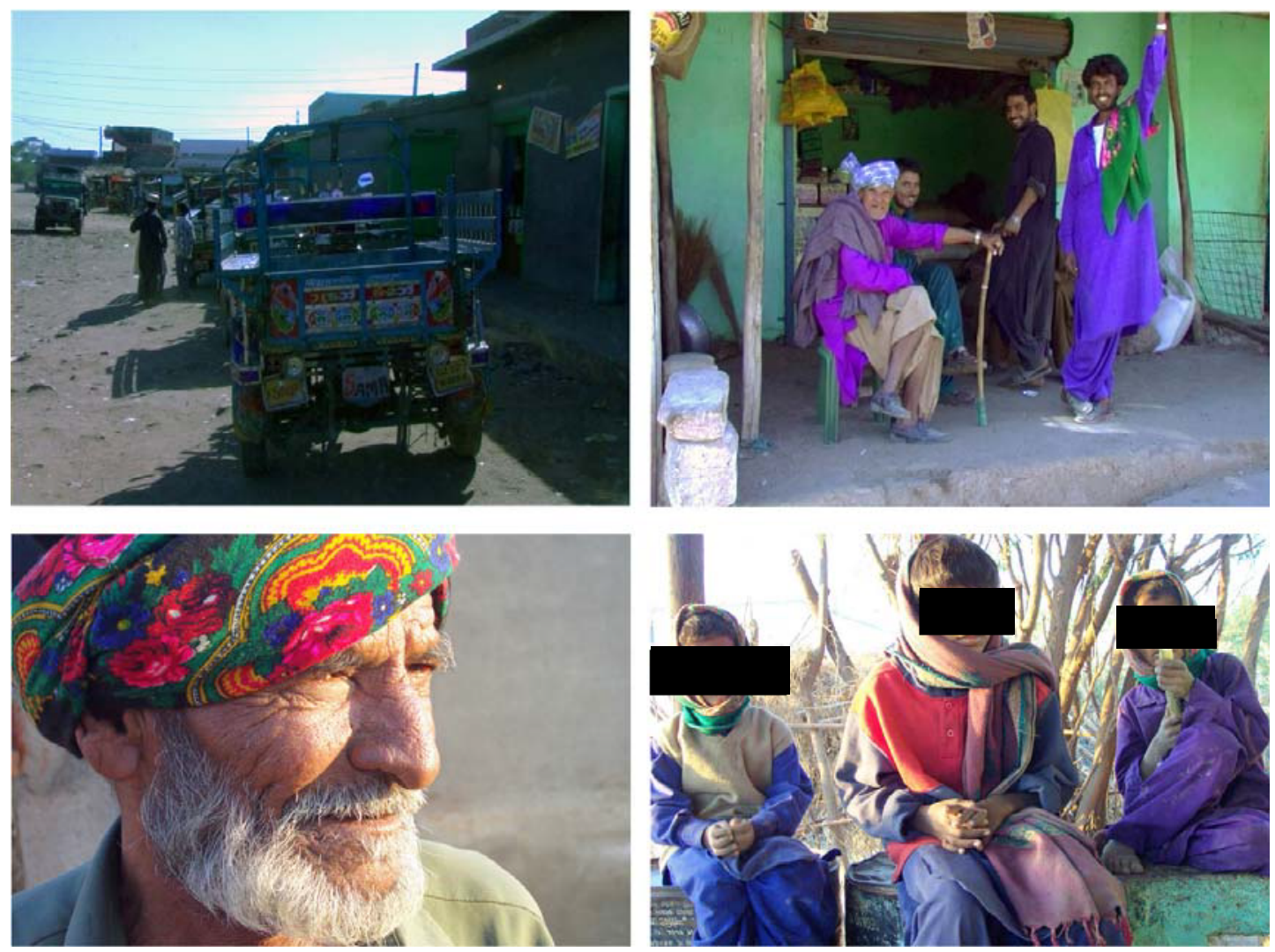

Fig.11. The motorbike rickshaws of Khavda and the small workshops with villagers on the streets. A man and boy wearing traditional headscarf

After riding around Khavda ${ }^{32}$ we began to search for the pilgrims and found a group on the main road. They were standing around a new open-fronted temple structure by the side of the road, where there were men and women lying down on mats, some were taking a nap and others were chatting. We walked around with the camera and I saw a group of tribal women sitting together, in a cool and shaded room. They were amused to see me and in unison smiled and arranged their pallu's ${ }^{33}$ as I filmed them. In a short time our friends from Bhuj met us and explained that this was where the pilgrims stopped for their lunch and that we should join them. We were led around a path that connected to another part of the structure where people were cooking, there were huge pots full of rice, dhal, puri bhaji and sheera ${ }^{34}$. As people were eating volunteers and helpers circled around offering more rotis, puri bhaji, dhal and water to everyone. There was a joyous atmosphere. As we finished our

\footnotetext{
${ }^{32}$ See Black Mountain - chapter 9.

${ }^{33}$ Pallu, is the end piece of fabric of the sari used to cover the head.

${ }^{34}$ Roti is a type of Indian bread, otherwise known as chapatti, Puri Bhaji is an Indian dish made up of puris, small, deep-fried rotis and a chickpea curry with potatoes. Sheera is a sweet dish.
} 
lunch, we were told that we should meet the pujari of the group who had arranged the pilgrimage and we were taken to meet him.

He was sitting in a room surrounded by what was obviously a select group of pilgrims. There was a desk at the back with photographs of the pujari on it, his photographs had flowers and incense around them as if it was a photo of a deity. He was the spiritual guru and leader for these pilgrims. As we entered, people stared and conversation came to a stop. We were told to sit next to the pujari who was sitting on the floor on a chattai - cane mat, he asked us who we were and what our purpose was. We immediately understood that he was not too comfortable with us being there. We were quite anxious to leave, having not been too enthusiastic to meet him in the first place, considering our growing discomfort during the pilgrimage. Amin struck up polite conversation with the pujari and he asked questions regarding our interest in the pilgrimage and about Islam and humanitarianism. At least ten minutes passed before we found a moment to stand up to leave, as we did so the pujari shouted Jai Shri Ram, Amin repeated the same chant as is the custom and the pujari shouted again, Amin repeated the chant again, and the pujari keep repeating Jai Shri Ram, each time getting louder and louder, animosity filled the air. A psychological confrontation took place in the room as the pujari knew Amin was a Muslim, and he made him keep proclaiming the words “Jai Shri Ram - Ram is the greatest”, as if this would make him understand who God really was. We left, turning down more refreshments, and walked back to the motorbike happy to be leaving.

Some of the pilgrims had already resumed their journey, while others were leaving in cars overloaded with people cheering and waving. We looked at the road ahead and saffron flags fluttered into the distance. We were both disturbed by the confrontation that had taken place, Amin especially, and once again we wondered if we should continue. We slowly followed the pilgrims, the heat was relentless yet they walked unaffected, cheering as we passed them "Jai Shri Ram”. We decided that we would continue straight up to Kalo Dungar so we could film the pilgrims as they arrived. The road up to the top of the hill was steep and quite treacherous; as we wound our 
way around the narrow road that cut between the most beautiful rock formations we wondered how the exhausted pilgrims would manage this final climb. We passed a number of army vehicles and kept stopping to admire the view of the salt plains of the Great Rann of Kutch that stretched out to the horizon.
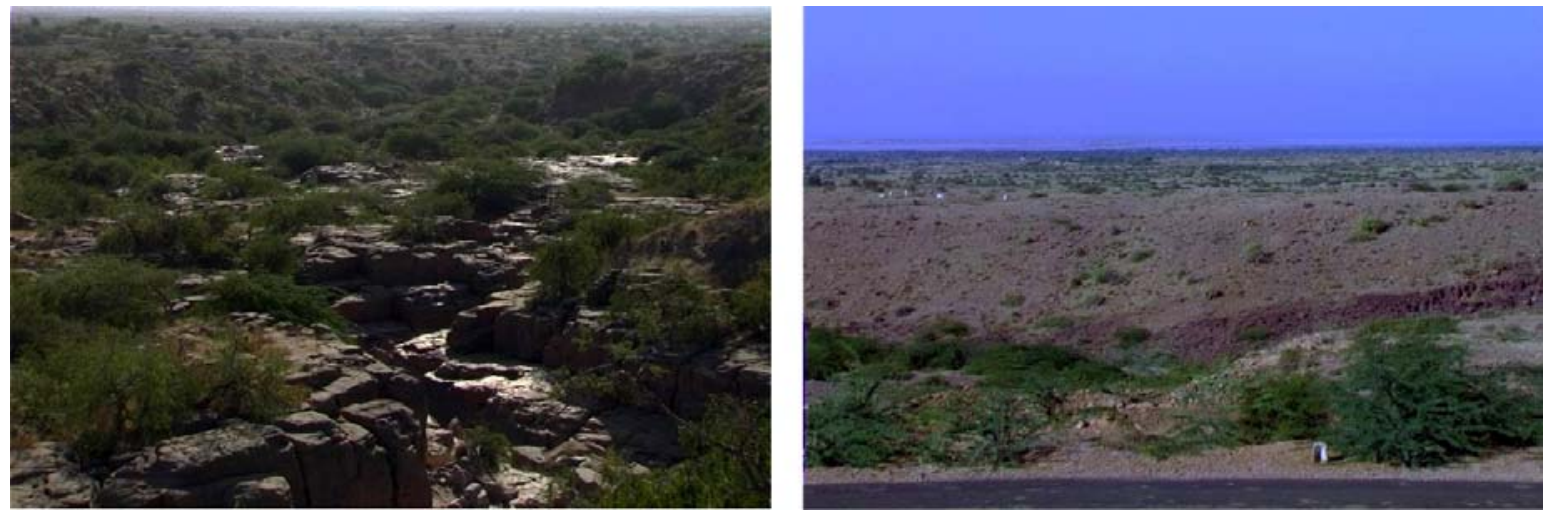

Fig.12. The rock formations on Kalo Dungar and the landscape of the Salt Plains of the Rann.

We arrived at the top of Kalo Dungar at approximately 4pm. At the entrance to the sacred hill was a small temple with an orange pyramid-shaped roof and painting of deities on the walls. We rode on past this temple towards the main temple. There were hawkers on each side of the path, some with plastic sheets on the floor and others with makeshift stalls. They sold offerings for the worshippers to give to the deity; these offerings included coconuts, scarves, prasad and nuts, all the usual things available for sale at temple sites. Other hawkers sold snacks of biscuits, crisps, cold drinks and water.
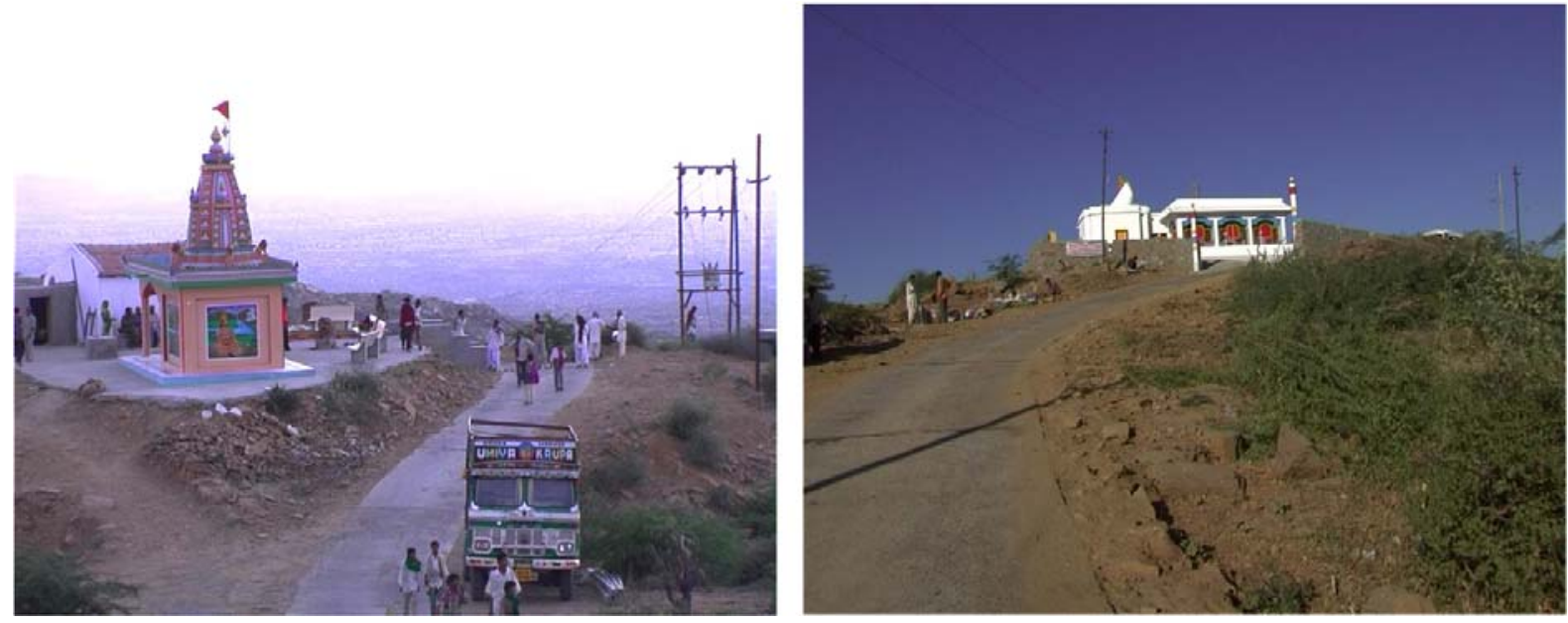

Fig.13. On the left, the small temple at the entrance to Kalo Dungar, the pilgrims arriving on foot and by truck and the salt plains of the Rann in the distance. Image on the right shows the road rising up to the main temple of Kalo Dungar with the statue of Dattatreya inside. 
We finally reached the temple of Lord Dattatreya. We did not go inside, as by this point we were feeling quite self-conscious and did not want to accidentally upset anyone. The temple was much larger than I had imagined, it looked new and freshly painted. Inside it stood the idol of Lord Dattatreya (see Fig.14. below) ${ }^{35}$.
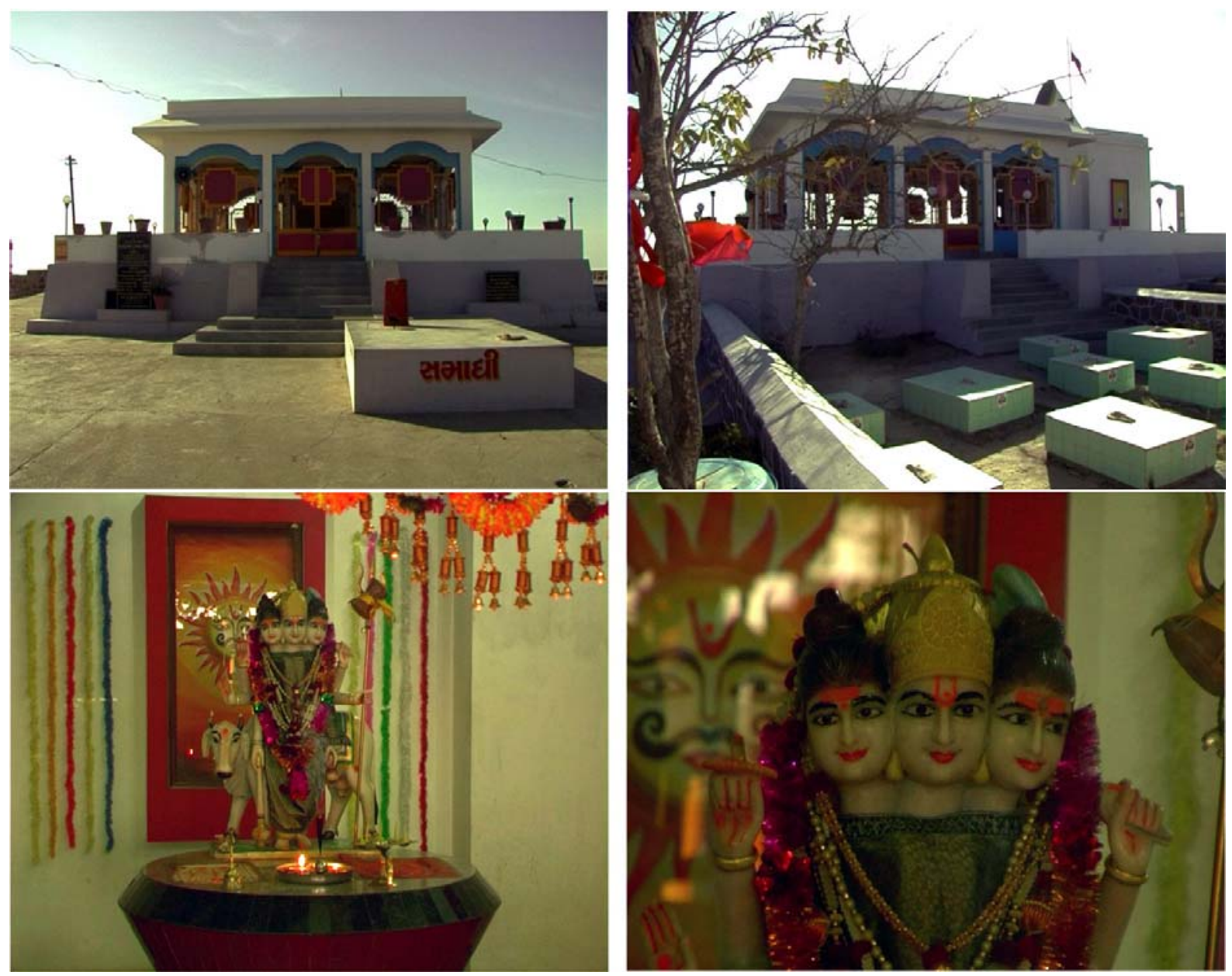

Fig.14. These pictures show the temple of Lord Dattatreya from the front and back, and the idol of Lord Dattatreya, with three heads, standing in front of a white cow, rosary around his neck and chakra in his hand.

Lord Dattatreya is depicted with three heads and standing in front of a white cow, with a chakra - disc-like weapon, in his right hand, a trishul - trident, in his left hand and the japa mala - rosary, around his neck. In the image above, one can see the three heads of Lord Dattareya that represent Brahma (the all powerful), Vishnu (the sustainer) and Shiva (the destroyer). The white cow, called Kamadhenu, is the divine cow that grants the wishes and desires of those who seek the Lord. It is believed that the chakra represents the universe with no beginning or end, constantly

${ }^{35}$ See Black Mountain - chapter 11 for our arrival and time spent at Kalo Dungar described herein. 
moving and changing. The trishul is to kill the ego and symbolises his transcendence beyond the ego, and the rosary is the symbol of meditation. What is not seen in this image are the other symbols: the damaru - drum, the sankh - conch shell, the Kamandala - the water vessel, four dogs that are normally depicted around him and finally the Audumbara tree which he is normally standing beneath. The drum is believed to awaken the sleepy, ignorant souls; the conch represents the eternal sound of OM, the expression of the spirit. The water pot is believed to hold the nectar of pure wisdom and with it the lord can feed the souls searching for knowledge. The four dogs represent the four Vedas and the Audumbara tree is the bearer of nectar that fulfils the wishes of those that worship it (www.dattapeetham.com, www.shriswami.org, accessed 19-01-08). Lord Dattatreya's followers believe that 'He who treads the path of Truth, regardless of what religion he belongs to, is treading the path of Dattatreya' (www.dattapeetham.com/india/datta/DattaLarg.html, accessed 19-01-08), they believe that 'His presence is not limited to any one country or sphere, as He is the Guru of all Gurus, the all-seeing, all-powerful, ever-present link between God and Man'(ibid). Despite this claim of omnipresence, there are a number of permanent places of worship to Lord Dattatreya. In Gujarat there are two temples the one at Kalo Dungar and another at Mount Girnar in the district of Saurashtra, where it is also believed that Guru Dattatreya once lived and where his footprints remain ${ }^{36}$. On the recently created website for Kalo Dungar it goes as far to state that there was once a cave that joins the two sites together (www.kalodungar.com).

Opposite the temple site there was Shamiana, an open bamboo structure erected with cloth tied tautly over the top, and blankets and mattresses piled up beside it. We were informed that this was where the men would sleep in the evening.

\footnotetext{
${ }^{36}$ The importance of these footprints is addressed in Chapter 6 - Ethnography Part 2, when we discover that on Kalo Dungar the footprint of another Saint who was believed to live on the hill, was once worshipped.
} 

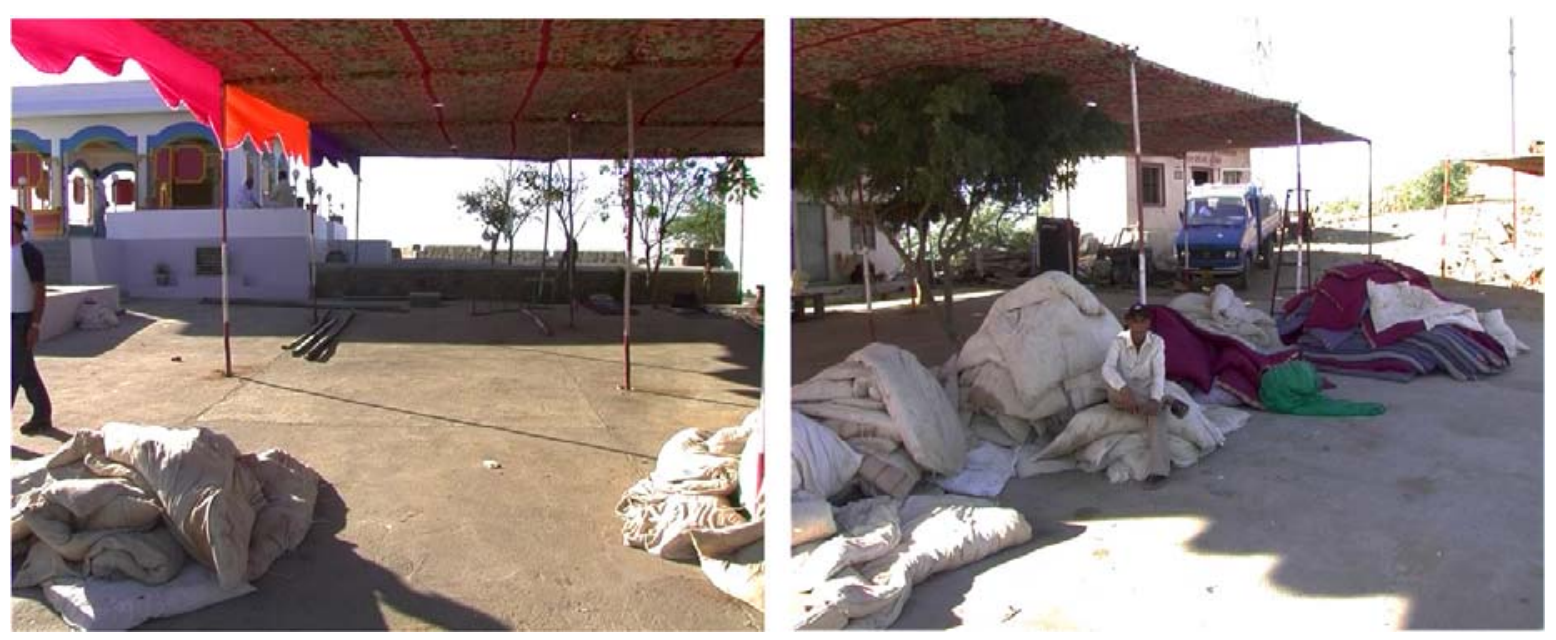

Fig.15. The Shamiana erected beside the temple for the pilgrims to sleep beneath.

Near the side of the temple site there was a cluster of small buildings painted in military-style camouflage patterns, and a satellite tower. These were the buildings of the Border Security Forces (BSF) military look-out. Pakistan was a short distance away and this being an extremely sensitive border, security was strict. As soon as our camera was spotted pointing in the direction of the outpost we were approached by an army officer. He seemed hostile and wanted to know why we had a camera and what we were filming. He specifically asked if we had filmed the military base; we assured him that we had not, and that our camera had not been on at that time, but he was not completely satisfied and asked us to play him back what we had recorded. He insisted we keep the camera off, and walked back to his base. This encounter left us feeling even more on edge. We walked away and began to talk to some of the pilgrims who had just arrived. We met a group of young boys who were sitting on one of the boundary walls of the complex. We interviewed them and with their permission, we filmed them. The first boy, Sailesh Kumar, was from Ghatseesa (the home of the boys on their bicycles whom we had met earlier) and had cycled from his village. He felt elated that he had completed the journey and was enthralled at the beauty of the temple site and its surroundings. He explained that he had come to see the newly renovated temple of Lord Dattatreya. Another boy, Praful J. Patel, had walked $150 \mathrm{~km}$ from his village of Gangapur. He had come on the pilgrimage because all his friends were coming and he wanted to join them. He was looking forward to helping serve the pilgrims the following day and said that he felt that the location of the temple was enchanting. After talking with these boys we met more pilgrims. We spotted one of the young cyclists whom we had chatted with earlier. 
He said that they had left their cycles in Drobhana, a village nearby, so that they could walk the last stage of the journey, he was happy and relaxed that they had completed their pilgrimage. The last pilgrim we spoke to before we explored the rest of the complex was Punjan Bhai who had walked 90kms from Neeruna. He informed us that he had been told to come on the pilgrimage by the RSS so as to take blessings from Lord Dattatreya ${ }^{37}$.

After speaking to the pilgrims we made our way down a long set of newly constructed steps opposite the temple. At the bottom there was a building; which was obviously a recent construction. It was an unusual building for such a remote place, being modern in design, and with a number of different rooms. It struck us that it might be possible for us to stay in one of them overnight.
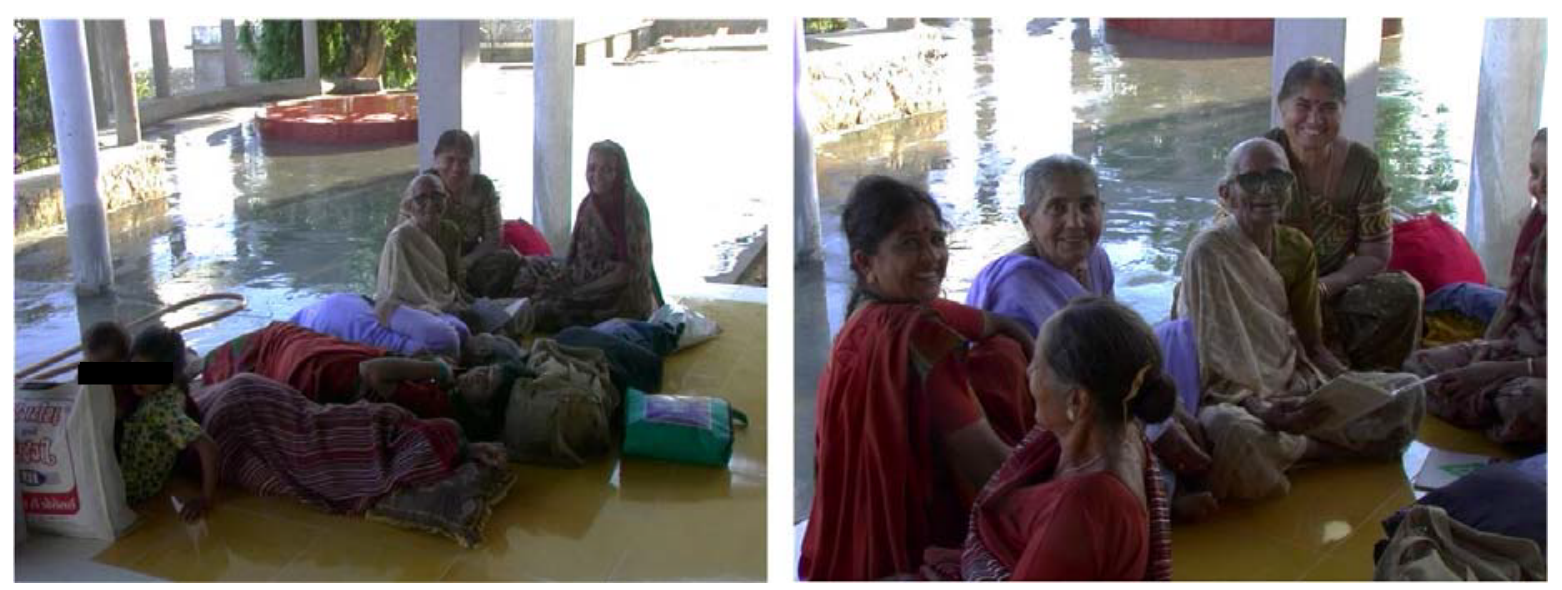

Fig.16. Local women sitting and resting reciting prayers after a long walk to Kalo Dungar.

There was a group of women sitting on a veranda and we put our bags down and I sat with them while Amin went to make enquiries. They recited prayers, verses from the Bhagavad Gita $^{38}$ and sang bhajaans ${ }^{39}$. They laughed and blushed as I filmed them. Behind them, workers were hosing down the courtyard and sweeping it clean. Amin returned with news that the new building we were sitting under was a Dharamsala ${ }^{40}$. We were told that it had been completed days before the pilgrimage and was due to be inaugurated the next day by a local spiritual guru, whom we later discovered was an important figure in the VHP in Kutch and Gujarat.

\footnotetext{
${ }^{37}$ Parts of these interviews can be seen in Black Mountain - Chapter 11.

38 The Bhagavad Gita is the one of the Holy Books of Hinduism.

${ }^{39}$ See Black Mountain - Chapter $11 \& 12$.

${ }^{40}$ Dharamsala is a guest house for pilgrims and used as a place of retreat for meditation.
} 
The sun was starting to go down and we made our way back up to the temple area. Many of the pilgrims were gathered around the back of the temple looking out at the sight of the setting sun. It was a breathtaking view, and we shared pleasantries with some of the pilgrims we had met en route; one was Dilip Bhai, whom we had filmed outside the temple in Bhuj. They were happy that we had been able to make it to the top of the mountain for sunset. As day turned to night there was a buzz of excitement, and suddenly people started moving from the temple and the Dharamsala up a small hill lined with shrubs and cacti. A man was banging on an empty cooking pot which made a reverberating sound around the hill. Another person had a cooking pot full of rice and was making her way to what looked like the top of a concrete water tank on the brow of the hill. A pilgrim informed us that they were calling the foxes. We realised that this was the ritual based on the legend that we had been told earlier in the day, and that the man banging on the pot was repeating "Lay Ung”. The foxes had started to come out from the undergrowth and they darted for the rice. We made our way quietly to the area where they were feeding in order to film them. The pilgrims seemed astonished by the sight of the foxes and it was obvious that this was a spiritual moment for them, as the legend became reality ${ }^{41}$.

But I felt cynical about an occurrence with an obviously naturalistic explanation (foxes accustomed to scraps being fed to them when a pot was hit) being taken for evidence of a spiritual truth. Indeed, my cynicism had grown during the day. I felt that the pilgrims were being manipulated, unaware of what seemed to me to be the sinister motivations of the RSS and the Hindu right-wing organisations. I was troubled with thoughts about what was really going on at this pilgrimage.

As the foxes dispersed, people stood in the moonlight looking out over the Rann, toward what some said were the lights of Pakistan, flickering in the distance. Some made disparaging remarks about Pakistan, while others just gazed, intrigued ${ }^{42}$.

\footnotetext{
${ }^{41}$ See Black Mountain - Chapter 11.

${ }^{42}$ We later discovered that these lights could not have been in Pakistan, the actual border was much too far away to see. However it was as if the pilgrims wanted the lights to be in Pakistan, this might have been instigated by the fact that Kalo Dungar was being propagated as a site that could protect 'them', and India, against the threat of Islam and the Muslims.
} 


\section{A digression: the border near Kalo Dungar}

The history of India and Pakistan is one of war and terror, partition itself being one of the bloodiest events in world history ${ }^{43}$, the trauma of which has left scars on both nations. Kutch now forms the border with the region of Sindh in Pakistan, and as Ibrahim, who has conducted extensive research on the nomadic tribal communities of Kutch, states, 'the border [between Kutch and Sindh] remain[ed] socially fluid even after decades of its territorial demarcation. There is little differentiation between one side and another in terms of language, religion, appearance or kinship and peoples' (2005). These similarities are not necessarily found only in the border areas, on the contrary, they are evident across both countries; they were, after all, once one. Over the years, as the political gulf has widened between the two countries, so too has the knowledge that it is religion and politics that divided them, culturally the similarities run deep.

The ethnic communities on each side include nomadic pastoralists, who migrate from place to place according to the needs of their herds. Even after partition there were trade links across the border, as well as families who had relatives on both sides. Because of this permeability, the border has always been a point of concern for the authorities. After recent wars between India and Pakistan 'further steps were taken to "seal" the border' (ibid) and certain policies were implemented with a view to securing the social boundary. Ibrahim discovered that efforts were made to reduce the high proportion of 'existing Muslim recruits in the police forces' in the area, as it was considered important to recruit 'persons of the other community (Hindu) to make up for the lack of balance' (ibid) ${ }^{44}$. Simpson addresses similar issues when he describes the history of cross-border trading from Kutch to Sindh, via the Great Rann of Kutch. Most people now believe that 'all that remains is criminalized traffic' (2006:318) in which ' ...He (The Muslim) is a spectral image, bringing guns, terrorism and trouble across the border in his gunny bag' (ibid). Simpson describes the prejudices faced by the local Muslim population on the Kutch border area where

\footnotetext{
${ }^{43}$ For further history regarding Partition see Chapter 3 - India's Pledge.

44 This issue of re-balancing the Hindu-Muslim population equation in border regions is used by the right-wing Hindu political community in much of their propaganda.
} 
...The majority of those accused by the press of smuggling are clearly innocents engaged in herding and cutting firewood. Occasionally, small caches of armaments are uncovered on the edges of the Rann, suggesting mischief does go on. However, the idea of infiltration and espionage is clearly hopelessly exaggerated in popular imagination (ibid).

Across India, indoctrination against Pakistan and its people has been such that there is a range of responses from disquiet to festering hatred. Some of these responses were evident at Kalo Dungar, as we looked out at lights, which the pilgrims believed to be flickering in Pakistan. It was evident at the beginning of the pilgrimage too, in the interview given by Dilip Bhai, where he states, that " $a$ few hundred friends, awakened people, have got together and have organised this journey. Just like how the borders of a country have to be protected by its army, similarly within the country it is the duty of us as citizens to protect these prevailing borders”. The Hindu right-wing organisations that organise events such as this pilgrimage attempt to intensify feelings of animosity against Pakistan, and the Muslim population of India, by creating negative myths around the Muslim community, who, in their opinion, should move across the border. Protecting this border where Muslims were in a majority, and organising an event such as the pilgrimage to Kalo Dungar, were important in order to project an image and create myths for the population to believe that the Hindu community was strong and organised.

\section{Leaving Kalo Dungar}

At the Dharamsala the group of women we were sitting with earlier were still singing, and they were now joined by other groups of tribal women. All the women sat together and sang tribal songs and bhajaans (prayers) throughout the evening. The sound of their voices filled the dark night ${ }^{45}$. The tribal men, who were perhaps the husbands of some of the tribal women singing, were lying under the cover of the Dharamsala in groups wearing their white cotton dhotis and kurta and pugidi's ${ }^{46}$. In this area there was a calm and relaxed atmosphere as everyone soaked up the surroundings and rested after their long journeys. At about 8pm food for the pilgrims

\footnotetext{
${ }^{45}$ See Black Mountain - end of chapter $11 \& 12$.

${ }^{46}$ Pugidi is one of the traditional tribal headwear of rural India, it is normally a long piece of cotton cloth, white in this region but in Rajasthan and other rural districts they are worn in a multitude of colours, which is twisted and wrapped around the head like a turban.
} 
was ready. We joined the pilgrims for dinner and continued talking to them about their journey and how they felt.

It seemed that many of the pilgrims were not sure exactly why they were there. They had come for simple reasons, such as: the other people in the village were going on the pilgrimage and had asked them to join them, or because they wanted to pay their respects to Lord Dattatreya. There did not appear to be any political or ulterior motive for them being there, or maybe they did not want to discuss such things openly.

After 30-40 minutes we made our way back to the temple area; we were feeling exhausted and undecided about whether we should stay overnight. By this time microphones and loud speakers had been set up in front of the temple ready for the next day and the atmosphere seemed to turn a little tense. Neither Amin nor I were feeling completely comfortable with our surroundings, nor with the prospect of sleeping in separate areas on the hill. Some of the organisers seemed even more uncomfortable with our presence as by now it had become completely obvious that the main reason for this pilgrimage was some kind of political rally the VHP were holding the next day. While we were walking around the temple, a pundit, dressed in a traditional dhoti and kurta $^{47}$, approached us. He seemed extremely hostile and asked us in an aggressive manner "why are you here?” and told us that that we did not belong. We decided we should leave ${ }^{48}$. We felt that all the eyes of the pilgrims on the hill were upon us, and we feared what might happen to us if we stayed. The build up of tension and the nervousness we began to feel at this point were very difficult to portray visually in Black Mountain, because the various confrontations throughout the day were not and could not be captured on camera. This meant that in the film the tension had to be explained through the voice-over. Our presence was not welcome any more and would certainly not be welcome there the next day, as things would become even more political and, from our point of view, potentially more threatening. A group of young men offered to take us down to Khavda in their car as now it was late and the road was narrow and quite dangerous on a bike. Two boys gave up their seats and took our bike down to Khavda as we followed in the car.

${ }^{47}$ Dhoti and Kurta is the traditional village dress for man and is normally made of white cotton.

${ }^{48}$ See Black Mountain - Chapter 12. 
Along the way we passed more pilgrims and locals making their way up the hill. Once we reached Khavda we made our way back to KMVS. Sitting on the khatlas ${ }^{49}$ outside our room we felt a great sense of relief. Once we had left Kalo Dungar we realised how oppressive it had been. We definitely would not be returning the next day.

\section{Back in Bombay}

After the events in Bhuj and Kalo Dungar, my fieldwork took us to six more pilgrimage places around Gujarat, but it was the pilgrimage to Kalo Dungar that changed my course of thinking and subsequently the course of my research. I felt I had finally found something that stirred my emotions. I decided that I wanted to discover more about the history of Kalo Dungar and why it had become of importance to the RSS and VHP.

Whilst in Bombay we met a friend from Lagaan days, one of the production executives. He was aware of my research and was keen to hear about what happened in the time that we had been away. To my surprise he was not at all shocked at hearing about a VHP rally in the guise of a pilgrimage and he advised me to read Sacred Spaces: Exploring Traditions of Shared Faith in India, by Yoginder Sikand. Through reading this book I learned a great deal about the changing nature of certain pilgrimage and spiritual sites in India, and more specifically, about the politically motivated Hinduisation of sites that historically had not been Hindu alone. This began a long and interesting journey of discovery regarding the history of the shared religious traditions of the sub-continent, which are discussed in the following chapter. I then return to the ethnographic account of Kalo Dungar, chronologically, with my second visit there, just over two years later in January 2006.

\footnotetext{
${ }^{49}$ Khatlas are traditionally wooden framed beds (sometimes now made of metal) with a rope crisscrossed across the frame that makes a suspended mattress. They are traditionally used in village India. They are used like sofas, kept outside homes on which the whole family can lounge.
} 


\title{
Chapter 5
}

\section{Syncretism: traditions of shared faith worship in India}

\author{
Syncretism - the combination of different systems of philosophical or \\ religious belief and practice
}

This chapter gives an overview of the history of traditions of shared faith in India, with specific attention given to Sufism, and to the various multi-faith pilgrimage sites, dedicated to Sufi Saints. This history is grounded in the concept of syncretism.

\section{Anthropology and syncretism}

Das claims that syncretism is an area which in the past has been 'trivialised' by anthropologists, as she points out, in 1970 Raymond Firth recognized that ‘anthropologists have made only passing references to syncretism’ (2003:11). Almost thirty years later, my search partly confirms Firth's view that syncretism is an underdeveloped subject area within the field of anthropology. Anita Leopold supports this view, stating that syncretism is 'considered one of the controversies in the study of religion, one that many scholars of religion would like to abolish' (2005:x). Stewart \& Shaw affirm that 'syncretism is an essentially contentious and contested term which has undergone many historical transformations and meanings' (1994: preface), it 'is not a determinate term with a fixed meaning, but one which has been historically constituted and reconstituted' (op.cit.6). Gellner (1997) goes on to recognise that syncretism is such a term that even if parties agree a definition there will undoubtedly be disputes as to which cases the concept should be applied, because 'contestation is part of the term's very use', in which case 'anthropologists need to exercise caution...but need not excise the term from their vocabulary' (1997:280). However he suggests that we must be resigned to the fact that there may never be any agreement as to which 'practices, religions, symbols and myths are syncretic' (op.cit.278). There is then 'an uneasiness about the term [syncretism] in post-modern anthropology: we hear far less about culture as syncretic than about culture as collage, as creolised, as fragmented, as "interculture"' (Stewart \& Shaw 1994:2). 
According to Das however, this global era makes 'syncretism...a prevailing event' (2003:11), offering an opportunity to 'reinforce greater cultural amalgam’ (ibid) as 'synthetic processes are multiplied and intensified' (Stewart \& Shaw 1994:2). It is hoped then that the 'inter-culturalism' and subsequent 'trans-cultural syncretism' (Misra 2004:10) of this global era enables different ethnic cultures that live together in a multicultural environment to work and live together in peace; therefore syncretism is an area of study that should not be ignored but rather persevered with.

Contributors to the discussion of syncretism tend to discuss the term in a religiocultural context; the most prominent are Stewart \& Shaw (1994), Gellner (1997), Leopold \& Jenson (eds. 2004), and Maroney (2006). In a review of Stewart \& Shaw's book Syncretism/anti-syncretism, Coleman summarises the intention of the book: 'to promote but also explore syncretism as an analytical category by examining not only "the politics of religious synthesis" but also "the competition between discourses about syncretism”' (1997:402).

In South Asia specifically ‘syncretism’ normally refers to an assimilation of religious and cultural behaviours between Hinduism and Islam. There is a growing number of studies of syncretism in this area: some of the main contributors being, Assayag (2004), Burman (1999, 2002, 2005b), Das (2003), Saheb (1998, 2003), Sila Khan (2003), Sikand (2003) and Van der Veer (1994) and others such as Bhardwarj (1987) Misra (2004), Nath Jha (1999), all of whom include reference to the effect of veneration of Sufi Saints on syncretic traditions in India. Das states that her aim is to try to develop 'a framework to comprehend the elusive and synthesized structure of Indian civilisation, from the vantage point of syncretistic religious and cultural traditions of India’ (2003:33).

\section{What is meant by syncretism?}

The Christian theologian Calixtus of Helmstadt (Georgius Calisen 1586-1656) was the first to use the term 'syncretism' in theological debate to mean 'the sinking of theological differences’ (Van der Veer 1994:196). An Oxford Dictionary (OED) definition of 'syncretic' describes it as the 'combining of different religions, cultures, or schools of thought' (2003:921), and an early use of the term by Lang (1887) describes the process of syncretism as one 'by which various god-names and god- 
natures are mingled so as to unite the creeds of different nomes and provinces'. The use of the word 'mingled' in this definition is one that I feel aptly describes the various developments of syncretic practice in India ${ }^{1}$. Burman states that 'syncretism is... a term used to refer to the mutual acceptance of elements of two religions'; this 'mutual acceptance' is frequently mentioned in the historical literature on India (2002:5).

The idea of selective borrowing in order to bridge gaps and smooth over differences so as to be mutually acceptable, occurs in other definitions too: an 'attempt to sink differences and effect union between sects or philosophical schools' (OED cited in Van der Veer 1994:196) and 'the borrowing, affirmation, or integration of concepts, symbols, or practices of one religious tradition into another by a process of selection and reconciliation’ (Berlin 1990, quoted in Van der Veer 1994:196). Michael Pye defines syncretism 'as the temporary ambiguous coexistence of elements from diverse religious and other contexts with a coherent religious pattern' (1971, cited in Leopold \& Jensen 2004:67), note here his reference to 'temporary', implying that there may well be a return to previous behaviours without the new elements, and 'ambiguous', indicating that the coexistence he describes can be complex and indistinct.

Stewart \& Shaw's basic definition reads; 'syncretism refers to the synthesis of different religious forms’ (1994: preface). Sila Khan (2003) fears that such definitions over-simplify the complexity of the types of dual identities that the term attempts to describe, leading to a failure to explain the mechanisms that lie behind the various phenomena labelled by it. However, another definition given by Burman from the Dictionary of Religion (1944) states that syncretism is:

The process of amalgamation of conflicting or at least different parts or principles of cultures - more specifically assimilation of foreign groups. The foreign elements disappear as psychological and cultural entities of the other majorities enter into the minority, and the majority adopts both the minority individuals and a selection of their cultural traits (Burman 2005:109).

\footnotetext{
${ }^{1}$ For other definitions and discussions of the term see: Das 2003:15; Hendry 1999: 144; Maroney 2006: 6 .
} 
This definition addresses some of the power issues that are also associated with syncretism, especially with reference to a religious body trying to conquer/convert another, whereby the indigenous group takes on traits of the foreign dominant group who in turn, to gain support, take on some of the indigenous traits. This process can be compared to the 'incomplete conversions' or half-conversions that took place in early Indian history with the arrival of the Arabs in the $8^{\text {th }}$ Century CE, where converts from Hinduism to Islam retained much of their previous beliefs and ritual traditions (Sikand 2003:8, Sila Khan 2003, see later in the chapter). Leopold and Jensen (2004) and Maroney (2006) give examples of syncretic traditions that developed in West and Eastern Europe, South America, the Middle East and Africa when the indigenous pagan and shaman traditions were retained or incorporated in a variety of ways into Christianity, Judaism and Islam, as kings, rulers, and missionaries respectively entered these regions.

Gellner, on the other hand, suggests that 'the basic definition of syncretism [is]....the unsystematic (or unsystematised) combination within a single tradition of elements which their originators intended to be kept apart' (1997:278). It should be noted that Gellner's definition is one that generalises what the term syncretism applies to, by removing any reference to religion or belief, this fits with Stewart \& Shaw's comment, and Misra’s view, of the global era as one of cultural collage, of transcultural syncretism. Gellner does not mention the 'mutual acceptance' or 'selective borrowing' noted above, but rather stresses the haphazard nature of syncretism.

Van der Veer suggests that 'the role played by syncretism in societies with religious cultures is played by the term multiculturalism in societies with secular cultures' (1994:196). Multi-culturalism can be understood as syncretism in secular societies where the 'debates shift from religion to national [and social] culture, from syncretism to multiculturalism and from conversion to assimilation' (op.cit.198). He rightly suggests that 'the debates and conflicts which are in India largely conducted in religious terms are conducted in the West in secular terms of race, ethnicity and nationalism' (op.cit.199). I would like to reflect on this comparison of multiculturalism and syncretism further. My experiences over the last few years living in India and researching in a religious-centric environment are in contrast to 
what I experience on the occasions when I return to Britain. The actuality here seems to me to be that in a multicultural secular society, multiculturalism is an everevolving entity, and to comply with it, governments and law-makers are constantly amending regulations and creating new laws in order for different cultures to live together in harmony, so that multiculturalism in society can thrive. Syncretic religious practices in India, in contrast, are born out of mutual borrowings from various sources. Since Van der Veer made his comparison between syncretism and multiculturalism, events on the sub-continent lead me to suggest that while multicultural practices change and develop, syncretic practices are vulnerable to criticism from teachings which are resistant to change, become fossilised through rigid and orthodox interpretation, and define these practices as impure. Syncretism, therefore, is not allowed to be an evolving entity as multiculturalism is, but rather is unable to sustain itself, due to intolerance of ambiguous and anomalous practices.

\section{Syncretism as opposed to acculturation}

At the beginning of my research, I thought that a relevant theoretical viewpoint for it might be 'acculturation', the process of assimilation of one culture into another. In fact, the term acculturation implies a slightly different process from syncretism, predominantly addressing the varying degrees of change that happen during the assimilation of one culture's traits into another. Stewart and Shaw explain that the concept of acculturation makes 'quantitative assumptions' in that when a person is in a new 'cultural setting' they 'will acculturate progressively...towards some ultimate completion' (1994:6). Put simply, the process of assimilation is progressive; however it reaches a completion whereby any traits of the original culture are completely replaced by those of the new. There is an 'accomplished cultural change' (Das 2003:14), which has an element of permanency (Stewart and Shaw 1994). Syncretism, on the other hand, implies a partial process where 'cultural traits and religious customs indeed survive in greater or lesser degree', therefore the process of assimilation is an 'incomplete and partial process' where 'the coexistence of dual religious beliefs and traditions’ prevails ‘determinedly and wilfully’ (Das 2003:14).

Herskovits, who was one of the first to examine the significance of the study of acculturation, wrote of acculturation in 1937 as 'the study of peoples whose modes of life are undergoing, or have undergone, extensive change as a result of 
ascertainable historic contacts with alien cultures' (1937:259). There is no mention here of any complete irreversible change, however he did refer to syncretism, according to Leopold, 'as being a dubious and incomplete stage in the acculturation process' (2004:145) ${ }^{2}$. I think it would be fair to suggest that there is an ongoing debate between those who refer to the theory of syncretism and those who refer to the theory of acculturation to explain cultural assimilation and change ${ }^{3}$. According to Das, syncretism has often just been 'included within the study of acculturation' (2003:14), however syncretism does in fact provide its own 'independent and demonstrative field of study' (ibid), which is being adopted for this thesis. In summary: acculturation refers to a complete assimilation of 'socio-cultural' behaviours whereas syncretism refers to a partial acceptance of 'religio and sociocultural’ behaviours.

\section{Why is the concept of syncretism important for this research?}

Kalo Dungar was, in the past, one of the very sites across the sub-continent that gave rise to shared faith traditions/practices (i.e. syncretic practices) based on religious mysticism practised by Sufis. The research findings suggest that the shared traditions of Hindu and Muslim communities in certain areas of India are now disintegrating. This disintegration became evident during the fieldwork that was undertaken and from subsequent literature research. Many of the definitions cited above refer to syncretism as the process in which different elements of religious and philosophical beliefs combine, giving rise to cultural and religious practices and rituals in which both communities share. In this research syncretism refers most specifically to what happens when 'religion travels' (Leopold 2004:8) i.e. 'when an established religion moves beyond the borders of its cradle far from its traditional territorial bounds and makes progress through areas that are founded on different cultural footings' (Maroney 2006:9). The fieldwork encounters described in the

\footnotetext{
${ }^{2}$ According to Leopold (2004) Herskovits became aware, later in his studies on acculturation and syncretism, of the non-static and changing nature of culture and described the 'dynamics of syncretism as being one of borrowing' which 'will always result in a new form being created with a distinctive quality of its own because additional changes which originated in the new habit are incorporated' (1941, cited in Leopold 2004:145). Here we see him (Herskovits) perhaps acknowledging that in this case some of the old habits remain. See also Redfield, Linton \& Herskovits 1936:149-152.

${ }^{3}$ There is much material on the theory of acculturation, see Herskovits 1936:741, Linton 1936, Redfield 1936, Teske \& Nelson 1974.
} 
following chapter allude to these types of traditions shared between many Hindu and Muslim communities in the region of Kutch, that are being threatened by the kinds of right-wing political activities described in the previous chapter. These activities are discussed in Chapter 7 as anti-syncretic.

I now turn to the history of syncretic traditions in the sub-continent with specific reference to the arrival of Sufism and the traditions it produced.

\section{History of syncretic traditions in the sub-continent}

South $\mathrm{Asia}^{4}$ is an area with a 'plural culture in which different religious groups coexist...Different languages and cultural groups have formed themselves into provincial sub-nationalities, but all within the same wider economic and cultural orbit, and within the same state' (Nath Jha 1999:25), this is reaffirmed by Faruqi (1999:12).

Syncretism exists not only as a vibrant tradition but also as a coherent cultural reality in different parts of India....people often adhere to multiple religious traditions without necessarily drawing boundaries between them, even though they may affirm their overt allegiance to one religion (Das 2003:9).

For me, the above quote epitomises syncretic traditions in India, where syncretic processes have occurred as a 'pre-reflective' response to the intermingling of one religious tradition with another, not something 'thought out and consciously appropriated by the people belonging to the different religious traditions or by the bearers of culture within them’ (Alam 1999:32). In India it has been a 'chief characteristic of Indian civilisation ever since antiquity to take over or assimilate or synthesise attributes from diverse cultures which came in contact with it' (Alam 1999:30). India’s immense size and geographical location has meant that a very large number of diverse cultures have arrived on the shores of Hindustan for centuries, including conquering empires such as the Aryans, Arabs, Sultans, Mughals and the European invaders from Spain, Portugal, Holland and Britain.

\footnotetext{
${ }^{4}$ South Asia is a term used to describe the region of the Indian sub-continent including Pakistan, Bangladesh and Sri Lanka, and is used in this thesis to refer to this whole region before and since the borders, as we now know them, were officially demarked.
} 
Many scholars working on religious pluralism and religious syncretism in India attribute the origins of syncretism to the arrival of the Mughal Empire (this focus may well be due to the current importance of Hindu-Muslim relations in India). However it is important to recognise that there were signs of cultural synthesis in South Asia hundreds, if not thousands, of years before this time, as long ago as 1700BCE. This was a time when Hinduism had not yet taken the recognisable form it has today and Islam as a religion had not even been established. Indeed, processes of acculturation and syncretism were 'set into motion as far back as the third millennium BC' and continued 'unabated during the successive periods of Indian history' leading 'to the intermingling of a variety of cultural traits and features' (Morin 1996). The Harappan or Indus Civilisation (3000-1500BCE) enjoyed 'extensive trade and cultural contacts with Mesopotamia, Persia, Afghanistan and the Mediterranean world’' (Morin 1996, see also Bose \& Jalal 1998:14).

These historical events are today referred to, and reinterpreted, to validate specific positions and agendas, such as support for syncretism or anti-syncretism.

\section{The Aryans}

It is to the Aryan invaders from the West (1500-450BCE) that the beginnings of cultural assimilation can be traced. It is believed that when the Aryans arrived in what is now Pakistan they came into 'direct and even active contact with the urban civilisation of the Indus cities' (Kulke \& Rothermund 1998:31)5. 'The Aryan 'conquest' of North India was.... a process of gradual institutional assimilation and socio-cultural integration' (Wolpert 2004:35) which was the beginning of the

Indus-Aryan cultural synthesis combining Indo-Harappan elements with their Central Asian Aryan heritage. It is quite likely that this population was responsible for the continuity of certain traits of Harappan civilisation, like the worship of animals and trees which changed and enriched the Vedic culture during the subsequent two millennia (Kulke \& Rothermund 1998:32).

Morin (1996) \& Wolpert (2004), drawing on the evidence from the Vedas as well as from archaeological discoveries, describe the kinship bonds that soon developed, as

\footnotetext{
${ }^{5}$ It was previously thought that the Indus civilization had come to an end prior to the arrival of the Aryans.
} 
well as the inter-marriage and 'economic interdependency' that materialised between the pre-Aryan groups who populated the villages, and the Aryans themselves (Wolpert 2004:41). The Aryans were arguably the first most influential culture to exist in this region prior to the Mughal invasion in the $11^{\text {th }}$ Century CE, nearly thirteen hundred years later. They

succeeded in impressing the stamp of their religion, philosophy, vocabulary, literary form and tradition, administrative system, in short their ideas and culture, upon the other races of India. Tribes that cannot claim with truth to have a drop of Aryan blood in their veins have accepted the Aryan influence (Sarkar 1998:9) ${ }^{6}$.

The most sacred and revealing evidence is 'their religious and philosophical ideas', which are found in the Vedas (Kulke \& Rothermund 1998:34). The Vedas are a corpus of texts which constitute the integral scriptural foundations of Hinduism, dating from between 2500 and 500 BCE. 'For Hindus...the traditions of Sanskrit literature are still sacrosanct [and] Vedic prayers are still said...the compositions of the ancient arya are not just history; they are the nearest thing to revelation' (Keay 2004:19)7 . Both India’s great Epics, “The Mahabharata” and “The Ramayana”, were written during the Aryan age, and reveal much about the history of this Vedic period $^{8}$. The Brahmanic interpretation of this period in Indian history and of their own relationship with the Aryans, as well as their focus on these religious texts, forms an integral part of right-wing Hindu politics today.

\section{The Mauryan Dynasty}

The next influential era was the rise of the Mauryan Dynasty under the monarch Chandragupta Maurya (324-301BCE), succeeded by Ashoka (his grandson) (268-

\footnotetext{
${ }^{6}$ The evidence of the Aryan civilisation is apparent in almost every context in India; the Sanskrit language is their legacy, a language from which most present day Northern Indian languages have been derived.

${ }^{7}$ The Rig Veda is the oldest and most important of these sacred works and literally translates as "Verses of Knowledge”, it contains '1,017 Sanskrit poems...addressed to various Aryan Gods...and is the world's earliest surviving Indo-European literature' (Wolpert 2004:24). The last of the Vedic texts - The Upanishads - contains the most 'mystical and metaphysical section' (Bose \& Jalal 1998:16, Keay 2004:30). This was a philosophy that 'led to the liberating insight into the identity of the individual soul (atman) with the soul of the universe (Brahman)...the philosophy of the Upanishads... radically changed the old Vedic religion and paved the way for both Buddhism as well as for the later development of Hindu philosophy' (Kulke \& Rothermund 1998:46).

${ }^{8}$ They are mythological epics that depict stories of tribal warfare, battles between maharajas, warriors, and heroic godly figures against each other and the forces of nature.
} 
231BCE) during whose rule the dynasty reached its ‘apogee’ (Bose \& Jalal 1998:17). The dynasty ruled most of what is now recognised as India and Pakistan for over 140 years (Bose \& Jalal 1998, Wolpert 2004). Historians have been able to gain insight into Ashoka's reign more than that of any other monarch thanks to the 'edicts he had carved onto the great rocks and polished pillars...that he erected...throughout the limits of his enormous empire' (Wolpert 2004:59) ${ }^{9}$. Ashoka was tolerant of 'all peoples of every faith, tongue, and stage of development [and] accepted all realities of the Indian subcontinent's regional pluralism' (Wolpert 2004:67), he was a 'living symbol of imperial unity for his people' (op.cit.64) ${ }^{10}$. This model of unity survived throughout the Mauryans’ rule which was almost as long as that of the British some 2000 years later whose record of unity however was unfortunately less impressive (op.cit.67). It was five hundred years later that South Asia experienced another single dynasty's rule of their land through the Guptas (320-700CE). During these intervening years South Asia experienced a long period of 'political confusion, instability, fragmentation and turbulence' which has been termed 'India's Dark Age'. During this time 'Vedic values and brahmanic authority had been undermined' and the teachings of the Buddha became more and more popular (Keay 2004:101-102), however 'the Dark Age proves to be softly illuminated by the steady glow of cultural integration' (ibid), in fact 'intellectually and artistically, this was a time of important growth and cultural syncretism' (Wolpert 2004:68). The Gupta dynasty saw a return to Brahmanical values, and they extended the tolerance established by Ashoka towards 'other religious and social beliefs and practices' (Bose \& Jalal 1998:19) ${ }^{11}$. This period in South Asia's history is referred to as the Golden Age by the Hindu population, whether this is because the rulers were Hindu, or that it was genuinely a prosperous and harmonious period is arguable.

\footnotetext{
${ }^{9}$ These carvings were made in the 'Brahmi script' which is the predecessor of the 'Devanagari script' of the modern Hindi language (Wolpert 2004:59).

${ }^{10}$ It is thought that Ashoka became a Buddhist monk during his reign.

${ }^{11}$ Sanskrit literature blossomed during the Gupta dynasty, with the development of classical poetry; it was also during this era that the Puranas, a classical literature of religious fables that continue to have a huge influence on Indian popular religious life, in which 'awesome figures of legend [and] obscure local deities... were duly transformed into worshippable images’ (Keay 2004:148), after years of compilation were completed. It was during this era that 'Hinduism as we know it today took [its] recognizable form' (Bose \& Jalal 1998:19).
} 
From this early history what is evident is that the longest ruling dynasties survived according to their ability to adapt to the diversity of the region, in supporting intercultural syncretic practices which included being tolerant towards different religions or atheistic practices. The ability to adapt continued into what is often referred to as the 'Islamic' period of Indian history, to the beginnings of which we now turn.

\section{The Arabs}

With the Arab invasion into Sind in 711CE 'Islam arrived....as a political force...' (Madan 2003:791) ${ }^{12}$. Rizvi suggests that 'even before the time of Prophet Muhammad' (2002:301) there were Arabs that had settled on the Malabar coast of India who followed pagan religious beliefs, as was the then practice in Arabia, worshipping a number of different gods (Lewis 2002:11), it was not until after their 'own Islamicization' that they began converting the local population that they now lived among (op.cit.301). The invasion in 711CE was small-scale and the invaders knew nothing of the people of Sind, their society, religion or language, neither were they aware of the political system of government that was in place. They received important cooperation from local tribal groups and it is argued that it was this that 'laid the foundations of multi-religious polities in which Islam and the Indic religions would coexist' it also 'sowed the seeds for an Indian Islam, accommodating Indian cultural traits and forms of social organisation' (ibid), many of which have been incorporated into religious practices. History informs us that the Arab community adapted well to the 'pre-existing political conditions' that confronted them (Bose \& Jalal 1998:27).

This adaptation most probably had political motives, the Arab forces having arrived on the shores of the Arabian Sea ready to conquer the 'Brahmanabad' and to see to it that “"the infidels”... were either converted to Islam or perished' (Wolpert 2004:106). They soon discovered that it would be 'virtually impossible for such a small minority of Muslims to have imposed new religious and social patterns on a country of a very different culture’ (Ansari 1992:14). Instead they devised a compromise 'by which the local population of Buddhists and Hindus were regarded as equal to the 'ahl-i-

\footnotetext{
12 See also Burman 2002, Keay 2000, Rizvi 2002, Sarkar 1998, Spear 1998, and Warren 2004.
} 
kitab (or 'People of the Book')'. 'Non-Muslims were allowed to practise their own religions unmolested' (ibid), and awarded 'Dhimmi' status, this was awarded to those who believed in scriptures based 'on the "partial revelation" of lesser prophets' (Wolpert 2004:107). The local women as 'Dhimmis' were even allowed to 'marry Muslims without needing first to convert to Islam’ (Ansari 1992:14).

The Arab forces eventually travelled from Sindh through western India, south along the Malabar Coast of Maharashtra and Karnataka all the way to the southern tip of India and to Sri Lanka. They developed trading routes from the Arabian Sea and their settlements grew in number, as they spread the message of Islam (Rizvi 2002).

\section{The Sultanate Period}

The major spread of Islam however came later with the invasions from the North in the $11^{\text {th }}$ Century ${ }^{13}$, which began in 1206 to $1526 C E$ when South Asia experienced the Delhi Sultanate who invaded the region from Afghanistan and continued during their rule to appropriate more southern areas like the Deccan. The Sultans, despite maintaining the superiority of Islamic sharia law, refrained from 'imposing [it] on a predominantly non-Muslim population, which was allowed to retain its customary religious laws'. It was this 'intermeshing of religious and secular law [that] was an intrinsic feature of the pact of dominance established by Muslim sovereigns' (Bose \& Jalal 1998:29). There was a succession of powerful Sultans, one of whom, Sultan Sikander Lodi (1489-1517CE) was thought to be 'the wisest and most dedicated, hard-working, and far-sighted Sultan ever to sit upon Delhi's throne’. It was his 'stimulus to learning and cultural creativity' that seemed to have helped 'several important [instances of] syncretism of Islam and Hinduism to emerge at this time, though Sikander himself was surprisingly orthodox’ (Wolpert 2004:121, Rizvi 2002).

\section{The Mughal Emperors}

During this period, the elite of Hindu society, the maharajas, 'were on the defensive' (Spear 1998:21), not able to further their empires, anxious to retain what they had, their 'dominant interest was adjustment to the fact of Islam in their midst, with its

\footnotetext{
${ }^{13}$ It was these 'Turkish, Persian and Afghan invasions of northern India...that injected the TurkoPersian content into the formation of an Indo-Islamic culture' (Bose \& Jalal 1998:28, see also Wolpert 2004).
} 
strange and repugnant ideas, values, and practices' (ibid). It was in this atmosphere and during the civil war that engulfed Afghanistan that Babur conquered the Punjab, later Delhi, and eastward to Bihar, to become the first of the Mughal Emperors in 1527 (Rizvi 2002) ${ }^{14}$. An accusation that surfaced against Babur in the late 19th Century CE claims that a general under his rule had 'destroyed a Ram temple to build a mosque in Ayodhya', a mosque called the Babri Masjid, named after the Emperor. This claim has caused much political and religious conflict in the last two decades (Bose \& Jalal 1998:37) ${ }^{15}$. Unfortunately Babur died before he could really establish his rule and therefore organise and govern the region that he conquered. That task was left to his grandson Akbar (1556-1605), who inherited the empire when he was thirteen years old from his father Humayun, the son of Babur.

\section{Akbar}

Akbar became the most renowned Mughal ruler in India, 'he was undoubtedly the greatest of the Mughal emperors, was an able leader of military campaigns, an astute administrator, and a patron of culture' (Bose \& Jalal 1998:37). He embraced Hindu philosophy and culture and enjoyed the company of Hindu intellectuals, musicians and artisans in his courts (Bose \& Jalal 1998, Kulke \& Rothermund 1998, Sen 1993), as well as giving them employment as governors and such like to help run his empire (Bose \& Jalal 1998). Akbar also succeeded in introducing a new religion (1580/1) based on the syncretic values he held, which were influenced significantly by Islam, Hindu and Zoroastrian beliefs, as well as Christianity and Judaism. This religion he called 'Din-i-illahi' or 'Divine Faith'. Its emblem contained all the religious symbols from all the above-mentioned religions. His aim was to establish a religion that incorporated every religious idea that he was attracted to, much to the dislike of the Islamic purists who began to worry about his religious affiliation (Bose \& Jalal 1998, Kulke \& Rothermund 1998, Sen 1993, Wolpert 2004). According to Maroney, this religion was one of 'the first syncretistic religion[s] created by a single person and as such - it is a unique and important product' (2006:151). In his personal life too, he practised syncretic values, among his many wives was a Hindu Princess

\footnotetext{
${ }^{14}$ Babur has been described as 'a poet and a man of letters, of sensibility and taste and humour as well. Wherever he went he laid out Persian gardens and his memoirs are dotted with references to natural beauties' (Spear 1998:23).

${ }^{15}$ More can be learned about this in Chapter 3 - India's Pledge.
} 
known as Jodhabai ${ }^{16}$, who was given her own room in his capital at Fatehphur Sikri, a room, which reflected her religious traditions ${ }^{17}$. Of course it is well documented that, much like his Arab ancestors in the 8th Century, Akbar's affiliation with Hinduism was politically necessary in order for him to be able to establish the 'IndoIslamic empire' (Bose \& Jalal 1998:40) that he envisaged ${ }^{18}$ and his marriage to Jodhabai was essentially a marriage of alliance.

During the rule of Aurangzeb, three generations later, the 'era of religious tolerance and Hindu-Muslim equality’ initiated by Akbar came to an end. In 1668 Aurangzeb outlawed Hindu religious fairs as well as abolishing new Hindu temple permits and the refurbishment of existing temples (Wolpert 2004:159). During his rigid and powerful reign Aurangzeb increased the size of the Mughal Empire (Bose \& Jalal 1998, Wolpert 2004). His death saw the beginning of its slow demise because law and order over its extensive territory could no longer be maintained.

The Mughal empire in India was the first of the Islamic empires that failed to completely 'Islamicize' the population it conquered, such was the diversity of traditions in the region (Rizvi 2002:301). It was during this Islamic period of Indian history that Sufism had its greatest influence.

Before moving on to the discussion of the Sufis, the relevance of the Arab, Sultanate and Mughal history must be addressed. The most important and obvious example of its relevance is the denigration of this period, specifically the Mughal period, by the Hindu nationalists. It is a reference point used by them to present a history of encounters, as battles between Hinduism and Islam and to denigrate the Muslim community by propagating them as a threat to the Hindu population. Primarily because they once ruled over Hindustan and, according to the nationalists, intend to

\footnotetext{
${ }^{16}$ The story of this romance has recently been made into an Indian film - Jodha Akbar.

${ }^{17}$ Jodhabai was the mother of Jahangir their son who would later take the throne from Akbar (Bose \& Jalal 1998).

${ }^{18}$ Akbar had created the most powerful empire of its time which was inherited by his son Jahangir (1605-1627) who was most interested in poetry, gardens, arts, women and wine. After a rather uneventful reign Jahangir was dethroned by his son Shah Jahan (1627-1658). Shah Jahan was the most lavish of the rulers and his love for architecture was his legacy rather than his rule; he became renowned for creating the Taj Mahal as a tomb for his wife Mumtaz Mahal. Shah Jahan was succeeded by his son Aurangzeb (1658-1707).
} 
do so again ${ }^{19}$. In contrast, this period is referred to by the Muslim population in conflicting ways; for example, the orthodox Muslims may refer to certain periods, such as the reign of Akbar, as being anti-Islamic, preferring the iron hand tactics used by his successor Aurangzeb. However, reformist Islamic groups refer, with pride, to the reign of Akbar, one in which Islam was represented in its true tolerant form. The Islamic period is also considered, both by Hindus and Muslims, as an era which left India with many cultural riches, especially in architecture and cultural exchange.

\section{The Sufis}

'The coming of the Muslims and establishment of their rule began the phase of Hindu-Muslim syncretism in India' (Saiyed 1995, cited in Burman 2002:17); this was mainly due to Sufism. The Sufis began to arrive on the subcontinent with the Arab traders in 711CE and in even greater numbers with the Delhi Sultanate and subsequently the Mughals in the $11^{\text {th }}$ Century CE.

According to Meier, the Sufis grew out of a group of followers of Prophet Muhammad, most probably from Persia and Iraq, who, 'not content with merely obeying his precepts... wished to enter into a closer relationship with God' (2002:117). It is believed that the term Sufi came about because these 'Muslim ascetics were identified by their coarse woollen cloaks known in Arabic as jama-esuf, which they wore as a symbol of their renunciation of the world' (Abu Nasr 1916:20; Warren 2004: 53), much like the Christian monks of Europe who for centuries had worn woollen clothing as a sign of their pious life and rejection of the material world, 'a silent protest against the growing luxury of the worldly' (Browne 1980:167). Of course 'the notion of poverty did not necessarily entail that of piety, but the world “pauper” did' (Meier 2002:117). Pauper translates in Arabic as faqir and in Persian as dervish, both terms that became synonymous with Sufism, especially in Europe (Ernst 1997). This was mostly due to the European travellers, who described the sight of these groups performing their rituals as the 'dancing, whirling and howling dervishes’ (op.cit.3).

\footnotetext{
19 This behaviour is evident in the following two chapters.
} 
In India the most common term for a Sufi is Pir. In Sufism there is an important tradition of master, which in Persian translates as Pir, and disciple. The master and disciple generally shared an intense bond and the disciple eventually carried on the teachings and title of their Pir, as a Pir himself. Many Sufis also claim a sayyid genealogy; sayyids are believed to be direct descendants of Prophet Muhammad and hold a highly respected position in most Muslim societies. If a Sufi or Imam (Muslim religious leader) claims such descent then normally the title of sayyid will prefix his name. During research we met with a sayyid who claimed to be a descendent of the Pir who resided at Kalo Dungar (see Chapter 6).

The Sufis are generally described as the mystics of Islam; however there has been debate as to whether they actually had an, 'intrinsic relation with the faith of Islam', European travellers of the $18^{\text {th }}$ Century (op.cit.9) found the practice of Sufism very different from that of Islam. To some degree this debate still continues. During my research and in general conversation with Indians from across the social spectrum, I found that not all were knowledgeable about the relationship of Sufism with Islam, nor agreed that Sufism developed out of it. However, 'Sufism has always maintained that its origin and foundation lay firmly in the inspired words of the Qur'an and the mystical statements of the Prophet’ (Warren 2004:54), and as Ibn Khaldun wrote 'Sufism belongs to the sciences of the religious law that originated in Islam' $\left(15^{\text {th }}\right.$ Century CE, cited in Ernst 1997:17) ${ }^{20}$. What distinguishes Sufism from the general practice of Islam is that the Sufis paid 'less attention to the legal and philological aspects of the Qur'an and the hadith (sayings of the Prophet), and more to their significance for the conduct of the soul' (Meier 2002:117).

The core principle of Sufism is to become close to God, to establish a 'personal relationship between the believer and God' (Saheb 2003:263), until the believer, the Sufi, becomes completely one with Him. This is normally achieved through meditation which often takes the form of singing 'Qawwalis'. 'Qawwali is a serious art meant to arouse mystical emotions, which may culminate in a real trance during

\footnotetext{
${ }^{20}$ There is a continuing debate between orthodox Islam and Sufism as to whether Sufism and the veneration of Sufi saints can really be considered a legitimate part of Islam (Ernst 1997, Saiyed 2004, Warren 2004).
} 
which the devotee is temporarily united with God' (Gaborieau 2004:ix) ${ }^{21}$. This would often induce the Sufi to whirl around in a trance - hence the title the 'whirling dervishes'. Once the Sufi achieves oneness with God, or 'fana' as it is termed, 'i.e. merging one's identity completely with the Almighty, in which the essence, the attributes and actions of the seeker become the essence, attributes, and actions of the God' (Gupta 2004:49), it is believed that they become mediators or interveners for other believers and so they can 'render direct or indirect help, where other help failed' (Meier 2002:120). Once fana is achieved by the Sufi then the state of 'baqa' follows when 'if they look to the right they see the God and if they look to the left they see the God' (Abu Sa'id ibn Abu'l-Khayr, cited in Gupta 2004:49). It is believed that once the state of 'baqa' is achieved the Sufi has

...transcended the world and gained possession of spiritual powers... bestowed on him by the grace... of God. The notion of gnosis also includes the final absorption into the essence of God or al-Haqq, as a result of which the Sufi is said to be no different from divinity itself...It is in the possibility of this final identity with God that Sufism differs radically from orthodox Islam (Warren 2004:55).

This closeness, intimacy, and identification with God invested them with such holiness that the Sufis became the Saints of Islam. 'Eventually the tombs of saints became centers of widespread pilgrimages' (Ernst 1997:30) as the Sufis' 'closeness to God [was] demonstrated by extraordinary power (baraka), which permits the performance of miracles (karamat)' (op.cit.68). The tombs where the Saints are buried are, according to Ibn Arabi, places that are 'affected by the concentration (himma) of the masters who lived and meditated there' (op.cit.72), which explains why miracles happen at these sites. In India, Hindus and Muslims flock to Sufi $\operatorname{dargahs}^{22}$, the name given to a sacred tomb where a Sufi Saint is buried, in search of peace and miracles. For many low caste Hindus, these graves became one of the only places of worship where they were welcomed, and it is therefore not surprising

\footnotetext{
${ }^{21}$ For further reading on Qawwali see Quershi 1986. To hear a Qawwali see Black Mountain chapter 13 .

${ }^{22}$ Many Sufis set up lodges called 'khanqahs', (similar to hospices) where they had settled, which became places where pilgrims, followers, or people in need could rest and find food. These acted much like the dharamsala in Hindu tradition which were described in the previous chapter.
} 
that an almost cult-like following of the Sufi saints developed (Sikand 2003) ${ }^{23}$. There are instances of Mughal emperors such as Akbar and other Muslim kings who paid regular homage to Sufi Saints (Saiyed 2004:240); 'rulers of the entire Mughal dynasty, believing that the blessings of Chishti shaikhs underpinned their worldly success, vigorously patronized the order', especially the shrine of Mu'inuddin Chishti at Ajmer (Eaton 2000:254, Gupta 2004).

Three orders of Sufi saints had appeared in India by the thirteenth century: the Chishti, Suhrawardi and Firdawsi, all of which appealed to the same mystical yearning of union with God, experienced by so many Hindus as well as Muslims and other 'God-intoxicated' seekers the world over (Wolpert 2004:118) ${ }^{24}$.

The influence of Sufism in India cannot be ignored and is commented upon by most scholars who write on Indian history and multi-faith worship ${ }^{25}$. The Sufis were arguably the most influential Muslims in India who became the agents of acculturation or ‘cultural mediators’ (Roy 1983, cited in Assayag 2004:44) 'encouraging different types of combinations and amalgams in the Indian meltingpot' (ibid). Sikand, for example, describes how many of the caste-ridden, fragmented Hindu communities, the lower strata of which became discriminated against, converted to Islam in 'search of social justice and self-respect' (2003:8). Their conversions took place at a time when the Sufis were spreading the word of Islam; they were extremely tolerant of other faiths and were content with a 'nominal acceptance' of their own faith (i.e. Islam); this enabled many converts to carry with them 'pre-Islamic beliefs and customs... [giving] birth to deeply rooted liminal religious traditions'(ibid). This phenomenon has been described as ‘incomplete conversions' (ibid), where converts continued to practice various pre-conversion

\footnotetext{
${ }^{23}$ See Black Mountain - chapter 13 for a visual journey to Sufi dargahs in India, accompanied by a Sufi Qawwali.

24 'Many of the conversions to Islam after 1209 were carried out by members of the Chishti and Suhrawardy orders' (Bose \& Jalal 1998:31). The Sufi orders developed as groups of Sufis around the $11^{\text {th }}$ Century formed teaching circles and residential institutions (Meier 2002), from these institutions different orders evolved which were born out of the 'experience of individual Masters' (Warren 2004:57), the most famous in South Asia is the Chishti order founded by Hazrat Khwaja Mu'inuddin Chishti.

${ }^{25}$ These include, but are not restricted to, Assayag 2004, Assadi 2003, Bhardwaj 1987, Burman 1999, 2002, 2005b, Das 2003, Engineer 2002, Ernst 2000, Mornin 1996, Saheb 1998,2003, Sikand 2003, Troll 2004, Van der Veer 1995 and Warren 2004. Yoginder Sikand has published numerous booklets addressing Sufism and the inter-faith encounter in India which are all available through him: ysikand@hotmail.com.
} 
rituals, many of which eventually became incorporated into their Islamic rituals and vice versa. As Assayag points out, 'even though the Muslims conquered the Deccan $^{26}$, they in turn were conquered by it... as the Muslim religion adopted attitudes peculiar to Hinduism and its architecture borrowed Hindu motifs and techniques' (2004:39).

The Sufis were able, through their migrations to different parts of India, to introduce an 'Islam coloured by local influences' to regions such as Sindh in the West (now a part of Pakistan), Bengal in the East, the Punjab in the North and the Deccan in the South of India, and it was because of this that they 'attracted a large following of Hindus' (Sikand 2002:50). Herskovits, the main contributor to the study of acculturation, drew attention to the 'impact of cultural "luggage”, he recognised that 'a group never becomes devoid of culture, not even under such pressures to abstain from their traditions' and therefore 'a person could be the carrier of several cultural traits at the same time' (cited in Leopold 2004:144). He was referring to the African and Caribbean slaves in America, however the same point applies to the Indian scenario, as described above. Droogers (2001) argued on the basis of his research into the Afro-Brazilian community, that 'humans are reluctant to give up their cultural or ethnic luggage’. However, as our minds cannot possibly contain complete information regarding our own cultures and those of others, they 'discriminate... select... and...reconstruct information communicated by others to fit [their] own form' (op.cit.156). In the Indian context then, when the local populace learned the new Sufi teachings, they understood and interpreted them according to the terms of their own culture. Perhaps, realising that the local people would not be able to relinquish some of their inherited cultural traits, the Sufis thus settled for 'incomplete conversions' as discussed above ${ }^{27}$. The Ismailis too (see below), according to Sila

\footnotetext{
${ }^{26}$ The Deccan is an area in Western India which now sits, for the most part, in the state of Maharashtra.

${ }^{27}$ It must be added at this point that there was most certainly political motivation too for this 'pragmatic missionary strategy adopted by the Sufis'; the more popular a Sufi Saint became the more powerful and wealthy he became. The growing strength of the Sufi orders became 'centers of anticolonial resistance in a number of areas' (Ernst 1997:205) as Christian Europe began to colonize the Middle Eastern and then south Asian regions. After colonization they were the 'strongest local institutions that remained' (ibid). According to Ernst, the colonial bodies feared the power that the Sufi orders held, aware of the fact that they were 'well organized and highly motivated groups' (op.cit.206). Ernst goes on to state that such 'Sufi institutions were co-opted into the colonial order' especially in the Indian Punjab where the British regime even inducted some Sufi leaders into
} 
Khan, absorbed many Hindu rituals into their own, and 'indigenized the Islamic tradition to the local Indian cultural environment' especially in the form of their ginans or devotional hymns (Asani 1991, cited in Sila Khan 2003:45). According to Ansari (1992) the Ismailis in the $13^{\text {th }}$ Century may well have been the first Muslims who succeeded in converting Hindus. And it was in Sindh (just across the presentday border from Kalo Dungar) that these first conversions took place

Islamisation in Sind was not achieved 'overnight'. Rather it took place over a period spanning a thousand years. It was a lengthy process of attrition, of continuing interaction between the carriers of Islam and the local Sindhi environment (1992:13).

This analogy of attrition can be applied across South Asia where in some instances it is clear that the complete Islamisation process 'could stretch over many generations and hundreds of years' (op.cit.24) something that Richard Eaton (1984, cited by Ansari 1992) discovered in his study of a Punjabi tribe, where the complete Islamisation of a name took over four centuries. In McMurdo's account of Sindh he observes the same phenomenon (Mubarak Ali 1985) and the same is true for Kutch (which shares many similarities to Sindh and the Punjab, both regions that now sit on the Indo-Pak border), where, as I discovered, many nomadic and tribal people, including the Samas, still carry parts of their ancestral Hindu names, especially those from the older generations. One can assume that the Islamisation process in Kutch, too, has stretched over generations.

\section{Universal and Local Saints - Legends of Miracles}

We have Mu'inuddin Chishti, the great propagator of Islam in the subcontinent. He represents the universal saint; the entire subcontinent, and even beyond, knows about him. In contrast are 'local' saints whose influence is confined to a few villages, a town, or at most a region (Saiyed 2004:243).

As the above quote suggests, there are a variety of Sufi dargahs of which most, according to literature, represent the 'local saint' definition used above. There are a 
number of extremely prominent Sufi dargahs, for example that of Mu'inuddin Chishti in Ajmer, Rajasthan, Hazard Nizamuddin in Delhi, Haji Ali in Bombay, Nagore-e-Sharif in Tamil Nadu and many more. These Sufis most probably became renowned not just for their teachings but because of the miracles that were performed at the site, as Warren states 'the mark of a great Sufi saint was his ability to perform miracles' (2004:67). This is confirmed by Khan who notes that 'legends... are the lungs of popular mystic culture’ (Khan 2004:282).

[i]t is...stories that make an event into a miracle and the worker of that miracle into a marvellous figure who can work yet more wonders that will each generate their own stories (Coleman \& Elsner 2003, cited in Badone, E. 2007:453).

These legendary miracles have taken many forms, varying from blessing a 'barren woman with children' (Warren 2004: 71) to curing the sick. To be given a son is still one of the most common wishes at a dargah. It is said that 'Emperor Akbar was blessed with a son in answer to the prayer of a Chisthi Sufi Salim, a descendant of the famous Saint Baba Farid ${ }^{28}$, (Gupta 2004:142). After his wife gave birth to a baby boy he built a dargah for the saint in the grounds of his palace at Fathepur Sikri, a shrine that is still venerated today. He named his son Salim after the Saint and made some fourteen pilgrimages to the shrine of Mu'inuddin Chisthi thereafter (Eaton 2000 Gupta 2004). Other common miracles performed by Sufis have been: interceding in relieving the pain of followers, 'causing miraculous escapes from danger of death' (op.cit.69), as well as miraculous cures of mental health problems. In India such cures are normally associated with exorcising a spirit or demon. Miracles and legends, however, are not restricted to 'universal saints', local Saints too have legends attached to them. There are thousands of local Saints' shrines dotted all over South Asia. As Ansari (1992) points out, 'by the end of the eighteenth century, it had become virtually impossible to travel more than a few miles in Sind without coming across the shrine of one saint or another' (1992:22). The Gazetteer of India for Kutch District in 1971 states that the numbers of fairs associated with Muslim Pirs taking place in that district reached a total of 42, with a congregation of over 104,000 people. This is in comparison to the 60 odd Hindu-

\footnotetext{
${ }^{28}$ Baba Farid was a popular Sufi of the Chisthi order, his disciple was Nizamuddin whose dargah in Delhi is an extremely popular place of pilgrimage and can be seen in Black Mountain - chapter 13.
} 
related fairs and festivals, a slim majority considering the Hindu majority population, three times larger than the Muslims of the district.

An example of a local shrine associated with a Saint's powers near to where I live in Maharashtra, is Kamar'ali Dervesh. The people who live around the dargah demonstrate the Sufi's powers. Eight men stand together round a boulder that weighs over 20kgs, each puts a finger under the stone and when they all call the Sufi's name together and lift, the stone rises into the air (see Fig.17, and Black Mountain - chapter 13). Some argue that there is a scientific explanation for this but others believe that it is a demonstration of the power of invoking the Saint's name. Kamar'ali Shah Dervesh is also famous for curing snakebites, the mentally sick and barren couples (Roy 2002). At a Sufi dargah it is customary to tie a red piece of string to the dargah, most commonly near the door or entrance to the grave, which is like leaving your wish behind for the Sufi to make come true ${ }^{29}$. Some Sufis become renowned for certain kinds of miracles. As Saiyed states: 'many of the local saints are supported only by given segments of the population, determined either by locality, social group, or professional group. There is thus a sort of "patron saint” situation' (2004:244). Saints are venerated depending on their forte, so to speak.

\footnotetext{
${ }^{29}$ For further reading on local Sufi Dargahs and Hindu-Muslim Syncretism in Maharashtra, Gujarat and Bengal see Roy 2002, 2005, for work in South India, specifically Karnataka, see Assayag 2004. For other reading on shrines across India see Sikand 2003 and Troll 2004.
} 

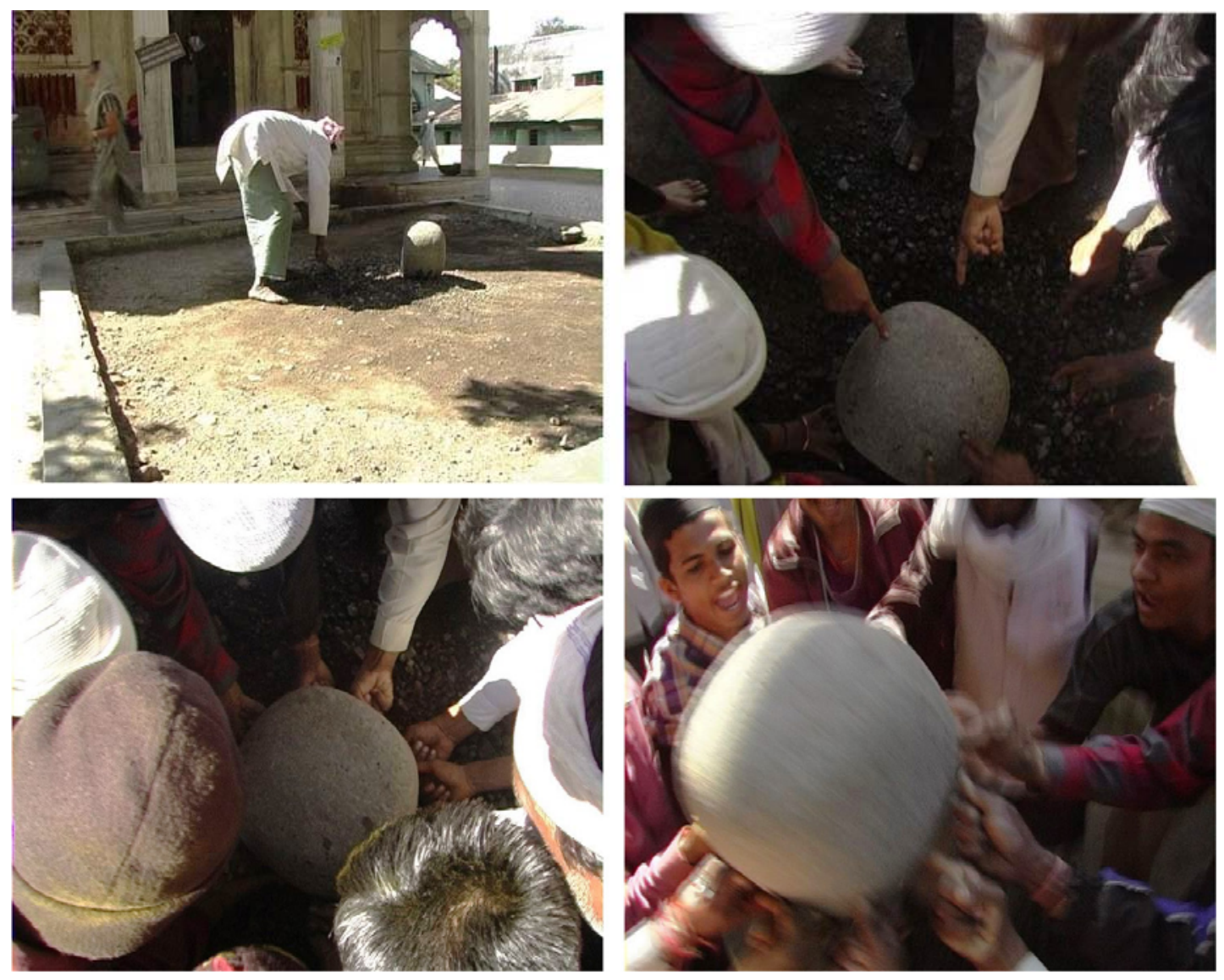

Fig.17. Images showing the demonstration of the Saint's power at Kamar'ali Dervesh. The caretaker prepares the area for the stone lifting; pilgrims gathering; placing their fingers under the stone and chanting in unison as they lift the stone.

\section{Syncretic Rituals}

One of the striking things about Sufi dargahs is not just the legends, and the presence of Hindus and Muslims worshiping together, but also the amalgamation of rituals from both faiths that is visible. Followers are normally guided through the rituals at the dargah by the caretakers, and it is not unusual for the caretaker to be Hindu even though generally they are direct descendants of the $\operatorname{Pir}^{30}$. The caretakers also undertake the three main ritual tasks of the dargah which are: to unlock it in the morning; to lock it in the evening, and to tend to the dargah, that is, to clean inside it, replace the cloth that is draped over the marble tomb, and light the oil light or candle that is always left burning.

\footnotetext{
${ }^{30}$ Just as there are examples of Muslims taking care of Hindu temples.
} 

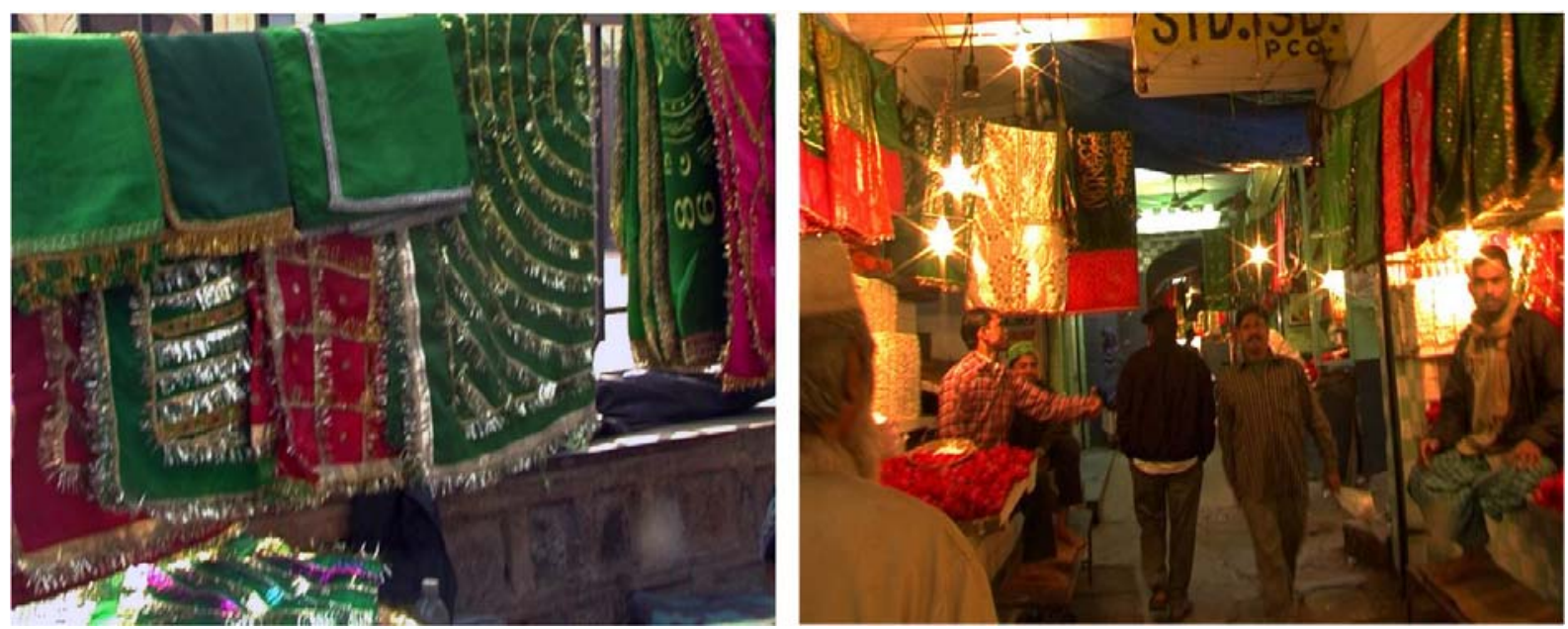

Fig.18. Image showing the pieces of cloth or 'chaadars' ${ }^{31}$ used to drape over the tomb, and the avenues of hawkers selling cloths and flower petals for pilgrims.

The other common rituals performed by pilgrims include walking clockwise around the tomb, making an offering and praying, which normally involves tying a red and yellow cotton thread onto the marble lattice walls that normally surround the tomb as a reminder to the Saint of their wish ${ }^{32}$, and throwing petals over the tomb (see Fig.19).
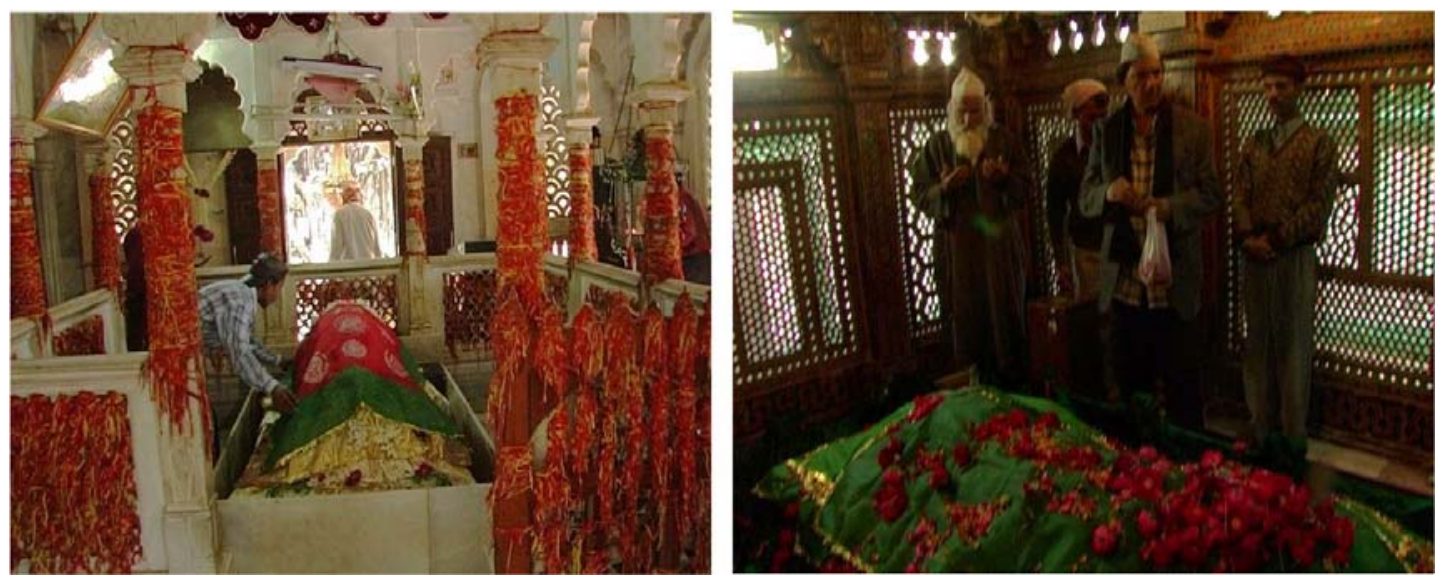

Fig.19. Image showing the tied threads on the tomb structure left behind by pilgrims and scattered petals on the tomb. Visual of these can be seen in Black Mountain - chapter 13.

This ritual of tying a thread to the tomb when asking for a boon finds its roots in Hindu tradition, as does walking around the tomb clockwise when taking blessings.

\footnotetext{
31 'Chaadar' means bed sheet and is used to drape over the tomb just as a bed sheet would be used to cover a person sleeping; it is a mark of respect.

${ }^{32}$ In most Dargahs women are not allowed into the actual tomb area but take blessings from the Saint around the outer area.
} 
The singing of Qawwalis and playing of musical instruments is an example of a shared ritual of the Hindu and Muslim communities. It is not uncommon to find pilgrims kissing the steps or floor of the entrance of the tomb before they enter, and kissing the tomb itself. It is also common for pilgrims to kneel at the tomb or even prostrate themselves, according to the cultural traditions of reverence for the pilgrim. Other kinds of 'rituals of various origins' are evident at the Sufi Urs which translates as celebration (Gaborieau 2004:viii). Urs is the name given to the anniversary of the Saint's death, when it is believed that he was united with God. These celebrations are held once a year and on these occasions Sufi dargahs are sites of communal amity. There are other festivals too, held at various dargahs, especially at Mu'inuddin Chisthi and Nizamuddin which are based on the Hindu lunar calendar.

There are two more points to make about Sufism before moving on. The first is that 'all over the subcontinent a number of Muslim saints are still regarded as the guardians and protectors of Hindu or Jain shrines' (Sila Khan 2003:21). It is not uncommon to find a Sufi dargah in the vicinity of a Hindu temple, especially if, for example, a temple is situated on a hill. A famous example that Sila Khan offers is the pilgrimage site at Ayyappa in Kerala, where 'Vavar is the guardian-deity of the God Ayyappa at the shrine of Sabarimalai' (ibid). Vavar was a disciple of the 'Kerala warrior-king Ayyappan who is believed to have been an incarnation of a Dravidian deity' (Sila Khan 2003b:4). Vavar's dargah has been 'continuously protected by Hindu rulers and its current caretakers' (ibid). Another famous example is on the island of Bet-Dwarka in Gujarat where, at the entrance to the Hindu temple site there is a Sufi dargah; in these cases the Hindu pilgrim will always pay respect to the dargah before entering the temple (Burman 2005b). There are many more examples of these syncretic practices.

The second point is the phenomenon of dual identities that are associated with some Sufi Pirs. It is not uncommon for a Sufi Saint to also have a Hindu identity. In 
these cases the Saint may be considered a Pir by the Muslims, and a sant ${ }^{33}$ by the Hindus.

Ramdev, Mallinath, Jambha, Jasnath and Ai Mata are said to have flourished in [the] fourteenth and fifteenth century...[a]lthough their present followers spare no effort to prove their Hindu identity, a thorough study of their traditions has shown that they have been perceived till recently (and are still perceived at times) as being endowed with a 'dual' (Hindu-Muslim) personality...[for example] Ramdev is also known as Ramshah Pir (Sila Khan 2003:18) ${ }^{34}$.

One reason for these dual identities is that these Saints had 'disciples from both communities and were, like many medieval Sants, "beyond caste and sects”' (ibid). However Sila Khan also suggests that these dual identities were due to covert missionary activities that the Ismailis especially were renowned for. In this context she refers to the now more common Hindu identity of some of these Saints as a trend towards the re-Hinduising of literature and rituals, a point shared by Sikand (2003) to which we turn in a later chapter. Perhaps the phenomenon of dual identities goes back to the issue of 'cultural luggage' that Herskovits addressed. Are Hindus and Muslims interpreting the Saint in whichever way suits their cultural conditioning, rather than actually sharing a dual spiritual association with each another? This element of doubt is supported by Werbner (1998, cited below) who suggests that the dargah is used for different reasons by each religious group, and Sila Khan (2003) who suggests the political motivations for dual identities of Pirs did not necessarily ensure a sharing of spiritual association of their followers. Saheb gives an example of a shrine 'located in Mahdhi village in Parthardi Taluka...Maharashtra' called 'Saint Kanifnath's shrine' where, for the Hindus it is a shrine of a Hindu Saint and prayers are conducted by a pujari [i.e. a Hindu priest], however the Muslims in the area consider it the shrine of a Sufi saint called 'Shah Ramzan Moti Sarwar', and their prayers are performed by a 'Mujawar (Muslim Priest)' (2003:264). Despite this, Saheb suggests that 'the saint...stands as a common saint for the Hindus as well as Muslims and his shrine becomes a common religious centre’ (ibid), which in this case helps in 'maintaining the communal amity among the believers of different

\footnotetext{
${ }^{33}$ A sant is a termed used to describe Hindu Gurus who were mystics, normally from the Bhakti movement, described below.

${ }^{34}$ Ansari (1991) and Warren (2004) also give examples of this phenomenon.
} 
faiths' (ibid) ${ }^{35}$. Van Der Veer too, states that Sufi Shrines attract Hindus and Muslims for different reasons, for Muslims 'a spiritual relationship with the Pir is of central importance. Hindus see the dargah as mainly a healing domain' (cited in Werbner \& Basu 1998:18l). Therefore 'the mere presence of Hindus at Muslim shrines...cannot be taken as a sign of a common syncretic practice of folk-religion. Rather the different meanings and values associated with visits to Muslim shrines must be carefully delineated' (Werbner \& Basu 1998:18) ${ }^{36}$.

\section{The Bhakti Movement}

Another group which encouraged syncretic values was the Bhakti movement. This is a mystical Hindu tradition which has many strong parallels with Sufism and vice versa. It is unclear as to when the Bhakti movement began, it is certain that it existed long before Sufism or Islam reached South Asia as it is mentioned in the Vedas. However there is a consensus that the movement gained popularity with the arrival of Sufism in the region (Raymond 1982).

The Bhakti movement, described as 'the finest flower of Indian syncretism' (Assayag 2004:153), was influential amongst the rural mass population, many of whom did not want to be pigeon-holed into a Muslim or Hindu identity, and as Sikand rightly states there remain 'scores of communities scattered across [the] vast subcontinent [who] still refuse to be neatly categorized as "Hindu" or "Muslim"... freely borrowing from diverse traditions to create their own way of understanding the world' (2003:3). It gained popularity when it began to make the passage to salvation open to everyone, in much the same way as Sufism did later (Hawkins 2004, Wolpert 2004). In doing this it rejected the Indian caste system that had developed through the Aryan Age and became a 'popular movement [that] emerged outside the confines of orthodoxy' (Kulke \& Rothermund 1998:132). There is some dispute as to whether the movement rejected the Brahmanical caste order completely or whether it was just 'making it more workable and acceptable to the discontented masses' (Ishwaran 1981:75). Initially the movement was divided and represented different sections of Hinduism. In the south there were traditions that were associated with the

\footnotetext{
${ }^{35}$ Saheb's main focus is the Sufi shrine of Nagore-e-Sharif in Tamil Nadu

36 This issue will be further addressed as the second part of the ethnography reveals similar tendencies, the issue is then further discussed in chapter 7 - Anti-syncretism.
} 
worship of Shiva and Vishnu, however, Hawkins (2004) points out a new tradition from the north began to emerge within the movement which was based on the idea that God had no form at all, suggesting that this movement was influenced by Muslim concepts. The person most commonly associated with this movement is Kabir (1469-1538CE); he was 'an illiterate Muslim weaver...[whose] poems and dedicated life inspired millions of followers to abandon their sectarian perceptions of Islam and Hinduism in favour of his syncretic path of simple love of God' (Wolpert 2004:121). Kabir's movement enjoyed a large following which included both Hindus and Muslims, and refused to be categorised by any religion. However, Hedayetuallah (1977) suggests that he was the 'consolidator of...Sufi and Bhakti strands’ (Hawley 1980:386).

Kabir, however, despite his syncretic teachings could not control his followers after his death. The tragic irony was that 'at the time of Kabir's death the disciples quarrelled over the manner of conducting the funeral ceremonies' (Yogananda 1995: 341). Legend goes that during their quarrel Kabir appeared to the disciples and pronounced his decision that half of his body should be buried according to Muslim rites, and the other half cremated, in accordance with Hindu rites. On seeing this vision the disciples obeyed, however, on removing the shroud that covered his body they found that there was nothing there but rose petals. The disciples duly split them in half, and the buried ones (i.e. Muslim-linked) are still venerated today (Yogananda 1995:341, Gottschalk 2000). There are many stories regarding disputes over the funeral rites of Saints that have had multi-faith followers, who, as touched upon above, associate the Saint with their own religion and therefore wish their last rites to be conducted in that religion's manner. Another famous example of this is Sai Baba of Shridi (see Warren 1999).

Guru Nanak, the founder of the Sikh faith, was also influenced by the teachings of Kabir and the Bhakti movement, both shared similar beliefs and are often used as examples of the quintessence of Indian syncretism. Nanak preached that Hindus and Muslims are all 'children of the same god' (Das 2003:20). He founded the Sikh faith on the premise of amalgamating various traditions from both faiths, perhaps, as Maroney suggests, as a reaction to Mughal rule and 'representative of a desire to create a religion that bonded elements of Islam and Hinduism' (2006:151). 


\section{The Ismailis}

One further religious group important in the development of syncretic tradition in South Asia are the Ismailis. Sila Khan (2003) and Ansari (1991) both discuss the contribution made to this tradition by the Ismailis, now globally known as the Agha Khani Ismaili Khojas ${ }^{37}$. Sila Khan states that

Ismailism has never been considered a potential source of influence and interaction by authors describing 'syncretic movements'. This may be due to the fact that Ismailism and its impact in the Indian subcontinent has not yet been thoroughly studied in contrast to Sufism (2003:25).

Both Sila Khan and Ansari suggest, with some validity, that rather than the Sufis, it was the Ismailis who first succeeded in introducing Islam in South Asia when they arrived in Sindh after the Arab invasion. Ansari suggests that the Ismailis arrived around the $13^{\text {th }}$ century after surviving in the Middle East by taking on the guise of Sufi dervishes. They 'dominated religious development in Sind for the next 300 years’ (1991:16). According to Ansari, they not only arrived with religious intentions but rather to re-establish their supremacy in the Muslim world which had been lost with the break up of the Fatimid kingdom. Hitti (1970) describes the slow missionary work of the Ismailis as 'one of the most subtle and effective means of politico-religious propaganda ever experienced by the world of Islam' (cited in Ansari 1991:16). In their bid to convert the local population, the Ismailis allowed the Hindus to retain basic elements of their faith and propagated it as a 'Sindhi variation of Ismailism’ (McLean 1989, cited in Sila Khan 2003:30). The conversion style of these Ismailis remained covert and individualised and slowly the 'Hinduization of the tradition' began as it infiltrated into 'local circles' (op.cit.33). The important point to make here is that 'without contradicting the basic doctrines and primary goals of Ismailism this process resulted in bringing closer Islamic and Hindu cultures’ (ibid). Sila Khan suggests that this closeness should not necessarily be termed 'syncretic' if one accepts the definition of syncretism by Nanji (1978), who states that the term implies, that a religious form has been devalued by its accommodation of others (cited in Sila Khan 2003:33). The Ismailis, she argues, did not devalue their religion

\footnotetext{
${ }^{37}$ It is interesting to point out here, although not directly relevant to this study, that my husband Amin comes from an Agha Khani Ismaili family.
} 
in their bid to make conversions, but took on other values from Hinduism in 'an attempt to convince the Hindus that the new faith they proposed was nothing more than the fulfilment of their former beliefs' (ibid). Sila Khan's understanding of syncretism is such that in her opinion the Ismailis did not encourage syncretic practices. However, a different view of syncretism, such as my own, might dispute this. Indeed, Sila Khan contradicts herself when she refers to 'the process of acculturation' (which I would consider syncretic) of the Nizari Khojas with respect to their ginans. Ginans are the devotional hymns and texts that are sung by the Ismailis as a part of their worship ${ }^{38}$, thus 'indigeniz[ing] the Islamic tradition [Ismaili faith] into the local Indian cultural [i.e. Hindu] environment' (Sila Khan 2003: 45, drawing on Asani 1991, my interpolations). Ginans are unusual in that they contain references to Hindu Gods, and to parts of the Mahabharata, as well as to Sufi Pirs, clear evidence of the syncretising of Ismaili worship, as is the fact that they are sung by the whole congregation, just like Hindu bhajaans. The authorship of the early ginans is also attributed to various Pirs and Sayyids (i.e. Sufis). Pir Saddruddin is accredited as one of the authors of such literature and as the 'Sufi who made the most valuable contribution towards the interaction between Hindus and Muslims’ (op.cit.37). He is believed to be responsible for the conversion to Ismailism of a Hindu caste called the Sindhi Lohanas, a large Hindu community from Sindh (Ansari 1992, Warren 2004). The Lohanas still exist in Kutch and, as I note in the following chapter, associate themselves quite strongly with the RSS and VHP organisations.

According to Sila Khan, as was mentioned above, the Pirs also took on Hindu names without giving up their original Islamic names. Examples of this are:

Nur Muhammad was equally known as Satgur Nur (from satguru the 'true guide'...in Rajasthan Pir Shams was called Samik Rishi or Samas Rishi. The Ismaili tradition tells us that Saddruddin adopted the Hindu names of Sahadev, Balram and Harchand (op.cit.48).

This history of the Ismailis reinforces the main point of this chapter which is to establish and acknowledge a history of synthesis, pluralism, and syncretism of

\footnotetext{
${ }^{38}$ According to Ansari (1992) these ginans share many similarities with Sufi and Bhakti traditions.
} 
religions in the subcontinent which gave rise to multi-faith shrines and sites of worship.

\section{Conclusion}

The arrival of the British and other European colonists on the sub-continent challenged syncretic traditions. The decennial census, introduced by the British, enumerated identity through religion and caste. There were many groups across the subcontinent that 'seemed to defy the simple logic of religious identities' and members of these groups were either forced to declare their identity as either Hindu or Muslim (Sikand 2003:14), or categorised as such by census officials. This subsequently encouraged the segregation of majority and minority religions and created a new political identity for both the Hindu and Muslim populations who would now all come under the terms 'Hindu' or 'Indian Muslim', despite the differences within their respective traditions and the syncretic aspects which blurred the distinctions between them (Bose \& Jalal 1998). As Sila Khan points out, 'the doctrines and the rituals, the beliefs and practices that we now readily subsume under the label "Hinduism”...can differ to the extent of being totally opposed' (2003b:8). It was an era when those who did not necessarily see themselves as Hindu ${ }^{39}$ were forced to label themselves for the sake of the Census. One had to be either, Hindu, Muslim, Buddhist, Sikh, Zoroastrian, Jewish or Christian, there was no longer any room for the ancient tribal pluralism and syntheses that had been such an integral part of the makeup of this ancient civilisation. 'Vast numbers of liminal communities' were transformed into 'unambiguous "Hindus" with the stroke of a pen' (Sikand 2003:15). This is something that continues and at times frustrates the reformist groups of Hindus and Muslims who object to what they consider as ‘impure’ elements who are bracketed into their religious category.

With the development of the census came the battle for supremacy: Hindus over Muslims and vice versa. Religiously motivated groups developed, such as the

\footnotetext{
${ }^{39}$ It must be remembered that Hindu was a term that was placed upon the people of the sub-continent by the ancient Persians and Arabs who 'referred to the land beyond the river Sindhu or Indus as AlHind or Hindustan, and the people inhabiting that land as Hindu'. It was later that the term Hindu was applied as a religious term for the population whose religious practices were never defined by a single term in the past (Bose \& Jalal 1998:2).
} 
Muslim organisations of the Muslim League that fought for the formation of Pakistan; and the Tablighi Jamat who fight for a pure Islam and are involved in the battle over Kashmir; as well as the Hindu organisations of the RSS, VHP, Shiv Sena, BJP and others, all of which fight for the purity of their religion. The Hindu organisations are concerned with the creation of a Hindu nation of India, just as, they claim, the Muslim League achieved its aim of a Muslim nation in Pakistan.

The last sixty-one years of India's independence too, as discovered in Chapter 3 India's Pledge, have challenged syncretic traditions even further, with a movement towards increasing hostility and ghettoisation, between the Hindu and Muslim religious communities. This has meant that the syncretic traditions described here have been affected immeasurably.

The causes, as well as the effects, of historical processes that lead to syncretistic formations vary a great deal depending on the historical, cultural, political and social climates (Leopold 2004:4).

This is certainly apparent with regard to South Asia.

The mutual religious tolerance discussed in this chapter is surprising considering that there are probably no other 'two religious ways of life more different than Islam and Hinduism' (Wolpert 2004:105). Hinduism is a religion that stands in such radical contrast to Islam that the Arab traveller al-Baruni wrote nine centuries ago " "we believe in nothing in which they believe and vice versa”' (quoted in Gaborieau 1995:222, cited in Lindholm 1998:227). But Saint worship in India, of whatever kind, be it Sufi, Hindu or Christian, remains the best example of current syncretic practice. As Maroney states, Saint worship is 'the great storehouse for folk-based, demotic expressions of religion, most often of a syncretistic variety' (2006:11). This is especially true with respect to colonised countries such as India where, he suggests, Saint veneration represents 'the syncretistic blending of elements of indigenous religions and cultures with that of their conquerors’ (ibid).

However, as the above quote from Leopold suggests, it is important to realise that the formation of syncretic traditions is dependent on, and may vary according to, the political climate in which they are formed. Just as there are arguments that India's 
syncretic traditions are deep rooted; there are also arguments that they are not necessarily naturally syncretic at all, but find their foundations in the politically motivated actions taken by rulers in order to be able to control a population whose diverse religious practices they could not and did not fully understand. Perhaps politics has been the creator and is now the potential destroyer of this illusion of syncretism; it may well be the case that communal hostility has always been present in India and has always been its downfall.

This discussion of syncretism shows that it has a cyclical nature. Not only do syncretic practices develop over time, but they also create anti-syncretic responses. In between periods of communal harmony and advancement of syncretic practices, there are periods of communal unrest and violence. This is reflected in recent times, when there have been lulls, or periods with only minor occurrences, which have erupted into the organised riot systems described by Brass (2001) - such as in 1992, and then in 2002. An example of this cyclical alternation between syncretism and anti-syncretism is evident at Kalo Dungar.

However it seems necessary for me, if nothing else, to believe that India's syncretic tradition is the foundation on which the country's relative communal peace has lain and on which it will lie in the future in order to ensure a harmonious future.

India has perhaps been living through this pluralistic challenge longer than the rest of us. Well before the advent of Christianity and Islam in the West, India was already experiencing the encounters of Hinduism, Buddhism, and Jainism with one another... Thus India, perhaps more so than anywhere else, became [and remains] a virtual "living laboratory" of religious pluralism with many of the world's religions living together...over several centuries (Coward 1987: viiii/x).

Past rulers must have appreciated and respected India's indigenous cultural traditions for them to go as far as to adopt them. This, according to Maroney, is 'a tribute to that land's [India's] long history of religious harmonization' (2006:12), as she took the different cultural influences that were bestowed upon her in her stride, creating the syncretic traditions evident today. 


\section{Chapter 6}

\section{Ethnography Part 2}

"History is very funny...because, the victor or the stronger rewrites it, always. Religion is a great tool; a site like Kalo Dungar is an ideal location, it works as a central focal point to gather people, and then a political party can flex its muscle. The so called 'white and black' has now been introduced to subjugate a section of the population - in order to gain power. By rewriting history they [the political parties] create a divide, wiping out any traces of synthesis and togetherness".

(Ashish Lakhia, Ahmedabad 2006).

Having understood the concept of syncretism and the history of shared faith traditions in the sub-continent, I wanted to return to Bhuj a year later (i.e. in December 2004) in order to experience the pilgrimage to Kalo Dungar again. I was eager to find out for myself if the rumour I had been told could be true; was there ever a Sufi Saint at Kalo Dungar? I also wanted to find out the reason for the political nature of the pilgrimage that we had experienced and I was aware too that there were certain sections of Bhuj and the surrounding areas that we needed to recapture on film. Unfortunately, it was not meant to be; in November 2004 I contracted hepatitis. And the opportunity to visit Kalo Dungar again, did not arise until another year later in December 2005.

It had taken a lot of cajoling to convince Amin that we should return to Kalo Dungar for the annual pilgrimage and it went against much of the advice and wishes of many friends and family who had also been disturbed by the tales of our previous experience. Amin was extremely sceptical about returning to Bhuj during the pilgrimage, and more in favour of a return when the fever of the pilgrimage and of a political rally surrounding Kalo Dungar had passed. But I was pretty adamant and on finding out that the Poornima - full moon - was falling on $15^{\text {th }}$ December that year we informed our friends in Bhuj of our imminent arrival. On the eve of our departure we went to dinner with friends who spent nearly two hours trying to dissuade me from going. In order to try to convince us they expressed to me the view that 'taking Amin to this rally is like taking an African-American to a Ku Klux 
Clan meeting'. I decided that night to delay our trip and we rearranged it for January, when the pilgrimage would be over and the atmosphere, less tense.

It was on $16^{\text {th }}$ January 2006 when we finally embarked upon the trip. This time we had our own jeep (bought earlier in the year) and decided to drive. The total distance by road from Bombay to Bhuj is about $900 \mathrm{~km}$ and to break up the journey we stopped overnight in Ahmedabad, to visit a friend of ours from Lagaan called Aditya Lakhia. We phoned Prakash Shukla ${ }^{1}$ informing him of our imminent arrival, and also our friend Dr Rao. On our previous trip we had not realised that we needed permits to travel to this border area and especially to use a video camera. Dr Rao, a friend and well-respected citizen of the Bhuj community, had many high profile contacts in the city, one of them being the Collector ${ }^{2}$, and he said would help us with these permits. We also confirmed that we could stay at the KMVS base in Khavda again, should we need to.

\section{On the way to Ahmedabad}

We departed from Bombay at 7.30am, sharing the driving as we covered the $545 \mathrm{~km}$ to Ahmedabad. The roads were surprisingly good, we stopped often, at various service stations and 'dhabas', ${ }^{3}$ and enjoyed the visual delights that travelling in India never fails to provide.

\footnotetext{
${ }^{1}$ As learned in the previous ethnography chapter, Prakash was the person who had informed us about the pilgrimage to Kalo Dungar and loaned us his bike.

${ }^{2}$ We discovered that the Collector was the best person to give us the required permissions.

${ }^{3} \mathrm{~A}$ dhaba is a traditional roadside resting place, they are frequented most commonly by the truck driving community for whom they provide an economical resting area and eating place.
} 

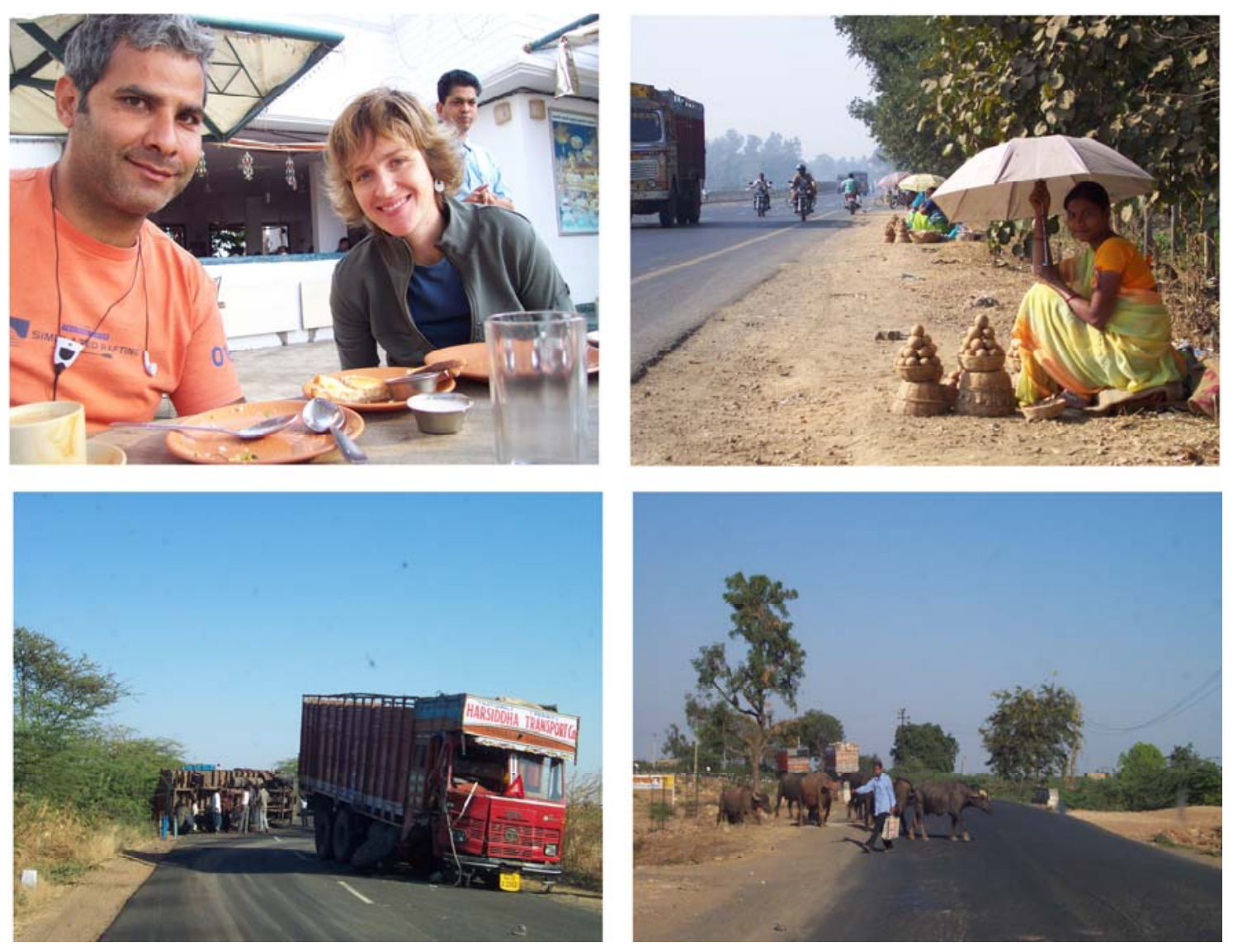

Fig.20. Drive to Ahmedabad

It took approximately ten hours to reach the Lakhias' home, which is situated in Paldi, a Jain dominated suburb in the city of Ahmedabad. The Lakhia family includes members who work as textile designers, and directors and designers of films, including documentaries. We discussed the subject of my research, and I began to talk to them about the pilgrimage site of Kalo Dungar. The family knew of the site and were able to tell of their own experiences and share information regarding the site and the surrounding area. I could not take all the information in and asked them if I could interview them the following day, and if possible record them with the camera. All agreed and we decided that due to this development we would delay our departure to Bhuj by one day; this was an opportunity not to be missed. Their information was extremely valuable as they themselves had made a documentary in Bhuj and had visited Kalo Dungar over 20 years ago.

\section{Ahmedabad}

The following morning ( $17^{\text {th }}$ January) we started their interviews. The main interview was with Ashish (elder son of the family and documentary film-maker). 
He had very interesting comments regarding the history of Sindh both before and after partition, as he has researched extensively the history of trade along what is now the India-Pakistan border from Rajasthan down to the south coast of Gujarat. Through that research he has gained an extensive understanding in regard to the movement of the tribal and nomadic communities in this area. And he made numerous comments about the changing nature of Kalo Dungar and the syncretic conditions of the area. I began by asking him to tell me about Kutch and its history in context to Kalo Dungar.

Kutch was a principal trade route; right from Bukhara through the Khyber Pass and was also part of the silk route, Arab traders also came through here to trade inland. This sheer infiltration [of people] is what spawned a synthesis of religions [in the area] because everyone needed one another to survive. Kutch has probably the maximum amount of varied nomadic communities. A few of them were Rabaris, Jats, Jadejas and Meghwars [these communities follow different religious traditions]. Most of them were cattle herders and traders, each one needed something from the other and they used to congregate at different times of the year at preset locations and transact business. These sites where the tribes intermingled became places of importance; marriages were held, fairs were organised, and prayers and rituals were performed, even exorcisms were carried out. Pirs - holy men - sermonised at these congregations and they were centres of philosophical discourse. The Pir concept too is a bit confusing. It is only prevalent here in the desert stretch of the Great Rann of Kutch and Rajasthan. Pir is a Persian word. Its origin is Islamic, but because their congregations were a fusion of varied tribes and cultures there was no one religion preached by the Pirs. There was an amalgamation. The rituals performed there were integrated in such a way that it became impossible to bifurcate them. When the resident Pir passed away he was buried at that site and from that day on, people paid their respects to his shrine when they revisited it. There was no black and white between Hindu and Muslim. Islam in Kutch had developed mostly from Iran. Upon the break-up of the Persian Empire everybody from the Baudeen, the B'hias to the Sufis, all those who had evolved from there, accessed India through Kutch. They would stop at these sites and rest, interact and trade etc. It was practical and convenient. Kalo Dungar was one such spot.

(Interview with Ashish Lakhia, Ahmedabad 2006).

Once I had returned from the field and embarked upon literature research, I went through my fieldwork notes and camera footage; at which point this interview 'came alive’ as I looked upon it with ‘an enlightened eye’ (Woodthorpe 2007:6). 
Going back to the interview, I asked Ashish if he could give me an example of the synthesis of religions that he had mentioned. He replied:

In Kutch it has been a tradition at some shrines, for Muslims to perform during the morning wake-up prayer and the evening aarti [prayer ritual]. The singing used to be accompanied by the shenai and the naubath, both instruments that were traditionally played and mastered by Muslims. There are various examples, Mata No Math (where Muslim musicians still perform) and Pirana Pir ${ }^{5}$ - where a Muslim Pir's mausoleum is still being taken care of by a Hindu Rabari and the Rabaris pay homage there; Haji Pir ${ }^{6}$ - where Jats still visit; Mira Datar at Unawa and Usman Pura ${ }^{7}$ near Ahmedabad, where exorcisms are carried out even today on many Hindus.

(Ashish Lakhia, Ahmedabad 2006).

All the examples he gave are famous centres that have embraced syncretic traditions and practices for hundreds of years; generally they are associated with different Pirs who had settled in Gujarat and Kutch and preached their pluralist teachings.

I was interested too, in Ashish’s personal experiences at the site of Kalo Dungar.

When you visit Kalo Dungar the first time, you are stunned with the visual. There is nothing for miles around but the desert, and smack in the middle of this stark white plain of the Great the Rann of Kutch is this huge black rock jutting out from under the ground, hence the name 'Kalo Dungar'. The contrast is amazing. Then the priest calls out to the foxes that come out of nowhere, if it is a bit late all you see is their glinting eyes as they congregate and eat and disappear just as quickly as they appeared. People believed in it as a place of spiritual significance. The legend goes that the Pir would feed the

\footnotetext{
${ }^{4}$ Mata No Math is a Hindu pilgrimage site in Kutch, which is venerated by many communities in the region, like many temples across India including at Bet Dwarka, Muslim musicians perform the music for the morning and evening aartis - prayers.

${ }^{5}$ The dargah of Pir Imam Shah Bawa is known as Pirana Pir. 'The sect is an off shoot of Ismailism' and preaches 'a Sufi inspired amalgam of Islam and Hinduism' and is also venerated by the Sat Panths or true path, a sect also associated with the Pir. The dargah is popular amongst many different communities 'belonging to different castes and religions' (Bunsha 2004; Burman 2005). This dargah has been under dispute for some time and has now been almost completely Hinduised. This is an issue that will be discussed in more depth in the following chapter - Anti-syncretism.

${ }^{6}$ Haji Pir is a Sufi dargah in Kutch that is venerated by Muslims and Hindus throughout the year. During the urs celebration thousands of pilgrims throng to the dargah, which is situated in the Banni region of the Rann, the pilgrims generally make the arduous pilgrimage on foot, walking miles to pay their respects (Burman 2005).

${ }^{7}$ Mira Datar is a dargah where many devotees go to be cured of mental or psychological disorders, and it is reported that many 'insane people can be seen within the shrine'; there even used to be a sanatorium there for the mentally sick. It is reported that most of the devotees that visit the shrine are Hindu (Burman 2005:60). Usman Pura is another such dargah near Ahmedabad city.
} 
foxes regularly and they would respond to his call. One day he ran out of food and so he cut off parts of his body and fed it to them. While he did it he repeated 'Lo Ung' - take my flesh. Interestingly till twenty years back there was no formal approach road [to the site]. The only way to get up the hill was to trek up and trudge all your goods up by camel or the like. On top of the hill there was no concrete structure, just a temporary kind of a small (delu) shack to relax under. It was a typical 'Pir sthan' - place of a Pir. There was no provision for an overnight halt, if one wished to stay he had to camp, but it was safer to leave before sunset. There was no one there for the evening aarti - prayer.

(Ashish Lakhia, Ahmedabad 2006).

Here Ashish tells the legend that we had heard during the pilgrimage, but gave us a new insight into the nature of the site in the past. His description was startlingly different from what we had seen at Kalo Dungar in 2003. The previous evening in our conversation we had discussed the present situation at Kalo Dungar and the political experiences we had encountered, so I wanted to ask Ashish what his feelings were about how these differences have come about and why.

Q: How did Kalo Dungar end up becoming what it has today? What do you think prompted such attention to it?

Ans: Sometime during the '80s there were huge border problems. Kalo Dungar is very close to the border. India's last check-post 'India Bridge' is just beyond it. The area is very difficult to man and there was a lot of infiltration as the border is very porous due to the terrain being very difficult to fence off completely. During the annual fair of the Pir, families used to visit the shrine for blessings from across the border, cattle fairs used to be held and trading used to be done, and even cross border marriages were solemnised. Then the B.S.F. [Border Security Force] set up an observation post and a base on the top of the hill; to facilitate the new post a road was demarked. Once a basic infrastructure was established, there was easy access to the top where the shrine was located, whoever was dominant at that time, took advantage of the situation and took over the shrine and converted it to suit their purpose. Once you get access, you gain control; get your right-wing into the act and then the media follows. Although Muslims inhabit the area they are not the dominant community so history can be manipulated.

(Ashish Lakhia, Ahmedabad 2006).

This history of the border between Sindh and Kutch has been reaffirmed in oral and published accounts, stressing its permeability, by nomadic pastoralists, traders, and families who had relatives on both sides (see Chapters 4 and 5). 
Ashish had also implied in his comments that once access to the shrine had been established the dominant community at the time can convert it to suit their purposes and can manipulate history because the community who live in the surrounding area, i.e. Muslims, are less powerful. I was eager to understand exactly what Ashish meant by 'history can be manipulated'...

History is very funny... because, the victor or the stronger rewrites it, always. Religion is a great tool; a site like Kalo Dungar is an ideal location, it works as a central focal point to gather people, and then a political party can flex its muscle. The so called 'white and black' has now been introduced to subjugate a section of the population - in order to gain power. By rewriting history they [the political parties] create a divide, wiping out any traces of synthesis and togetherness.

(Ashish Lakhia, Ahmedabad 2006).

This comment, quoted at the beginning of the chapter, seems to me to sum up the situation at Kalo Dungar. I wondered whether what we had witnessed there two years earlier was an incident of 'rewriting history' (as Ashish describes it) by a political party, forcing a much more subtly varied population into binary categories of 'black and white' or rather 'Hindu-Muslim', removing any traces of syncretic practices? Or was there even more to it than that?

After this interview there were a couple of phone calls to make, which turned into further interviews and meetings. One of these was with Azhar, who had been working on the re-development of Bhuj post-earthquake. Co-incidentally, he had now moved to Ahmedabad. His attitude on the phone was initially very apprehensive and suspicious but eventually he said we could meet him in the evening.

On accepting the appointment of re-development officer, after the earthquake in 2001, with the agreement of his company Azhar had moved to Bhuj, where he faced many unexpected obstacles, which primarily included the changing political nature of the Kutch state; something that was reflected in the state of Gujarat at large, when during this period it saw wide-spread, violent riots between Hindu and Muslims under Chief Minister Narendra Modi. During and after the riots in 2002 the state turned hostile against the minority Muslim community. The aftermath of the riots changed the way people thought and the re-development of Kutch after the 
earthquake provided a primary opportunity to bring this hostility to Kutch.

According to Azhar, and as I later discovered from articles written by Ed Simpson (2006, 2006b), much of the re-development of rural Kutch depended on various financial donations, from the VHP and other organisations like them, that sponsored the re-development of whole villages and townships in order to spread their political messages and polarise communities, in effect by building religious ghettos.

A public-private scheme for the reconstruction of earthquake affected villages was implemented by the government. Through this scheme the VHP secured the village at the supposed epicentre of the earthquake and a Hindu sect with strong links to the VHP, in unofficial partnership with the RSS, reconstructed other settlements in the region...Much of this reconstruction work was highly discriminatory and, as Hindus moved into their new houses amid the fanfare of visiting dignitaries, Muslim families quite literally huddled under ragged tarpaulin shelters on the periphery of the new villages (Simpson 2006b:319).

Simpson talks with reference to villages within Kutch, but according to Azhar, even in cities like Bhuj, people were building their new homes like forts, and communities were alienating themselves from one another. The Government was supporting this kind of re-development which was changing how the city was being planned. The rally we witnessed on Kalo Dungar was perhaps a part of the discriminatory reconstruction work that Simpson mentioned, and a part of the flexing of political muscle that Ashish had touched upon; as was the growing RSS network in Bhuj supporting the ghettoised fortification of the re-development in Bhuj that Azhar talked about. We had witnessed ourselves what else came with this reconstruction of rural Kutch;

Rebuilding these villages was accompanied by proselytization, the construction of educational services, training classes for rural temple priests and, in the village of Khavda, a new temple dedicated to the central deity of the sect that had reconstructed the settlement (Simpson 2006b:319).

The temple referred to was surely the one used in the rally to Kalo Dungar where the pilgrims had stopped for their lunch (see Chapter 4). 
Azhar had been emotionally disturbed by the developments that he witnessed while living in Bhuj and had even started writing a book based on his experiences ${ }^{8}$. By the end of our meeting he had warmed to us and before we departed he gave us names of people whom he thought would be able to help us in Bhuj -including historians, librarians and museum curators. He also spoke about a friend of his, Farhana Ibrahim, who was living in Bhuj at the same time he was, undertaking her $\mathrm{PhD}$ research. She had just completed it, focussing on 'boundaries and borders', she was researching the nomadic tribes that cross the border from Sindh in Pakistan to Kutch, in India. Coincidentally, she was expected in Ahmedabad that evening. Azhar said he would see if she would be interested in meeting us the next morning before we left for Bhuj; the next day he gave me her mobile number and we arranged a meeting for midday.

The Lakhias had also given us an introduction to Umesh Jadia, the curator of the Kutch Museum, which was hit extremely badly by the earthquake, he said he would meet us on the morning that we arrived in Bhuj. I had remembered meeting him during the shooting of Lagaan. He is a musician and works towards the preservation of the art of old Kutchi folk music with other local Kutchi musicians.

We had arranged to meet Farhana at a café, and there I asked her about her PhD. Her thesis researched the nomadic tribes of Kutch, specifically the Jats, whose unique wandering crisscrossed the India-Pakistan border intermittently, and has continued to do so since Partition. The thesis also touched upon political developments in the same area pre- and post-earthquake. I narrated to her my experiences during my previous research trip to Bhuj and the political rally we had become a part of, which had been the driving force behind my decision to further research the site of Kalo Dungar. Farhana too, had some unpleasant, politically loaded, experiences during her research, such as the inauguration of a Kutchi village that had been sponsored and redeveloped by the RSS, and the inauguration of the new temple at Kalo Dungar where she witnessed similar political events to those we had seen. Accompanying

\footnotetext{
${ }^{8}$ He started researching and writing the book officially while he was still living in Bhuj and told us that he had shared some of his knowledge with fellow researchers, some of whom had used that information in their own theses, without giving him any credit. He explained to us that these experiences were the reason for his hostile attitude towards us on the phone.
} 
her at these functions was another researcher, Ed Simpson, who was researching in Kutch at the same time (I refer to his work in other chapters and later in this one).

Farhana Ibrahim comes from a mixed background; her mother is a Hindu and her father a Muslim. She was brought up with a combination of religious beliefs. However, much like Amin, even though she is not a practising Muslim herself, because of her name she will always be considered a Muslim. This has led her to have some uncomfortable experiences and feelings while living and researching in Bhuj and the surrounding villages of Kutch (some of which mirrored Amin's experiences as an assistant to me in the field). Farhana advised me on some historical literature that I could pick up in Bhuj, as well as her own articles, and informed me too, that there was very little written history on Kutch; that I would probably have to rely, as she and other researchers did, on the oral histories that are abundant in the region. When living in Bhuj she had met a man called Mohammed Hussain Khatri, known by most people as Khatri Bhai ${ }^{9}$. He was extremely knowledgeable on the region of Kutch and had a keen interest in anthropology and research and he had become her research assistant during her fieldwork and now helps many students with research, working as a translator and guide. She gave us his number and told us to meet him once we reached Kutch. The meeting ended and we left for Bhuj immediately, arriving there at about half past ten that evening.

\section{Back in Bhuj}

After breakfast, we met up with an old friend, Prakash Shukla (a Hindu), who helped us to find the house of Mr Umesh Jadia, the museum curator, with whom we had a set up a meeting the previous day. He had already left for the museum, which had moved into a makeshift building while the original building was being repaired. I had met Mr Jadia on a previous occasion and he remembered that we had taken a photograph together outside the old museum and written contact details in his book, which he removed to show me. This re-acquaintance with each other broke the ice and we began discussing my research. Mr Jadia speaks English but he is not very confident. Normally in situations like this, once people realise I understand Hindi

\footnotetext{
${ }^{9}$ As noted earlier in the thesis, Bhai - means brother, and it is added after a man's name as a mark of respect, just as Didi, or Bhen (in Gujarati) meaning sister, is added after woman's name. Mohammed Hussain Khatri is referred to as Khatri Bhai for the rest of the ethnography.
} 
and that Amin is with me to translate anything I don't understand, they tend to converse in Hindi, which is how this interview continued. Before formally starting the interview we asked Mr Jadia if he minded Prakash being present, and if he had any objection us recording the interview on camera, explaining to him that the film we were making was to be a part of the research. He happily obliged.

I should add here, as I mentioned in the methodology chapter, that knowing the sensitiveness of the research we were very careful how we explained the research topic to certain people. It was important that we gauged the person we were talking to in order to discover whether or not we would be able to convey the political nature of the research. Generally we would assume that if the person we were interviewing was Hindu we would avoid mentioning the political nature of the pilgrimage we experienced, or discussing the political side of the research in any detail. At this stage we were still to discover and understand the different aspects of Kalo Dungar. Asking different questions to different individuals dependent on their religion could perhaps be viewed as ethically incorrect, however, the sensitive nature of right-wing Hindu politics needs to be dealt with delicately as the backlash of dispute or irritation, on the part of the supporters of right-wing politics is too unpredictable and potentially gruesome to want to test. Having discovered the changing political situation in Kutch from speaking to Azhar and Farhana, and from our own first hand experiences, we knew that we were in a vulnerable situation should anyone take offence at our inquisitiveness regarding any potential political development around Kalo Dungar.

With this in mind we explained to Mr Jadia that on our previous visit we had been fortunate enough to join the pilgrimage to Kalo Dungar where we had heard pilgrims talk about a Saint who had lived there and fed his limbs to the local animals. They believed that he was an avatar of the Hindu God Lord Dattatreya. We explained that we were trying to find out more about the history and identity of the Saint. Mr Jadia confessed that he did not know too much about Kalo Dungar but he speculated that there was a Saint called Menkan Dada who was worshipped in a village called Dhrang. This Saint was also associated with animals, as he wandered with a dog and a donkey and had given himself up to helping others. We asked Mr Jadia where exactly the village was and he said it was about $20 \mathrm{~km}$ away from Bhuj. On hearing 
the distance of this village from Bhuj I realised immediately that this was probably not the story of the Saint at Kalo Dungar. It was also a fairly recent legend, as the Dada had died only about 50 years ago. When we finished talking, Prakash had become quite agitated and began writing furiously on some paper. We wondered what he was doing and felt slightly embarrassed. He was writing 'Kalo Dungar' and 'Lord Dattatreya' at the top of the paper and 'Dhrang' and 'Menkan Dada' at the bottom. He then forcefully drew a line in-between, implying that the places and people were different, and that the legend of Menkan Dada was a completely separate story. Amin and I tried to pacify him as he had got quite upset. In an adamant, but calmer mood, Prakash went on to justify his opinions with geographical facts explaining distances and historical periods. With all this clarified Amin asked Mr Jadia if indeed he thought what Prakash was saying was correct. Mr. Jadia thought for a couple of seconds and then said that he did not know the exact history of Kalo Dungar. When Amin asked him who he thought the holy person of Kalo Dungar might be, his answer was, 'that is also difficult for me to answer'. After his interview we got up to say thank you and were about to pack our camera away when the clerk, who had also been listening to the interview, requested us to interview him. So in the presence of Jadia and Prakash, Amin asked him in Hindi to tell us about Kalo Dungar, and he began to say that the Saint at Kalo Dungar was Lord Dattatreya. Amin asked him if he knew who the Saint or person might be, or even his name, but he confessed that he was not sure of the history. We turned off the camera and while talking, Amin divulged the name of the Saint, 'Pachmai Pir', that we had heard from the Lakhias in Ahmedabad, and asked both men if they had heard of him. We had not mentioned this name earlier so as not to influence anything that they might have known themselves, but on hearing this name the clerk got extremely excited and began saying 'Yes! Yes!' agreeing that it was in fact Pachmai Pir who had come down as the avatar of Lord Dattatreya. Amin asked him if he had any further idea about the identity of Pachmai Pir, who he was, where he came from, or where he had gone? But the clerk drew a blank. He just kept repeating “It was Pachmai Pir for sure! Lord Dattatreya had come down to earth in the form of Pachmai Pir!" We had not recorded this conversation, and we asked the man if he could speak about Pachmai Pir and what he knew of him on camera, and we took his interview again. 
Q: What do you know about the history of Kalo Dungar?

Ans: I have always been interested in Kutch's History. Here [at Kalo Dungar] Guru Dattatreya was called Pachmai Pir. He was 'Pachmai Pir' because Pachham means 'West of Kutch' and because the temple is situated in that area. The reincarnation of Dattatreya who appeared there is believed, by the locals to be a Pir and therefore he is addressed as Pachmai Pir.

Q: Where does the word 'Pir' originate from?

Ans: Pir is a Muslim word, but those we believe to be a Saint, we address them as 'Pir'.

(Museum Clerk, Bhuj 2006).

After recording this interview, we walked over to a large map of Kutch pinned on the wall in the office. The map showed Kalo Dungar situated in the Northern region of Kutch and we stood discussing its location. Mr Jadia and the clerk both agreed that the Pir could have been called Pachmai Pir because he came from the west. We were confused and as the clerk moved his finger from Kalo Dungar towards the west his finger stopped on Sindh, now a part of Pakistan (see Figs.21 \& 22 below) ${ }^{10}$. This brought silence to the room, even we were quiet. Prakash broke the silence, dismissing the idea that Lord Dattatreya's avatar, the Pir, could possibly be from 'Pakistan'. Mr. Jadia too dismissed the clerk's analysis and told us that we should meet some other people, local historians, who might be able to tell us more. And he gave us three names and numbers.

The clerk associated Pachham with the Pir, however he did not refer to the region of Pachham in which Kalo Dungar lies. It is not clear why the island or region Pachham, mentioned by the clerk and illustrated in Figs.21\& 22, has that name. In one Bombay Gazetteer it is mentioned that Pachham, out of the four other islands in the north of the Great Rann, lies at the most western point. Otherwise it seems Pachham, as an area, is only really famous for Kalo Dungar which is the highest mountain standing 1437 feet above the Rann (Campbell 1880).

10 These interviews are not shown in full in Black Mountain, but can be viewed in part in Chapter 14 . 


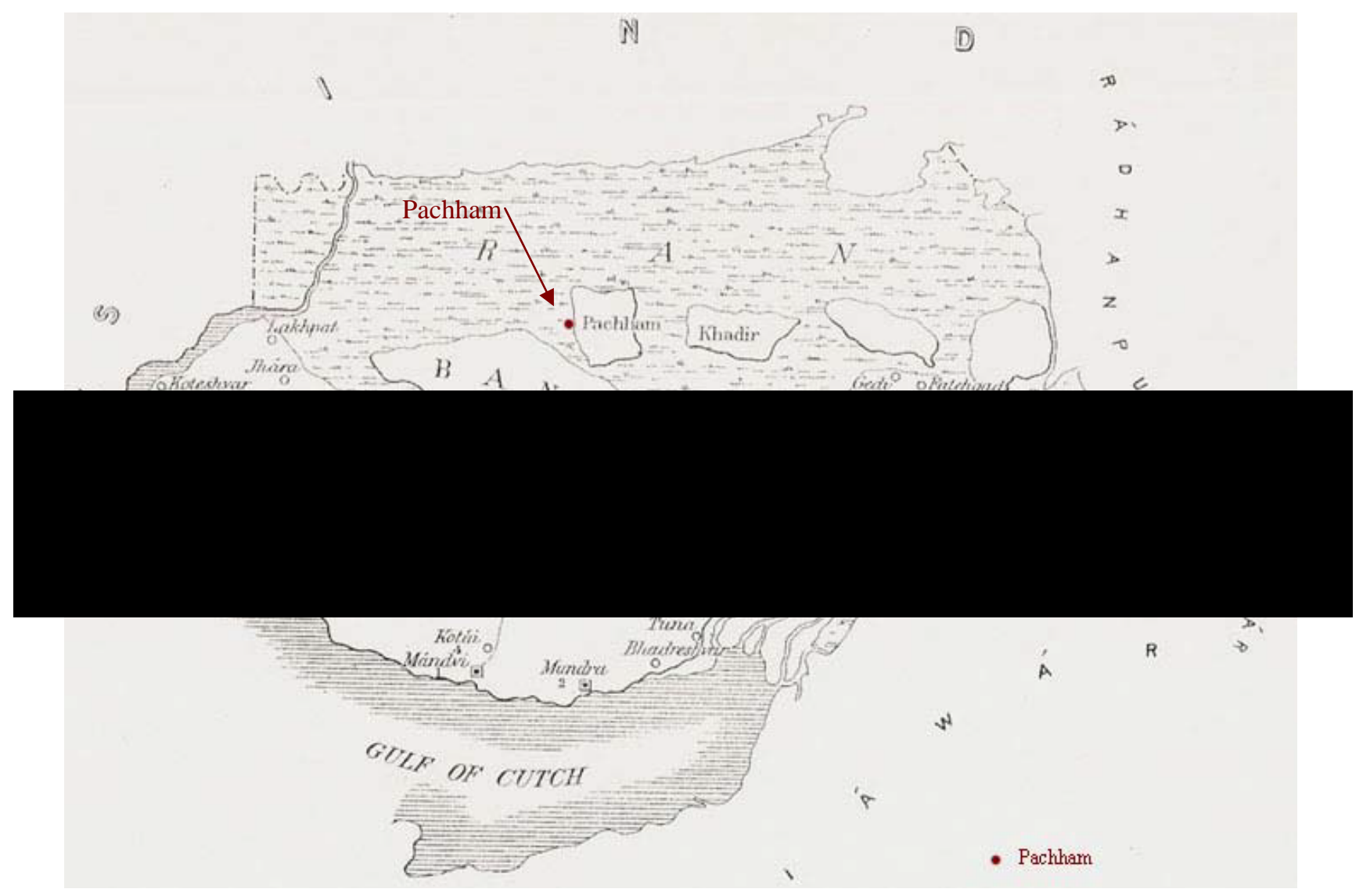

Fig 21. Map illustrating the area known as Pachham. Source: Bombay Gazeteer1880

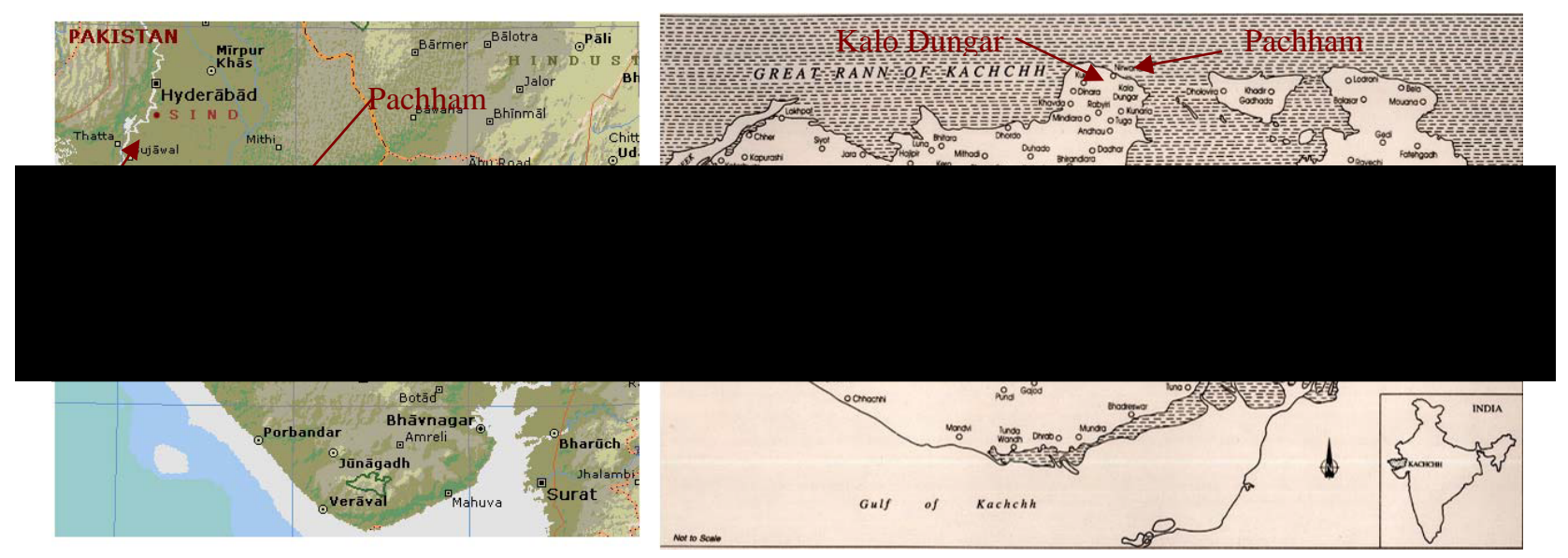

Fig.22. Map on the left illustrating the region of Kutch and Pachham in relation to Sind, and on the right Kalo Dungar in relation to Pachham. Source: Map 1 - Source:@2006 Microsoft Corp

Realising that discussions about Pachmai Pir were creating a slightly uncomfortable atmosphere, we changed the subject to the work Mr Jadia was doing with the local Kutch musicians. He invited us to an evening concert that the musicians were performing for some American tourists on Monday $23^{\text {rd }}$ January, at a small tourist village that had recently been built just $15 \mathrm{~km}$ from Bhuj. We accepted and agreed that we would meet him there. 
After the interview we discussed with Prakash his outburst in the office. He explained his frustration on listening to what he thought was the wrong story being told by Mr Jadia. I realised that ideally during interviews it was preferable that Prakash was not present. This was perhaps going to raise problems for me in that, not only might there be differences of opinions and outbursts such as the one we experienced, but also an interviewee might not be comfortable speaking in front of another person as well as the researcher, especially if the material is sensitive, and more so if that person is known to them locally. These are issues that become evident later in the research. Ideally I should have informed Prakash that during the interviews he would need to wait outside, however the dynamics were such that this would have given offence, especially as he was helping us in other ways.

Over lunch Prakash was keen to ensure that we did not take the theory of the clerk seriously; he was obviously feeling quite disturbed with the idea that the Saint could come from Pakistan ${ }^{11}$. When we explained to him that we had returned to find out more about Kalo Dungar his immediate response had been, 'well there is a temple to Lord Dattatreya, you know, I know, everyone knows, and that's that really!' We spent the next few hours trying to find out how to contact Khatri Bhai as his number had changed, and we decided to meet Ranju, a very old friend of ours from our Lagaan days. She is a tailor and owns a small boutique in the market very close to Aina Mahal. We told her why we were back and the people we were planning to meet, including Khatri Bhai (whose name we had been given by Farhana), and whom we were not sure how to find. Ranju told us that she also knew Farhana quite well from the time she was living and researching in Bhuj, and also knew where Khatri Bhai lived, we could walk to his house from her shop. This we did, and saw a man walking in our direction, he was slim, tall and bespectacled, about 50 years old, it was Khatri Bhai. At his house we explained to him how we had come by his number. He was extremely happy to hear about Farhana and our meeting with her, and over chai we talked to him very briefly about our intended research.

\footnotetext{
${ }^{11}$ It is almost forgotten by people that the area known as Pakistan, during the time that we are referring to with regard to the Saint at Kalo Dungar would have been a part of the whole sub-continent known as India. However in local perception, being from Pakistan is associated with being Muslim, which in Prakash's mind, at this point, did not sit comfortably with his views about the Hindu aspects of Kalo Dungar.
} 


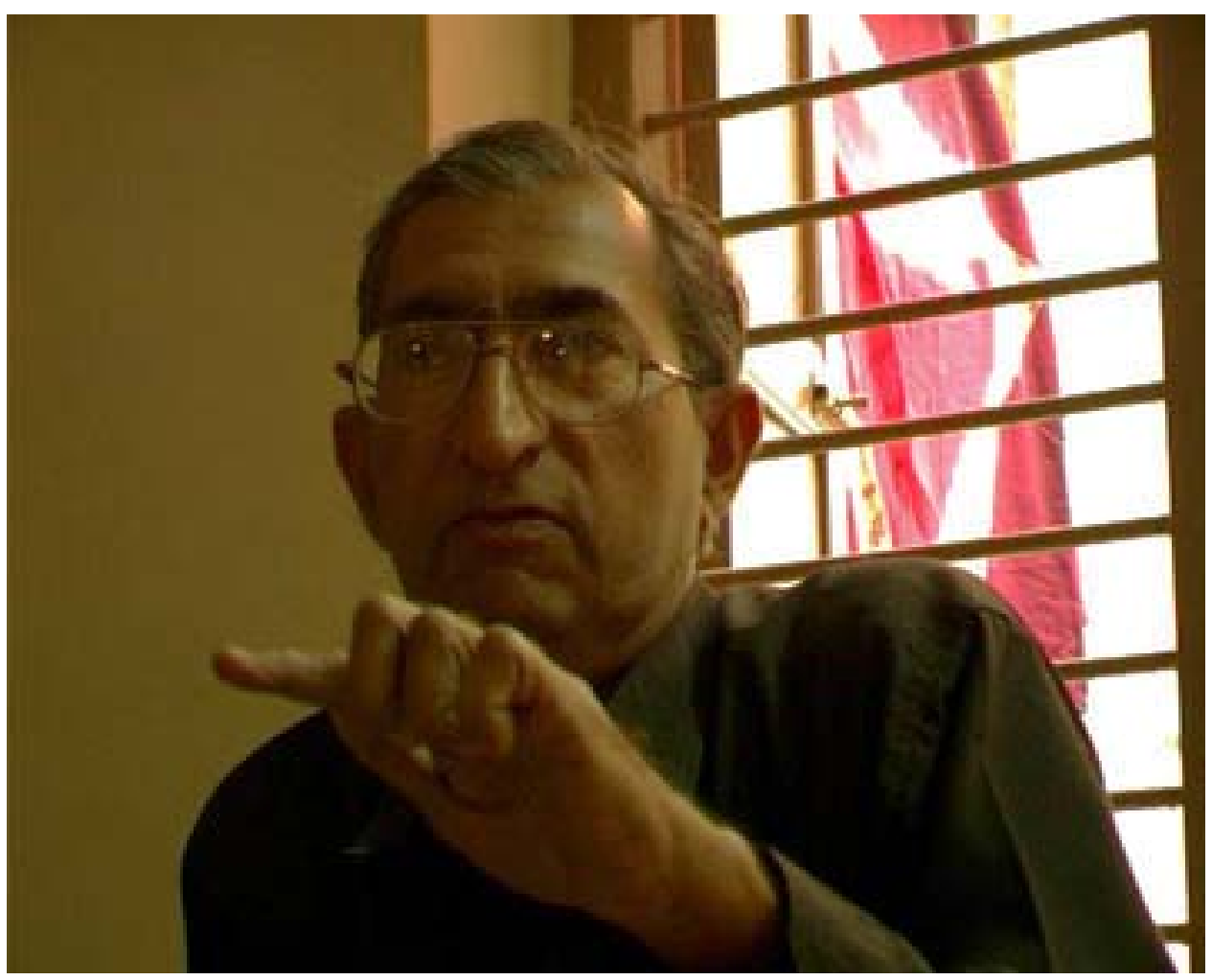

Fig.23.Khatri Bhai in his home, also see Black Mountain - Chapter 18.

We asked Khatri Bhai if we could interview him regarding anything he knew about Kalo Dungar and before we began if we could record his interview on camera. He was slightly shy and awkward about it, but in the end agreed. I was conscious of the presence of Prakash throughout this interview, as was Khatri Bhai, and my questions were cautious. He told us that it has been a site that people have visited for many years, and that there was a temple to Lord Dattatreya. I asked him if there had always been a temple to Lord Dattatreya on the site, and he agreed that there had been, but that his knowledge of the place was very little, and that it would be necessary to ask local people who lived in the vicinity of Kalo Dungar. He said too that he would like to think about it more seriously. Once the interview was over and the camera turned off, Amin expressed the view that I had asked a leading question. Even though I was aware that my questions had been weak due to the presence of Prakash, I had not realised that one of them was leading. And after an audible argument between Amin and myself, Khatri Bhai agreed that my questions had led him to agreeing that there had always been a temple to Lord Dattatreya on Kalo Dungar. I felt slightly embarrassed, especially given the presence of Khatri Bhai and Prakash, and a further discussion between Amin and myself ensued, regarding the possibility of a Saint called Pachmai Pir at Kalo Dungar and the dispute regarding 
whether the Saint was Lord Dattatreya or Pachmai Pir. This led Khatri Bhai, who interrupted us, to divulge the fact that there was some conflict of opinion regarding this site. At this point Prakash, who had been in the room throughout the interview and subsequent discussions, piped up, saying 'there you go Amin Bhai, please record that on camera'. He was referring to Khatri Bhai's comment regarding a conflict. However, it was obvious that Khatri Bhai would not repeat these words on record. For a Muslim like him it would not be sensible to do so, and he would probably not be comfortable speaking about any possible communal conflicts publicly, especially not on camera. However we realised at this point that we had met someone who could help us try to discover a different story ${ }^{12}$, if there was one, about Kalo Dungar. We asked Khatri Bhai if he would be able to think of anyone who might be able to shed more light on the subject. By this time, Prakash had calmed down (he had once again, become agitated during the discussions taking place) and Khatri Bhai told us that he knew of two people. One was a man called Lakhmeer, who lived in the village of Drobhana at the foothills of Kalo Dungar, and the other was Gofoor Bhai, who was a self-taught historian. Khatri Bhai told us that he was inspired with our subject, and our zeal in trying to find out more about Kalo Dungar and that he would like to help us. He said he would contact Gofoor Bhai and set up a meeting with him as soon as possible, and that if we wanted he would come to Drobhana to help us find Lakhmeer.

Before we left we asked Khatri Bhai what our financial arrangement would be with him, as we were well aware that helping researchers was now his livelihood. He told us that this was a new journey and a challenging discovery for him and that he would not want to charge us anything, we protested, but he insisted. We left agreeing that if our permits were arranged we would leave for Drobhana on Saturday.

As we were walking back towards the market and our car, I felt upset with Amin for arguing with me in Khatri Bhai's house, but was unable to talk about this with him as Prakash was with us. I had been unsure how to ask Khatri Bhai about Kalo Dungar in the interview, mostly because of the way Prakash had been behaving, especially towards the idea that Pachmai Pir might have come from Sindh, and with regard to

\footnotetext{
${ }^{12}$ See the beginning of Black Mountain - Chapter 18, for our first encounter with Khatri Bhai.
} 
our questioning of the presence of Lord Dattatreya on Kalo Dungar, something he had grown up believing. I felt his presence was becoming a bit of a hindrance; I felt guilty for feeling this as he had gone out of his way to help us at every step.

We headed straight for Ranju's place, sharing with her the developments of our successful visit to Khatri Bhai, and thanking her for her role in this. Amin decided it would be best if I stayed at the shop whilst he dropped Prakash home. When he returned to the shop, exhausted, he explained that it had taken him all the time he had been away to convince Prakash that he did not need to be with us throughout the day, or feel pressured to accompany us on any of our trips to Drobhana and Kalo Dungar. In order not to offend Prakash, Amin had agreed to a dinner at his home with his family, and a get-together at his house with all the Bhuj actors who had worked with us on Lagaan. I was relieved to discover that Amin too, had been feeling the pressure of Prakash's presence. As a Hindu and as a local, it is likely that his presence would prevent any Muslim or local person disclosing any information about Kalo Dungar other than Dattatreya. Finally able to talk freely, I explained to Amin that my questions to Khatri Bhai had been weak because I had felt very awkward about pressing for more information as I did not want to upset Prakash any more. Amin told me that one of the reasons he had started arguing with me in front of Khatri Bhai was to see if he had anything more to say regarding Kalo Dungar, as throughout the interview he had been very cautious. Amin had thought to himself that if Khatri Bhai realised our desperate need, seriousness and passion about discovering more about Kalo Dungar he might feel more willing to help us. Well, it may have been an unconventional methodology but it had certainly worked. The reverse psychology had definitely succeeded in producing more information, although I was not sure where exactly it fitted in to my ethical approach to the research process, however I let that pass.

During dinner we told Ranju about another man who we were supposed to meet called Wazir Bhai. She said he was a good friend of hers and that he was leaving for Bombay tomorrow. She offered to call him and he agreed to meet us at half past ten the following morning. We managed to set up a meeting with Dr. Rao too, for after our meeting with Wazir Bhai, and I also called Mr. Premod Jethi at the Aina Mahal museum to fix a meeting with him. 
When we asked Wazir Bhai about Kalo Dungar and filmed his reply of the history of the Saint that had lived there, he looked at us blankly. He had the same puzzled expression on his face, shared by most of the other people we had met when asked the same question. After a long silent pause, he, like most others, conceded that he had no knowledge of this particular person or place. We changed the topic completely and asked him about the word Pir that had been mentioned with regard to Pachmai.

Q: Where does the word 'Pir' originate from?

Ans: 'Pir' is a word used in Sindh, to address an elderly person, but its origins are Persian. 'Pir' is used for a spiritual person or an aged person. In Kutch 'Pir' is associated with a spiritual person. ${ }^{13}$

(Wazir Bhai, Bhuj 2006)

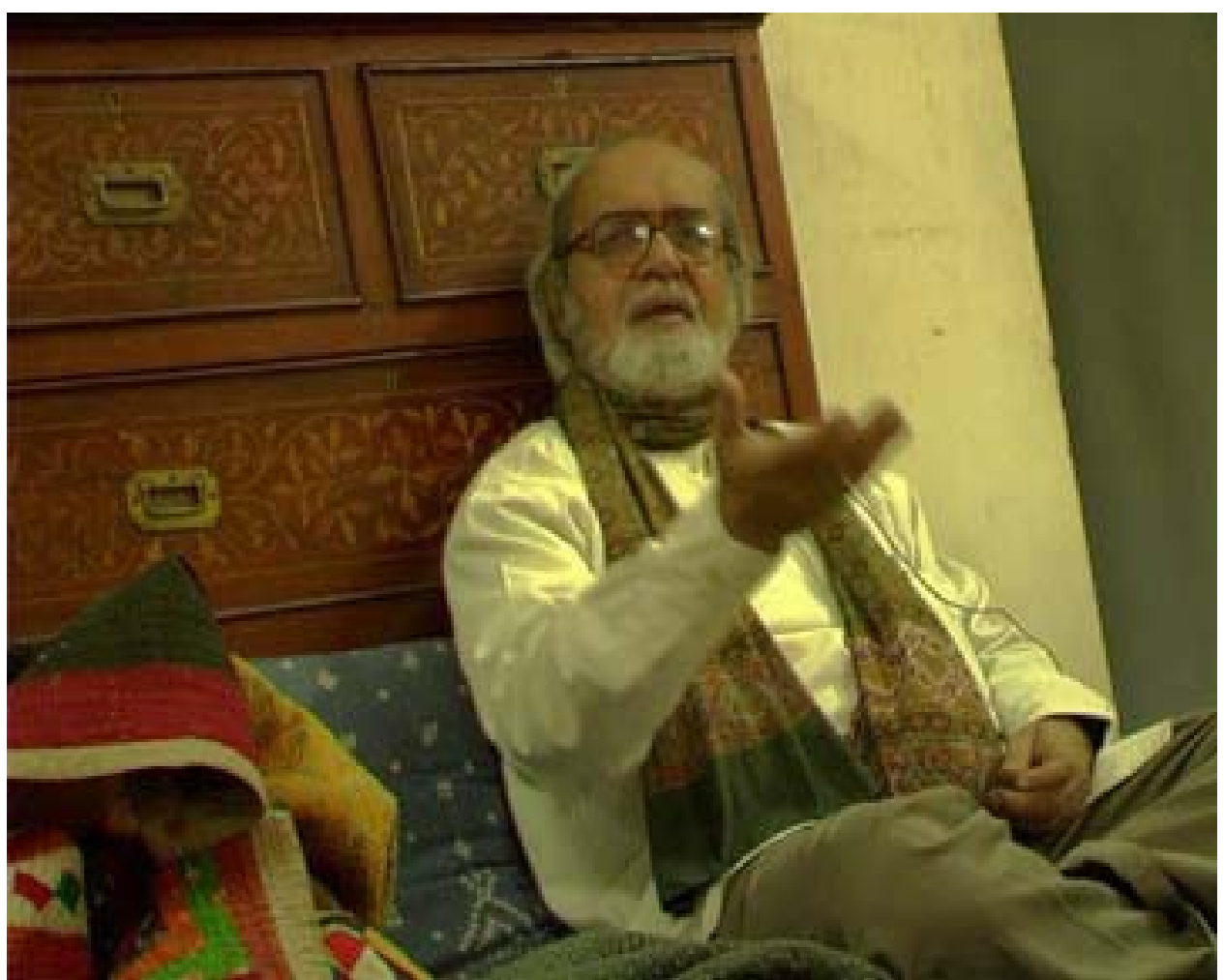

Fig.24 Wazir Bhai discussing the meaning of [a] Pir.

Pir was a term normally associated with a Muslim Saint, as it is a word associated with Persia and the Islamic region of Iran and Iraq, and it was important for the film that someone other than myself explained this. We left Wazir Bhai's house to meet Dr Rao. Dr Rao was as usual extremely busy and after a quick chat he said, 'come

\footnotetext{
${ }^{13}$ See Black Mountain - Chapter 14.
} 
on follow me to the collector's office, I can introduce you to him and then you can take it from there'.

We were called into the office and Dr. Rao introduced us to the Collector. He had seen Lagaan, and knew of Amin as Bagha from the film. The ice was broken immediately. We explained to him our reason for being in Bhuj and asked him if he could possibly grant us permission to travel to Khavda for my research, and for permission to use our camera, as part of my project was making a documentary film. The collector looked at us quite baffled and asked 'but why do you need permission? Why?' Amin and I knew from our past experience that we were often asked if we had permission to be in the area, especially when we were filming, so we persisted. Amin explained to him that when border officials or the police see a 'white face' armed with a camera they, for some reason, begin to ask questions. The Collector interrupted again and said

see in India people try to increase their authority by making up rules, actually the requirement for permission to many areas of Kutch has been abolished, and quite some time ago at that, however I understand your predicament and if you give me a letter requesting for permission I will give you a reply granting you the same.

(The Collector, Bhuj 2006)

Dr Rao quickly intervened and suggested that we go and get a print-out of a letter asking for permission, which we did and promptly dropped it back at the Collector's office. Next, we called Mr Vaidya, a historian and contact that Mr Umesh Jadia had given us the previous day. And then we made our way to the museum at Aina Mahal to meet Mr Jethi.
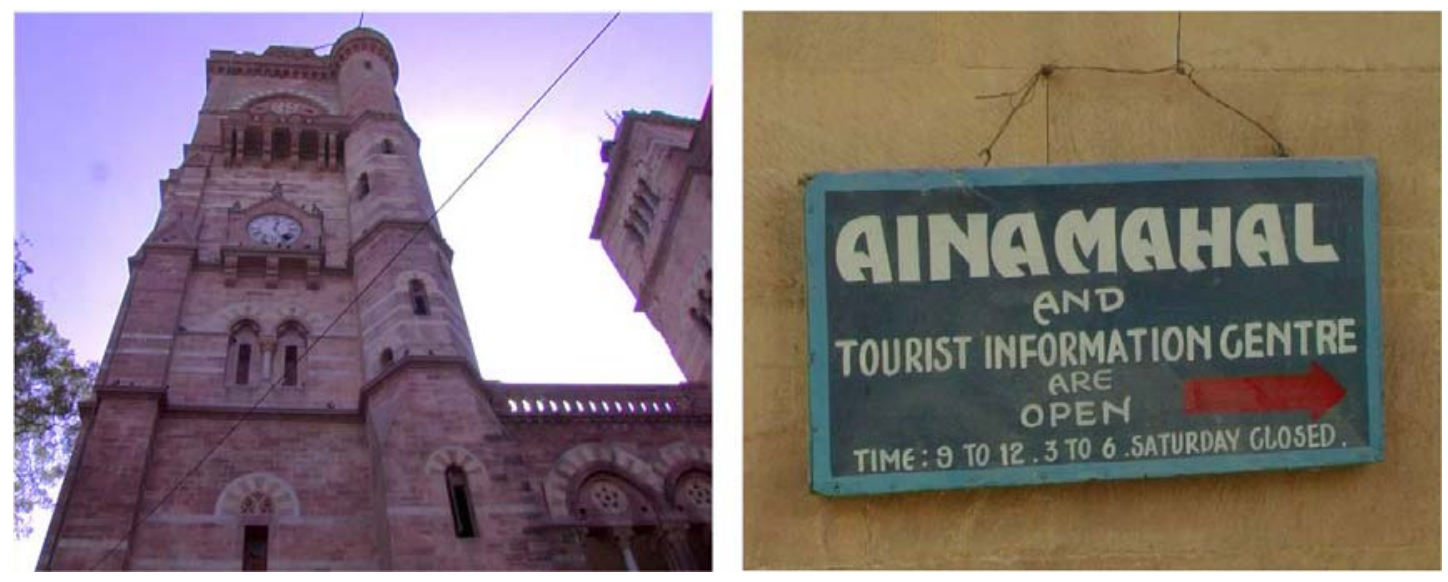

Fig.25. Pragmal Palace and Entrance board to Aina Mahal. 
We were about fifteen minutes late by the time we entered the museum. We removed our shoes before crossing the threshold when a man sitting behind a wooden desk with a glass top stopped us and gestured us to sit down, we were not completely sure who he was (he later turned out to be Mr Jethi). While we waited, I looked around and Amin began talking to the man at the desk telling him that we were trying to find out more about the pilgrimage place of Kalo Dungar. We got a surprisingly negative reaction: 'what is there to find out? There is nothing to ask. It was Lord Datta who visited there and stayed and that's about it'. We were a bit startled as he did not see the point of us trying to find out more about that place. Although we did not know him or his political preference we soon realised that his immediate reaction of 'Lord Datta', meant that more than likely he would not entertain any other possible history, at least that's what experience had taught us so far. After having gauged his standpoint regarding Kalo Dungar, our behaviour was a good example of being vague about our interest in the site, and we explained to him that we were researching pilgrimage sites, and Kalo Dungar was one of them. He was not very impressed and said that 'as far as importance, on a religious level goes, there are quite a few pilgrimage sites that would be considered more important than Kalo Dungar, so why Kalo Dungar?' We explained that we had once been on the pilgrimage to Kalo Dungar and had heard the pilgrims talk about a man, 'Lord Dattatreya' who used to reside on the hill and feed the foxes, and that we wanted to try and discover who the avatar was or rather the identity of that person. He insisted that it was a known fact that Lord Dattatreya was the one and only Saint to have lived or been worshipped at Kalo Dungar. I was quite taken aback by his reactions and realised that this was obviously not a topic he was very comfortable discussing, and he seemed to hold extremely strong views about it. At this point I had unfortunately boxed this man into sitting on the right of the political fence.

Amin continued to probe the man, and eventually he seemed to relax somewhat and we began chatting with him further regarding the museum and the earthquake. It was during the course of this extended conversation that Amin discovered that he was $\mathrm{Mr}$ Jethi. Slowly he began to warm to us further, we chatted to him about Azhar who had suggested that we come to meet him and we discussed our involvement with Lagaan and my previous visits to the museum. He too discussed his background, 
and his family's role in working for the royal family of Kutch. We were taken by surprise when after some time he asked if we were going to take his interview on camera, and said he would share with us the history he knew of Kalo Dungar with us.

We were happy to accept his offer and a more formal interview began, with him telling us, in English, about the legend of Kalo Dungar ${ }^{14}$.
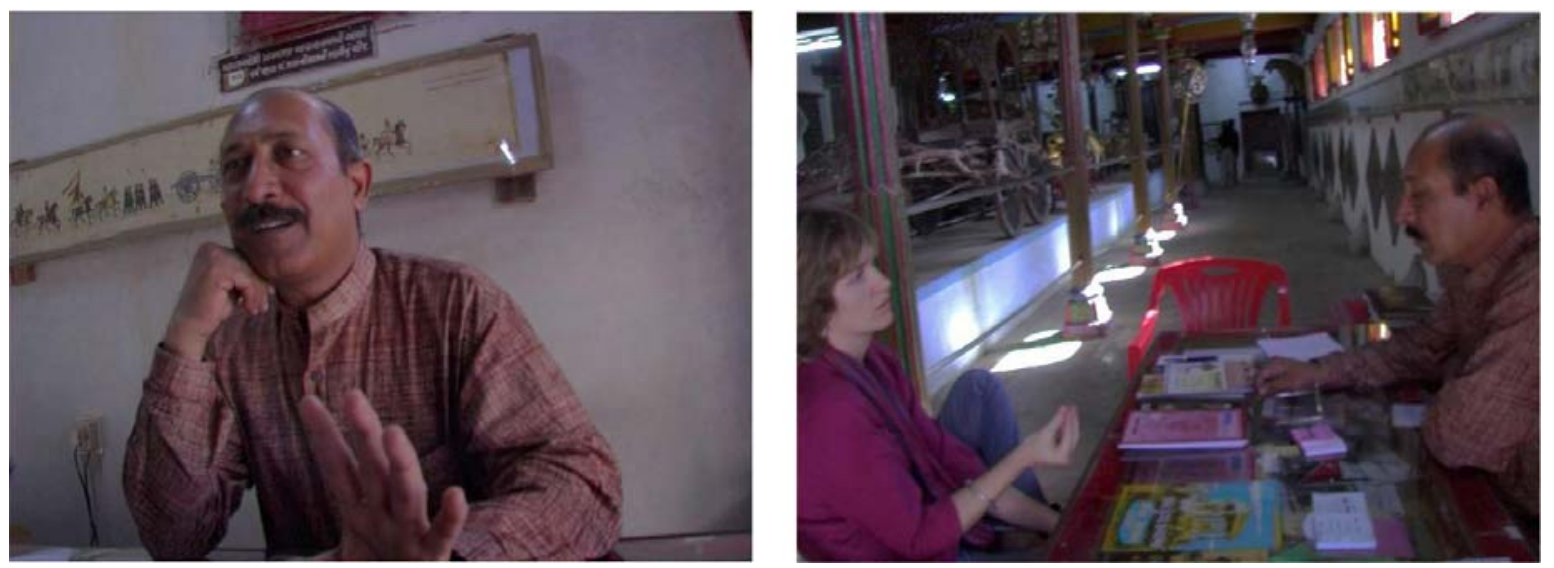

Fig.26. Mr Pramod Jethi, Mr Jethi and myself with the museum artefacts in the background

Actually in the Dattareya temple there was one Sadhu or holy man we can say. I don't know the name, but in that time he was feeding the everyday fox the food, but one time he had no food. That time he cut his body and it's called 'ley ung', 'ley' means take 'ung' means body, 'take my body' 'take my body', and it became 'long long'. So actually the fox name is not 'long' but it became 'ley ung' 'ley ung' 'long long'. So these are the actual words, that 'ley ung' means, 'take my body'.

(Pramod Jethi, Bhuj 2006)

After hearing the legend of the foxes, I asked Mr Jethi if he knew who the Sadhu was that he had mentioned.

That Sadhu, actually in history there is no evidence about this thing, history has only the legend story, and in Kutch like these there are many stories, but sometimes we can't get the name also. But there is a legend story, which means something, happened and somebody was there. That we can believe, somebody was there, but we don't know who it was or what his name was. So it's something in history, we can't answer for that.

(Pramod Jethi, Bhuj 2006)

\footnotetext{
${ }^{14}$ This interview can be viewed in Black Mountain - Chapter 16.
} 
I probed Mr Jethi a little further as to any other identity the Sadhu may have had:

No, No, we have no names also. If we are talking about the Kalo Dungar there is no evidence, no evidence you can say 'this name', you know. And it's called Pachmai Pir. Now you know, one other story is Pachmai Pir, so Hindu and Muslim both have worshipped the Pachmai Pir. Now Dattareya was there or maybe another God was there or maybe somebody was there we don't know. So Pachmai Pir or the Dattatreya is the same? The people will say it's the same, but when you say this 'what is the proof of the Pachmai Pir', we have no evidence. But this you have to find, maybe the some very old people, maybe in village, Sindhi people, they are living on that side, maybe they can give you, because actually story is from there. So what the local people from Drobhana say.

(Pramod Jethi, Bhuj 2006)

Azhar, who had given us the contact with Mr Jethi, had clearly said to us that he was a good friend of his, but humorously commented 'I could never work out his political stand, it always confused me'. I was experiencing something similar to this as suddenly Mr Jethi opened up regarding another side of the story of Kalo Dungar. His acknowledgment of Pachmai Pir was extremely exciting as was his mention of Drobhana, the village we were going to visit with Khatri Bhai over the weekend. Before we left I bought among other things, a copy of a book that Khatri Bhai had lent me, called The Black Hills of Kutch and a book that Mr Jethi had written himself based on his research in the area. I felt positive that Mr Jethi had opened up about another version of the story of Kalo Dungar; however, we both felt troubled too as we realised that trying to collect information about the ways in which the history of Kalo Dungar had been manipulated was a difficult task.

We made our way to meet Mr Vaidya, a local historian. After our initial introductions, we got straight to the point about Kalo Dungar; we did not elaborate on our research but explained to him that we were here to discover in what avatar Lord Dattatreya appeared at Kalo Dungar ${ }^{15}$. His response to our question came abruptly: 'Kalo Dungar is Lord Dattatreya'. It became clear, very quickly with $\mathrm{Mr}$

\footnotetext{
${ }^{15} \mathrm{Mr}$ Vaidya, as his name suggests, is a Hindu. Through our other interviews we had learned that a sensible ploy in asking about Kalo Dungar was to ask a general question about the history of the site, and if necessary accept the Hindu belief in the presence of Lord Dattatreya at the site and ask in what avatar he lived there.
} 
Vaidya, as it had with Mr Jethi, that mentioning politics or the political events we had experienced at Kalo Dungar would probably not be possible.

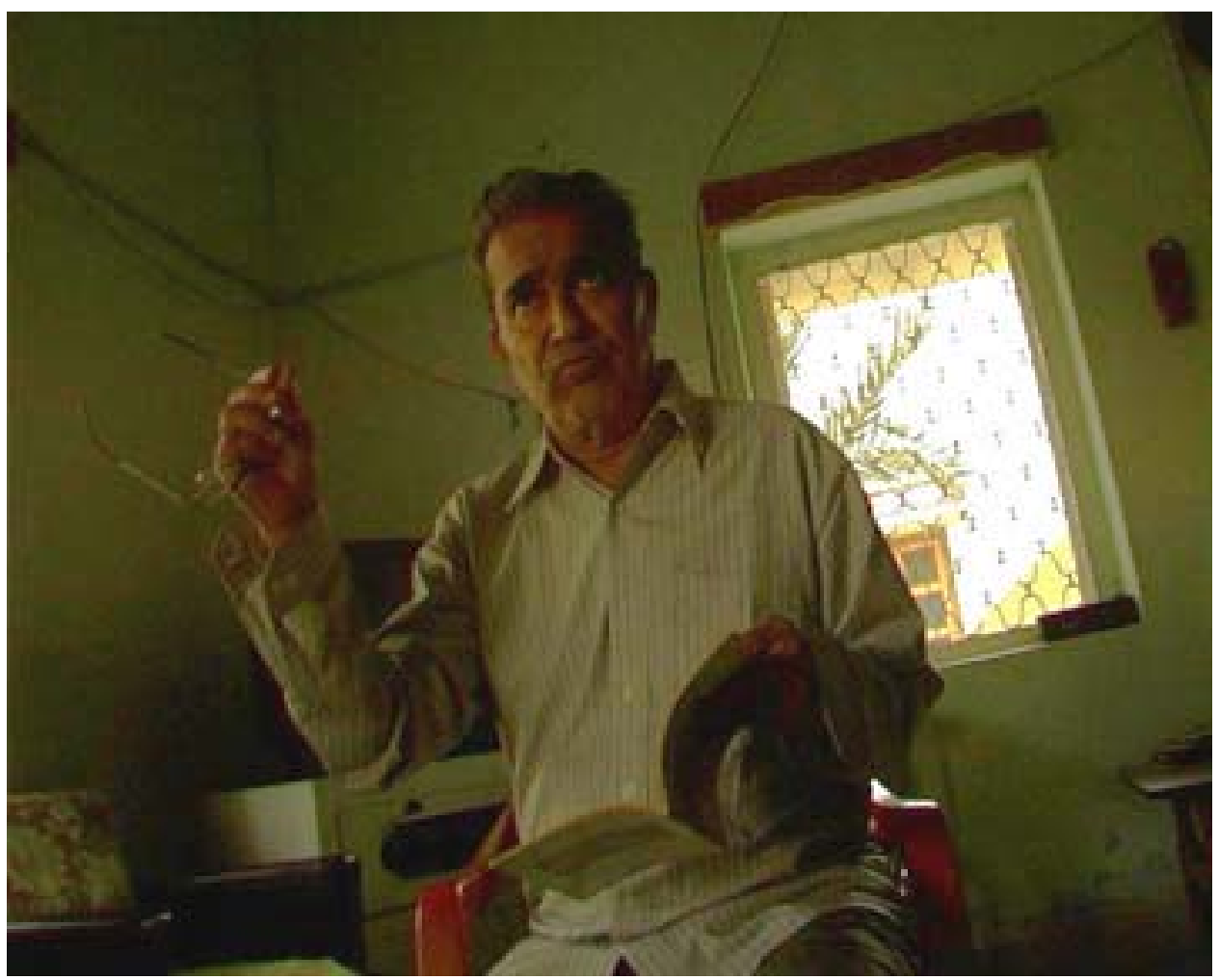

Fig.27. Interview with Mr Vaidya.

As mentioned earlier, the line phrase 'Kalo Dungar is Lord Dattatreya' said often in an aggressive manner, had become synonymous for me with a Hindu orthodox or even right-wing position. In this instance this reaffirmation of Lord Dattatreya at Kalo Dungar suggested a belief in the ‘Hinduisation' of Kalo Dungar and more than likely a belief in the Hindu right-wing ideology of creating a Hindu state ${ }^{16}$. The adamant way of affirming 'Lord Dattatreya' at Kalo Dungar, is almost a defensive position, conveying a sense of insecurity that the informant feels about discussing anything else regarding that site. Of course the same can be said of a Muslim informant, but their insecurity is in a completely different context. For example, Khatri Bhai took some time before he alluded to the possibility of anything else than Dattatreya at Kalo Dungar. His insecurity in discussing other histories comes from a fear that in suggesting something against what the right-wing political movements

\footnotetext{
${ }^{16}$ The ideology of the Hindu right-wing organisations in creating a Hindu nation is discussed in Chapter 3 -India's Pledge, and in the following Chapter 5 - Anti-syncretism.
} 
may be doing in the area, could cause him and his family trouble, even harm.

However, one could at least elaborate with a Muslim informant, and suggest through different questions, the possibility of other stories including the political aspect of the current situation at the site.

After the first negative reaction from Mr Vaidya, Amin went on to suggest that logically there should be some further history to Kalo Dungar, as with regard to Hindu philosophy, the Lord or God himself never appears in his original or Godly form but rather disguised in an avatar. Mr. Vaidya gave a perplexed reaction to this statement, and so we tried to explain further that, when we had joined the padh yatra (pilgrimage by foot) to Kalo Dungar, we had been told by some pilgrims that it was an avatar of Lord Dattatreya who had lived on Kalo Dungar while others just said Lord Dattatreya. We said that if there was an avatar of Lord Dattatreya we wanted to find out more about him. Mr Vaidya immediately launched into an explanation regarding the historic significance of Lord Dattatreya. When he finished we explained to him that we knew the history of Lord Dattatreya, having been told it by many pilgrims. Mr Vaidya, looked at us frustrated and said 'so then what is left to research?' By this point Amin's frustration had increased too and he said to $\mathrm{Mr}$ Vaidya: 'Who was that avatar who used to sit on the hill? What was his name and in what guise did he transcend from the heavens? Who was that man?' ${ }^{17}$ The interview as seen in Black Mountain - chapter 15 begins from this point with Amin asking the final part of his question:

Q: Who was that man?

Ans: Actually there is a story which has...I mean, eclipsed from my mind. But there is a story, who was that person, why he gave this away to a dying animal, to feed from his own body. There was some Rushi, Rushi you know, some ascetic, that much I can recollect, but actually it had appeared.

(Mr Vaidya, Bhuj 2006)

\footnotetext{
${ }^{17}$ At the start of this interview we had asked Mr Vaidya if he minded being filmed and he gave us his permission, but not all of the interview fitted into the film. However, without the earlier sections, it is not completely obvious why Amin's questioning seems so hostile and aggressive and why Mr Vaidya is seen somewhat indifferently flicking through a small book, in which he is trying to find some reference to Lord Dattatreya.
} 
Mr Vaidya got up and found a book which he spent the rest of the interview flicking through whilst talking, dismissively. He began talking about a 'Rushi' (a Hindu Sadhu or ascetic, to use his own words), and he mentioned the legend regarding feeding the animals, one aspect of Kalo Dungar that everyone agreed on. Amin continued to press Mr Vaidya about the 'Rushi' and told him the other stories we had heard about the site.

Amin: When we went back and told this [story of Lord Dattatreya and the legend] to our friend, that person said that this avatar, or this so called avatar was a Muslim Sufi, was a Pir, he was...

Before Amin could finish Mr Vaidya interrupted,

That is stretching too much. Because this is very long, from very long, Muslims arrived in India at about $8^{\text {th }} 9^{\text {th }}$ century, this is much before that. This is in our Puranas, so this can't be that you know. It is not possible, that's what I believe. Now the person...

Mr Vaidya in the quotation above suggests that the legend of Kalo Dungar was something from the Puranas. On reflection I am sure he was referring to Lord Dattatreya at this point and not the site of Kalo Dungar itself, as the legend of Lord Dattatreya as a deity is said to be mentioned in the Puranas or possibly the Vedas, which means he is a much older historical religious figure than a Pir could be in India. In other words, if Lord Dattatreya or his avatar had visited Kalo Dungar, then the legend, according to Mr Vaidya, would have occurred before a Pir (meaning a Muslim Saint) of any kind had even arrived in India. Amin pressed Mr Vaidya by making suggestions regarding the Pir's name, but did not say 'Pachmai Pir' directly, rather he started to say something similar; this was to see if Mr Vaidya was aware of Pachmai Pir himself, without being told by us directly ${ }^{18}$.

Amin: Someone says its Pesh...

Mr Vaidya: Imam

Amin: No Puncham Pacham Pir.

Mr Vaidya: Pachmai Pir.

Amin: Yes they are saying it's Pachmai Pir.

\footnotetext{
${ }^{18}$ Again, one can argue that there are ethical concerns to consider at this point. But this research situation has led us to understand that people were not willing to put forward the idea of Pachmai Pir on their own accord, but rather, after much probing, this name might surface.
} 
After this short probing by Amin, Mr Vaidya acknowledged the Pir, Pachmai.

Mr Vaidya: Pachmai Pir, yes, Pachmai means Western, 'Lord of the western side'. Now Pir does not connote necessarily Islamic connection, Pir is a big man, you are a Pir for me.

He had immediately dismissed the idea that Pachmai Pir connoted an Islamic connection; this seemed strange as neither Amin nor I had suggested that Pachmai Pir was a Muslim, but of course it is a well-known fact that a Saint with the affix of Pir was indeed a Sufi, and therefore a Muslim. This was perhaps why Mr Vaidya immediately dismissed this possibility, by suggesting that Pir purely connotes that the man was a 'big man'. Amin probed further by pointing out a contradiction that Mr Vaidya had made when even agreeing to the name of Pachmai Pir. Because earlier he had said that it could not have been a Pir, as the legend on Kalo Dungar existed before the Pirs arrived:

\footnotetext{
Amin: But then Pachmai Pir was very recent, they are saying Pachmai Pir is not before the $8^{\text {th }}$ ?

Mr Vaidya: He can't be before that.
}

The conversation had, by now, become quite confused, and Amin too was getting quite flustered:

\begin{abstract}
Amin: Ya, so they are saying, then...see what is happening, every time we meet somebody they say a different story. But nobody is actually sure about what it is. But everyone says, one thing they are all very sure about, is that it is Dattareya. But then if they are not sure about who the person is then how can they know it is Dattatreya?
\end{abstract}

In a roundabout way he was trying to make the point that there were no facts, and no one could say for sure that it was Dattatreya or anyone else at Kalo Dungar, so $\mathrm{Mr}$ Vaidya, in his response, backtracked from his first outburst at the beginning.

Mr Vaidya: Dattatreya, they have just a...they have put an idol there so people feel that it is Dattatreya. 
Realising that Mr Vaidya had gone back on his rather aggressive outburst at the beginning of our meeting, that 'Kalo Dungar was Lord Dattatreya and that was it', Amin questioned his position.

Amin: That means you cannot say beyond reasonable doubt that it is Dattatreya?

Mr Vaidya: But the thing is that - suppose if somebody else feels that it is something else does not matter, does not matter anymore. There are so many views, you can't say this is the right view. As you have observed, that it may be Pachmai Pir.

Mr Vaidya had a point. We learned from the previous chapter regarding the mystics of Islam, the Sufis, or the Ismailis for that matter that in many instances, people believed what they wanted from their legends, people even believed in the different identities that the Saints adopted. Amin kept probing:

Amin: Then somebody said it might be Menkan Dada.

Mr Vaidya: Menkan Dada, yes Menkan Dada, you know Menkan Dada is a reincarnation of Laxman, Lord Rama's brother, now these are very strange things you know. These are all legends, these are not the facts.

It was interesting here that Mr Vaidya identified Menkan Dada immediately with another reincarnation of a Hindu god, just like the legend of Lord Dattatreya. $\mathrm{Mr}$ Vaidya even suggested that all these 'legends' were not facts, but, he implied, mere stories. This is an unusual standpoint considering that most Hindu mythology is believed by many to be a reality; people believe that the Hindu Gods really existed and walked on Indian soil. To suggest them as not fact, as not reality, was something quite ground breaking. However Amin had one last question in response to Mr Vaidya's statement that all these legends are not facts.

Amin: Then how you said that it is Dattatreya [who was at Kalo Dungar] if it is only legend and not a fact?

This question from Amin had finally got Mr Vaidya's attention as he looked up from his book, for what seemed like the first time since he had opened it, and said:

Mr Vaidya: You see incarnation you know, that's what, it is all concept you know. Dattatreya never roamed in the bare, in blood and 
flesh. But then it is our belief you know, even for Ram or for any other God for that matter; it's all a concept. We have to believe and there is nothing wrong in believing. Because Ram, Ram was never born. Neither was Vishnu; they are all stories you know. Just to keep you busy and towards the legends or towards the good deeds. That is the main idea and therefore it is not bad as long as it does not hurt anybody else and it keeps you busy and you have no time to do wrong things...that is the idea. So you will find scores of legends. They are not reality.

I was surprised by this answer, he had just said that Ram or Vishnu were never born and that the point of these legends was to keep people busy and doing good deeds, and by doing that, they were not causing any harm to anyone. Of course he was right, the Hindu religion and its books are based on myths and legends, which on the face of it do no harm, and there is nothing wrong at all in believing in them or in the faith that is produced out of them. However, the legends and the mythology are being manipulated and that manipulation is definitely causing harm. The whole Hindu right-wing ideology stems out of the belief and manipulation of these legends. The Babri Mosque in Ayodhya had been demolished because of belief in Ram as a real entity, as the site was thought to be his actual birthplace.

After our interview had finished, a friend of Mr Vaidya's arrived at his house and we were introduced as people who were doing research into Lord Dattatreya. The friend himself was no more aware of Dattatreya then anyone else, but he immediately suggested that we would find it hard to discover very much unless we wanted to investigate folklore. He said that he was also a researcher; his subject was the wall paintings of Kutch and the stories they represent. It seemed pertinent that if Lord Dattatreya was in fact a deity worshipped throughout Kutch that this man would probably have seen drawings depicting him, as the tribal wall paintings are famous for reflecting religious belief, practice and socio-cultural information. We asked him if we could ask him a couple of questions on camera regarding Lord Dattatreya in Kutch and he obliged:

Q: Have you seen a picture of him [Lord Dattatreya] in your research?

Ans: No in my observation I have so far not seen any picture/wall painting of Dattatreya. 
Q: And you have been researching since?

Ans: Since the last five years I'm documenting wall paintings of

Kutch. So far I've not seen any picture/wall painting of Dattatreya.

It may not suggest very much, but at least as far as his research was concerned there was not much evidence of the worship of Lord Dattatreya in the district.

Incidentally, this was a stand that most local people agreed with. Lord Dattatreya had not been a deity commonly worshipped in local Kutchi religious practice.

During what had become a quite exasperating meeting with Mr Vaidya we had received a call from Prakash, who, upon hearing that we were at Mr. Vaidya's home, came to meet us. They were acquainted and when they met Prakash inquired as to how the meeting had gone. Mr Vaidya replied: 'your friend Amin is a monologue! He does not give people a chance to have a dialogue!' We realized that our questions had perhaps been too direct and maybe caused Mr. Vaidya some discomfort. Amin immediately apologised and explained that discovering who might have been the avatar of Lord Dattatreya was becoming a difficult task which sometimes left us frustrated. We left with us all in jovial mood and headed straight for the Collector's office to pick up the permission letter we hoped was waiting for us. After some more formalities we were given the letter, and we called Khatri Bhai to inform him that we could definitely go to Kalo Dungar the next day.

As we prepared for dinner at Prakash's house and the get-together afterwards, Amin told me that he had had a few sleepless nights over the engagement. He reminded me that some of the actors who would be present for the get-together were the very members of the Hindu right-wing party, the RSS, who had helped us remain a part of the pilgrimage to Kalo Dungar on our last visit, when the issue of Amin being a Muslim had been raised. He was worried that they would ask questions pertaining to our second visit, which might lead them to suspicions of our presence and this in turn would cause them to alert their RSS cardres. Looking back at the situation now, I realise that I must have conveyed my feelings to Amin that his reactions were completely paranoid. This had not helped his state of mind, as he exasperatedly explained to me, that I had no clue what we had got ourselves involved in by undertaking this research. He expressed his worries, and went over the story with me 
that he would narrate to the actors should they be too curious. In many ways I was shocked at Amin's suspicious and guarded attitude. The last few days I had been totally oblivious to all that he was feeling. And I was starting to realize that in India, due to the problems that have occurred in the past, the kind of insecurity and paranoia Amin was feeling was probably something felt mostly by the Muslim community who have lived within extremely aggressive and hostile environments, and been faced with constant prejudices, unlike that of any other community.

We had dinner with Prakash and his family, after which the rest of the guests arrived. They were excited to see Amin back in Bhuj, and it was not long before they asked us the reason for our return. Amin told them that we were back to find out a bit more history about Kalo Dungar as I was working on 'Pilgrimage in India', and more importantly, he was writing a script about unity and love shared between the Hindus and Muslims and how syncretism in shrines like Kalo Dungar had helped that. He told them that it was the love story of a Hindu boy and a Muslim girl. Everyone thought it was a fantastic idea and no one seemed to take any offence to our poking around the history of Kalo Dungar and, more than anything, were quite taken with the idea of another Bollywood blockbuster based around a story in Kutch. Amin was finally relaxed. Later in the evening Jagdish Bhai arrived; he heads the RSS unit of Bhuj, and to our great surprise he took us aside and gave us two DVDs of the footage that had been taken during the last two pilgrimages to Kalo Dungar, the ones we had missed. We had been asking him for this footage for the last two years and had almost given up; however here it was in our hands with Jagdish Bhai apologising for the delay! After an evening of reminiscing we excused ourselves due to our early morning arrangements with Khatri Bhai the next day.

Khatri Bhai was ready and waiting for us at the set pick-up point, co-incidentally opposite the same Swaminarayan temple in Durbar Gadh where we had started our pilgrimage two years ago. We stopped for breakfast on our way out of Bhuj during which time we gave Khatri Bhai a complete insight into our experiences at Kalo Dungar, about the pilgrimage, the politics and our problems. He listened intently and once we had finished, we told him that on knowing the facts, if he was not comfortable he did not have to continue on the journey with us. He thought about it 
for a couple of minutes before he answered our question. He said he felt it was a complex subject and that we had definitely stumbled upon a taboo topic, however he was very keen to help, as he believed that the antisocial elements of right-wing politics had definitely changed the fabric of the society he lived in, in a substantial and increasing way. We had an interesting discussion about the changing nature of politics in Bhuj; Khatri Bhai described the changing times, and the reasons why the Muslim community in Bhuj, and the Kutch district, felt more and more marginalized; he felt that since the genocide in Gujarat state in 2002, even though the riots did not reach Kutch, the politics in Kutch had changed and he described how he and his family felt more threatened. Then he said something that I will never forget. With a distressed expression on his face he said, 'one can say that the earthquake changed the geography of Bhuj, and the genocide the mentality'. I could feel the pain in his voice as he continued, 'I was born and brought up here. I can't say that we never had differences between the Hindus and us [the Muslims], but they were not unbridgeable ones. Now since the rebuilding of Bhuj, this town of ours has been ghettoised beyond repair'. The genocide in 2002 incited and spread hatred throughout the state of Gujarat and the earthquake gave the right-wing politicians an in-road into Kutch, a region that had previously escaped much of the communal hatred that has plagued Gujarat over the years.

After putting our cards on the table during breakfast we felt very positive as we hit the road that travels North towards the Great Rann of Kutch and Kalo Dungar. We kept filming along the eighty-kilometre drive. We reached Khavda at about lunchtime. As you enter Khavda there is a line of shops, some selling chai and we stopped at one of them. As I got out the car I covered my head with a scarf, as a mark of respect in the largely male gathering that was outside. Khatri Bhai was already making inquiries and establishing contacts with the local men around us. Some of the locals greeted him and they chatted, he was obviously a known face in this area. They spoke Kutchi amongst themselves, which is the local dialect - a mixture of Sindhi and Gujarati. Khatri Bhai managed to get some confirmation as to the current whereabouts of Lakhmeer and we headed straight for Drobhana, where we were told he lived. After Khavda there are a few small villages like Drobhana which are situated around the foothills of Kalo Dungar; the whole area is populated largely by Muslims. 


\begin{tabular}{|c|c|c|c|c|}
\hline State: Gujarat & District: Kachchh & & & \\
\hline Sub-district: Bhuj & Village: Drobhana & & Males & Females \\
\hline \multicolumn{2}{|c|}{ Area of village (in hectares) } & $3,687.59$ & & \\
\hline \multicolumn{2}{|l|}{ Total population } & 4,173 & 2,184 & 1,989 \\
\hline \multicolumn{2}{|c|}{$\begin{array}{l}\text { Scheduled castes population } \\
\text { (normally defined as Dalits) }\end{array}$} & 169 & 88 & 81 \\
\hline \multicolumn{2}{|c|}{$\begin{array}{l}\text { Scheduled tribes population } \\
\text { (normally defined as Adivasis) }\end{array}$} & 0 & 0 & 0 \\
\hline
\end{tabular}

Fig.28. Population Composition of Drobhana. Source: Census of India 2001: accessed 9/12/2007

Unfortunately exact details on the religious makeup of this village, or any specific village for that matter in Kutch, are not available in the Indian Census, there is only a general religious breakdown given for the district (as illustrated in Chapter 4). So it is impossible to say how many of the 4,173 population are Muslim, however, as illustrated, the scheduled caste population, which is generally defined as the Dalit population, is relatively small in this village, compared to that of Khavda which is stated as 484, and the tribal community is zero compared to 1000 in Khavda. According to the census the village of Drobhana spreads over a larger area than Khavda and the population is larger than that of Khavda, which stands at 3,203.

\section{Drobhana}

Once we reached Drobhana we stopped at a small shop at a junction, and asked for Lakhmeer's house (Fig.29 below).
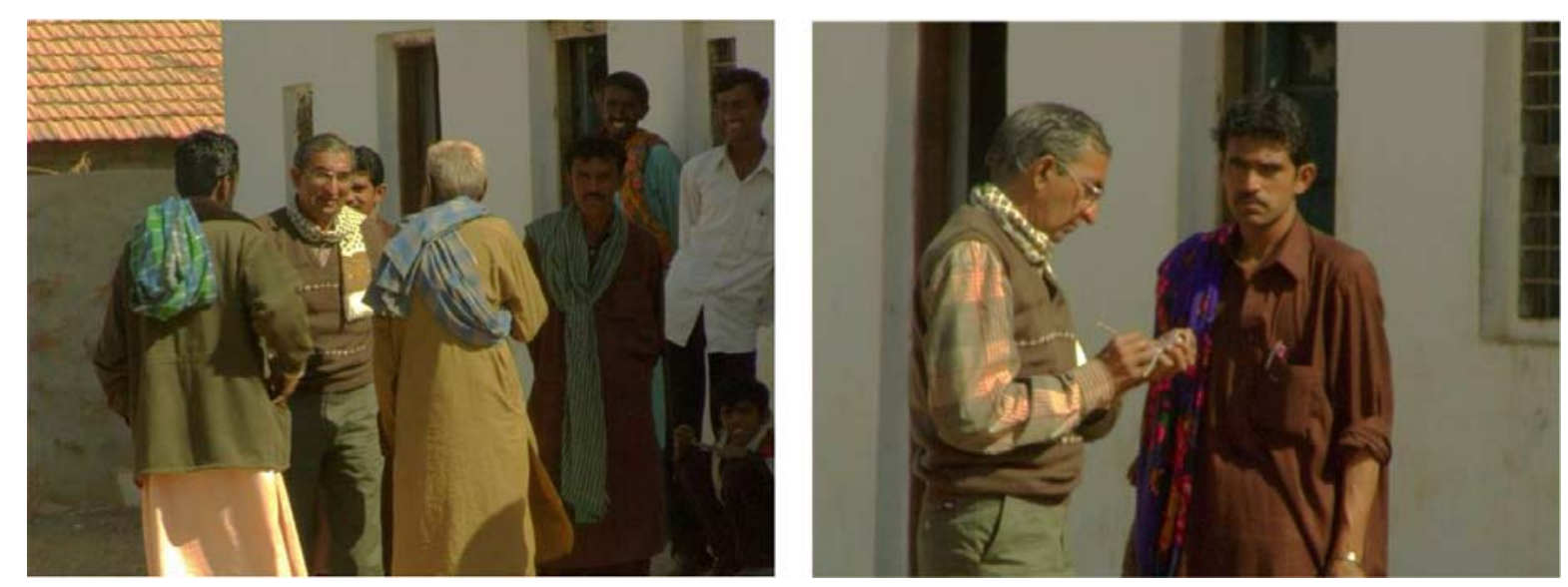

Fig.29. Khatri Bhai asking for Lakhmeer at the local village shop. 
Someone wearing a traditional Pathani suit in royal blue with the local headscarf around his head told Khatri Bhai to sit on his bike so he could take us to Lakhmeer's house and we followed in the car.

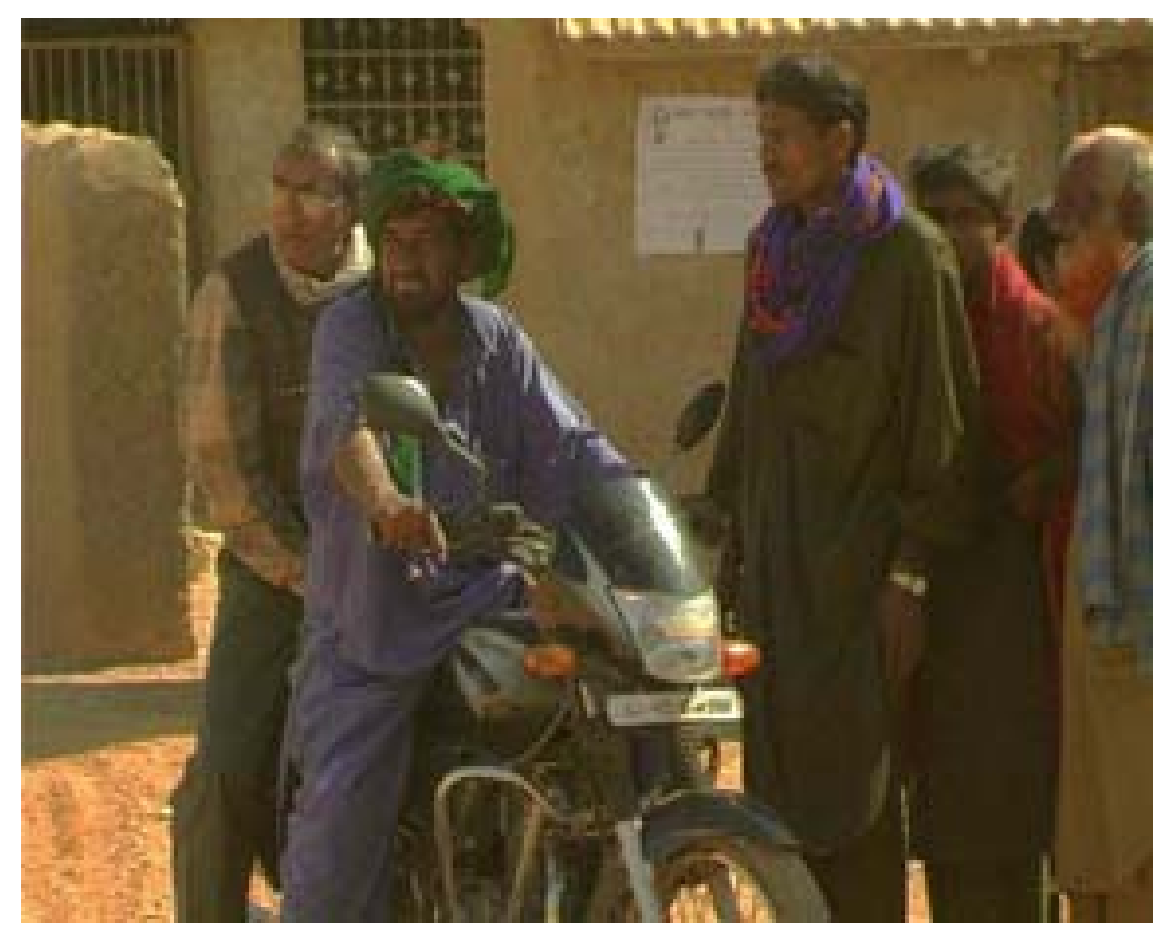

Fig.30. Khatri Bhai sitting with Amar Mehraj Sama who led us to Lakhmeer's house.
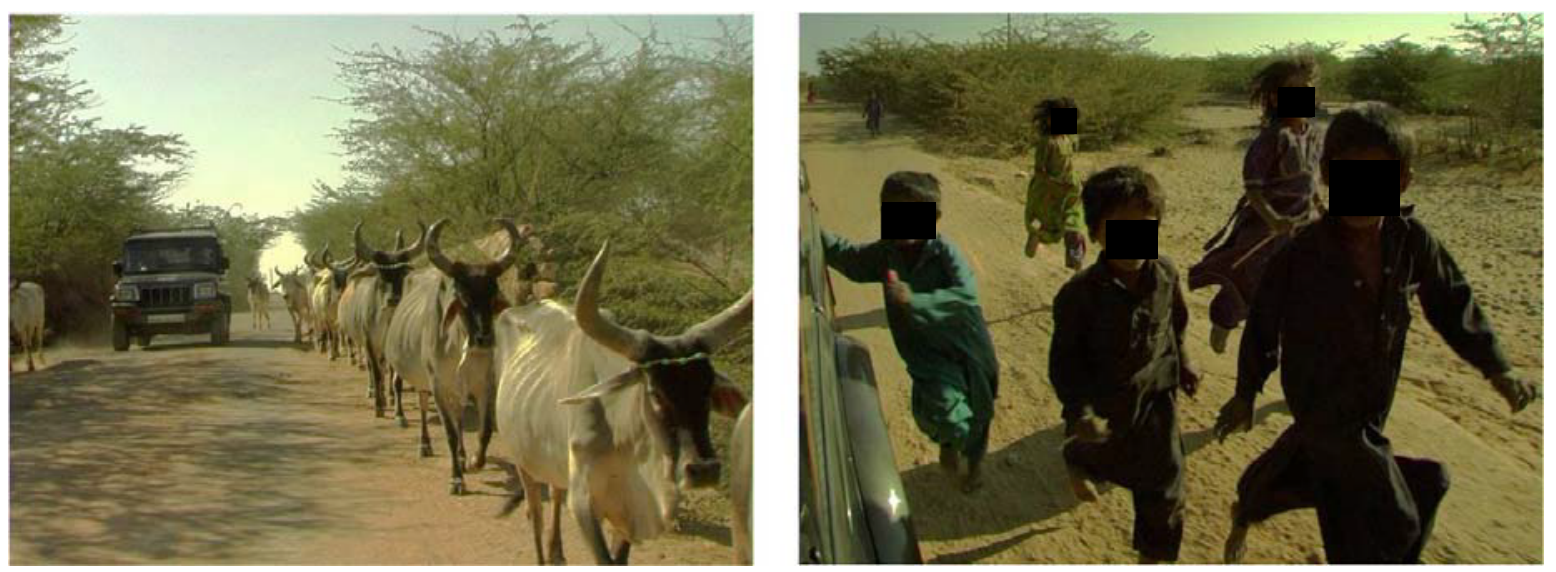

Fig.31. Driving to Lakhmeer's house.

It turned out that he was Amar, Lakhmeer's brother. Khatri Bhai knew Lakhmeer from when he used to work in the State Bank of India, in Bhuj. We parked the car and Lakhmeer led us into the courtyard of his house; Khatri Bhai excused himself as he wanted to go to the local mosque and give Namaaz. In the courtyard Lakhmeer 
and Amar put out khatlas and covered them with beautifully stitched patchwork quilts.
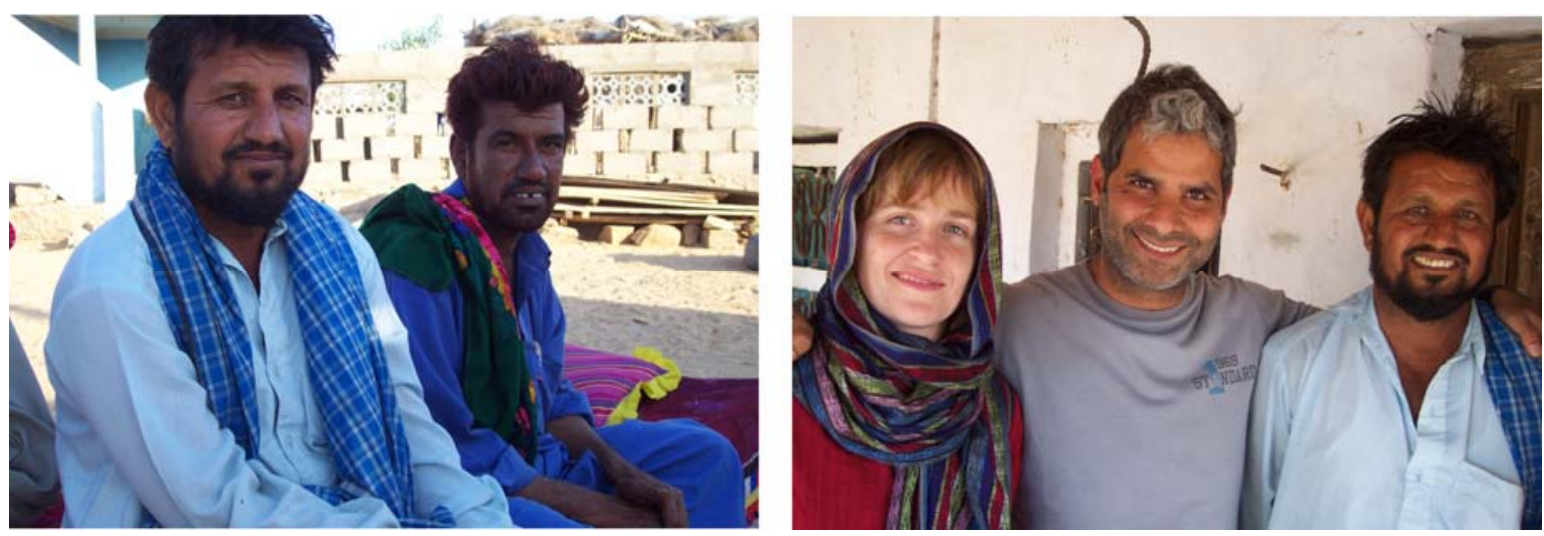

Fig.32. Lakhmeer and Amar Mahraj Sama and Lakhmeer with Amin and myself.

Khatri Bhai returned and we were sitting comfortably on the khatlas talking with Lakhmeer and his brother Amar. Amin began to explain our research to the two brothers; he told them that we were trying to find out about the history of Kalo Dungar and the man that, we had understood, used to live on the hill. They both reacted instantly, and for the first time, compared with our previous interviews, positively. They began telling us immediately what they knew about the man who had lived on Kalo Dungar. For the first time since we had started this research and interviews we had met someone who did not look perplexed and quizzical at our question regarding Kalo Dungar's history. Amar, in fact turned out to be the more talkative of the two brothers and we realised he had a story to tell, so we requested him to pause and asked them if they would mind us recording their interview. They were happy to oblige and I quickly set up the camera on my lap and we began the interview. Amar explained that he had never met or seen the man who had lived on the mountain and the story he knew had been narrated to them through generations, down the ages. Amin began the interview by asking his name ${ }^{19}$

Q: Please tell us your name, your age and a little about yourself? Ans: My name is Amar Meharaj Sama, I'm around 40 years old. Earlier we used to stay on the mountain you know where 'Pachmai Pir' is, next to it we had 200 goats that used to graze there. We know from our ancestors that we, the Samas, were originally from Pakistan. And even we were initially Jadejas, Hindus.

\footnotetext{
${ }^{19}$ This interview as well as Lakhmeer's interview can be seen in Black Mountain - Chapter 18\&19.
} 
It is interesting to note in this first anecdote, references to local history. In Chapter 4, a brief reference was made to the nature of the border between India and Pakistan and specifically, in this region, to the border between Sindh and Kutch. Amar associates his history with that of Pakistan, not even established at the time to which he is referring. What he in fact probably means is that his ancestors were from Sindh (now situated in Pakistan). However, it would seem that the feeling of belonging to an ancestral history that finds its roots in Pakistan was important. Perhaps it is this association with Pakistan that the right-wing Hindu organisations feel threatened by when they state, in their propaganda, that all Muslims should go back to Pakistan, as if this is where they were always from.

A brief history as to the development of the Samas is given in Chapter 4, however, in the Gazetteer of India, Gujarat State, Kutch District 1971, they are classified as 'cultivators, cattle breeders and dealers', following 'social customs similar to those followed by other Muslims'. Described as Sunni Muslims by faith, they are recorded as living in two areas, 'the Samas of the west [who] keep their Hindu bards and have also spiritual guides, pirs. [And] those in the east [who] honour the ordinary Maulvis’ (1971:Chapter III:137).

That said, Amar continued to tell us about the history of his ancestors. Amin asked whether Jadeja was the tribe that his ancestors belonged to originally before their conversion.

Yes, our tribe departed from Pakistan by camel, and were headed towards this area. On route they met him, and asked him which place would be good for them to settle down in. So that man gave our people a branch.

Q: Who gave the branch?

Ans: That Pachmai man, the man on the hill, he handed them a branch. He said, "Take this branch along with you", he said, wherever you stop for the night, plant this stick in the earth and leave it there. By morning if leaves have appeared, that is where you should settle. So they did as they were told, and the next morning the stick had sprouted leaves. From that day on our people took it upon themselves to prepare food for Pachmai Pir and would take it up to him. $10 \%$ of fruits or whatever else that was harvested in our fields would be kept aside as his share, and offered to him [Pachmai Pir]. Initially on the hill there was an open-roofed structure. And on the floor below were the imprints of feet on a stone. That was all that was there, then they broke that structure, in 1980 I think. Yes it was 
in 1980 and I saw them erect a temple in front of my very own eyes. Before that there was a Gombus (dome) like [structure] and imprints of feet. And next to it was a little Mosque, just like ours is, like people built in the olden days. We used to live up there and have spent a lot of time there. At least fifteen to twenty years. Near there is a sumdah [water-hole], we used to stay there and graze our goats. Only now they have renamed it 'Dattatreya', since the last four to five years. Because we were aware of the facts, when they changed the name we opposed them. When the baniyas [local business community] changed the name, we said it is written in our history that Pachmai is the Pir of the Samas. And he belongs to the Samas, no one else. But they changed the name and made it 'Guru Dattatreya'. We moved to court and wrote, our [Pachmai] Pir was ours, we will not object if you believe in him [or not], you can pray to him, ask him to fulfil your wishes, do whatever you please, but please, do not change the name. So they agreed they would not change the name.

It must have been around the year 1930, I may not be accurate, but around 1930 a Maulvi [Muslim leader] named Abdarahim arrived from Pakistan. Until then we used to stay on top and worship Pachmai, but after his arrival, Abdarahim informed us that to worship a man was not the right thing to do. He told us to stop that practice, to offer namaaz and worship only the Almighty. When a new person says something, not everyone listens. Initially only $25 \%$ felt he was right and took his advice. But over time most of our people stopped worshiping there. The Meghwars, Thakkars, Harijans and Baniyas who used to frequently worship there too, continued to go up to the hill.

When the Pir had passed on, once a year during Badrav, we would all go up to the hill, and on the first Monday after sighting the full moon we would all have a fair on the hill.

(Amar Meharaj Sama, Drobhana 2006)

We were somehow not surprised by Amar's interpretation of the history of Kalo Dungar; there had to be some reason why the VHP had taken such an interest in the site. In fact Kalo Dungar, as I later discovered from archival research, is alluded to as Pachmai Pir on a number of occasions especially in the old British records kept in the form of Gazetteers. For example, James Campbell in the Bombay Gazetteer as far back as 1880 mentions 'Pachham Pir' as 'the highest point in Cutch, 1437 feet above the Ran'. He then talks about the island of Pachham but not the Saint himself (1880: Chapter 1-p14). Later on, however, in 1971, the Gujarat State, Kutch District, Gazetteer of India, talks about Pachmai Pir in more detail. In the section sub-titled 'Saints and Pirs', Kutch is described as a place: 
fortunate in having a number of Saintly persons who served the people of this land irrespective of cast or creed. Motivated by the service to humanity, they moved from place to place... and impressed the people by their preachings and Saintly character (1971:142).

It goes on to state that the followers of these Saints and Pirs were 'people from all strata of society including Harijans and Muslims' even more importantly however, 'the most notable among them were Dada Menkan, Guru Dharamnath, Haji Pir, Pachmai Pir and Jesal-Toral (op.cit.142/3 emphasis is my own). Pachmai Pir is mentioned as one of the most notable Saints of the district, and he and his counterparts are then described in more detail.

Pachhmai Pir, so called from the Pachham area was associated with the early rulers of Kutch. He came from Sindh and settled on Kalo Dungar or black hill, the tallest in Kutch. He is identified with Dattatreya, because like Dattatreya he had with him a jackal who was his constant companion in his mission of serving the people. His footprints are still worshipped on the top of Kalo Dungar. This Hindu Pir is worshipped by both Hindus and Muslims. According to a curious custom, jackals are offered sweets by the temple priest on a particular day and if they do not appear it is considered an ill-omen. As there are no roads, pilgrims visit the shrine on camel. The lamp lighted daily on the hill can be seen from Khavda, a long distance away. Before partition people from Sindh also used to come to pay their respects to the Pir (op.cit.144).

This description of Pachmai Pir is most significant, primarily because he is identified quite clearly in a government document, which to some degree verifies his existence at one time in history, in addition to the local oral history that we received from Amar and other Sama villagers. And secondly because the Saint is described as a Pir, denoting an Islamic origin, unlike the other Saints with which he is grouped (apart from Haji Pir), who can be identified by their names as coming from a Hindu lineage. Thirdly, it is most interesting that in 1971, Pachmai is associated with Dattatreya, however, this association is made purely due to his association with animals, and the jackal, the legend of which we have heard on numerous occasions. But the association with Hinduism does not end here, as in the next line he is described as a Hindu Pir - something that I am not sure is even possible, as the very origin of the word Pir, as we learned from Wazir Bhai earlier in this chapter, and from the previous chapter, is derived from Persian. It was only Mr Vadiya who 
made a point of saying that a Pir did not necessarily mean a Muslim. However, going on the literature available and the most common definition of this word, I would have to disagree with this point. In 1971, obviously the road to Kalo Dungar had not been built, and it is an interesting reference to confirm that this Pir was worshipped by people from Sindh before Partition; something that Amar's account also suggests. Amar's account of the history of Pachmai and the Sama forms a base that was consistently reaffirmed by other villagers through the day.

Amar's brother, Lakhmeer, whom we had originally come to meet, spoke next.

Q: Please tell us your name, your age and a little about yourself?

Ans: I'm Lakhmeer Meharaj Sama.

Q: Even your name is Meharaj Sama?

Ans: He is my brother.

Q: Younger or older?

Ans: He is younger than me. May I add something to what my brother has said?

Q: Ok, what is it you want to add?

Ans: In all Dargahs [mausoleums] that exist, whether Hindus or Muslims believe in them, the person buried there will be a Muslim. Dargahs do not exist in Hinduism. His name was Shah Darus Hussnani he was a Muslim, but they addressed him as Pachmai Pir. Pachmai means 'from the West', and a Muslim Saint is addressed as Pir. As a symbol of his continuing presence, his descendants had used a stone, that had embedded upon it imprints of Pachmai Pir's feet, created where he used to stand while he prayed five times a day.

Lakhmeer confirmed his brother's story, however he too, reemphasised the point that, firstly, dargahs in general are associated only with Islam and not Hinduism; there was no Dargah at Kalo Dungar as Pachmai had obviously not died there, however his point is that the practice of venerating a Dargah or Pir is of Islamic origin, and he reconfirms the point that a Pir is a Muslim Saint. Another part of the story he added to was that Pachmai Pir was in fact Shah Darus Hussnani, this was a name we had not heard from anyone else until now. The other part of the story he reconfirmed was that of the footprints. I did not remember seeing any footprints at Kalo Dungar when we had visited, one can only assume that this practice has ended and the footprints are no longer present. 
Our interviews with Amar and Lakhmeer gave us more than I had imagined, for the first time since we had come to Bhuj we had heard a different name than Dattatreya, in fact we had two, Pachmai Pir, who, according to Lakhmeer, was a man by the name of Shah Darus Hussnani. After talking for a bit longer with both the brothers, we walked around the surrounding areas of their village, meeting the local village children. We took photos of them and showed them to them on the LCD screen. Cameras are commonplace in many parts of India now, but deep in rural India the excitement had by children, and even adults at times, as they witness themselves on a LCD screen of our camera never ceases to amaze.
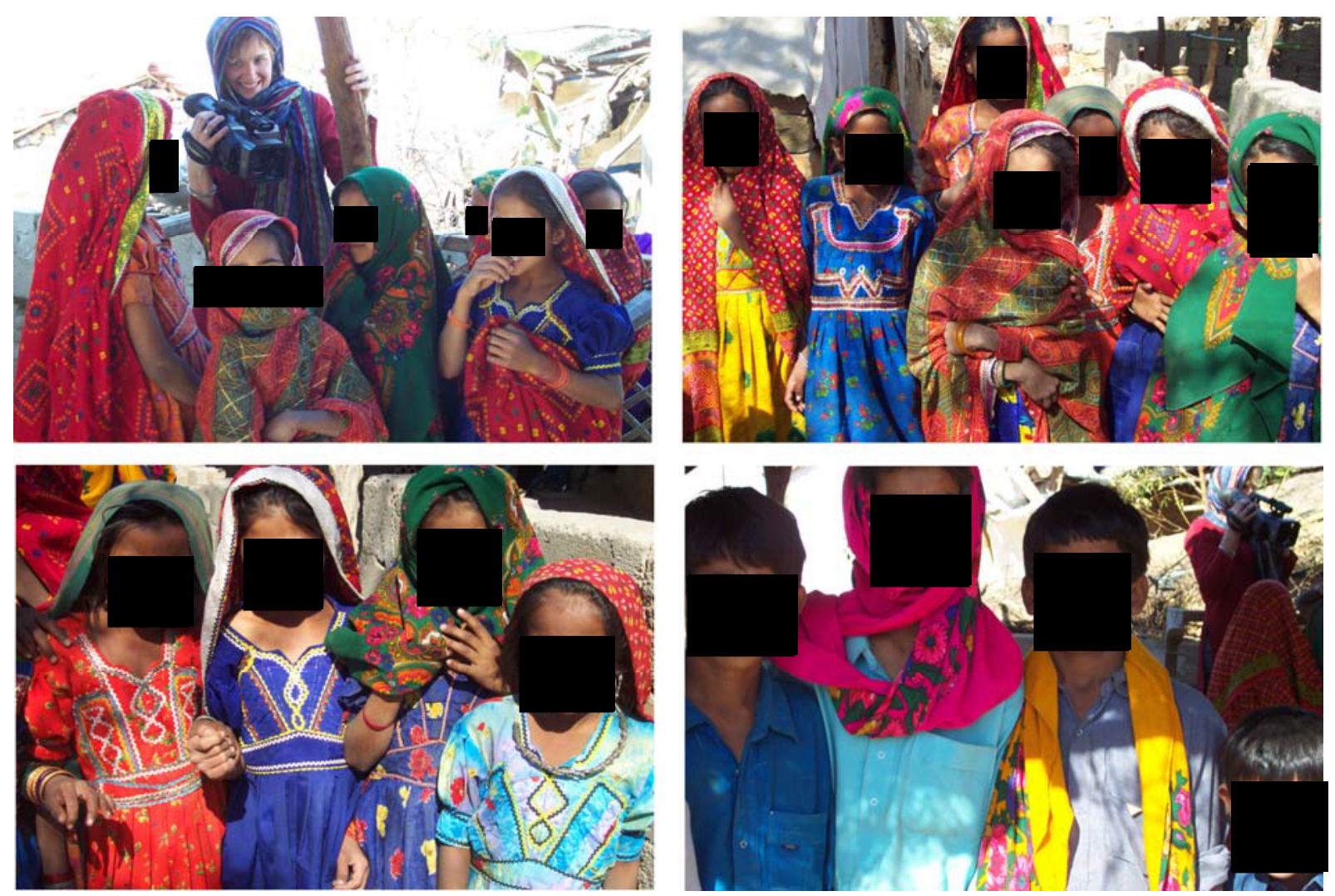

Fig.33. Children in Drobhana near Lakhmeer's house. 
On our return to Lakhmeer's house we found that lunch had been prepared for us.
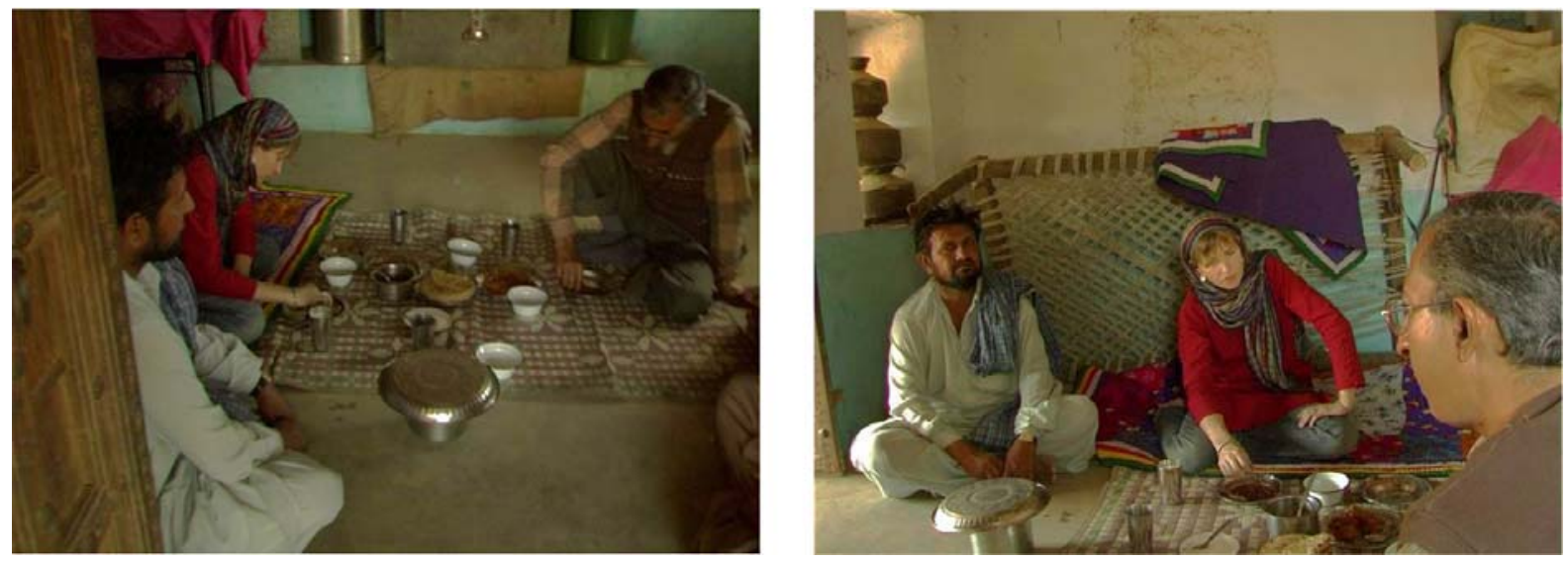

Fig.34. Lunch at Lakhmeer's house.

During the interview with Amar he had told us about a man who lived in Drobhana called Ummer Bhai, he was over 90 years old and Amar thought he would surely have more information on the history of Kalo Dungar and Shah Darus Hussnani. While waiting for Ummer Bhai, we decided to go up to Kalo Dungar to see if there was any further information we could collect, as well as being able to film further footage of the temple and surrounding buildings. Two of Amar's nephews joined us in the car. On the way up the mountain, we stopped a number of times to take footage of the jeep and the approach road to the top ${ }^{20}$. This time from the top of Kalo Dungar the view of the Rann seemed clearer and even more beautiful, and through our binoculars we were able to see what is known as 'India Bridge', the last check post before the border. There were just a handful of people milling around, unlike the last time we were there, so we were able to walk around the temple and view the idol of Lord Dattatreya more clearly as well as the Dharamsala. Things looked much the same as they did before, only building construction was completely finished. Up by the temple we spotted a Sadhu who was living at the complex, he was dressed in traditional saffron robes with an extremely large pair of sunglasses, they were black and I thought that maybe he was blind. We approached him and asked him if he would mind talking to us, at this point his mobile phone rang and we stood at the doorway to his room. On putting down the phone he told us in no uncertain terms to leave and talk to the temple manager if we wanted any further

\footnotetext{
${ }^{20}$ Just as we had predicted we were stopped by some plain-clothes police officers who asked us for our permit to be in the area but when we produced it we did not have any problems.
} 
information. After this encounter we didn't feel very comfortable about staying longer and decided to go back down to Amar's home and try locating Ummer Bhai.

On the way down from Kalo Dungar a car passed us heading back towards the mountain top. The young boys who had accompanied us recognised that the man travelling in the car was Mukesh Zhaveri, primary financer of the temple construction at Kalo Dungar and a local MLA (Member of the Legislative Assembly) for the BJP. Impulsively I felt that we should turn around so that we could go and meet him, this was met with a rather cold reaction by everyone (remember I was sitting in a car with people only from the Muslim community). And Amin reminded me rather sarcastically that it would not really be a good idea to go and try and interview the man, a fierce right-wing politician, obviously instrumental in the redevelopment of the site, with a car full of local Muslims, asking questions about the changes at the site. This is another example of how being with Amin affected some of the avenues of information that might have been otherwise available to me.

When we arrived back at Amar's house, Ummer Bhai was unfortunately not to be found, but instead of him Amar had arranged for someone else to talk to us - Hussain $\mathrm{Ali}^{21}$. One more khatla was brought and he took a seat opposite us. Amar brought tea out for us all while Amin, with Khatri Bhai’s help, began asking the old man about Kalo Dungar in the local language of Kutchi. He spoke directly and to the point, and at times was quite humorous in his idiosyncrasies, making Amar, Lakhmeer and the others around us smile.

${ }^{21}$ This interview can be viewed in Black Mountain - Chapter 19\&21. Where the character of Hussain Ali can be fully appreciated. 


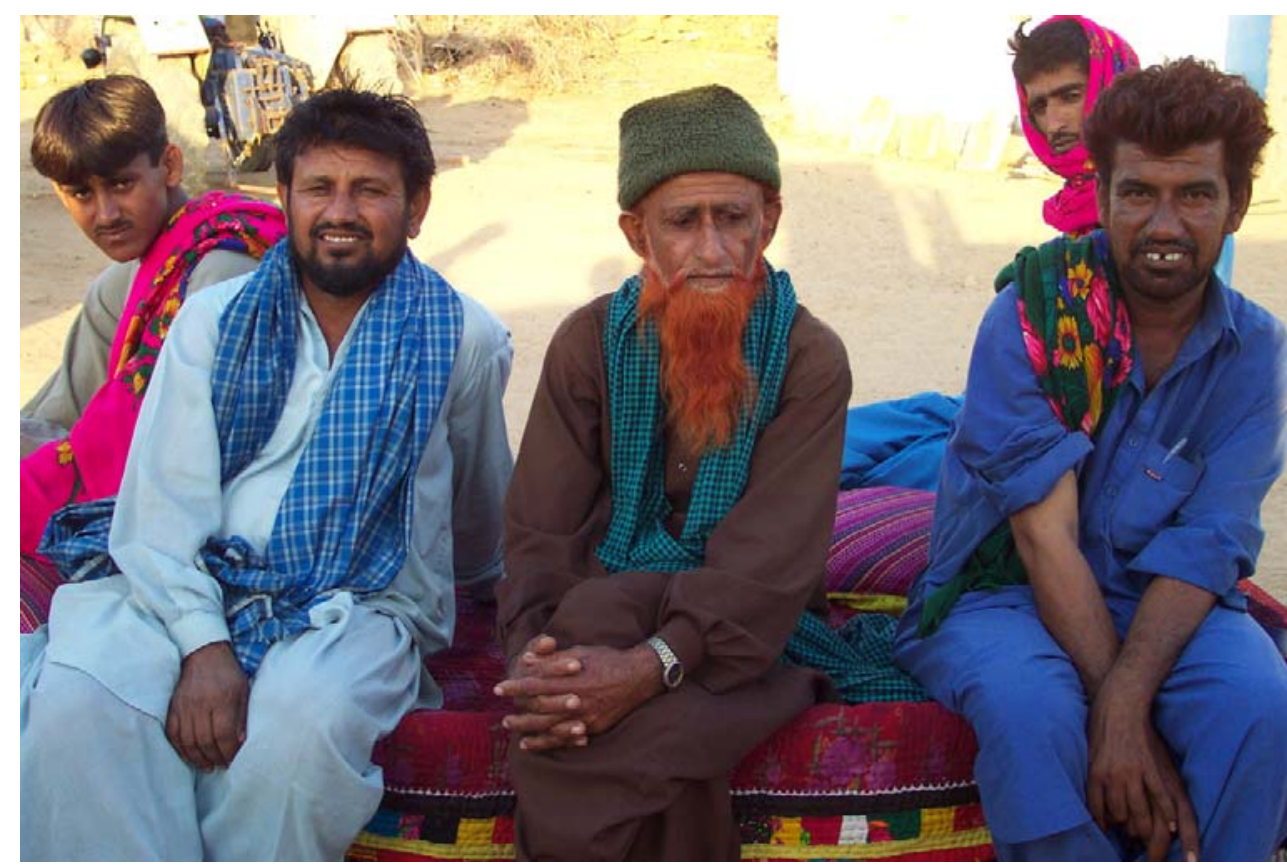

Fig.35.Hussain Ali in the middle, sitting on the quilt covered khatla with Lakhmeer (left) and Amar (right).

Q: What is your name?

Ans: Hussain Ali.

Q: How long have you been living here?

Ans: I was born here. I have been here sixty years.

Q: What is the name of your village?

Ans: This is my village, Drobhana.

Q: What was the name of the man who used to live on top of Kalo Dungar?

Ans: Shah Darus Hussnani, understood? He had come from Pakistan, understood? His name was Shah Darus and his father's name was Hussain so people would call him Shah Darus Hussnani.

$\mathbf{Q}$ : Then what happened to him?

Ans: People have only got a glimpse of Pachmai, nothing more than that.

He showed himself here for a short time and left. Now there is no presence of Pachmai left here. He [Pachmai] had been there and our people took the imprints of his feet that were left behind, then they started to worship them, saying, 'He was our saviour' then they built a mosque near it and they used to pray there.

Q: Then why did they stop praying there?

Ans: In spite of being Muslims we did not know all the dos and don'ts of Islam. We had only accepted Islam, we used to offer Namaaz, but we still used to worship mystics, and worship at mausoleums. Then when we realised the true ways of Islam we stopped worshipping at such places and so the Hindus took them over. No one gave any attention or thought to that. That place does not matter to us anymore.

$Q$ : If it does not matter to you anymore then why did they change the name? 
Ans: One day, at another mausoleum of ours a few of them [Hindus Lohanas/Meghwars] came and consumed alcohol. Our fellow Muslims got agitated and we destroyed that mausoleum. Even that mausoleum belonged to a Muslim, Rabbana, they used to worship him as well. But we destroyed the dargah [mausoleum], that action scared them [the Hindus - Lohanas/Meghwars], so now they have quickly changed the name to 'Guru Dattatraya'. They fear that because Muslims have stopped believing they will break and dismiss the mausoleums. So that this does not happen, they have changed the name and have made it a Hindu Mausoleum. This move ensures them security, as now if we do destroy the shrine that will lead to communal disharmony.

Q: They say this man fed his limbs to animals?

Ans: That is a lie, the local priest who used to sit around in the hope that someone would feed him, and give him some alms that would help him get by, threw his leftovers to the foxes. Someone saw that and said, the 'legendary man' [Pachmai] has returned. 'The foxes feed off his hands, he truly is the reflection of the mystic Pachmai', but it was the local priest, a simple trick of his hands, it was nothing else. What he did was, do you know foxes, when a man lives alone, he throws his leftovers to the local animals and they come and eat. Over time the animals befriended that person as they realised that he would not hurt them. So the foxes would come, and he would feed them, who, the local priest not Pachmai.

(Hussain Ali, Drobhana 2006)

It may seem a strange way to describe an interview, but it was enchanting and Hussain Ali was captivating. Like Amar and Lakhmeer, he talked about a man on the hill, Shah Darus Hussnani, also known as Pachmai. But the most interesting part of the interview was his interpretation of the current conflict and the reason for the changing interpretation of the identity of Pachmai Pir. It was quite disturbing to hear Hussain Ali talk about the demolition of a previous dargah so flippantly. The fact that they did not worship Rabbana Pir anymore meant that it was all right to demolish his dargah, rather than see it denigrated by Hindu pilgrims. Perhaps the fear that the shrine at Kalo Dungar might meet the same fate had been one of the motivating factors for the Hindus to manipulate its history.

The Sama community of Drobhana fully admit that they have abandoned the worship of Pirs and dargahs because, as they came to learn and understand Islam, they realised, or rather were advised, that venerating anyone other than Allah was heretical. It was, as Hussain Ali implies, a leftover practice from their previous traditions. In terms of syncretism, if we take the examples of Sila Khan and the 
Ismailis or the history of the Sufis, Hindus in these regions who converted to Islam most probably did so through Pirs, such as Pachmai, and it was them that they began to venerate as they showed them a new path and even gave them an equality not attained in their previous caste. In this conversion the practice of idol worship carried on through the Pirs and was shared by other faiths too as they performed miracles and gained respect across communities. However as these 'incomplete converts' learned the so-called 'true' ways of Islam, these practices gradually faded away.

Hussain Ali also referred to the foot imprints that Amar had mentioned. He explained that when Pachmai left Kalo Dungar his followers cast his footprints in stone and began to venerate them, even constructing a mosque, according to him, nearby. This was somewhat similar to the story Amar had told us. All the people that had now gathered around the khatlas who were listening agreed that the cast of those footprints was still present at Kalo Dungar but had been included into the temple setting. We realised that when we went to the hill earlier in the day we had not seen the footprints, or at least had not thought to look out for them. We decided at that very moment that we should go back up the hill to try and see for ourselves if the footprints were still there. It was about $4.30 \mathrm{pm}$ and if we hurried we would make it before sunset.

We went back up the mountain with Amar's nephews and Khatri Bhai. Once we reached the top I took out the camera and went into the temple to see if I could see the footprints that had been spoken about, I could see the statue of Lord Dattatreya and to the left of the statue was a pair of footprints carved into the white marble. It was obvious that these were not the footprints spoken about by Amar and Hussain Ali. These were typical of the emblems or symbols common to most Hindu temples. It was later that I discovered that footprints are also associated with the only other Dattareya temple in Gujarat at Mount Girnar, where it is believed Dattatreya’s footprints remain. After seeing the temple we walked around the complex once again, and we noticed that near the Dharamsala there was another set of footprints under a small tiled roof near a tree (see Fig.37). The setting of these footprints was more in common with what had been described to us in Drobhana, for the main reason that they were under a small covered area. I was sure that it was not the same 
gombus (open structure with a dome top) that had been described to us by Amar and Hussain Ali, the nature of this structure was quite different and was obviously a recent addition. However, I thought that if what the people of Drobhana said was right then perhaps this was where the original footprints had been kept and this new set of footprints had been rebuilt so as to not to upset the karma of the previous Saint, Pachmai, to whom perhaps some earlier Hindu worshippers once paid homage. However, these footprints were the same in appearance as the ones by the side of the deity in the temple, cast in white marble and painted with saffron orange detail, reenforcing their Hindu origins.

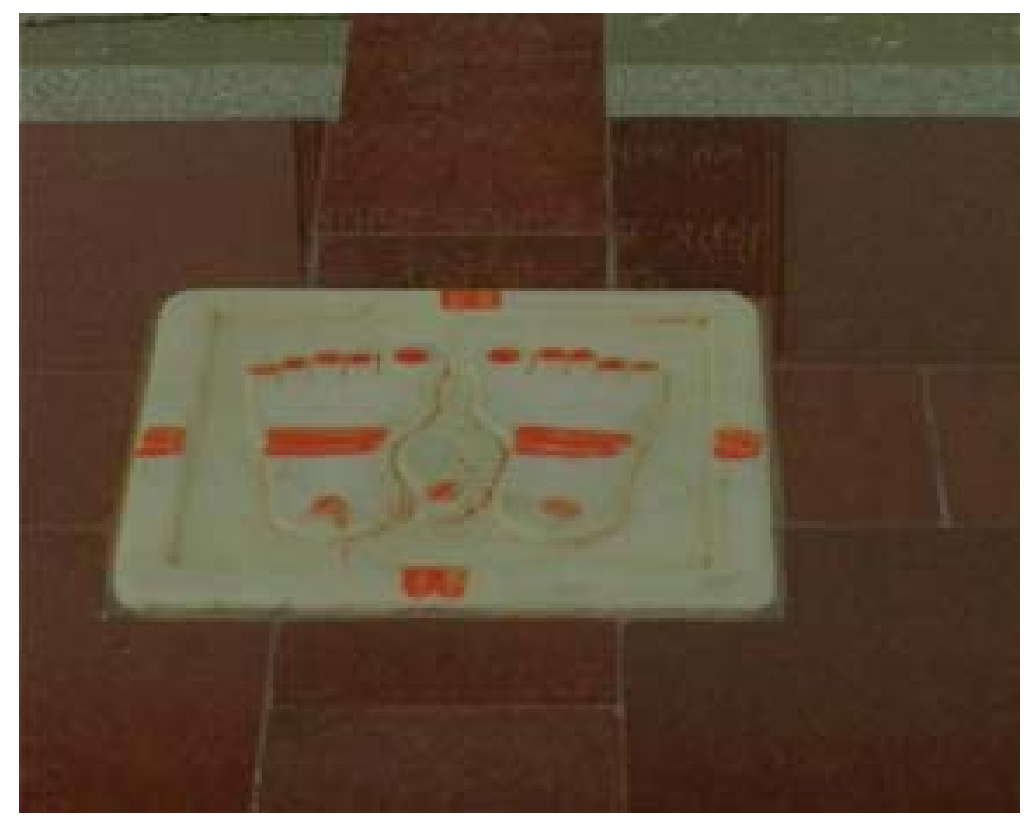

Fig.36. Footprints visible at Kalo Dungar near the Dharamsala under a tree.

While we were looking at these footprints we met the manager of the temple site, he invited us into his office and gave us a small leaflet-like brochure that had information about the temple and its history, with colour photographs. It is printed only in Gujarati. It gives a history of the site, including the legend of the foxes that Hussain Ali had so readily dismissed, and the various aspects of the site's new developments. There is a specific paragraph that gives an account of the footprints we had been looking at. 


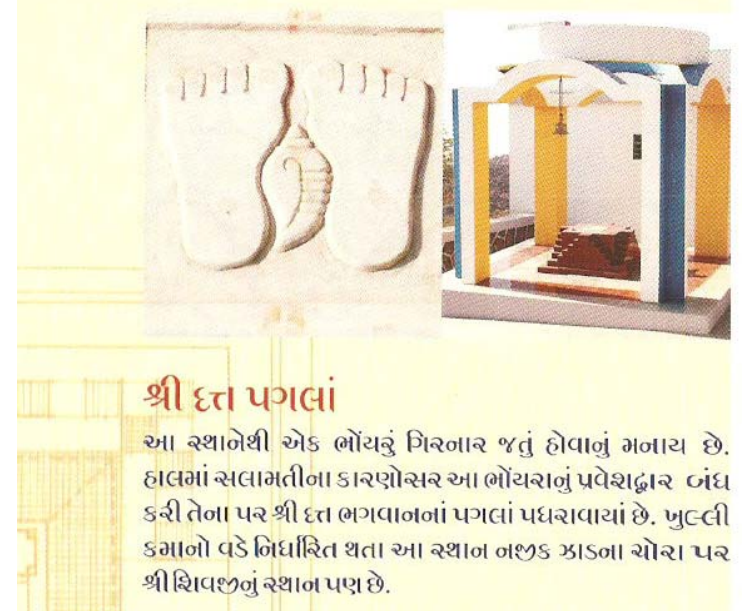

Fig.37. Picture from Kalo Dungar brochure of the area that has been specifically built with Dattatreya's footprints placed in the centre with an explanation as to why they are there. In this picture the feet have not yet been painted with the saffron orange as depicted in Fig.36.

The paragraph in Fig.37 states that the footprints are covering a cave, which for the safety of the public has been covered over (and as mentioned in Chapter 4, on the new website for Kalo Dungar it is stated that the cave was an opening to a tunnel which led to another site to Lord Dattatreya on Mount Girnar). From the photo and having seen the actual structure, whatever was at this spot before had been completely covered over so that no access can be obtained at all. Unfortunately there was no one with us who had visited the site in the days of Pachmai described by Amar and Hussain Ali, and they themselves would not come up to the site with us; this meant that I could not determine whether, the possibility that this structure had replaced the old gombus, had any legitimacy.

The manager had a simple office which had a small shrine in the corner of which Dattatreya was the main deity. He told us that he lived at the complex and that since the Dharamsala was constructed they receive many more visitors to the temple. This is confirmed in the brochure and by other recent events with regard to this site. The last page of the brochure gives a brief background to the site, stating that this is where Sri Datta once performed penance. It is known as Pachham Dev and is most popularly known as Pachmai. We have already discovered that Pachham is the name of the region in which Kalo Dungar lies, however the use of the word Dev immediately implies a Hindu god which is often referred to in Hindi as 'devi'; the name Pachmai is mentioned but Pir is not. According to the brochure, Pachham Bet (Pachham Island) was once known as Shesha Patan, something I have not been able 
to confirm in my archival research. It then states that there was once a small Mandir on this site with eight pillars and in 1988 a statue of Lord Dattatreya was placed inside it. Amar had stated in his interview that he thought somewhere around 1980 the gombus at which they worshipped had been demolished. However, according to the brochure, the temple had collapsed in the earthquake of 2001 and, thanks to Mukesh Bhai Zhaveri and his family, this new temple and guesthouse (Dharamsala) had been erected, and was opened to the public in February 2003. Since its development it had drawn many more pilgrims. The involvement of the Zhaveri family is affirmed by Ed Simpson (2006b), who in his research had discovered Kalo Dungar as one of the victims of the development of right-wing politics post earthquake. We return to his comments on Kalo Dungar later in the chapter.

The brochure further states that the site is now considered one of the most important pilgrimage sites in the region, as well as a popular picnic site which the government is planning to further expand. This expansion is reaffirmed in a newspaper article on www.expressindia.com titled 'Rannotsav' (Rann festival) written by D.V. Maheswari. The theme of this year's (2008) festival held on $20^{\text {th }}$ February is 'the cool and calm atmosphere at night under the moonlight in the vast expanse of the salt desert'. Kalo Dungar is mentioned specifically as the spot where an 'ancient temple of Guru Dattatreya' is situated that gives a 'marvellous panorama of the Rann, which looks like a seamless vast white sheet with its upper crust laden with salt'. It is mentioned that Narendra Modi (the chief minister of the state responsible for the atrocities that occurred in 2002), chose the Rann as the festival location himself; he is quoted as saying that 'no place on Earth looked so cool and calm in the moonlight as the Rann’. The article also says that the district collector, R.R. Varsani, had informed them that: 'there was a move to develop Karo Dungar as a permanent site for future festivals' and that nearly twelve crore (million) rupees was 'spent on creating permanent infrastructure facilities to transform the area as one of the district's main tourist spots'. The three day Rannotsav was to start in Bhuj where participants in the festival will be shown all the historic places of the city and the following day taken to Kalo Dungar 'to participate in the fair to be organised as part of 'patotsav' of the Dattatraya temple'. Special tents are to be built for the tourists in villages at the foot of Kalo Dungar, including Drobhana. The collector states that the 'main purpose of organising the annual festival was to promote tourism in the border 
district and showcase the region's rich and untouched cultural heritage' (www.expressindia.com). There is also a new website that has been set up called www.kalodungar.com which started in March 2008, this gives different accounts again of Kalo Dungar and is obviously a part of the expansion and redevelopment described above.

While we were still talking to the manager someone informed us that the foxes or jackals (there is some dispute as to which they are) had arrived for their food. Our previous footage of this ritual was poor due to lack of light, so we quickly took the camera and started to film it again. Sure enough the foxes came to feed on the rice given by the resident temple caretakers. After the foxes had dispersed, the sun had set and it was time to drive back to Amar's house and see if Ummer Bhai had returned to the village - he had not. It was seven o'clock in the evening and although we did not get a chance to meet Ummer Bhai we felt we had had a fulfilling day and achieved some of the goals we had set for ourselves. In Drobhana we had finally met some people who had known another history of Kalo Dungar and it made me feel like our perseverance and belief that something else had happened at Kalo Dungar at some time in the past, was justified.

Khatri Bhai was keen to return back to Bhuj rather than stay overnight, and we later discovered that he has never stayed away overnight from his house, so he was pleased that we did not insist on staying in Khavda. Over the next few days we did get our interview with Gafoor Bhai, who talked endlessly about his knowledge of world history, but nothing of Kalo Dungar.

\section{Back in Bhuj}

I wondered if there was anything more for us to discover about Pachmai Pir, Kalo Dungar and Dattatreya or whether we should be thankful that we had not run into any trouble whilst probing into the site, and leave for Bombay. However, we decided that a trip back to Drobhana was necessary to try again to meet Ummer Bhai. We were hopeful that Khatri Bhai would join us on our return trip and decided that we would ask him over lunch. Prior to meeting Khatri Bhai for lunch at his house we found one of the only bookshops in Bhuj and spent some time looking at the books; I thought it most likely that any publications relating to the region of Kutch would be 
found here. While I scoured the bookshelves, Amin, in his restlessness, was talking to the shopkeeper. Once I found the copies of most of the books that have been written on Kutch over the years, I realised that he had got out the camera and was in the middle of interviewing the young shopkeeper ${ }^{22}$.
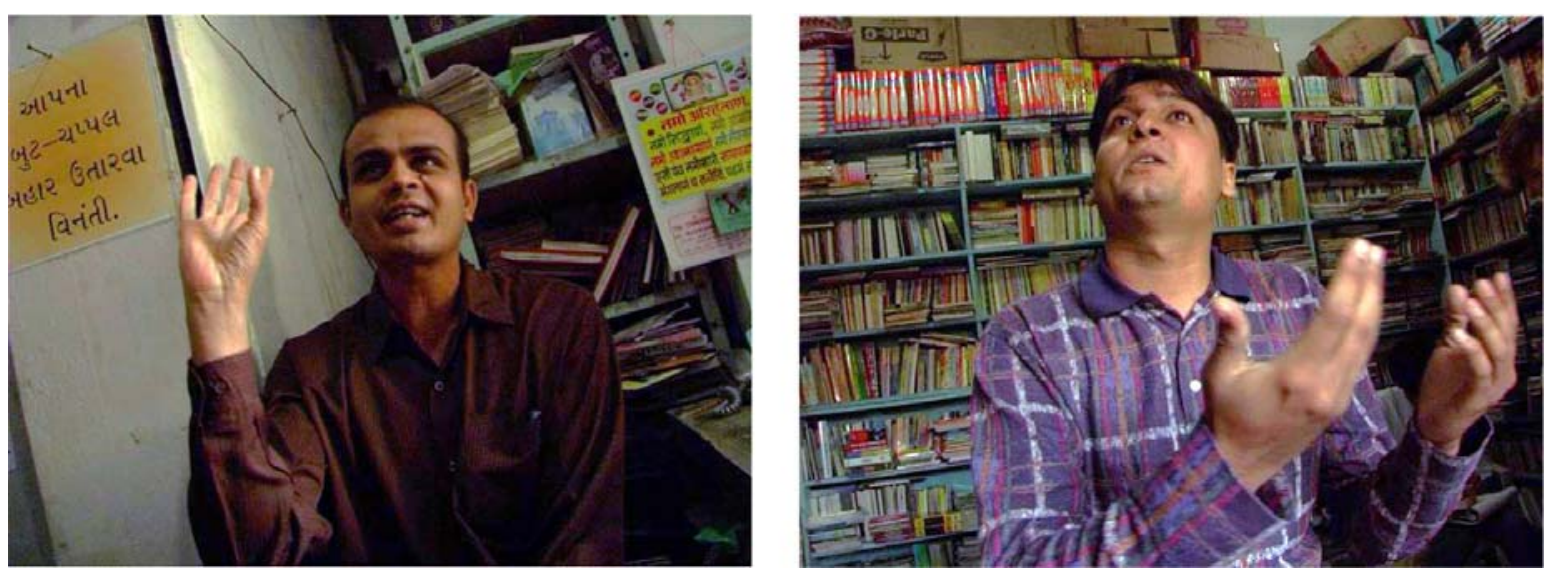

Fig.38. Left photo is Dharmendra Shah, Librarian and on the right Maulik Davda, sweetmeat shop owner.

Q: What is your name and occupation?

Ans: Dharmendra Shah, I am the caretaker, I've graduated in Library Science.

Q: Can you tell what guise the reincarnation of Lord Dattatraya adorned when he came to the spiritual site at Black Mountain?

Ans: In my opinion Lord Dattatreya had not come, but there are some imprints of his feet there, upon viewing those marked foot prints people have said that he (Lord Dattatreya) was there but no one has ever seen him.

Q: Then whose imprints are those? Were they of a person?

Ans: Yes.

Q: Who was that person?

Ans: Yes, it's important to find the answer to this question, but till today no one has said, who 'He' was, they say 'He' was a reincarnation but when 'He' came and where 'He' went is not known, I think 'He' must have passed from there, that is why those marked footprints exist there.

Q: How and why do these things happen?

Ans: In my opinion as time passes by, new and different folklore becomes associated to it, and those people who want to exploit it for their benefit, take different stories and attach them, keeping their own interests in mind, they make their own analysis and announce the same.

Q: Why does this happen?

Ans: In my opinion no one investigates this, people come visit the shrine ask basic things and go back. But if someone will explore it

${ }^{22}$ This interview can be seen in Black Mountain - Chapter 17. 
some more information might be divulged and that will benefit everyone.

Q: When you realise all this, how does it feel?

Ans: I feel very sad. In here I can acquire knowledge from books, but my regret is that I can't pass it on and educate the rest of the society. I feel happy and hopeful when people like you come here and work so hard and expose the truth, and pass on that factual information to the people.

Dharmendra did not know who it was who had lived on Kalo Dungar, but his reference to the footprints at the site suggested this was common local knowledge. However the transcript of the interview conveys a sense of helplessness and frustration regarding the fact that, in his opinion, sometimes folklore is exploited by various bodies for their own cause. His comments at the end of the interview were very touching, as for some reason he felt that, by people like us asking questions and trying to find out the different aspects of a certain piece of folklore, maybe other information, (although I would hesitate to use the word 'factual' as he does), might be gained and passed on to other people.

Apparently as a result of discussing our research after his interview, Dharmendra telephoned his friend Maulik and asked him to come over to the bookshop immediately; when he arrived, Dharmendra told his friend that we were trying to find out the history of Kalo Dungar. Maulik informed us that he and Dharmendra discussed things such as the true foundation of different aspects of folklore, or political activity that was going on around them, with each other whilst sitting in the bookshop. As it happened Maulik's father is one of the Trustees of Kalo Dungar and he and his family are committed believers in the shrine. He told us stories of his childhood; such as the first time his parents had taken him to Kalo Dungar to shave his head, which is considered an auspicious act. He spoke about Kalo Dungar and the controversies surrounding it, saying that the change in Kalo Dungar had happened over recent years. Some time back, the collector of Bhuj had requested the Hindus of Bhuj to visit Kalo Dungar more often in large numbers so as to make a 'Hindu presence felt' in the border area, because he (i.e. the collector) feared otherwise it would turn into 'another Kashmir' of India. Maulik expressed to us the view that the increased interest in Kalo Dungar and its changing face was political, but he felt that there was nothing wrong in this as he believed it was important to 
make the Hindu presence felt, in what is a largely Muslim-dominated area sitting right on the border with Pakistan. After this initial conversation, we asked him if we could record his interview with the camera and he obliged. However he did not repeat the information given above, rather he discussed other aspects ${ }^{23}$.

Q: What is your profession?

Ans: I own a sweetmeat shop.

Q: What would you say if I asked you in what 'form' did Lord Dattatraya come to Kalo Dungar?

Ans: No one would question this, or even ask a question like that! If you question the local priest, or the trustees, my father is one too, they talk in circles, but will end up saying that it was Lord Dattatreya. No one here really knows the truth, and because the literacy level is low, if people are asked, 'do you know the facts?' they will never admit that they don't! If you ask them, 'do you know to drive?' They will promptly say 'Yes! Come along!' In the same way, no one will refute the story, [of Dattatreya] but no one really knows exactly! No one ever goes into reasoning, if some people say something, it is accepted. If people tell someone here that 'he's got a fever' he will believe it and accept that he is ill because everyone is telling him that. Because of the low literacy level here, blind faith is prevalent. If a few people call a gathering, and announce, 'there is a presence here!' It will be accepted and believed, that Yes! Here there was a Pir or whatever! Now if that is true or not, is another story, but it will be accepted, that is the tradition.

Q: What happens if you question these things?

Ans: A question mark comes up that's all. What else can happen?

Because the more you think or question, the quicker you lose your faith! It's not that I have too much faith myself, but because my father believes, as the traditions demand, the hair on my head was shaved off at 'Kalo Dungar'. All the members of our family, and relatives visit the temple regularly even now, so it has become a ritual, and I go too, no particular reason as such, I feel a sense of calm and peace and I enjoy the beautiful view, so I go, other than that, I have not given it much thought.

Both Dharmendra and Maulik expressed the notion that questioning or discussing the meaning or reason of a certain belief in something, like Kalo Dungar for example, was not a consideration. People were prepared to accept whatever might be told to them, especially concerning religion, and it was the lack of literacy amongst these people which encouraged a type of 'blind faith'. This unquestioning attitude of the general public meant that, according to them, folklore could quite easily be manipulated to suit the political needs of whichever party was concerned, they

\footnotetext{
${ }^{23}$ For the recorded interview see Black Mountain - Chapter 17.
} 
obviously did not include themselves in the category of 'blind faith' followers, and seemed to put, perhaps, an unjustified amount of trust in literacy as a means of awakening awareness.

In Indian terms, the statements that they made were quite controversial. For Maulik especially, considering the standing that his father has in Bhuj and at Kalo Dungar, it was extremely bold to speak of the place in the way he did and to admit that questioning faith was not something accepted or allowed in the society within which he lived. On the other hand, he openly expressed the view that a majority population of Muslims near the border was indeed a worry for the Hindu community, and admitted that he did not feel that readdressing this balance or making a Hindu presence felt in the area was a bad thing. These two young men gave what is perhaps a younger educated generation's viewpoint of current affairs. The older generation, members of which formed the majority of my interviewees (that is, historians, museum curators, researchers), rarely admitted such views, or would agree with them, maybe because of their more traditional backgrounds. It was one of the most interesting interviews I had recorded, and it felt to some extent, apart from our interviews in Drobhana, one of the most honest in the expression of views.

Much of what Maulik says in the interview is confirmed by Simpson (2006b), who alludes to the political activities in Bhuj which have occurred since the earthquake in 2001 and since the Gujarat riots of 2002:

For the last few years, nearby hamlets [of Kalo Dungar] have been promoted by the Sangh parivar ${ }^{24}$ as hotbeds of insurgent activity. In April 2001, Sudarshan, the RSS leader, came to inaugurate a number of post-earthquake developments with Mukesh Zaveri...Some time later, Zaveri told me frankly that their mission had been to instil a sense of nationalism among the villagers (2006b:319-320).

Kutch in the past was a district that sat relatively aloof from the right-wing political reputation of the state in which it now lies. It was not caught up in the riots of 2002 and has had very little communal conflict to speak of, if any. Simpson goes on to state that after the visit of Mukesh Zhaveri and the RSS leaders in 2001, a new

\footnotetext{
${ }^{24}$ Sangh Parivar is talked about extensively in Chapter 3 - India's Pledge, but to recap it is basically a term used for all the Hindu right wing political organisations that are currently working towards a Hindu Rashtra.
} 
organisation called the 'Border People’s Welfare Society 'was formed, coordinated by the local RSS branches, in which they undertook specific activities to increase their strength in the border regions, just as they had been advised by their leaders.

They organized the construction of a public road to the summit of the Kala Dungar, demolished a Jain temple with the complicity of the Zaveri family who were closely associated with the deity and built a much larger temple in its place. They then started to 'Hinduize' the public face of the god and attempted to develop for it a reputation for divine protection over a dangerous border. Over the last few years, they have given momentum to an annual pilgrimage to the temple from Bhuj by bussing in hundreds of 'pilgrims' to enliven the area with strong nationalist sentiments and to celebrate the ritual protection of the highly symbolic border from Muslim predations from within and without...Thus, it has come to pass in the north of Kachchh that many Muslims have experienced marginalization from the government [and] by the government...in the name of majoritarian polity (ibid).

The reference to a previous Jain temple at Kalo Dungar is the first one I have come across and cannot be verified, however what is significant is the point that the Hindu right-wing organisations were trying to build nationalist sentiments, by 'hinduizing' Kalo Dungar in order to establish 'divine protection' near a ‘dangerous border’ in order to prevent Muslim transnationalism between India and Pakistan. The pilgrimage to Kalo Dungar and the subsequent interviews in the bookshop confirm this point.

It is established that the issue of the border poses an extremely important element to Hindu nationalist activities at Kalo Dungar. Anderson and O’Dowd point out that an important element of cross-border relations relies on whether or not the peoples of the border areas share the majority national identity, either through language or religion, especially 'if the region has more in common with the neighbouring region across the border' (1999:597). In this case, the Muslims living near the Rann probably share more in common with their neighbours in Sindh considering that many of them had come from that region in the first place when it was a part of India. On a border like this, that has been created so recently, just sixty years ago, the similarities between the people who live in close proximity either side of the border will most likely be far more than any similarity, if any at all, that might exist between those same people, and their fellow countrymen, who live in the heartland 
of that country. This phenomenon is described as transnationalism, 'whereby borderlanders...share the values, ideas, customs and traditions of their counterparts across the boundary line' (Donnan \& Wilson 2001:5). The Jatts, for example, recall a past in which they shared close relations with the rulers of Kutch and Sindh where fodder and grazing land was plentiful. This contrasts directly with accounts of their present status in which the Jatts find themselves stigmatised 'first as Muslims, and second as residents of an area in close proximity with the Pakistani border. In both senses they are regarded as potential threats to the integrity of the Indian nation imagined in Gujarat as Hindu Rashtra’ (Ibrahim, 2004: ). The Samas are perceived in the same light, converts from Hinduism, they are regarded as a threat to the Hindu nation state primarily as Muslims who, through their oral tradition, believe their origins to be rooted in the other side of the border in Pakistan. Post-earthquake, the Muslim majority of Kutch has been subject to what Ibrahim terms 'selective invisibility' as 'non-Muslim, non pastoral groups...began to receive especially large amounts of aid and new villages with concrete houses and temples were constructed for them by Hindu politico-cultural organisations such as the VHP' (op.cit. ). The reason for this, she claims, is because 'social boundaries...that transgress political boundaries, often pose the greatest threat to the nationalist vision of a bounded sovereign state’ (Ibrahim 2005).

'Borderlands are sites and symbols of power: Guard towers and barbed wire may be extreme examples of the markers of sovereignty which inscribe the territorial limits of states' (Donnan \& Wilson 2001:1). Military borders, however, are obviously only one type of defence; this border was not being secured just by military means but by religious means too. Perhaps the pilgrimage site of Kalo Dungar had become the 'guard of the border'. In a case like this 'military might must compete with, and in some cases accommodate, [religious forms] of power in the borderlands of nationstates' and the role that religion can play in 'affirming border identities and regions [and] in the strengthening or weakening of the nation-state' (ibid).

\section{Back in Drobhana}

The interviews with the young men in the bookshop had given me more motivation to revisit Drobhana. We went straight to Khatri Bhai's house after the interviews and when we informed him over lunch that we were planning on going back to Khavda; 
he told us that he wanted to join us. We headed directly to Drobhana. After failing to find Lahmeer or Amar at home we tried to think how else we could find Ummer Bhai and decided to head to the central point of the village (where we had met Amar on our first visit) where there was a small shop, mostly selling grains, which doubled up as a gathering point for some of the local men and kids. We were told that Ummer Bhai had gone to Khavda for the day and that he would return in a couple of hours. It was already five o'clock in the evening but we thought we could wait. In the meantime Amin took out the camera in the shop and asked questions to the men sitting inside. I was waiting in the car outside, not quite aware what was happening, but sure that the local shop was probably not a place, at this time in the evening, that women frequented, so I was happy to wait outside and interact with the groups of children that gathered around the car. The conversations in the shop reaffirmed much of what we had previously learned from Amar and Hussain Ali. However this time there was a group of local people all agreeing as to the history of the site of Kalo Dungar. Amin asked general questions about Pachmai and Kalo Dungar and he got collective responses, however three men in the shop shared the most information (see Fig.39) ${ }^{25}$.

Q: Which caste did Pachmai Pir belong to?

Ans: First man - No idea?

Ans: Second man - Wait I know, he was a Saiyid, a Saiyid ${ }^{26}$.

Q: Saiyed? What was his name?

Ans: Shah Darus Hussnani, understood? He had come from Pakistan, understood? He was a Muslim, there used to be a mosque and he used to offer namaaz there. Initially only the Jadejas stayed here, then they converted to Islam

$\mathbf{Q}$ : And what are you?

Ans: I'm a Jadeja.

Q: You are a Jadeja?

Ans: Yes, that's right.

Q: How many Jadejas around here?

Ans: There are only Jadejas here, no other caste came here.

Q: But you are a Sama aren't you?

Ans: Yes those who converted to Islam are known as Samas, originally I'm a Jadeja

\footnotetext{
${ }^{25}$ These conversations can be seen in Black Mountain - Chapter 19\&21.

${ }^{26}$ It should be recalled from the previous chapter that Saiyid (also spelt sayyed or saiyed) is the caste most common to Pirs, who consider themselves direct descendants of the Prophet Mohammed.
} 
The men reaffirmed their ancestral roots as Jadeja Hindus and the identity of Shah Darus Hussnani. They also confirmed that there was once a small mosque on the hill at which Pachmai offered namaaz. They spoke confidently and surely of these facts. Amin then asked them about Lord Dattatreya.

Q: Who was Dattatreya?

Ans: Dattatreya was no one, they changed the name now. Not from the beginning. It was never Dattatreya. Now it became Dattatreya. And now they call it 'Guru Dattatreya'. It was called 'Pachmai Pir', 'the Saint from the West'

Q: What was it called?

Ans: Initially it was 'Pachmai Pir'.

Unsure if Amin had understood what they were saying, the man in the shop looked at Khatri Bhai and told him in Kutchi - You explain to him, does he understand? To which Amin answered himself, in Kutchi - Yes I can understand. It is a lovely interaction between them, as the man is at a loss as to why Amin is asking him to repeat his answers. Then they look at Khatri Bhai who is standing by the door and repeat their answer.
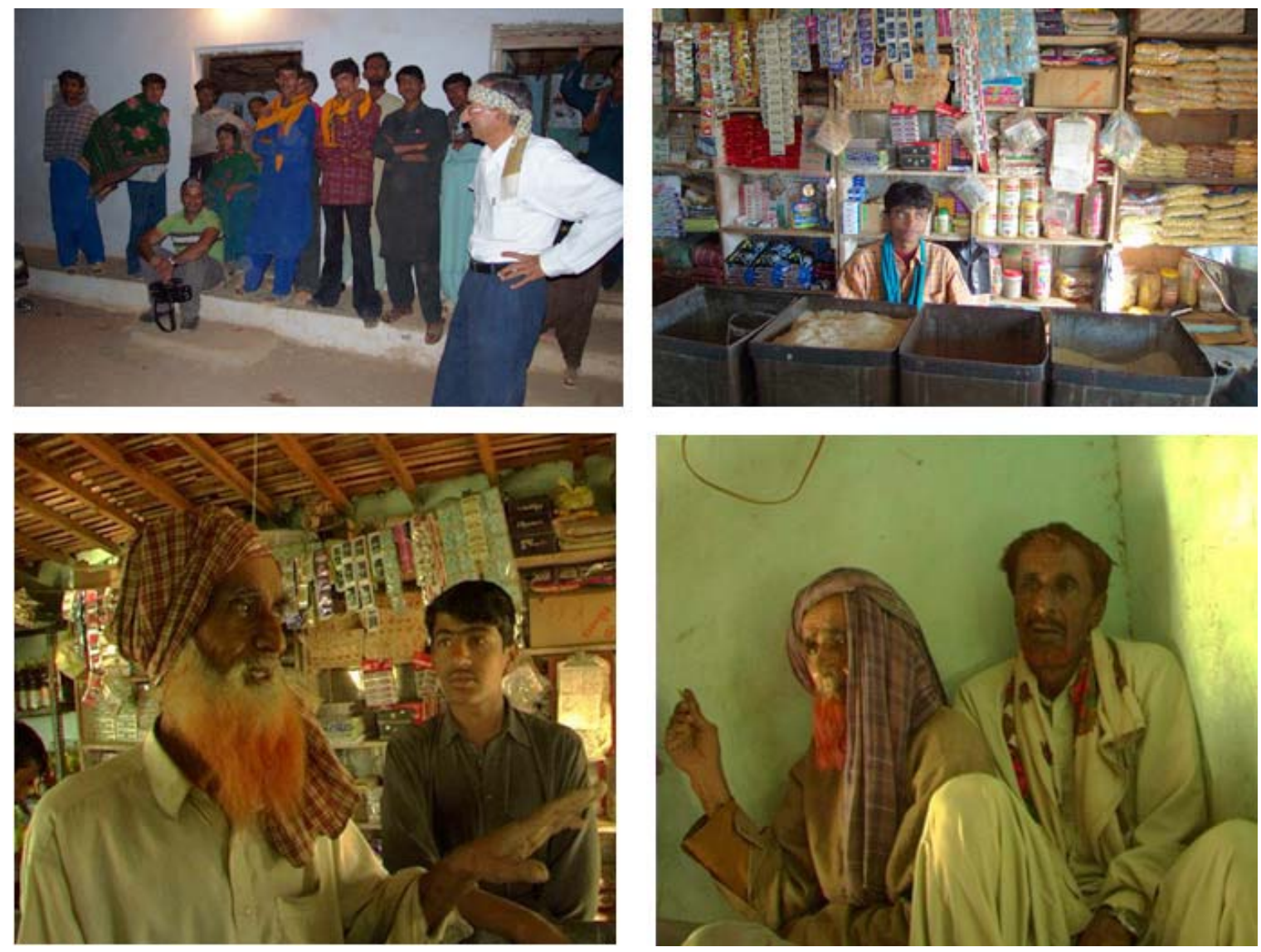

Fig.39. From top left - Amin and Khatri Bhai outside the shop. Inside the shop with the different grains and items available. The three local men who had most information to share about the site. 
Ans: Initially it was 'Pachmai Pir', means 'the Saint from the West', and now they call it 'Guru Dattatreya'. The name has been changed. $Q$ : What is the reason for this?

Ans: The answer for that lies with those people who believe in Dattatreya. These changes have occurred in the last ten years.

Q: Why did all this happen?

Ans: People of the business community made these changes, I think it was them, (Lohana/Baniya community). At first they put an idol of their Guru there, then the name. The Muslims used to offer namaaz there, and there were foot imprints there. There were no statues of their idols up there then. Now they have changed things and have put statues of their Idols.

Q: Whose footprints were there?

Ans: Pachmai Pir, he had left, but the imprints of his feet remained, people worshipped those imprints. There is no grave of his here.

There were about six people in total in the shop and no one had offered any other version of the story. However, Amin recalls that towards the end of the conversation the older men began to talk in a slightly disparaging and negative manner about the Pir, and there seemed to be, what Amin described as, an uncomfortable exchange of looks and suddenly the discussion was toned down. These looks were in the direction of one of the younger men present in the shop. He had been part of the earlier discussion, but only when the history and name of the Pir was being discussed. When the question of why the followers of the Pir had stopped going to Kalo Dungar was asked he had been quiet, now one of the men mocked him and informed Amin and Khatri Bhai that this man was a descendant of the Pir, and that he would be happy to tell us more about it in detail. The others in the shop smirked as this was said. When the discussion ended we asked them if Ummer Bhai might be on his way back. The young man, the so-say descendant of the Pir (whose name we discovered was Mohammed Ali Shah) offered to take us to find Ummer Bhai; he said he could talk to us on the way, and if we could not find Ummer Bhai then there were other people he knew of who would be willing to talk to us. He got into the jeep somewhat sheepishly, almost as if he did not want anyone to see him joining us. We drove out of Drobhana towards a village called Raterdiya. In the car he said he had not been comfortable talking in front of the other villagers as they would not like what he had to say. But he did not mind us filming his interview ${ }^{27}$. He said that his

${ }^{27}$ This interview can be seen in Black Mountain - Chapter 21\&22. 
family were the descendants of the Pir which is why the villagers were mocking him and calling him 'Pir Bhai'.
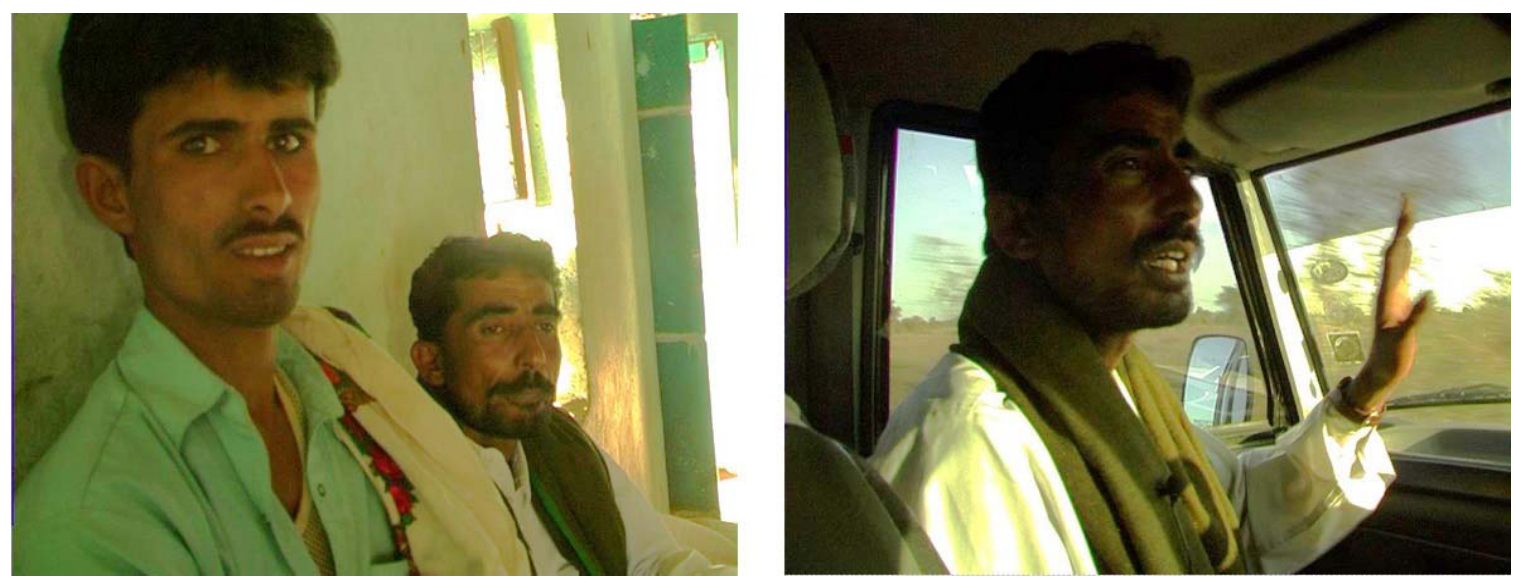

Fig.40. Descendant of the Pir sitting in Drobhana shop (man on the right) and talking to us in the car.

\section{Mohammad Ali Shah}

Q: Why did they call you Pir?

Ans: They called me that in front of you but they don't believe in us.

Q: So a Saiyid is called a Pir?

Ans: A Saiyid is a leader, it is also a title bestowed to the heir or descendant. It is a title bestowed upon and passed down from one generation to the next. Our family is bestowed with the title of 'Pachmai'. In Rajasthan and in Pakistan my family also have the title of 'Pachmai', my cousin Aziz is the heir there.

Q: Where in Pakistan?

Ans: In Degrigadh near Mirpur.

Q: So what is done there?

Ans: My family and our descendants live there and carry on our 'Pachmai' lineage. Pachmai Pir was my Great Great Great Grandfather. Samoi is a place in Pakistan, these Samas migrated from Samoi and came here and started to worship my Grandfather. They believed in him until a Maulvi [Muslim leader] arrived from Pakistan, and told the Sama tribe not to believe in Pirs, as it was a sin in Islam. Since then they stopped.

Q: So what happened to Pachmai Pir after that?

Ans: The Maulvi came and announced that visiting shrines was blasphemous, so the Samas stopped visiting Pachmai, then after a while a few Samas returned. When they returned my Grandfather was upset and said there was no need to worship him. The next time they went back up to meet him, he was no longer there. All of our ancestral history is recorded and kept in a book.

$\mathbf{Q}$; Where is that book?

Ans: At the Dargah in Rajasthan.

Q: So when the name was changed to Dattatraya, why did you not object? 
Ans: How could we? The majority of our own fellow worshipers had stopped visiting and praying at the shrine, because they were told it was blasphemous in Islam, so now how can I object to the change in the name, we are a minority here, there are only four of our family houses in the whole village.

Mohammed Ali Shah claimed that there were other sites in honour of Pachmai Pir in Rajasthan and Pakistan. It would take further investigation and confirmation of these sites to be able to locate them. Mohammed and his family were no longer respected in the village as they once had been, due to the changing nature of the practice of Islam in the area. Since the arrival of Maulvis in the area, veneration of Saints had stopped, and now, ironically, even those who claimed descent from the Pir could not worship at Kalo Dungar. Since its Hinduization only Hindus visited the site.

Mohammed Ali Shah was obviously bitter and upset that the village had rejected the Pir, his family was small and they could not fight the onslaught of right-wing Hinduism alone. He told us of another man named Raaiebji Raiderjee, who was also a Sama and knew more about the history of Kalo Dungar. He lived in a village called Raterdiya, which was fifteen kilometres away, and we drove across the desert to get there. When we arrived, the village shop owner told us that the man we were looking for was in Khavda, but would be back soon as the sun was going down. It became obvious that Khavda was like a social gathering place, many of the villagers from surrounding villages went there to have chai and a conversation, especially in the afternoons. While we were waiting, a few more villagers appeared and sat with us outside the shop (see Fig.41). The villagers asked us what we were doing and Mohammad Ali Shah, Amin and Khatri Bhai explained to them. An 80-year-old man named Pachanjee began to talk about Kalo Dungar and the Pir. He could not hear well and so it was not easy to converse with him, but then some others joined in too. One farmer called Nandajee Amarjee Sama spoke at length, he told a similar story that we had heard from the other villagers in Drobhana and reiterated the fact that the man on Kalo Dungar was called Pachmai Pir, however he could not remember his actual name. He also said that the Pir was a Muslim and that he had a large following from all the local communities. As Panhwar (1979) states 'Cutchis pay equal respect to Muslim Saints and Pirs and Hindu Deities. This has been so since eight hundred years’ (1979:16). 

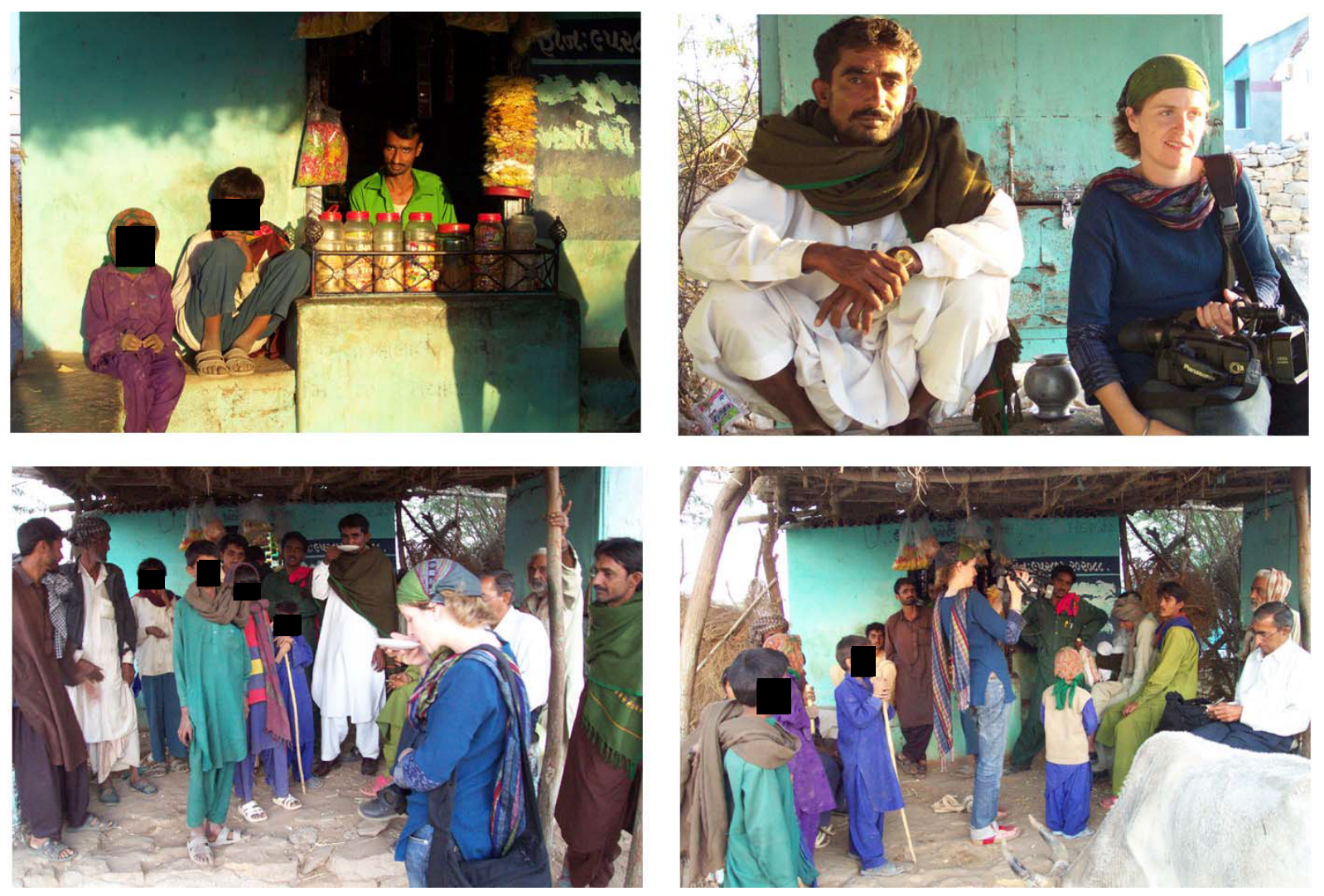

Fig.41. From top left, the local shop in Raterdiya. Myself sitting with Mohammed Ali Shah.

Drinking chai from a saucer in the traditional village style. Filming the local people.

According to this local Muslim population, Pachmai Pir was universal, but he was not an example of a Saint that was venerated under different religious identities, i.e. Hindu and Muslim. He was Pachmai Pir. The name of Dattatreya, according to these locals, was a very recent development. So information such as that given on the ACHA (Association for Communal Harmony in Asia) bulletin website may not be entirely correct. In one of its articles dated 1998, it is stated that

The communal amity prevailing in the district can be seen from the number of pilgrims, both Hindus and Muslims, visiting the 'Kala Dungar' (black hillock) shrine. While the Hindus consider it to be the abode of Lord Dattatreya, the Muslims worship Peer Pachhmai (ACHA bulletin, 12/16/98, special human rights issue, accessed 701-08).

In fact, as far as local history is concerned, it should read that the Muslims and Hindus used to worship Peer Pachmai, but now only Hindus worship Lord Dattatreya. The villagers of Raterdiya were extremely welcoming. But as the sun began to set we decided to leave, we met a tractor rickshaw five minutes into our journey and the man we had waited for, Raaiebji Raiderjee, was in the vehicle. We 
requested his help in our research and he got down from the rickshaw. Standing in the orange glow of the sunset, Raaiebji Raiderjee told us all he knew about Pachmai Pir; his tale was very similar to the accounts we had already heard. Frustratingly he told us that he was not really the man with all the answers, but instead we should speak to his friend Ummer Bhai who lived in Drobhana, where we now headed, but when we arrived he was not there. We thanked Mohammad and as we left Drobhana we though to ourselves that perhaps Ummer Bhai did not want to talk to us about Kalo Dungar, after all, this was a subject that not everyone was comfortable discussing. It was at this point that I realised how lucky we had been with the people we had met in Drobhana, none of whom had minded us asking questions or answering them. At times when you don't face obstruction it is easy to forget the actual sensitiveness of the subject that we were discussing. Khatri Bhai too, realised that it was important that we protect the identity of our informants from Drobhana as it would not be fair to put them at risk. We reassured him, just as we had our informants during our field trips, that protecting their identity would be of primary importance.

On our way back to Khavda, Khatri Bhai suggested that we should perhaps meet with people from the Lohana community who were the Hindu caste that now looked after the shrine at Kalo Dungar. As we approached Khavda I suggested that perhaps he was right and we should stop and ask around. However, Amin was not comfortable with this, it being dark and Bhuj still two hours away. He explained that the Lohanas, now quite involved in the Hindu right-wing activities at Kalo Dungar, would probably not appreciate us questioning the myth surrounding Lord Dattatreya and Pachmai Pir and the origins of the religious site. We might also be putting ourselves at risk. Khatri Bhai told us that the Lohana community were specialists in local Indian sweets of Kutch, and most of them owned sweet shops in Bhuj and all over Gujarat. Khavda was famous for its sweets. It suddenly dawned upon me that Maulik Davda, whom we had interviewed in the bookshop earlier in the day, was a Lohana; we had even bought a box of sweets from his shop called Khavda sweets. We had met his father in the shop, whom Maulik had told us was a trustee of the temple at Kalo Dungar. We had learned that Maulik's father was associated with the RSS and was working with the local politicians in accordance with the developments 
at the pilgrimage site. He would definitely not have taken kindly to too much questioning regarding Dattatreya. And upon being told by his son about our interest in Kalo Dungar and the identity of the avatar that had lived on the hill, he had, in a very matter of fact manner, looked at us both and said, 'well it's Lord Dattatreya, what else is there to know?' Maulik's words came to my mind... 'No one would question this, or even ask a question like that! If you question the local priest, or the trustees, my father is one too; they will all talk in circles, but will end up saying that it was Lord Dattatreya'. Amin reminded me that we had already interviewed a lot of people from the Lohana community, as many of the pilgrims whom we had met during the pilgrimage two years earlier were Lohanas. With this in mind I felt that for now, we had probed enough.

On our way back to Bhuj we thanked Khatri Bhai profusely, without his help we would never have been able to build the relations that we had so fast. Khatri Bhai's reply came, 'don't thank me, I wish to thank you. I learned something too you know.'

For now this fieldwork was over, it was time to head back to Bombay and start piecing up the film and working on the other aspects of my thesis. But, before we left, tonight was the night that we had been invited to the music concert by $\mathrm{Mr}$ Umesh Jadia a week earlier. The venue was on our way back to Bhuj, and we would just make it in time for the performance. The three of us went directly for the show. There we bumped into an old friend of ours, Judy Frator, an American woman, who runs an NGO in Kutch called Kala Raksha. Coincidently she was the tour organiser for the visiting group for whom the concert was being held. After the concert we gave Judy a lift back to Bhuj, and hearing about our research, she advised caution considering the sensitiveness of the subject. She told us that many local people, and Kutchis and Gujaratis who had moved abroad do not take very kindly to the negative press that they have been receiving concerning Gujarat's politics and the well publicised support it receives from non-resident Indians living in America and England. She felt that we must be careful whom we showed our film to and with whom we discussed our research. In her opinion, after living over thirty years in Bhuj and working in Kutch, things had changed; it was not as politically peaceful as it once had been. We assured her that we would be careful. We dropped Khatri Bhai 
at his house and said our goodbyes. We drove back to Ahmedabad then onto Bombay the following day.

\section{Back in Bombay}

Fully recuperated from our trip I unpacked my bag and stumbled upon the DVDs that had been given to us by Jagdish Bhai. We had not been able to watch them in Kutch, due to our hectic schedule. There were three DVDs, one containing the pilgrimage in 2003, and two previous pilgrimages. I found watching the DVD quite distressing as Amin translated their content. They contained hours of footage, little of which it was possible to include in the film or to describe fully in this written text. However, I will summarise here some of the elements in the DVDs which are shown in the film Black Mountain (see Chapter 20). They showed pilgrims at the beginning and during the pilgrimage, and the speeches made, some of which spoke of the importance of pilgrimages and celebrations in uniting a community. In this speech amidst fluttering saffron flags and politically charged banners, the pujari of the temple, from where the pilgrimage began, spoke ${ }^{28}$ :

This [pilgrimage] is an important exercise. It ignites the desire of unification within us. If we all don't unite now in the future we will have to sell-off our Holy Shrines. Subsequently, because of Christianity's three point agenda. Today they have to sell off their churches. In London today we own three or four such temples that were initially churches. We purchased them and converted them into Swami Narayanan Temples. How did this happen? Why did they have to sell their churches? Only one problem! They have no festivals. No reasons to celebrate. Whereas in Hinduism we believe in celebrations, these occasions have a deep-rooted connection with our Indian culture. What is that connection? If we don't celebrate occasions, people won't meet and interact with one another, occasions act as a medium. They bring people together and create a sense of brotherhood amongst them. Where brotherhood prevails, there the society gets strengthened. And only a strong society can stake their claim on religious places.

Dattatreya Jayanti, for which this pilgrimage to Kalo Dungar is made, was one such occasion. This speech, as are the ones below, is an example of how myths are created about other religious communities or social groups in order to create passionate feelings against them. In this case the Christians in Britain are the target.

\footnotetext{
${ }^{28}$ See Black Mountain - Chapter 6.
} 
Britain and the West are often presented in this region of the world as an example of an amoral society, where a lack of faith and belief has caused the degradation of the people and culture. The most significant element of this speech as far as this research into Kalo Dungar is concerned is the last comment, 'only a strong society can stake their claim on religious places', was that then the intention of these pilgrimages to Kalo Dungar?

The next excerpt I wish to use is one made by a local organiser of the pilgrimagecum-rally who, in the DVD, is giving an interview to the local media on the pilgrimage route, he states that 'today citizens, members and leaders of the Lohana Community have gathered here in large numbers, along with leaders of the VHP, RSS and BJP. In the presence of all these leaders the pilgrims have begun their journey'. This short statement reinforces the central involvement of the Lohana community that was mentioned above, and the importance of the Hindu right-wing political parties and organisations in the event. Watching the DVDs reinforced my perception of what I had experienced; it confirmed that the identification of the object of veneration at Kalo Dungar as Dattatreya was a political act in order to remove the stain of Islam and the local Muslim Pir from the religious site. This was confirmed as I watched the speeches given at the rallies at Kalo Dungar. The most obvious one, to begin with, is that of the Chief Officer of the Local Municipality of Bhuj (see Fig.42). He states:

During my tenure here as 'Chief Area Officer' for five years, from 1995 to 2000 in this jurisdiction of 'Kalo Dungar', whenever our leaders or trustees required any permissions for any developments to be made up here, I always said Yes! What prompted all this progress of Guru Datta here? We were all very worried because, initially this place was named 'Pachmai Pir'. But since the VHP started its propagation this site for Guru Datta has started to belong to the Hindus, and has become a site for Hindu pilgrimage. From 1995 to 2000 during our party, the BJP's regime, for the progress of 'Guru Dattatraya' we acquired and cleared many grants. As you can see this new road; we had commissioned the road works, it cost (the government) around 1.5 to 2 million rupees. 


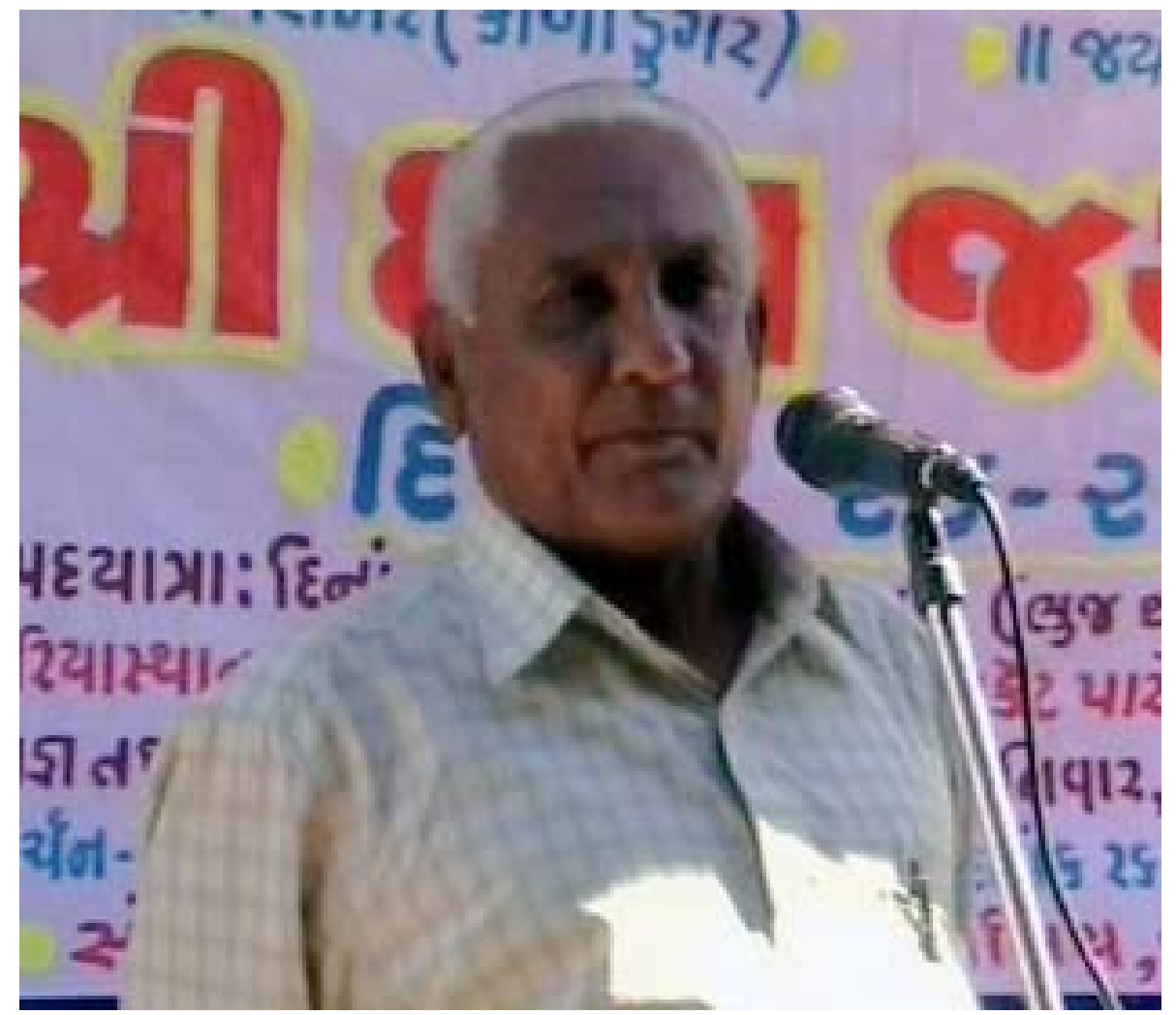

Fig.42. Chief Officer of the Local Municipality at Kalo Dungar VHP Rally.

This speech can be seen in Black Mountain (Chapter 20) and explicitly illustrates the Hindu agenda at Kalo Dungar. There was now no need for speculation, it had been stated quite clearly by the government worker/politician in this speech. As can be seen in the film, this speech, as are the others that follow, is spoken with conviction and, to me, arrogance; there is no remorse or tentativeness in the tone, this development at Kalo Dungar is something to be proud of, not to shy away from. The following excerpt makes specific reference to the Muslim populated area of Kalo Dungar, the speech is delivered in threatening tone (see Black Mountain - Chapter 20).

In this area there are many impure elements (the Muslims). They have got the news that thousands of us have gathered here, in the sanctity of 'Lord Datta'. Thousands of Hindus have congregated. And now they (the Hindus) are cheering their gods.

He proceeds to harangue the crowd with chants of,

Say Jai Shri Ram - [Salutations Lord Rama] Jai Shri Ram [Salutations Lord Rama] Say Jai Guru Datta [Salutations to Lord 
Datta], Jai Guru Datta [Salutations to Lord Datta], Bharat Mata ki Jai [Hail Mother India]. Bharat Mata ki Jai [Hail Mother India].

As he says each chant he encourages the gathered crowd to say it louder until the final chant to the Motherland is made with impressive response to which the politician responds in what sounds to me to be in the most arrogant and provocative tone, 'Yes, that's right!' It was almost as if he wanted to make sure that the Muslim population that lived in the surrounding villagers could hear the Hindus gathered. This incitement of hatred continued in further speeches in which the significance of the border location of Kalo Dungar is addressed. Again these speeches too, are delivered in arrogant and intimidating tone. They can all be viewed in Black Mountain (Chapter 20). The first speech states that 'the Borders of our country are like the clothes of our Mother, it is the duty of every son to protect them'. Implying that this border region needed to be protected, there is specific reference here to the Mother too, which also refers to the land itself, within Hindu right-wing ideology the land of India is the Motherland. The second speech I quote refers to the importance of increasing the Hindu population on the border (see Fig.43).

In Kutch this area at the border near Kalo Dungar is especially important. When we stand on top of Kalo Dungar we can view the entire Rann in a single glance, as well as the last of the villages of Kutch, like Kuran or Drobhana and our border [India-Pakistan]. So my friends, we have to aspire to achieve our goal of re-settling our fellow patriotic [Hindu] brothers in this vicinity. They need to settle here and their numbers need to increase so that this sensitive border area can be monitored. As we have all noticed after the earthquake in this border-touching area, patriotic people like us [i.e. Hindus], are migrating and moving away, and our borders are being left unguarded. Only if we stay alert and maintain caution, will we be able to maintain control over these betraying, unpatriotic, anti-social elements [i.e. Muslim]. Now that this mission has gathered momentum, having established this 'Guru Dattatraya' temple here, on this 'Kalo Dungar' also known as 'The Guard of the border!' we have a vantage point from where one can keep watch on the entire border. This fabulous occasion and organisation can only be the brainchild of the RSS. Bharat Mata ki Jai [Hail Mother India]. 


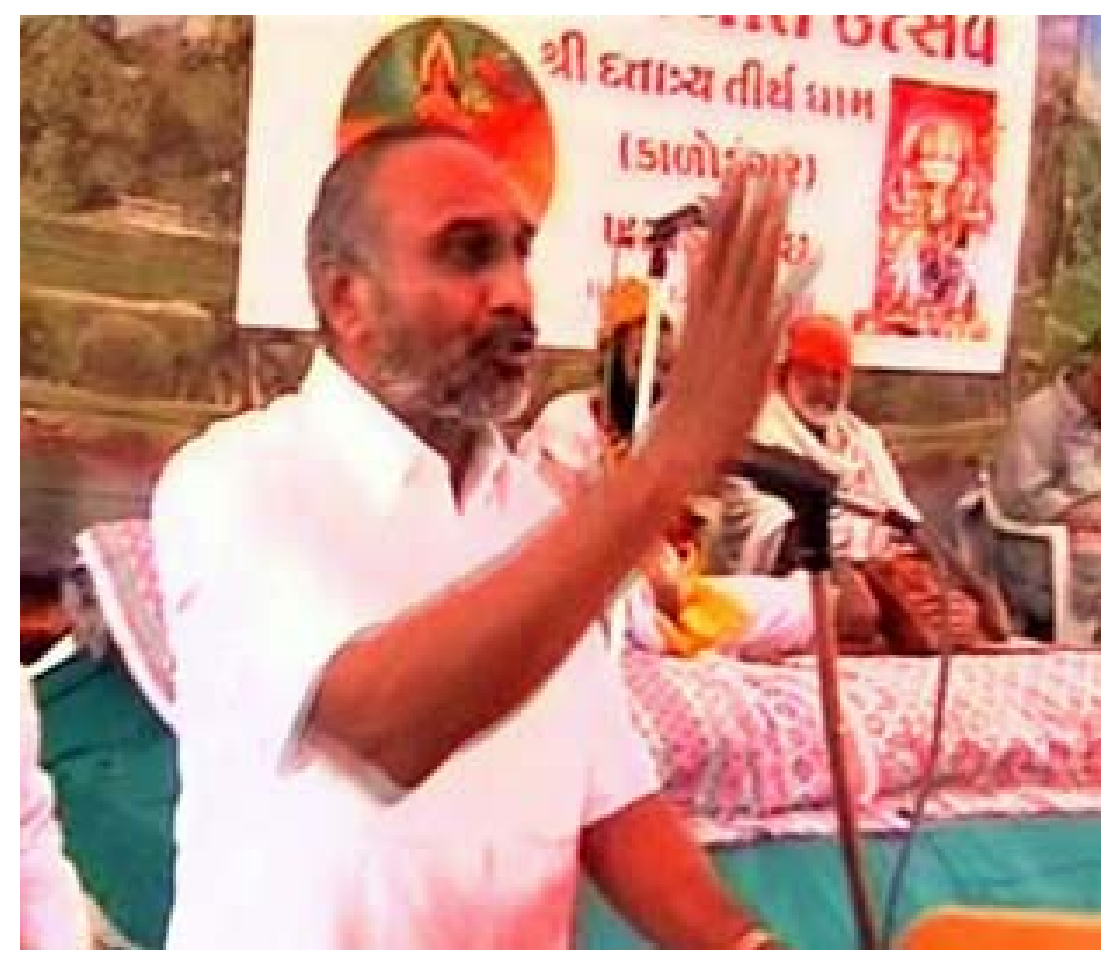

Fig.43.Politician speaking at rally on Kalo Dungar.

This speech highlights the evident insecurity and paranoia that the Hindu community feels - at least, those who support the right-wing sentiments, and chooses to instil through their Hindutva ideology into their followers. If one looks at the people in the crowds shown during the footage (also seen in Black Mountain - Chapter 20 and Fig. 44 ) it is evident that they are people from the villages of Kutch, people who, due to their lack of literacy, can be rallied for causes like these and their ideas manipulated, just as the two friends in the bookshop had stated. Often these villagers are given money to vote for certain parties and they view these types of occasions as an outing presented to them as a holy pilgrimage, but costs them nothing. They receive free food, water and somewhere to sleep, they enjoy a kind of picnic, a break from their hard and difficult lives, and through it all they make a pilgrimage to God and receive his blessings in return. 

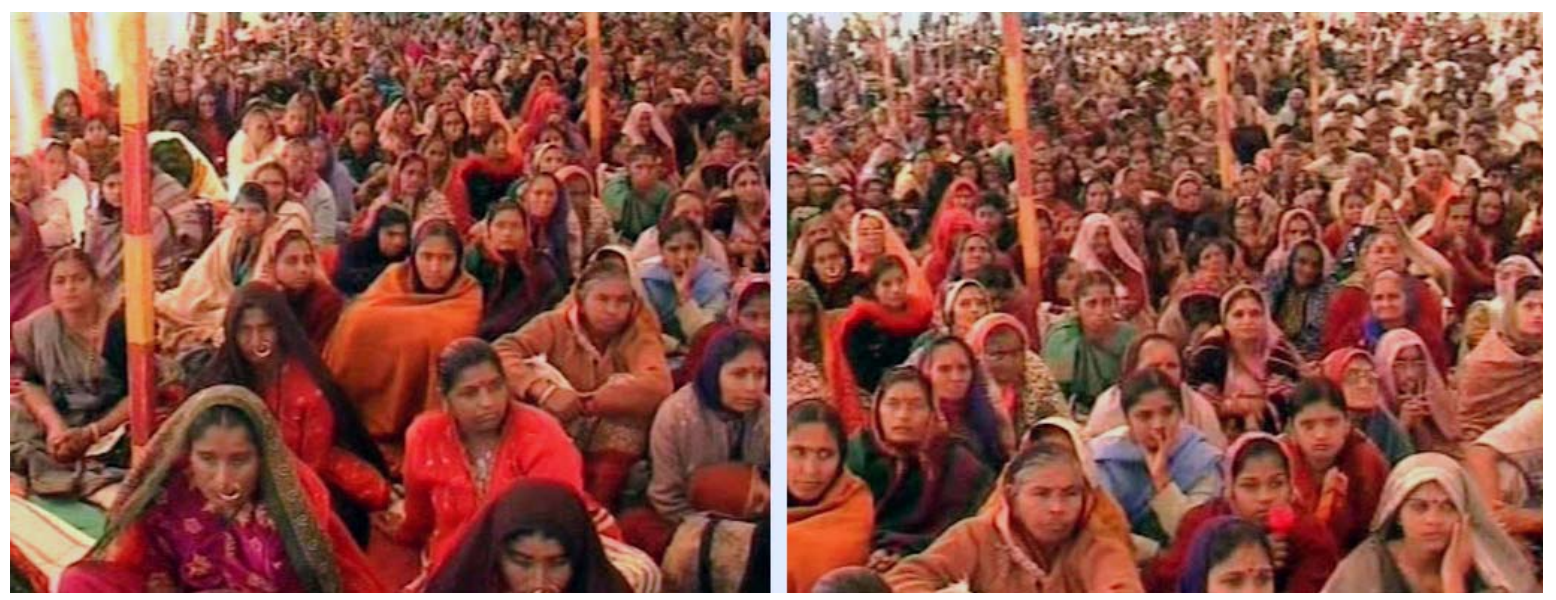

Fig.44. Pilgrims gathered for the political speeches at Kalo Dungar.

They can perhaps be convinced that it is people like them who need to resettle in this border region and guard the border, just as Guru Dattatreya on Kalo Dungar is now the 'Guard of the Border' and can keep a watch from its high vantage point. Another speaker highlighted the problem of the increasing population of the Muslim community and chose the now common arguments used to denigrate the Muslim community (see Black Mountain - Chapter 9).

In the last fifty years $12 \%$ of the population of non-Hindus has increased. They are now trying to manipulate $85 \%$ of the Hindu population. The problem is how to address those feelings of insecurity within the entire Hindu Population. It is about the insecurity of our Nation, we are all well aware of the problems that have been discovered in the small towns situated along the borders of our country. All the small and big businesses are being monopolised by the aggressive minorities, the Muslims. Because the Hindus have no other way to earn their livelihood they are running off and migrating to the heartland. This is the challenge we need to combat. It is not just a challenge for only those Hindus staying, in those small towns, this is a challenge that we have to combat all over in our own country. To derive a solution for this problem, we need the support of the entire Hindu community. They [the Muslims] are busy increasing their population and numbers. That is possible firstly by bearing children, and secondly by having four wives per male, and thereby twenty-five kids per family, they are multiplying briskly. It's not just the Muslims; in fact a lot of Christians too are doing these things.

This speaker touches on the right-wing Hindu parties' argument that the Indian constitution is not being applied equally to all citizens as the members of the Muslim community are allowed to practise Sharia law, which permits Muslim men more than 
one wife, and thus the Muslim population is able to increase faster than the Hindu one (the assumption is that all Muslim men will practise polygamy, which is actually not the case). He adds that due to the increasing Muslim population the small businesses are being taken away from the Hindu population. He also adds that this phenomenon is specifically present in the border areas, which is causing the Hindu communities to move to the heartland. It is well known that the Muslim population are an extremely astute business community, and these statements once again highlight the irritation of the Hindu right-wing followers with the success of the Muslim population and their (Hindus’) insecurity that they (Muslims) should not become too powerful in their (Hindus') majority country. Of course, when these statements are understood in the context of the actual size of the whole Muslim population, which makes up about $12.5 \%$ of the entire country, they seem unreasonable. Unfortunately the actual statistics of the ratio of Hindu to Muslims in the border areas are not readily available, so it is difficult to compare actual figures.

It is this kind of anti-plural, anti-syncretic behaviour (i.e. making such speeches) that I argue is contributing to, if not fuelling, the breakdown of syncretism in India today. These actions by right-wing Hindu groups are ensuring that any syncretic place of worship where it is possible for them to stake a claim on, is being redefined as exclusively Hindu. I am not implying that the Muslim population do not have their own orthodox and right-wing agenda, they do, which is, as we discovered from the people of Drobhana, also contributing to this breakdown, as the Muslim populations are taught to follow a more orthodox Islamic practice, and even go to the extreme of demolishing sacred sites. There are examples too, of Muslims staking their claim on syncretic places of worship, such as Ajmer, where, even though the dargah certainly still enjoys a syncretic following of pilgrims, there has been a mosque built within the site and its Islamic inheritance is clearly stated and maintained. However in my experience of this research, specifically, it was the Hindu right-wing which was the more active body, it would take further research in this field to discover if these 'takeovers' were also being undertaken by local Muslim populations. From my research the evidence suggests that this is not so, the majority of cases in which these 'takeover' bids are happening are by the Hindu right-wing community rather than the other way round. 
I would like to end this section of the chapter with one last speech from the DVD footage that we received. Made by a Hindu Pujari, the speech presents a clear indication of the interpretation of history from the Hindu right-wing ideology, which often presents the Muslim and Christian community as conquerors who tried to convert the races of the world including the Hindu population of India (also seen in Black Mountain - Chapter 9).

In Europe the Christians destroyed many traditions and cultures. The likes of Rome and the Greek culture, the Druids of England, they destroyed them all, they even captured Africa. The Muslims destroyed the cultures of Persia, Mesopotamia and Babylon. For over a thousand years now both these barbaric races, the Christians and the Muslims have attacked us. But they still have not succeeded in destroying us. Even today one billion of us Hindus are living together, here on Earth.

He goes on to state that the world has erected walls to defend itself whereas at Kalo Dungar God has given a natural wall, the highest point over which to watch the movement of the enemy.

People all over the world erect walls, but this Black Mountain is special. The Great Wall of China - to protect them China erected the Great Wall. But here in our case, God has already given us a 'Great Wall'. No one can compete with this one.

He finishes with a statement regarding the cultural roots of Muslims in India.

There is something I want to tell them [the Muslims], their blood [their roots] will not match those from Saudi Arabia, nor do their features match those living in Saudi Arabia. If you follow their ancestors, you will find that they were the same as ours. Our very own people who converted to Islam under pressure, at that time. I request them to remind themselves of their ancestors and trace their roots.

I had listened to Amin's anxieties about being in Bhuj undertaking my research, but somehow the reality of his fears had never completely dawned on me. Suddenly they did. The hatred preached at the pilgrimage of Kalo Dungar was something I had not witnessed first hand before. In some morally naïve way I felt like I should inform the authorities of these activities with the tapes as evidence, after all, inciting hatred against other communities goes against the Indian constitution; it states in the Indian 
Penal Code, Section 153a that 'promoting enmity between different groups on grounds of religion, race, place of birth, residence, language etc and doing acts of pre-judicial to maintenance of harmony' is against the law and suffers a sentence of up to three years.

Amin laughed at my reaction reminding me that this was only one minor example of a national campaign which is played out publicly for all the authorities to hear, and for most of them to support. One only has to recall three recent events to understand that the government authorities of this sub-continent are not particularly interested in taking a stand against this kind of communal behaviour. The recommendations of the Sri Krishna Commission, a report which openly indicated the almost singlehanded involvement of Bal Thackeray and his Shiv Sena party in the 1992 riots in Bombay, has never been put into effect; nobody has ever been brought to trial regarding the riots. In contrast, most of the Muslims involved in the bomb blasts that occurred in reaction to the rioting and massacring of the Muslim population have been brought to trial and sentenced. Just recently (February 2008), it was announced by the Maharashtra state authorities that now the Sri commission report would not be reopened for fear that it might incite more communal violence regarding an issue that occurred over fifteen years ago. Nobody was outraged by this or even reacted, it was just accepted and people went about their normal lives, almost resigned to the fact that this was inevitable. Just as they did when Narendra Modi, who has been reelected into power in Gujarat twice since the horrific pogrom in 2002, was proved to be actively involved in organising the pogrom. With the evidence collected by Tehelka magazine ${ }^{29}$, the national election commission under the government of the Congress could have prevented Narendra Modi from even standing for the recent state elections in Gujarat, due to his misconduct. However, instead, it was ignored, bearing evidence to the supposedly secular Congress party’s weakness for communal vote bank politics (discussed in the following chapter); they are very aware how popular Modi is in Gujarat and would not risk losing their own Hindu vote bank by bringing him to justice.

\footnotetext{
${ }^{29}$ This proof comes through recorded evidence, taken undercover by Tehelka magazine, of conversations and meetings of men and women who admitted to massacring hundreds of Muslims during the three day pogrom, in which they state that Narendra Modi had told them directly that they had three days to do what ever they wanted. A small minority of the population were shocked as were many of my family and friends, that this exposé of the Chief Minister, of one of the largest most influential states in India, hardly even grabbed headline news.
} 
I felt after hearing the VHP's propaganda that I would like to hear the voice of the Muslim. Why was Islam in India abandoning its dargahs and instead working towards a more isolated notion of Islam? Impulsively I began to interview all the Muslims I knew who lived in our vicinity. The most interesting encounter happened in the hair salon outside our home in Bandra, Mumbai. It is run by a Muslim and has about six Muslim employees. We asked them about their opinion on the practice of dargah veneration. One of the employees is called Andaleep ${ }^{30}$, he expressed the view that it was mentioned in the Holy Quran that Sufis and mystics should be respected, which means that they were important religious places for all Muslims, but some sects (and he mentioned the Tablighi specifically) within Islam strongly objected to venerating at these shrines as prayers should only be offered to Allah. He acknowledged that there were different interpretations but he felt it should be a personal choice, if some people wanted to use a medium like a Sufi saint to reach Allah then they should be allowed to do so.

Another man in the saloon, who was blind, joined in the conversation stating that 'many people say it's blasphemous'. We asked him if he agreed with them and he said 'no, in my personal view I don't agree with them. It's about one's own personal view. Some believe, some don't, but I feel no one should be forced'31. A Maulvi or leader, also works in the salon, so we asked him why he felt it was blasphemous:

Starting to believe in something new, introducing practices that were not prevalent during the time of our Prophet, and practising them is blasphemous. Starting new rites or ritual within the practice of the religion is blasphemous.

One of the barbers at the salon, Taufeeq, reacted to the Maulvi, arguing that in order to reach God one needs a medium. He argued, 'how can one jump and reach the top of a building? One would need a route, a medium like steps, a link to reach the top'. An argument ensued between the Maulvi and Taufeeq ${ }^{32}$, as the Maulvi reiterated to Taufeeq that 'bowing one's head in front of anyone other than Allah is disallowed, it's blasphemous'.

\footnotetext{
30 The interview can be seen in Black Mountain - chapter 23.

31 The interview can be seen in Black Mountain - chapter 23.

32 The argument can be seen in Black Mountain - chapter 23.
} 


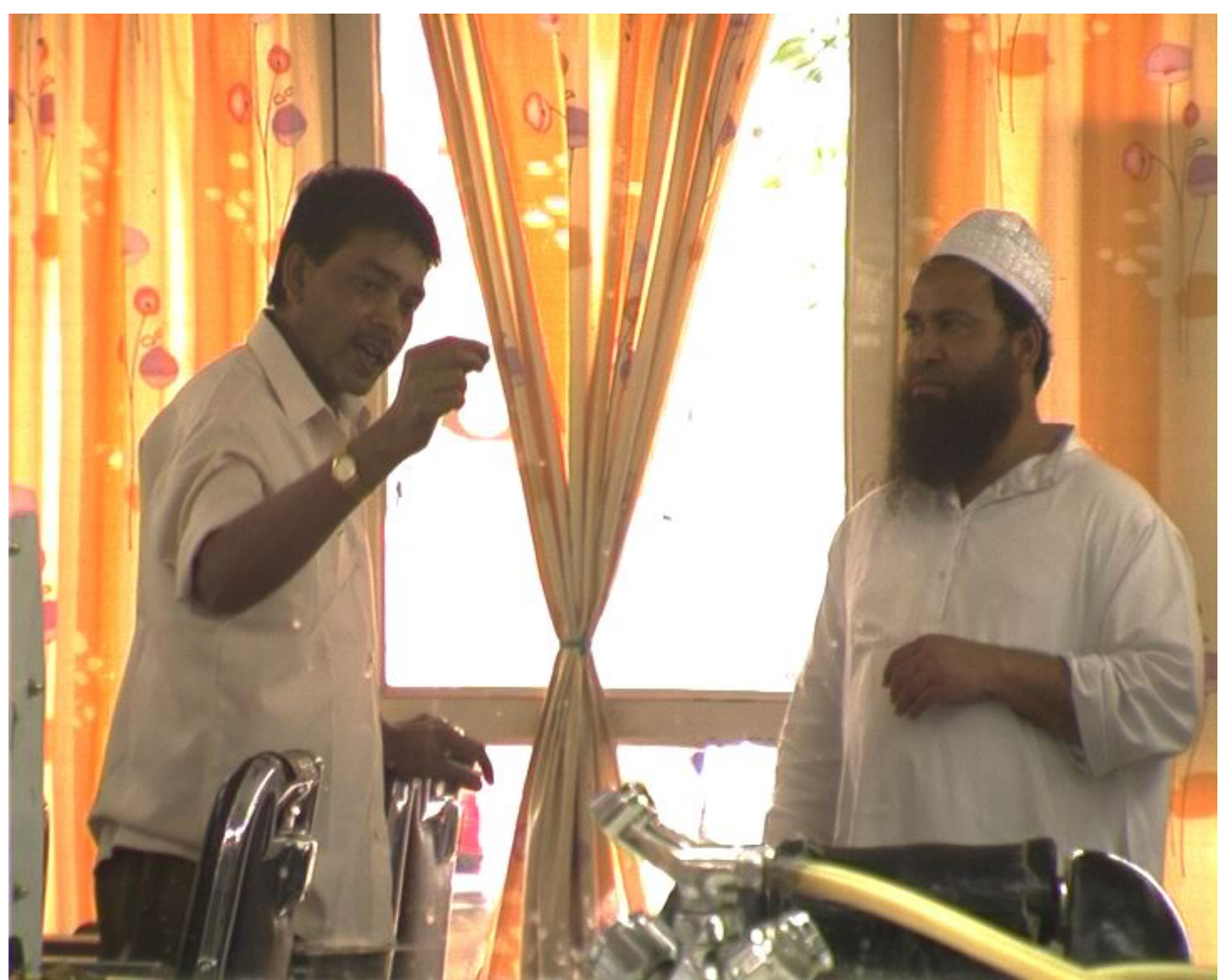

Fig.45. Argument in Salon, Taufeef (left) and Maulvi (right).

\section{Taufeeq:}

You say, 'going to such places is wrong', but if we feel and believe, that by visiting such a shrine, it benefits us and helps us, then without doubt we will continue to go there. Even if you try, you can't stop us.

\section{Maulvi:}

Even if that practice is detrimental to our religion?

\section{Taufeeq:}

No! How is the practice detrimental to our religion?

\section{Maulvi:}

You are only looking at your worldly gains!

\section{Taufeeq:}

No I'm not, I'm only following the religion.

Maulvi:

And how are you doing that?

\section{Taufeeq:}

All these dargahs and Sufi shrines have not been made by the Hindus.

The statement made by Taufeeq at the end received no reply from the Maulvi and the fight ended. Taufeeq had a point, these shrines have not been made by Hindus, they had most definitely been made by Sufis, i.e. Muslims. However, as was stated above by Andaleep, it is about interpretation, and the Quran is a holy book open to 
different interpretations, and it is these interpretations that create so much unrest and disagreement within the faith itself. The other person in the salon, the blind man, had other pertinent comments to make with respect to Kalo Dungar when we asked him why he felt fewer Muslims were visiting dargahs these days:

Because now people of other religions are staking their claim on them, so Muslims don't go there often, as they have now kept their [Hindu] idols in there.

Q: How do you feel when places like these, where everybody used to frequent and pray become inaccessible?

Ans: It does not feel good.

Q: Why?

Ans: Because they have now installed idols in there, how can we bow before idols? At dargahs we don't bow, we only pray through the Saint, requesting him to put in a good word for us to the Almighty to fulfil our wishes. We pray that this person [Saint] had prayed so much to you Oh Allah! Through him please fulfil our dreams.

This was the view of one particular Muslim. The Hindu claim over many of these sites was a deterrent for those Muslims who would like to continue the practice of worshipping at dargahs. The following chapter provides other examples like Kalo Dungar where previously Sufi dargahs have been Hinduised, slowly erasing an 'ancient institution sustaining a system of linked centres that helps bind together the incredibly diverse peoples of the Indian subcontinent’ (Grodzins Gold 1998:1). Grodzin makes this comment in the context of pilgrimage sites in India, however it is most pertinent to Sufi dargahs.

\section{Conclusion}

Before ending this chapter, I think it is relevant to allude to the emotions that this research stirred during the fieldwork and the literature based research that was undertaken.

Fieldwork, at its core is a long and social process of coming to terms with a culture...the workings and understandings may be symbolised by fieldnotes, but the intellectual activities that support such understandings are unlikely to be found in daily records. The great dependency commonly claimed to exist between fieldnotes and fieldworkers is not and cannot be so very great after all (Van Maanen 1988:118, in Dubisch 1995:118). 
This statement encapsulates much of my experience, in the sense that my field notes and film footage provided a record of what I had undertaken, encountered and experienced in the field. However they do not provide what Van Maanen describes as the intellectual activities that enable an understanding of field experiences after the fieldwork is over. These activities were active constantly as I interacted on a casual level with friends and family in India during and after my fieldwork; through these interactions I understood in more depth other aspects of communalism, specifically, how it is dealt with and interpreted by those who have been born and have lived amongst it everyday throughout their lives. It is difficult to describe the palpable tension that discussions regarding communal hostility generates in these situations, especially when in the company of people, who in my experience, represent much of the urban upper middle class of Bombay, who refuse, or at least find it very difficult, to listen to anything negative or controversial spoken about their country. Misplaced patriotism and jingoistic viewpoints suddenly rise to the surface when the debate arises as to whether or not India faces its own type of Hitleresque fascism in the RSS, VHP, BJP and their sister organisations. I often found myself speechless at the closeted fascism that I faced when discussing aspects of my research. I realised that I, who was reading about right-wing politics and the fascist values that it represents, was in my research, very much involved in the psyche and activities of these organisations, and in my outsider-like newness to the subject I viewed these regimes with distain, and was concerned with what they represented; I found myself voicing these concerns quite often. However I remained surprised by reactions from people ready to defend these groups and their actions, convinced, that in my concern, I was over-reacting. On many occasions instead of facing the reality, people were all too ready to denigrate the West's immoral, unreligious society rather than face the current argument related to pertinent issues in their own (society). Bubbling communal tension was all too palpable for me, whereas, it seemed, that for all those who have grown up with this communal tension, it was all too far away to worry about; they just went about their daily lives.

According to Dutton (2007), the ethical guidelines set down by the ASA (Association of Social Anthropologists of the United Kingdom and the Commonwealth) state that 'one should not expose those one is studying to knowledge they have not requested and, therefore, one should be very cautious in 
critiquing their religious perspectives' (2007:12). This may be an ideal, ethical standpoint, however in reality, at least in the case in point, communalism is a common subject and news item, it is not as if people are not already exposed to it. Perhaps on reading this guideline, I should have refrained from imparting my concerns to people, however the situation in which I live means that I am surrounded by friends and family who are not necessarily my subjects, so they often become a sounding board for expressing my emotions. I would agree with Dutton when he states that 'although it has traditionally been argued that we, as anthropologists, should ensure that nobody ever feels threatened...such feelings will arise in normal human relations' (op.cit.13), and I would argue, can often give the anthropologist a further insight into their subject.

During my research I found myself all too often depressed and emotionally tearful by statements people made, or chapters I read, and as I have described above, during the fieldwork process emotions were often hard to control and made fieldwork at times extremely difficult. Sometimes it was weeks before I was able to pick up a book to face the reality of India's communal problems again and again. Newspaper articles telling of petty communal scuffles where 'just' a couple of people were killed, glared out at me, communalism was becoming like my shadow, everywhere I turned it faced me. I am quite sure these emotions affected the way I viewed my research and the way I interacted with people, finding it at times extremely claustrophobic to be in India at all. Similar instances, although in a completely different context, are described by Woodthorpe, in her reflections on doing research that involved spending extended amounts of time at cemeteries.

Overall, most of my time spent in the field was emotionally draining and physically exhausting, and for the majority of my time I was pretty miserable. Not only that, but as time passed in the field I also found myself becoming increasingly sensitised to issues surrounding grief and mourning. (Woodthorpe 2007:4).

As I reflect, I too had become sensitised to anything communal, however I would say that this sensitivity enabled me to view things in a different way and it became all too apparent to me that the activities of the pilgrimage to Kalo Dungar mirrored the problems facing India on a national macro-scale. As Dutton suggests: 
emotion can be extremely useful in a variety of ways: it can evoke thought, it can rekindle the fascination and keep one interested, it can be a means to empathy and greater understanding, it can prompt deeper reflection on one's method and position, it can alert one to phenomena that would otherwise remain unnoticed and aid in interpreting them (2007:13).

Dubisch states that through all of her experiments in writing reflexively her main goal is to present 'a place and a way of life as experienced in the particular set of activities that cluster around a pilgrimage site' (1995:7). In my experience the activities and way of life that clustered around my pilgrimage site were in fact quite reflective of other activities happening around the country as I became aware of the commonness of communal clashes. It became evident that any study on pilgrimage is not just about religion or spiritual beliefs but also about aspects of social behaviour engulfed in a web of behaviours that represent society. It is now recognised that the study of pilgrimage offers a means for the anthropologist 'to transcend localism and to tie into regionalism, nationalism, economics, politics and larger religious traditions’ (Dubisch 1995:39/40). After all

the site can be understood only as a setting for a wide range of behaviours, embodying multiple meanings and goals, and as both a part and a manifestation of many other aspects of a society historical, social, political, economic, and religious...the site is...a vehicle...for seeking to understand larger social, cultural and political processes (op.cit.7).

In my experience of India, the pilgrimage to Kalo Dungar indeed represented many aspects of society and definitely provided an environment in which I grew to understand the 'larger social, cultural and political processes' abounding in India at large.

Not just as a pilgrimage site but also as a border region, Kalo Dungar, in my mind, represented many other features of India's political culture, as Donnan \& Wilson state, more often than not borders today 'mirror the changes that are affecting the institutions and policies of their states, but also point to transformations in the definitions of citizenship, sovereignty and national identity' (2001:4). I was sure that the activities at Kalo Dungar mirrored the changes affecting Gujarat and the politics of Narendra Modi, however I wondered if they also mirrored the changing nature or transformation of what was defined as India's national identity. Was 
India's national identity becoming synonymous with being Hindu? Were the Hindu right-wing, therefore, achieving their goal? Donnan \& Wilson go on to contend that 'borders are not just symbols...of these changes...but are often also their agents' (ibid). After the experiences at Kalo Dungar I can only but agree. This border was certainly an agent, or a reason at least, for the political activity that I witnessed, and it had become an agent for the changes described above; the region was perceived as over populated with Muslims who found their cultural traditions more similar to those across the border. I don't hesitate to state that this micro-example of Kalo Dungar reflects the much larger agenda of the BJP and its sister concerns to reaffirm the national identity of India as a Hindu State. 


\section{Chapter 7}

\section{$\sim$ Anti-syncretism}

Anti-syncretism: the antagonism to religious synthesis shown by agents concerned with the defence of religious boundaries (Stewart \& Shaw 1994:7).

Throughout the late $19^{\text {th }}$ and $20^{\text {th }}$ Century shared religious sites such as Kalo Dungar and others described later in this chapter have been politically targeted. Over the last century, as described in previous chapters, communities that once straddled a space between Hinduism and Islam have been manoeuvred into the equivalent of opposing political camps. This came about with the introduction of the census and then with the subsequent growth of orthodox Hindu and Muslim groups that have endeavoured to support campaigns for 'proper' conversions and for what they perceive as a necessary move away from 'impure' religious practices to 'pure' ones. One of the results of this behavioural trend has been that,

In many parts of India Sufi dargahs where 'Hindus' and 'Muslims' would earlier worship together, have been converted into Hindu temples through force or fraud...the properties that some of them possess and the regular stream of donations make them a lucrative [political] target...(Sikand 2003:15).

In recent years the politically instigated conversion of (mainly) Sufi dargahs into Hindu equivalents has been most prevalent. This chapter intends to draw on examples of this behaviour to illustrate the development of anti-syncretic behaviour within the sub-continent. It is acknowledged that some of the reformist Islamic groups, such as the Wahhabi, have protested against Saint worship since the arrival of Sufism centuries ago, however the focus here is primarily the Hindu nationalist organisations that have more recently influenced anti-syncretic manifestation within the sub-continent, mainly because of the following:

- the power struggle between the ideas of 'pure' and 'impure' religious traditions.

- the breakdown and subsequent failing of the political legitimacy of the secular democratic regime due to the complex secularism practised by India's 
government which has enabled the growth of what are fascist-style, rightwing, religio-political groups.

- the fuelling of an already existing crisis of national identity by the right-wing Hindu organisations to the extent that the 'current generation appears to be more deeply conscious of its communal identity than at any other period in post-independence India’ (Misra 2004:238).

These factors combined have given rise to a growth in communally motivated violent behaviour, which can be understood using the theory of schismogenesis. It is acknowledged that syncretism, especially with regard to Saint worship, attracts antisyncretic behaviour, as those faiths that share a site as a place of worship often do so within the constraints of their own religious orientation.

\section{Power as a factor of anti-syncretism}

Droogers' argument is that 'syncretism is an expression of a power struggle' (2005:226). In general terms the word 'power' refers to 'control over resources' (op.cit.220); in a religious context, power is 'exercised through management and control' of the religion, including control of its rituals (ibid). However, despite the evident importance of power to the syncretic argument, Droogers acknowledges that in most definitions of syncretism the power dimension is ignored, and it is the intermingling or 'mixing of religious influences' that is focussed upon (op.cit.226). From my research this seems to be true, it is the fear of inter-mingling that generates the power struggle within the purist element of a religion, therefore consideration of the power dimension is essential in any use of the concept of syncretism. Van Der Veer too recognises this:

syncretism refers to a politics of difference and identity and that as such the notion of power is crucial in its understanding. At stake is the power to identify true religion and to authorize some practices as 'truthful' and others as 'false' (1994:196).

Within these power dynamics then, are indigenous notions of 'true' and 'false' or, what I would rather term, 'pure' and 'impure’ religious practices. It is argued by anti-syncretists that syncretism is a process which destroys the 'purity' of a religion, that is, what is believed to be its original form or essence. The 'purists' see 
syncretism as the infiltration of symbols and meanings, possibly even rituals, from other incompatible religious traditions, into their 'pure' religious traditions and thus as a type of ‘contamination' (Stewart \& Shaw 1994:1) or as ‘devaluing’ (Nanji 1978, cited in Sila Khan 2003: 33). Droogers expresses the view that 'syncretism implies access to a double stock of meanings, more often than not jealously guarded by competing religious elites who do not appreciate such mingling, and who will use their power to prevent it from happening' (2004:220). So it is normally the 'purists' who, in their dislike for religious inter-mingling, become anti-syncretists, and feel it necessary to eliminate any syncretic practice such as that experienced at Kalo Dungar and other such sites.

The term syncretism is often used 'pejoratively...by the defenders of the true faith. It is seen as a loss of identity, an illicit contamination, a sign of religious decadence', a 'corruption of the truth' and in some cases an 'attempt to secure unity at the expense of truth' (Pyre 1971, cited in Van Der Veer 1994b:197). As syncretic religion became more popular through the Sufi and Ismaili traditions, it faced resistance from both Muslims and Hindus. The Muslims believed that it was 'a threat to the purity of Islam' and Hindus considered it to be 'a denial of the essential truths of their religion and a threat to the very fabric of society' (Hawkins 2004:76).

The initial detractors of Sufism, which is held as the cornerstone for much syncretic practice that has evolved in India, were the reformist Islamic group - the Wahhabis. Wahhabism was founded in Saudi Arabia by a 'religious reformer named Muhammad ibn al-Wahhab (1703-92) [who] set out to purify Islam’ (Maroney 2006:71, emphasis in original). Wahhabism believes that 'Sufism and shrine worship, which were in fact expressions of popular and folk Islam, were idolatrous distortions that should be rooted out' (ibid) and Wahhabists, in their purist beliefs, have 'tried to turn the clock back on...broad heritage, to lay bare the essential message of the Prophet in its primal simplicity and purity' (op.cit.14). The Wahhabis were the main influence on the opponents of Saint worship in India in the nineteenth century (Gaborieau 2004b, Van der Veer 1994) believing it makes the Muslims 'resemble the heathen Hindus among whom they live' (Gaborieau 2004b:201). Van der Veer refers to another reformist group too, the 'Naqshbandi Mujad-dadi', an early reform movement of South Asia, 'reverently opposed to saint 
- and tomb-worship' (1994:58), as well as the Deoband movement, which is considered the 'stronghold of anti-Sufism' (ibid). These organisations would rather reverse much of what Islam had become in order to spread its word; as Maroney states, Islam 'spread (in part) due to its adaptation to the cultures it found' (2006:14). According to Droogers, too, 'at the origin of a religion, syncretist processes are often essential to the formation of that religion', however, 'once a religion is established and religious founders have completed its codification, these syncretist origins are forgotten’ (2005:226). In which case, 'where before syncretism was a strategic necessity’, Droogers argues, 'now purism is felt as inevitable’ (op.cit.233).

A similar pattern prevails in right-wing Hinduism. As learned in earlier chapters, there has been a strong element within Hinduism that, in their wish for a pure Hindu Rashtra, also attempts to diminish or change the status of these same shrines. Even though idol worship and Saint veneration is a key factor of Hindu ritual, venerating a Muslim Saint is not considered to be upholding the pure version of Hinduism, practised and believed in by organisations such as the RSS, VHP and BJP. These impure, syncretic elements, according to these organisations, also add to the increasing threat of the Muslim population to Hinduism, and this produces a sense of identity crisis. I would like to discuss further the idea of 'pure' and 'impure' religious elements and the importance of upholding the 'pure' in order to maintain the upper hand in the power struggle against the 'impure'.

Mary Douglas, in Purity and Danger (1966), examines the ideas of pollution and purity in 'primitive' religions. Notions of purity are used to uphold social order by societies, or as in the case of my research, religions, which perceive themselves as under threat. By eliminating 'impure' religiously syncretic practices the purists then make what they perceive to be a 'positive effort to organise the environment' (op.cit.2). This comment by Douglas is made with regard to dirt; however I feel that it holds much the same meaning with regard to the argument for 'pure' religious practices, where eliminating the impure elements will only have a positive effect on the efforts to re-organise religious tradition as it is believed that the purer the religion the stronger it is, and more capable of resisting potential threats. The so-called purists are affected then, if members of their community are involved in worship that may not be seen as completely pure to their religion, as they believe that these 
‘impure’ practices weaken it. For this reason followers are encouraged away from intermingling and shared faith worship.

Another point within this discussion of power and purists is that the purists themselves and the religion they practice are more often than not 'fraught with compromise and diluted when deemed necessary or expedient', after all 'modern fundamentalist movements are moulded by the modernity they seek to escape or exclude' (Maroney 2006:71). Douglas makes a similar point when she states that

the native of any culture naturally thinks of himself as receiving passively his ideas of power and danger in the universe, discounting any minor modifications he himself may have contributed. In the same way we think ourselves as passively receiving our native language and discount our responsibility for shifts it undergoes in our lifetime (1966:5).

In the context of anti-syncretic behaviour and the groups that represent it, the same holds true. For example, whether it be the VHP, RSS or the Wahhabis, they often forget the adulterated religious practice that they may have inherited and the adulteration that they themselves submit their religion to, when interpreting it in a one-dimensional manner. This is especially so within their condemnation of 'ideas likely to confuse or contradict [what they perceive as] cherished classifications' (op.cit.37). What the purists forget is that any 'classification' gives 'rise to anomalies' (op.cit.40), which, according to Douglas, must be confronted, especially if they 'defy its assumptions' (ibid.). In this case they 'cannot ignore the anomalies', if they do, they produce a lack of confidence in the system itself, or in this case the religion (ibid). Hindu right-wing organisations are a fine example of this; it is the fear of the breakdown or disintegration of their religion and therefore of their identity that spurs the need to denigrate the followers of another religion they see as threatening, i.e. Muslims, who in this case also contribute to an impure practice within Hinduism, as Hindus venerate at Sufi dargahs. The difference here being, that these impure practices do not necessarily produce a lack of confidence in the system, rather the right-wing organisations instil this lack of confidence themselves in order to achieve their goals. But most certainly, the anomaly, i.e. the syncretic practices, eventually creates an anxious state within the purists who consider the practices dangerous, and therefore the anomalies produced by the systems of 
classifications, such as syncretic practices, inevitably become 'central objects of religious concern in...society’ (Douglas 2002:194), and should be resisted.

According to Leopold and Jensen who quote Droogers, "“anti-syncretism” is an inevitable consequence of "syncretism”, , because of the 'determination of religious leaders to control the production of religion' (2005:154/155) in general. This need to 'control the production of religion' can be compared to the need to control the classification that defines the religion, as mentioned above. The anti-syncretic religious leaders in their struggle for power then, have to control the meaningmaking, as well as making rules about the treatment of anomalies, such as syncretic practices.

In order to illustrate his ideas of the importance of power, Droogers provides a model in which he attempts to explain the different levels of power struggles within extreme forms of religious construction. It provides a useful framework for understanding the anti-syncretic elements in religious construction in India. In order to show the applicability of Droogers' model, I have reproduced it below, giving an example of the Indian equivalent in each category with a full explanation of the model, and its application in the Indian context.

\begin{tabular}{|l|l|l|}
\hline DIMENSION & \multicolumn{2}{|c|}{ CATEGORIES } \\
\hline INTERNAL & $\begin{array}{l}|c| \\
\text { Religious specialists } \\
\text { Hierarchical } \\
\text { E.g. Islam, right-wing Hinduism }\end{array}$ & $\begin{array}{l}\text { Lay believers } \\
\text { Inclusivist } \\
\text { Hinduism in its pure form }\end{array}$ \\
\hline EXTERNAL & $\begin{array}{l}\text { Believers } \\
\text { Hostile } \\
\text { Orthodox right-wing leaders i.e. } \\
\text { Maulvis, Brahmins }\end{array}$ & $\begin{array}{l}\text { Society } \\
\text { Sympathizing } \\
\text { Mosques, temples, churches }\end{array}$ \\
\hline NATURAL & $\begin{array}{l}\text { God, gods, spirits } \\
\text { Revelatory } \\
\text { God/s reveals himself/themselves to } \\
\text { certain people who become } \\
\text { religious founders i.e. Mohammed }\end{array}$ & $\begin{array}{l}\text { Believers } \\
\text { Right-wing religious leaders } \\
\text { who impose their meanings } \\
\text { on God. }\end{array}$ \\
\hline
\end{tabular}

Fig.46. Modes of Religious Construction - adapted to the Indian context. Source: Droogers (2005: 223)

Droogers states that this model was developed for the study of religion and in turn syncretism; it defines the extreme elements of religious construction, depicting the importance of power in religious meaning-making. He begins by differentiating 
three dimensions in modes of religious construction. Each dimension and its categories can be understood in the context of power. For example, in the internal dimension, there are two categories, hierarchical and inclusivist. The hierarchical includes those religions that have leaders, or certain people that occupy positions of power, and therefore represent that religion. There are different levels of power, the amount of power that the respected person has over the religion or over believers will determine its hierarchical level, if they have very little power, they fit into the inclusivist category instead. An obvious example of the hierarchical category is the Roman Catholic religion with the Pope. In the context of India, both Islam and Hinduism fit into the hierarchical category; in Islam, within the Shia sects there is a living Imam whom they follow, and in the Sunni sects, even though they do not have living spiritual leaders who claim descent from the Prophet, they have self-created spiritual leaders such as the Ulama and Maulvis. Within Hinduism it is the same, Hinduism as a religion is diverse and despite popular belief, a relatively recent construct, it does not have one living authority, however within the caste system there are self-created leaders, generally Brahmins, who have taken on the role of spiritual leaders, in their capacity as the most educated and most pure, within the caste system. There are self-appointed authorities too, in the form of leaders of organisations such as the VHP. However, in its pure form, Hinduism would fall into the inclusivist category, as strictly speaking it is a philosophy or way of life, which individual lay believers can follow according to their needs and wishes.

The external dimension too has polarised categories, hostile and sympathizing. The hostile category is described as one where a religious group, 'critical of its social and cultural context' considers itself exclusive, and attempts to impose its beliefs on the rest of society projecting the characteristics of its meaning-making as the only 'true one' (op.cit.222). This category is exemplified by the purists of the right-wing orthodox groups of Hinduism and Islam, who try to project to their followers and society that their religion, and their interpretation of it, is the most authentic. On the other side you have what Droogers calls 'sympathisers' who, rather than criticise the social context of their religious group, approve of it, so 'religion and secular forms of power legitimate each other' (ibid). Droogers gives the example of state churches. In India, the temple, church and mosque could all be used as examples of 'sympathisers' (i.e. sympathetic institutions), because they fit into secular society and 
the individual power of each is legitimated by, and works alongside, the social structure and power of the state or local government. This is due to the fact that religious personal laws, among other things, are given political legitimacy in the Indian constitution, so, for the worshippers of each religious centre, the state and the 'parish', so to speak, govern them equally. The influence of religion on the secular nation-state of India is then perhaps more evident than in other secular nations.

Lastly, in the supernatural dimension, there are two extremes; one that proposes that there are "those to whom God has revealed himself", who in turn have become founders of those religions, such as Mohammed. And there are those who 'impose their meaning' on God (or gods) and 'make Him/them behave according to their will' (ibid). In the anti-syncretic and Indian context I suggest that the second category of 'explorative' believers are those leaders who have guided their followers on the teachings of God according to their imposed meanings, in order to preach to them hostility towards another religious group, as in the case of the VHP against the Muslims, and the birthplace of Ram in Ayodhya.

How does this model help us? I believe it provides a tool to explain religious structure in the anti-syncretic debate and the different aspects of the power struggles that the religious structure contains; in Droogers' words, it is the 'interrelationship' between these different components described in the model that 'determine[s] that religion's particular profile' (ibid), or in this case, the way anti-syncretic groups are able to justify their existence within the religious construction. It is suggested that each of the six modes of religious construction can be said to have consequences for the chances that syncretic processes will take place, however it has been interpreted here that the different modes have consequences which provide an opportunity for anti-syncretic processes to develop.

The next dimension that, I argue, allows the influx of anti-syncretic behaviour is that of political legitimacy and secularist politics. As stated above, the breakdown of political legitimacy and the subsequent failure of secularism also give rise to the development of anti-syncretic behaviours. It is important to understand in more detail the effect that a breakdown of democracy and political legitimacy has had on Indian politics and the growth of anti-syncretic elements that it caused. 


\section{The breakdown of legitimacy and the secular practice of the state}

Writers such as Young (1993), Bose (1997), Corbridge and Harriss (2000) all talk about the question of legitimacy in Indian politics and how it affects the political system. As Bose (1997) suggests, India went though a 'crisis of legitimacy' during the 80s and 90s which culminated in an 'organic crisis' of the state. Corbridge and Harriss (2000) refer specifically to a 'catastrophe' which describes a breakdown of legitimacy ultimately affecting political stability. Hayes (1993) explains the term 'legitimacy' by stating that in developing countries the pressures of modernization and globalisation have led to a breakdown in the legitimacy of the political system. This is a view supported by Lessinger (2003) who believes that India's political struggle of legitimacy stems from the pressures of globalisation, as opposed to those who suggest that this political breakdown is due to communal tensions that exist in the sub-continent and have been used for political and religious gains. According to Hayes (1993) the development of communal violence in the 60s and 70s was one of the products of economic development. In the early stages of economic development political burdens multiplied and political participation expanded which resulted in the breakdown of political institutions. Therefore to enable political development there needed to be a certain amount of political stability. This political stability usually manifests itself in a context of functioning political institutions, which as I mentioned earlier in the thesis, during the Indira Gandhi era were completely broken down ${ }^{1}$. Hayes gives an account of what political institutionalisation actually stands for, in which he quotes Randall \& Theobald in explaining that it lies in 'the capacity of the government to "absorb, reconcile and act upon diverse pressures and demands to which it is subjected”' (1985:85, cited in Hayes 1993:11). To succeed in this it needs 'to establish or maintain its legitimacy' (ibid). Hayes suggests that in the political context 'legitimacy is of crucial concern to political stability' (ibid).

Legitimacy, according to Hayes, has two interrelated aspects. The first is the set of political 'norms and values...that are shared to make a political system possible' (Razi 1990, cited in ibid). And the second is based on the extent to which the 'politically salient sections of the population' are satisfied with the political activities

\footnotetext{
${ }^{1}$ Indian historians are agreed that Nehru had developed a very strong tradition of political institutions in India after Independence, in order to ensure that a good democratic political foundation could be built.
} 
of the government in the areas they believe are important, if they are satisfied then there will not be a legitimacy crisis (ibid). That is of course unless a political regime inherits a low legitimacy, or a regime is ineffective and therefore is incapable of building its own legitimacy, as Diamond et al state,

regimes that begin with low legitimacy also find it difficult to perform effectively, and regimes that lack effectiveness, especially in economic growth, find it difficult to build legitimacy (Diamond et al 1990:10, cited in Hayes 1993:11/12).

Good politics and acceptable economic growth do not automatically mean that there will be no threat to the legitimacy of a government; these threats, Hayes writes, are normally associated with 'religious, ethnic or regional political manifestations' and he uses India as an example of this when a growth in communal disturbances 'threatened to tear apart the fabric of the Indian statehood' (ibid). This kind of threat (i.e. communal) might be realised in an attempt at 'legitimate and non-legitimate domination of one person or group over others' (Hart 1985:631, in Hayes 1993:12). If for example a political party is in power and is believed by the people to have an amount of 'social legitimacy', the population on the whole will accept them. However, if the people do not believe that the party or politicians have 'social legitimacy' then those 'aspiring to dominate', i.e. the political party in question, and their opposition, may well resort to violence in order to establish themselves. This will create a 'non-legitimate domination which is likely to be unstable and unconducive to maintenance of social order' (ibid).

There are many examples of this kind of attempt at 'legitimate and non-legitimate domination' in India's Independent political history, the call for a State of Emergency by Indira Gandhi and the demolition of the Babri Mosque are the most obvious examples, as was Rajiv Gandhi’s intervention in the Shah Bano affair, along with other religiously motivated acts carried out by the Sangh Parivar throughout the '80s and '90s. It was this religio-political non-legitimate dominance that in the end caused the public to turn to religious leaders as sources of authority, precisely because of the lack of legitimacy and hence authority on the part of civil secular governance. 
Rajiv Gandhi and his mother had both left behind unstable atmospheres of communal disorder when they were assassinated and with them a definite lack of legitimacy which contributed to the final 'organic crisis' described by Bose (1997) and the ‘crisis of legitimacy' described herein. This in turn gave rise to communal - antisyncretic - elements in the political system. These elements may well have already existed within the religious context, however their legitimisation through the political system enabled them to gain more power and influence on a much larger section of the population, not just upon their specific followers.

From my personal interpretation of India's political history summarised in Chapter 3 - India's Pledge, I am inclined to believe that both Hayes and Diamond et al make reasonable points, however they fail to take into consideration the possible role of the government itself in the breakdown of political institutions. A government's untimely or inappropriate intervention in certain aspects of governance can provide a politically unstable environment that contributes to a crisis of legitimacy. In the case of India, when Indira Gandhi came to office there was a notable decline in the political institutions set up by her father, Nehru, and it was a direct decision by her, followed by her son Rajiv, to practice politics using communalism as a tool, in order to maximise their party's (i.e. Congress) vote bank. This created the communal threat Congress found itself up against in the late 1980s, 1990s to 2002, which culminated in the government threatening its own political legitimacy and subsequently Indian statehood. I am not suggesting that there were not threats to Congress, there were communal movements such as the RSS and VHP who have played on the issues of identity, ethnic and regional divisions as well as the economic factors described above. However, these movements have always been considerably weaker politically than the Congress, until Indira Gandhi herself opened the door of opportunity for them to politically challenge the government. They were able to take up this challenge because of the politically unstable environment that had been created which made it easier for India's fascist regimes in the Sangh Parivar to build strength.

\section{Crisis of secularism}

In the light of the discussion above, I would like to argue that this breakdown of political legitimacy and crisis of the state finds its roots in the complexities of the 
secular system of governance that Nehru believed so faithfully in, and on which India's constitution is built. There is an ongoing debate, given the nature of India's socio-political make up, as to whether or not secularism is a form of political governance that best suits India's political and social needs, and whether or not it can be sustained as a current form of governance. Some commentators such as Nandy (2007) have argued that secularism is already dead in India, taking a final bow during the Gujarat pogrom in 2002. And even if others are not in complete agreement with him, there is certainly 'a broad consensus that there does exist a contemporary “crisis” of secularism’ in India (Needham \& Rajan 2007:1).

Secularisation, according to over two centuries of sociological inquiry, was considered as 'one of the key historical revolutions', as after the Enlightenment many believed that 'religion would gradually fade in importance and cease to be significant' in people’s lives and in society as a whole (Norris \& Inglehart 2004:3). Secularism was the political model that stood for the 'ideal of absolute freedom of expression and of the equality of rights independently of religious affiliation' (ibid). Religious faith, which prior to the Enlightenment, was the corner stone of every country's political regime, was to be sidelined, at least in those countries that chose secularism as a political ideal. Today the idea of a worldwide secularisation process is losing its validity, as apart from the rich nations of the world, which some argue are indeed fulfilling the secularisation theory, the rest of the world 'is as furiously religious as it ever was, and in some places more than ever. This means that a whole body of literature by historians and social scientists loosely labeled "secularization theory” is essentially mistaken’ (Berger, cited in Norris \& Inglehart 2004:4).

In the aftermath of Partition, secularism was a political ideal that seemed almost an impossibility; however, today, India 'is officially a secular republic which gives equal status to all the religions practised within it' (Gellner 2001:338). India’s secularism and its journey to establishing a secular state has been fraught with uncertainties and inconsistencies. Disagreement has been rife as to whether or not $\mathrm{Nehru}^{2}$ brought to India a Western concept of secularism which 'sought the

\footnotetext{
${ }^{2}$ Nehru, the founder of India's secular constitution, was, in my opinion, a rare Indian who 'never placed his faith in religion' (Khilani 2007:90), he held faith in reason, believing that 'through reasoning, moral ends and goals were themselves determined, and by reasoning for oneself one took
} 
separation of the spheres of state and religious authority, broadly to correspond to the domains of public and private life' (Needham \& Rajan 2007:20), which could not fit in with the religio-centric nature of Indian society. Nehru and Mahatma Gandhi were at loggerheads in drawing up the Indian constitution after Partition, as Nehru wanted

a strict separation between religion and politics, while Gandhi...advocated 'tolerance' and pluralism, as opposed to rationalist secularism, as a means of promoting the harmonious coexistence of different religions and religious communities in the Indian polity (op.cit.15).

Eventually, the 'Indian state has chosen to interpret secularism differently: it has undertaken the charge to ensure the protection of all religions' (op.cit.20, emphasis in original), (perhaps more Gandhian in its approach), which in turn has blurred the boundaries of where secularism can be drawn in political matters. Secularism in India was intended to unite the 'recently partitioned and heterogeneous nation', to give freedom and protection to the 'number of sizeable minority religious communities who constituted it', to reform the Hindu practice of discrimination according to caste and to ensure the modernisation and progress of the nation (Needham \& Rajan 2007:20). This posed many contradictions, as some saw this protective interest, giving the minorities special treatment from the state, as violating the core principles of secularism. The 'protection' of all religions, according to right-wing political bodies, has meant that not only do they view secularism as antireligious but they also perceive it as anti-national, and, actually 'pseudo-secular' in character, being ‘ethno-accommodative’ (Gould 1998: 523). This has ‘allowed minorities to be "pampered”, thereby preventing the creation of a truly national state’ (Brass 1998:486). The term 'secular’ was established by its American founding fathers, in order to create a “'wall of separation’ between church and state’ in order to 'promote religious freedom' and 'to prevent the establishment of one religion above all others in a religiously plural society' (ibid). It would seem obvious, then,

responsibility for one's commitments and moral beliefs' (ibid). Nehru was aware 'there was a long and refined Indian history of reasoned argument, about ethical life and action' which aided the development of moral truths (op.cit.91). Nussbaum, too, recognises that the 'famous love of talk and argument' and the 'long tradition of public debate and of high quality free press' in India along with the 'proverbial independence of mind', has enabled India to sustain the increasing challenges' that it has faced, including that of 'quasi-fascism' (2007:331). 
that it would be rejected by right-wing political bodies who seek religious dominance. Commentators such as Madan (1992, cited in Brass 1998) have suggested a replacement of secularism with a pluralist model that respects all religions but does not grant special privileges to any particular one. I would argue, that such is the primary goal of secularism, if you apply the core meaning of it intended by its founders ${ }^{3}$. Perhaps the 'contradictions' and 'inconsistencies' that the varied form of Indian secularism raises are where its weakness lies. They can be found particularly with the introduction of separate systems of personal law ${ }^{4}$ and in the fact that it is essentially very difficult to extricate oneself from the religious system in India (Nussbaum 2007). At birth, a child is 'immediately classified by a religion and thereafter comes under that religion's legal system' (2007:143), which highlights a contradiction in the Indian system in that it is extremely difficult to practice the 'free exercise of religion' (ibid) that secularism supports.

The major contradiction in the secular system, which is not specific to India, is one which stems out of the attempt to 'convert secularism into a principle of interreligious pluralism...instead of separation of state and religion' (Brass 1998:490), which is in itself an 'anti-secular position' (ibid). A system that tries to extend respect for all religions inevitably 'opens a space for intrusion of all kinds of denominational and non-denominational practices' (ibid). Despite the goal of secularism to separate religion from the system of governance it is in practice difficult to fulfil this goal. There are few examples in which religious sentiment has not crept into the political system. The most obvious one at present is the evangelical Christian religious beliefs that are present in the American political system, and, as Brass points out, the 'pledge of allegiance to the American flag' that requires citizens to be 'loyal to God if they are to be loyal to the United States' (ibid). Van der Veer observes that there is little evidence of 'a ruthless state policy

\footnotetext{
${ }^{3}$ With the original idea of a secular state in mind 'to promote religious freedom' secularism would appear to be the most appropriate model of politics for India, which is historically religiously pluralist. ${ }^{4}$ Some personal laws were established during the British era, only Islamic law was introduced prior to this period, around the $13^{\text {th }}$ Century. Hindu religious law was a project begun by the British after the introduction of the Census. The Parsees 'won the right to be governed by their own separate system of personal law' in 1864, and by this time the Christians too were following their own plural set of personal laws as were the Jews (Nussbaum 2007). Nehru retained these personal laws in his secular constitution to ensure equality and personal rights to all religions respectively, this was mostly due to his anxieties that the Muslims who stayed behind after Partition should have faith that the Indian constitution would support them.
} 
to secularize Indian society', rather the state seems to have a 'diminishing ability to arbitrate conflicts, such as the temple-mosque [Babri Masjid] controversy' (1994:13). With this point in mind I would argue that the crisis of secularism and the simultaneous crisis of political legitimacy that India has experienced, lies in the inability of the state to protect its minorities and to uphold religious harmony; the very reasons why secularism was declared as the best political system for the positive development of India.

Having accepted the range of reasons for the varied form of secular politics that India adopted, it is apparent, given the communal tension that India is currently embroiled in, that secularism could not fulfil its perhaps overly-burdened role in keeping the various peoples of India unified. Can this arguable failure of secularism have contributed to the growth of anti-syncretic behaviour that we witness today? Maybe. But I would argue, along with Brass, that rather than being the fault of 'secularism' as a political philosophy, it is the 'failure of the Indian state' (1998:500), in upholding their secular constitution that allowed the infiltration of communal and anti-syncretic behaviour patterns into the political field.

Pandey describes this failure as 'an altered inclination of the Indian state' (2006:185) away from its secular values, resulting in a precarious state of communal unrest and lack of communal unity; as Alam states 'when the state is perceived to have failed, mobilisation by communal forces becomes relatively easy’ (1994:183).

I now intend to turn the discussion to the kind of violent behaviour that I see as a product of this failure, or rather as a product of the deviant behaviour and subsequent altered inclination of the state.

\section{Communal violence $\&$ riots}

I see the behaviour at Kalo Dungar and the similar behaviour (i.e. politicisation) found at other such sites as a form of communal violence. Although at Kalo Dungar, there was no instance of physical aggression the atmosphere was such that it could have instigated violent behaviour, both through the psyching and mobilisation of the Hindu gathering during the rally speeches, and through the potential reaction of the local Muslim community. 
There are a number of different theories associated with communal violence, many of which can be applied to this research and specifically to the anti-syncretic behaviour described in this chapter. Larson makes important observations about claims to religious truth which can be compared with the 'pure' and 'impure' religious beliefs discussed above. He affirms that 'one of the most central tenets of religious belief is its unconditional belief in truth', which in turn becomes an 'undeniable reality' (2004:110). This issue of truth can quite easily be exchanged with that of pure and impure religious belief, as we observe an intolerance of different religious truths to each other. It is the belief in a single claim of truth that, according to Larson, is 'one of the most fundamental violence-conducive elements of religion’ (ibid).

I intend to look at the development of these anti-syncretic and often violent communal patterns of behaviour through the theory of Schismogenesis (Bateson 1958). In many ways I see communal violence as a product of Schismogenic attitudes and behaviour. The theory was first used to analyse the emergence of Nazism in Germany, and can thus also be applied to the rise of right-wing Hindu politics and to the way that political rhetoric, through the schismogenic process of 'separation and disconnect', can manifest itself in us 'moralizing our way into violence’ (Hampden-Turner 2004).

Schismogenesis is the 'process of differentiation in the norms of individual behaviour resulting from cumulative interaction between individuals’ (op.cit.175), which, according to Wolff, is a process that in its definition is 'closely related to “acculturation”' (1944:62). Syncretism, too, can well be described as a result of cumulative interactions of individuals from different religions, which ultimately produce differentiation in the normal behaviour of those individuals or groups. Antisyncretism and communal violence can also be described as differentiation in the patterns of normal behaviour. Although communal unrest and anti-syncretic activities may occur frequently, and even in recognisable cycles, one could still argue that they are examples of extreme forms of behaviour and only involve very small numbers of people despite efforts to influence large segments of the population. 
Bateson suggests that 'many systems of relationships, either between individuals or groups of individuals, contain a tendency towards progressive change' (1958:176) which, in some cases, leads to symmetrical schismogenesis where a competitive situation develops between two individuals or groups. When two groups interact in this way a contest results regarding 'who is superior', neither backs down to the other's boasting or shows of bravado, rather they begin to compete verbally and at times this can escalate into a physical violent conflict. Contrastingly, complementary schismogenesis is where one individual or group responds to the other's competitive behaviour by reacting submissively. Both these types of interaction can be related to the Hindu-Muslim situation.

The nature and patterns of all these interactions is complex and are perhaps best illustrated in the table below which is derived from Bateson's theory. 


\begin{tabular}{|c|c|c|c|c|}
\hline $\begin{array}{l}\text { Schismogenesis } \\
\text { Behaviour Patterns }\end{array}$ & \multicolumn{2}{|c|}{ Symmetrical } & \multicolumn{2}{|c|}{ Complementary } \\
\hline Group/Individual & Hindu $(\mathrm{H})$ & Muslim (M) & Hindu $(\mathrm{H})$ & Muslim (M) \\
\hline Interaction 1 & $\begin{array}{l}\mathrm{H} \text { behaves with } \\
\mathrm{H} \text { in } \mathrm{AB} \text { manner }\end{array}$ & $\begin{array}{l}\mathrm{M} \text { behaves with } \\
\mathrm{M} \text { in } \mathrm{AB} \text { manner }\end{array}$ & $\begin{array}{l}\mathrm{H} \text { behaves with } \\
\mathrm{H} \text { in EF manner }\end{array}$ & $\begin{array}{l}M \text { behaves with } \\
M \text { in } G H \text { manner }\end{array}$ \\
\hline Interaction 2 & $\begin{array}{l}\mathrm{H} \text { behaves with } \\
\mathrm{M} \text { in } \mathrm{XY} \text { manner }\end{array}$ & $\begin{array}{l}\text { M behaves with } \\
\mathrm{H} \text { in XY manner }\end{array}$ & $\begin{array}{l}\mathrm{H} \text { behaves with } \\
\mathrm{M} \text { in ST manner }\end{array}$ & $\begin{array}{l}\mathrm{M} \text { behaves with } \\
\mathrm{H} \text { in UV manner }\end{array}$ \\
\hline $\begin{array}{l}\text { Reaction \& } \\
\text { Responses }\end{array}$ & $\begin{array}{l}\mathrm{H} \text { and } \mathrm{M} \text { behave } \\
\text { the same manner } \\
\mathrm{H} \text { with } \mathrm{H}=\mathrm{AB} \& \\
\mathrm{H} \text { and } \mathrm{M} \text { respond } \\
\text { the same but diffe } \\
\mathrm{H} \text { with } \mathrm{M}=\mathrm{XY} \\
\text { Each behaviour } \\
\text { element of cultur } \\
\text { behaviour } \mathrm{AB} \text { wi } \\
\text { be the same wher } \\
\text { and by } \mathrm{M} \text {. }\end{array}$ & $\begin{array}{l}\text { with each other in } \\
\text { i.e. } \\
\mathrm{M} \text { with } \mathrm{M}=\mathrm{AB} \\
\text { to each other in } \\
\text { erent manner i.e. } \\
\text { \& } \mathrm{M} \text { with } \mathrm{H}=\mathrm{XY} \\
\text { vill have an } \\
\text { al difference, i.e. } \\
\text { ll not necessarily } \\
\text { manifested by } \mathrm{H}\end{array}$ & $\begin{array}{l}\mathrm{H} \text { and } \mathrm{M} \text { behave } \\
\text { different manner } \\
\mathrm{H} \text { with } \mathrm{H}=\mathrm{EF} 8 \\
\mathrm{H} \text { and } \mathrm{M} \text { responc } \\
\text { different manner } \\
\mathrm{H} \text { with } \mathrm{M}=\mathrm{ST} \text { \& } \\
\text { However, each g } \\
\text { recognise the oth } \\
\text { different behavic } \\
\text { will therefore rec } \\
\text { is intended to be }\end{array}$ & $\begin{array}{l}\text { with each other in } \\
\text { i.e. } \\
M \text { with } \mathrm{M}=\mathrm{GH} \\
\text { to each other in } \\
\text { i.e. } \\
\mathrm{M} \text { with } \mathrm{H}=\mathrm{UV} \\
\text { oup will } \\
\text { er's culturally } \\
\text { ural patterns, and } \\
\text { ognise whether it } \\
\text { ostile or not }\end{array}$ \\
\hline Result & $\begin{array}{l}\text { If XY = Bravado, } \\
\text { communal disput } \\
\text { follows:- } \\
\text { Bravado vs. Brav } \\
\text { Uncontrolled Riv } \\
\text { Hostility = Syste } \\
\text { i.e. violence }\end{array}$ & $\begin{array}{l}\text { often the case in } \\
\text { es, the result is as } \\
\text { ado = Rivalry } \\
\text { alry = Hostility } \\
\text { m Breakdown }\end{array}$ & $\begin{array}{l}\text { Reactions and R } \\
\text { both groups in th } \\
\text { completely diffe } \\
\text { The action of on } \\
\text { this type of inter } \\
\text { assertive and the } \\
\text { submissive i.e. } \\
\text { If H is assertive } \\
\text { submissive and v } \\
\text { This interaction } \\
\text { hostility and syst } \\
\text { i.e. resentment o } \\
=\text { violence. }\end{array}$ & $\begin{array}{l}\text { sponses between } \\
\text { s category are } \\
\text { ent. } \\
\text { of the groups in } \\
\text { ction will be } \\
\text { response will be } \\
\text { A will be } \\
\text { ice versa } \\
\text { vill also lead to } \\
\text { em breakdown } \\
\text { submissiveness }\end{array}$ \\
\hline
\end{tabular}

Fig.47. Table illustrating behaviour patterns and elements of Schismogenesis. Group $H=$ Hindus, Group $M=$ Muslims 
The behavioural patterns categorised by Bateson have been applied in the table above to the Indian context with respect to Hindu-Muslim communal disputes. Communal disputes, minor and major, occur regularly between Hindus and Muslims, and can be understood as instances of symmetrical schismogenesis. To give an example, a certain sub-group of the Hindu community, a group of youths, will have behaviour patterns common to them which are described above as AB. This consists of their basic informal intra-group interaction, i.e. within that group of youths, which will be very similar to that of a group of young Muslims, although there will undoubtedly be some cultural differences. There will also be situations, where these groups interact with each other too. For example, if a youth group has a mixture of friends from different religious backgrounds, their interactions with, and their reactions to each other, might at times be the same as they would be with people from the same religious background. So there will be instances where the interaction can be tabulated thus:-

\begin{tabular}{|l|c|}
\hline Hindus with Hindus $=\mathrm{AB}$ & $\begin{array}{c}\text { Hindus and Muslims with } \\
\text { each other }=\mathrm{AB}\end{array}$ \\
\cline { 1 - 1 } Muslims with Muslims $=\mathrm{AB}$ & \\
\hline
\end{tabular}

However, in the situation of a simmering conflict, these behaviours change. The interactions and reactions between members of the group from a common religious background will be the same, but when there is interaction between individuals from different religious backgrounds, it will differ. This can be tabulated as below:-

\begin{tabular}{|l|c|}
\hline Hindus with Hindus $=\mathrm{AB}$ & $\begin{array}{c}\text { Hindus and Muslims with } \\
\text { each other }=\mathrm{XY}\end{array}$ \\
\cline { 1 - 1 } Muslims with Muslims $=\mathrm{AB}$ & \\
\hline
\end{tabular}

In conflict situations there is little intermingling of the communities, and behaviour within their own community is in one mode but when faced with the other community behaviour will change to another mode.

The point of this typology of schismogenesis which makes it so relevant to communal conflict, is that Bateson describes the behaviour pattern of XY as 'boasting'; he was basing his terms on the interactions he had witnessed in New Guinea, whereas in the Hindu-Muslim situation 'bravado' or 'aggression’ are more 
appropriate terms. In simmering communal conflict situations and during conflict, the two communities are aggressive in their reactions to each other. In many situations this bravado and aggression involves denigration of each other's cultures and practices, neither of the groups is prepared to back down, and ultimately this interaction leads to conflict and violence. This type of interaction can be compared to a situation between football supporters at a match. The supporters of the winning team boast about their team and their win, the losers, rather than submitting to this behaviour, are psychologically charged up too, and respond with equally aggressive or boasting behaviours and indulge in the denigration of the other team, and physical violence usually ensues.

Categorisation of behaviour patterns in terms of the typology of complementary schismogenesis yields even more specific insights. The term complementary schismogenesis suggests an assertive-submissive interaction. In the Hindu-Muslim situation this term can be applied to each community. Historically the Muslims have been assertive and the Hindus submissive in their reactions. Let us take the example of the Mughal period. Admittedly the Mughals do not represent the present Muslim community, however, I use them as an example, given the importance of their rule in India to the right-wing Hindu argument at present. When the Mughals ruled, they were, in schismogenic terms, the assertive party, even to the extent of aggressive behaviours such as demolishing temples and replacing them with mosques. The Hindus being ruled by them responded submissively, accepting their behaviour. Later accounts by Hindu writers retrospectively responded by defining (or reinterpreting) the Mughals’ behaviour as anti-Hindu aggression, in an attempt to move, after the event, from a complementary to a symmetrical schismogenic position. It should be remembered that during Mughal rule there was not a cohesive Hindu community, rather a population with varied beliefs and traditions, some of which can be associated with what is referred to as Hinduism today.

Currently, the Hindus, now a more organised entity, are the assertive actors and the Muslims submissive in their reactions. The right-wing Hindu community use the example of Mughal rule to denigrate the present Muslim community: 'the conservative Hindu nationalist' projects ‘a thousand-year-old “civilizational” conflict in which the Muslims, militarily victorious and politically ascendant for centuries, 
tried to impose Islamic civilization on their Hindu subjects through all means' (Karkar 1996:15) and assert their ownership of the 'motherland' to the Muslims. Karkar uses the term 'cultural memory', referred to elsewhere as 'collective memory', to describe 'the imaginative basis for a sense of cultural identity' used to enforce the negative elements of the Mughal past (op.cit.18), especially in generating conflict or in times of already heightened conflict. A cultural or collective memory is one wherein a group can free its history from any actual historical context (ibid), which is required in order to project a chosen past. This chosen past is made up of chosen traumas, described by Karkar as 'events which cause a community to feel helpless and victimized by another and whose mental representations become embedded in the group’s collective identity’ (op.cit.50). Specific traumas are chosen in order to 'mythologize, psychologically internalise and thus constantly dwell upon a particular event from their history' which is 'reactivated again and again to strengthen a group's cohesiveness through “memories” of its persecution, victimization, and yet eventual survival' (op.cit.50). These collective memories are 'transmitted through generations' (op.cit.13) and each generation creates its own version of the past, which at least in India, seems to have produced in the Hindu community an increasingly negative image of the Muslim community, ensuring further hostility and distrust. As Brass affirms, the Hindu community lives

their imagined past in the present and perceive every imagined wrong, especially those imagined to have been done by Muslim conquerors, as if it happened yesterday, not 500 years before... They blame the Muslims for the loss of their past and of the monumental evidence of their former greatness in North India, which they believe was destroyed by Muslim generals and rulers (2003:383).

One of the problems that haunts the Hindu population, too, according to Brass (2003), is the 'trauma of partition', as the communalist Hindu fears that 'the Muslims are capable of demanding another “division of India”' (2003:325).

In the majority of communal incidents the Muslims are submissive in their reaction to this kind of collective memory which is often used in order to generate support against them. Even if the interaction escalates into violent conflict, the Hindu 'mobs' are generally too large and too well politically supported for the Muslim community to retaliate. There have of course been exceptions to this rule wherein the submissive 
reaction of the Muslims has transformed itself into a symmetrically equal aggressive response. An obvious example is the explosion of twelve bombs by members of the Muslim community in Mumbai in 1993, after the demolition of the Babri Masjid in Ayodhya and the subsequent three months of massacres against the community by the Hindus.

Schismogenesis, then, basically describes a process of reaction by one individual or group to another. It can be compared to the process of cause and effect, wherein H's reaction to $\mathrm{M}$ may instigate $\mathrm{M}$ to react in a different way to $\mathrm{H}$ and conflict and hostility results due to the series of different and unexpected reactions. The definition by Brox highlights this when he states that the concept of schismogenesis refers to the 'escalating conflict that may occur when two groups, expressing opposite or conflicting values, confront each other' (2000:389).

In the case of Hindu-Muslim violence in India, there are many contributing factors which affect the simple reactions of $\mathrm{H}$ to $\mathrm{M}$ and vice versa. The inter-personal reaction and responses are not necessarily left to their own devices, in many situations the relationships and the reactions of one community to another are instigated and generated through various other channels, for example, politicians. Brox, using an engineering analogy, proposes that 'a useful image of schismogenesis may be a perversely functioning governor, creating vicious circles, as small disagreements are allowed to generate larger disagreements, the schism between the opponents grows cumulatively’ (op.cit.388). Brass (2003) refers to this kind of action as an example of an 'institutionalised riot system' (2003:32/258). These systems exist, according to Brass, in places where riots are endemic. There are 'persons and groups [that] occupy specific roles in the rehearsal for and the production of communal riots' (op.cit.32). 'Conversion specialists' are one example 'whose task it is to decide when a trivial, everyday incident will be exaggerated and placed into the communal system of talk, the communal discourse, and allowed to escalate into communal violence' (ibid). Within the riot system there is a 'multiplicity of roles', including 'informants who carry messages to political group leaders' (op.cit.33) of specific incidents that have potential to affect communal relations. These informants are termed 'fire tenders', who 'keep the embers of communal animosities alive' by bringing to the notice of various authoritarian bodies 
communally sensitive situations (ibid). There are propagandists and rumourmongers too, who use various media and word of mouth to pass on messages. Then there are recruiters, who gather crowds in order to create mobs. This constant 'tending of communal divisions and animosities' generates a kind of control that enables the right planning and 'timing of riots' (op.cit.31). Brass rejects the claim that riots only occur as unexpected spontaneous breakouts of violence that happen due to a build up of tensions. He admits that strained relations are precursors to communal tension, but this tension is not always a 'natural' but rather a politically created one. He suggests that there are then two types of riot situation, the spontaneous and the organised. In his research on Hindu-Muslim relations in a northern Indian town, riots were more often than not organised amidst a palpable communal tension that existed in the city most of the time. He goes as far as to liken the events of riots to a theatre production in which many different actors have roles to play, one of which is to make the event 'appear spontaneous' (op.cit.358). There are of course examples of organised riots that become disorganised as they increase in size, 'most riots contain elements of organization and of randomness...the larger the crowds become, the more diverse and random their goals' until 'all hell breaks loose' (Brass 1996:21). A prime example of this is the demolition of the Babri Masjid in Ayodhya, where L.K Advani is quoted as saying that he did not expect them (i.e. kar sevaks) to actually demolish the mosque. Processes such as these are labelled by Tambiah using two pairs of concepts, the first pair of 'focalization and transvaluation' explain how 'microevents at the local level' can escalate and 'cumulatively build up into an avalanche' eventually becoming a 'macroevent or master narrative labelled an "ethnic conflict"' where the incident has escalated out of control usually 'between two antagonistic ethnic groups' (1996:257). The second pair of labels, 'nationalization and parochialization' (ibid), refer to the opposite process, in which a national event or national issue is reproduced at a local level 'where it explodes like a cluster bomb in multiple context-bound ways' (ibid). According to Tambiah

nationalization and parochialization...relate to each other as a topdown, center-to-periphery process, while focalization and transvaluation involve a bottom-up, periphery-to-center aggregating and generalizing process (ibid). 
The demolition of the Babri mosque is an example, in Tambiah's terms, of nationalization and parochialization; the national event was the issue of Ayodhya and the mosque and one of the parochial localised effects was the bombings in Bombay in response to escalating riots after the demolition. Local events such as the rally at Kalo Dungar have in other instances built up to become state-wide riots and national issues. The Gujarat riots of 2002 are also an example of focalization and transvaluation". Tambiah rightly suggests that these 'two set of processes...together provide us with a way of describing and interpreting current ethnonationalist conflicts and their paths of collective violence' (op.cit.258).

The last element of riot production and communal violence that I wish to address is that of rumour (Brass 1996, 2003, Jaffrelot 1996, Tambiah 1996). This is an important element with reference to Kalo Dungar because the merging of rumours, myths, folklore into undisputable facts is used in order to change the historical context of the site. Brass distinguishes between 'gossip-mongers' whose rumours and gossip rarely ignite communal clashes, and the specialised role of 'rumourmongers' 'whose activities are integral to the dynamic process of riotproduction' (2003:361). Rumours started in riot production normally consist of the report of evil acts attributed to the enemy which inflame the aggressor to respond with ‘destructive violence’ (Tambiah 1996:236). The advantage with using rumours as a source of riot production is that they are generally 'anonymous in origin, and they cannot be traced to definite culpable sources' (op.cit.281). It is rumours of this kind that are not only used in the context of riot production but also as a device in changing the historical context of religious sites like Kalo Dungar. In this example, even though violence has not transpired, rumours are used in order to 'fuzz' history and create new myths regarding the religious origins of the site. Rumours regarding the site are started in order to create a new history which slowly becomes a part of the folklore and myth of that site, the re-creation of this history keeps the issue of the site alive in the minds of the local people, which eventually helps sustain or create

\footnotetext{
${ }^{5}$ Another element of communal violence that escalates out of control, according to Jaffrelot (1996), is that when it gets out of hand often the credibility of the instigators diminishes. This happened after the demolition of the Babri mosque (Jaffrelot 1996:448/458/468). When the focal issue is removed, as with the mosque (which was literally destroyed), generating further support becomes more difficult. Another collaborative issue has to be created, or sought (Jaffrelot 1996).
} 
hostility between the two communities, much like keeping alive the communal tension described prior to rioting.

The fact that there was no physical violence at Kalo Dungar made many people question the importance of the site as the main focus for my research, I see these responses as testimony to the fact that violence has become so much a part of the Indian political and social system and communal instability, that if violence does not ensue "it's obviously not really a big deal", it is simply forgotten that nationalist networks may not only use violence as a tool to dominate and threaten the minority community. The fact that violence has been used in the past and that the consequences of it have been so grave, is enough for the minority communities not to defend themselves in situations such as Kalo Dungar where they find themselves greatly outnumbered compared to the rally volunteers, and find no support within the political and societal system on the ground, so even if they wanted to object to the changes, they are not in a position to do so. This is highlighted, to a degree, in the case of Kalo Dungar, the local Samas did in fact raise objections to the changing of the name, in the local court, however there objections made no impact; gradually the Samas themselves abandoned the site, those left behind, such as the descendant of the Pir, could do nothing without their support.

A third type of interaction outlined in the theory of schismogenesis (not tabulated in Figure 47) is that of reciprocity, which is defined by Bateson (1935), as not always leading towards a schismogenesis because of its reciprocal nature which allows the interaction to balance itself. For example, reciprocal schismogenesis occurs if each group depends on the other for business. Since the riots of 1992, Bombay, despite many minor communal incidents within the state, and major communal incidents nationally, has managed to sustain its peace, many believe, due to the fear of the business community that a series of riots would plunge them into financial debt, political instability and possible recession. It is not clear how the business community manages to 'control' these communal incidents so that they do not escalate, however, where hatred is incited or bombs exploded, it seems, from my experience of living in Bombay, that control of 'reaction' of both communities is what prevents escalation. Aiding this is an element of exhaustion that resides in a large segment of the population who are just tired of communal conflict, which 
ensures that the fire tenders' aim of stoking the smouldering communal fires is more difficult to achieve.

Bateson suggests that reciprocal interaction may eventually become an example of complementary schismogenesis. In this instance one group takes on the behaviour of another and vice versa, they may also begin to display individual behaviours different from one another, as is the case at some syncretic religious sites. I would argue, however, that syncretic practices show signs of being reciprocal and complementary from the outset in order to become syncretic. As discussed in previous chapters, in the development of syncretic practices, generally groups take on each other's behaviour in the initial stages of their cultural amalgamation, however, there is the possibility that the behaviour of those very groups may gradually polarise as the need for syncretic amalgamation between the cultures diminishes, which eventually leads to the development of anti-syncretic practices. So, syncretic practices can lead to anti-syncretic behaviour, which can be understood thus,

$\{$ need $\rightarrow$ compromise $=$ syncretism $\}$ \{end of need $\rightarrow$ end of compromise $=$ antisyncretism\}

In other words, while there is a need for a religion to establish itself, one religion accepts another and there is a synthesis of religions which leads to syncretism. Once a religion is established, and therefore its need for acceptance from another religion is no longer necessary, then anti-syncretic behaviour surfaces (this process is also depicted in a concluding flow diagram at the end of this chapter, see Fig. 48\&49).

There is another example of reciprocal interaction in terms of syncretic practices if one considers the issue of interpretation at a syncretic site. For example, there are instances when the Hindus see the Saint in the light of their religious orientation and the Muslims in the light of theirs, which leads us to question the validity of defining these sites and the behaviour at them as syncretic. Schismogenically then, perhaps to start with, Hindus and Muslims exhibit behaviours of X\&Y at site Z, which is when they are both worshipping the Saint $(\mathrm{Z})$ in reverence to his spiritual powers, without necessarily bringing it into the body of their own religion. However eventually, this 
evolves into each religion exhibiting separate behaviours of $X \& Y$, wherein the Hindus believe in the Saint in their religious terms and exhibit only $\mathrm{X}$ behaviour and Muslims exhibit only Y behaviours for the same reason. In this case, behaviour that was reciprocal becomes symmetrical. Bateson (1935) suggests that the reciprocal pattern does not tend to lead into schismogenesis, however in this instance it might, as the separate behavioural patterns that develop become polarised and eventually lead to anti-syncretic practices.

With the discussion of such organised forms of violence in mind, I think it is important to address the debated issue as to whether or not the Hindu right-wing organisations are bodies that can be termed fascist.

\section{Fascism}

There is an argument that the form of cultural and regional politics practised by the Sangh Parivar has expanded into what some describe as a clearly fascist political regime (Casolari 2003, Jaffrelot 1996, Krishna 2003, Patnaik 1993). I think it is fair to say that for most, the Gujarat Pogrom was the final act by the BJP and its allies that seemed to qualify them to be formally labelled 'fascist'. There can be no doubt, as illustrated earlier in this thesis, that the foundations of Hindutva and the organisation of the RSS have been inspired with the ideals of European fascism. However, whether or not they and the Sangh Parivar can be defined as 'fascist' is yet to be agreed. Many authors accept it as an indisputable fact. Fascism is defined in the Oxford English Dictionary as 'a system of extreme right-wing dictatorial government' (1994:289), and according to Krishna, implicit in most fascist movements is 'a form of genocide and ethnic cleansing' which she argues is very much present in Sangh Parivar politics (2003:4). So, can the Sangh Parivar or any of its members be defined as truly fascist? Jaffrelot, in reference to the RSS, states that because the 'RSS's Hindu Nationalism has been to down-play the role of the state we cannot classify it straightforwardly as a fascist movement' (1996:63). In other words, their goal was not to capture the state, whereas Hitler's Nazism aimed to create a 'Germanic State' (op.cit.62). Another differentiating factor between Nazism and Hindutva is the 'long term programmes' planned by the Sangh Parivar that begin with targeting the grassroots, unlike the 'seizing [of] power and constraining [of] society from above' practised by Hitler (op.cit.61). The third important difference 
stated by Jaffrelot is the lack of a supreme leader in the Sangh Parivar. Both Italian and German fascism relied on the authority of 'the central figure of the leader' (op.cit.64). These arguments are mirrored by Puniyani (2002) in which he refers to work by Vanaik (1994), although he does also highlight similarities between European movements and the Sangh Parivar. Puniyani also refers to Kitchen’s (1976) definition of what the core of Fascism demands,

an ultra-conservative movement rejecting liberal values, which projects the sovereignty of nation as the absolute supreme, glorifies martial spirit, projects the dictatorship of a supreme dictator, and calls for the subordination of rights of individuals to the state's sovereignty. It tends to identify the 'enemy' as the 'culprit' for all social ills, terrorizing the social psyche and suspending human rights. The social background to this ideology and social movement is fear within the propertied classes...the core of the fascist movement is a threatened middle class, fearful of the oppressed classes against a backdrop of economic depression or scarcity in resources (in Puniyani 2002:32).

Jairus Banaji (2003) too offers a definition of fascism which he sees as having three core ideological levels. 'The rational core of every fascist ideology is nationalism'; at the second level there are 'cultures of authoritarianism and repression, be it social repression, family repression or sexual repression'; and at the third level violence is often 'common praxis' which involves 'organised action or the common action of organised groups' (op.cit.24), much like the organised riot systems discussed above. The goal of the Sangh Parivar as an organisation and their Hindutva ideology fulfils most, if not all, of both these sets of criteria. Firstly the BJP and the Sangh Parivar do represent, or at least play on, the ultra-conservative and at times repressive nature of Indian society and culture. A prime example of this, as Krishna (2003) highlights, is the issue of sexual repression in Indian society beginning with the foetus of a girl child and the disconcerting statistics which bring to light the culture of the 'genocide of the unborn' (2003:6). In the eyes of Krishna this is a clear 'manifestation of repression and oppression inherent in the social structure' (ibid) ${ }^{6}$. Social repression also manifests itself in the inherent caste system of Indian society, and in the repression of minorities. As the quote from Puniyani (2002) above suggests, fascism

\footnotetext{
${ }^{6}$ The repression of the female sex manifests itself within the repeated abortion of female foetuses but also in many other aspects of society. There is some solace to be found, as Banaji points out, in the development of feminism in the '70's which countered and continues to counter, certain aspects of fascist behaviour.
} 
feeds on the middle-class fear of the lower, oppressed classes; the majority support for the BJP is from the middle class strata of Indian society (Patnaik 1993), who fear that the increasing power being given to OBC's (other backward castes) through the established reservations for these groups, as well as reservations for religious minorities, will become a threat to their own success and survival. 'The BJP became a voice for an alienated middle class' growing in numbers far more quickly than the growth of the state economically (Freitag 2005:226). The BJP certainly desires a more authoritarian state, not headed by one dictator, but rather, some would argue, by the collective dictatorship of Hinduism. The final criterion set out by Banaji violence - is one that the BJP and Sangh Parivar certainly practise, as illustrated throughout this thesis.

Using the criteria chosen above and understanding how they apply to the Sangh Parivar regime is, for most, enough to establish their fascist nature. Nandy, for example, in an article written after the Gujarat riots, focuses his discussion on Narendra Modi, who he claims is a 'classic, clinical case of a fascist' (2003:240), who apparently meets all the criteria of an authoritarian personality. Nandy wonders how a Chief Minister of state who 'presided over' rioting gangs, often praising their actions then later justifying them, has not been summoned by international human rights groups. He asks, 'if Modi's behaviour till now is not a crime against humanity, what is?' (op.cit.239). The same has been said about the once Deputy Prime Minister, L.K Advani, serving at the time of the Gujarat Riots of $2002^{7}$. That neither man has been brought to justice in terms of the Indian Penal Code (referred to in the previous chapter) seems to reinforce the view of a breakdown in the political legitimacy of the state.

Writers like Patnaik state that

many people stop short of describing the Ayodhya outrage and its sequel in terms of a rise of Fascism in our country, and prefer to restrict themselves to the use of the word communalism. In my view however the communal carnage and the pogroms against the minority community that occurred in cities like Bombay and Ahmedabad are the outward and horrendous manifestations of a deeper and more sinister trend, namely of Fascism. (1993:69).

\footnotetext{
${ }^{7}$ For more on communal activities associated with L.K Advani, see Chapter 3 - India's Pledge.
} 
Patnaik's argument is that communal rioting and communalism are the forms that fascism takes in India, this is something mirrored by other writers. However others argue that because of the religiously motivated nature of the communal aggression in India it cannot qualify as fascism (Bapat 1994, cited in Puniyani 2002). However I would argue that the Sangh Parivar and its Hindutva ideology are variations on a fascist theme, the biggest variant being its overtly religio-political nature.

One more important element to end this particular discussion is the view of Krishna, who suggests 'fascism has never been, and should never be seen as the creation of a party or a leader' (2003:7). As Banaji states, 'German fascism was not the creation of the Nazi party. Rather, the Nazi party was, arguably, the creation of German fascism' (2003:23). German society had paved the way for the rise of fascism. Much the same can be said for India, which had become a 'society [that] was clearly ripe for the picking by a political force like the Sangh Parivar' (Krishna 2003: 8). India was a society arguably already 'fascisized' by the repression and oppression of women, lower castes and minorities; by the continued state of poverty and lack of means of meeting basic physical needs; by the festering division of identities and by the continued denial of an efficient judiciary and justice system. And finally India's breakdown of political legitimacy, the failure and unaccountability of democratic institutions and the subsequent growth of authoritarian politics have all allowed the growth and success of the fascist power of the Sangh Parivar.

It is these collective issues discussed thus far that have, I argue, encouraged the growth of anti-syncretic elements in some sections of Indian society, which is arguably an inevitable progression from the initial influx of syncretic practices through years of infiltration of outside rulers and colonists.

I would like to move the discussion now to the final component of this chapter. This section addresses the association between ritual and violence or contestation, and the increasing trend of 'politicising dargahs'. The ritual, i.e. pilgrimage, and the violent antagonism that pilgrimages can generate and their subsequent use in the nationalist cause are central to the following discussion. 


\section{Ritual/pilgrimage, violence/ contestation and the politicising of dargahs}

Pilgrimage...involves a journey from one's village or town to a sacred center and back and its performance seems to reinforce the notion of a wider community of believers. This ritual seems then to lend itself eminently for linkage to the discourses and ritual practices of religious nationalism (communalism) (Van der Veer 1996:156).

Van der Veer's definition of pilgrimage lends itself perfectly to the subject of this thesis. However, before going on to discuss the use of ritual in the nationalist cause, it is important to briefly review previous studies on the subject of pilgrimage. Many of which do not consider the issues mentioned in the quotation above.

One of the earliest and most influential studies of religion was Elementary Forms of the Religious Life (Durkheim 1915). Even though, as Bowie (2006) recognises, this work was not directly concerned with pilgrimage, Durkheim did discuss the subject of religious festivals suggesting that they were 'occasions for social regeneration and moral unity' (2006:239). Bowie goes on to state that 'many studies have followed Durkheim in emphasising the ways in which pilgrimages weld together diverse communities and various social strata into more collective entities’ (ibid). Both Karl Marx and Victor Turner, although from completely different perspectives, saw pilgrimage as a social process. Marx, in keeping with his anti-capitalistic stance, believed that pilgrimages, in presenting the 'myth of social equality' (ibid) among pilgrims, helped to legitimize the domination and oppression of the lower classes who, in the environment of the pilgrimage, forgot the social inequalities they faced in their normal lives. This point leads on to Victor Turner and Edith Turner's (1978) interpretation of pilgrimage as 'anti-structural' - 'a limited break from the routines and familiar context of an ordinary, settled social life' (Morinis 1992:19). In this anti-structural environment, claimed the Turners, pilgrims experienced 'communitas', best described as a unified mental state, most probably due to the 'common purpose' of their journey, that of devotion and worship (Bowie 2006:240). There has been fervent debate regarding the theories of Durkheim and Turner. Those put forward by Turner, as Coleman (2002) recognises, are invariably employed as 'a point of departure' for any 'anthropologists who embark on the study of pilgrimage' (2002:356). However, as Bowie rightly points out 
while pilgrimages may act as a force of moral regeneration (Durkheim), may make people content with their lot in their everyday life so that they no longer struggle to improve their condition (Marx), and may cement bonds of communitas (Turner), equally they may not (2006:240 emphasis in original).

Coleman and Eade (2004) too, suggest that the theoretical concepts of Turner, despite their huge influence, have 'run the risk of taking studies of pilgrimage down a theoretical cul-de-sac', most notably in the implication that pilgrimage could be somehow 'divorced from more everyday social, political and cultural processes' (2004:3). Rather, as Coleman and Eade suggest in quoting Dubisch, instead of divorcing themselves from everyday social structure, pilgrims 'do not sever, even temporarily, their social bonds, to leave behind the social networks that enmesh them in everyday life' (1995:95, cited in Coleman \& Eade 2004:13). In my interpretation and experiences, Dubisch would seem accurate in her interpretation of places of pilgrimage when she states that

a pilgrimage site is connected in complex ways to the non-sacred world around it. It has economic, social, and political ramifications for the local community, the region and even the nation (1995:39).

this sits in contradiction to the idea that pilgrimage is an 'anti-structural' event lying outside the social structure of everyday life. But I would take issue with the view that pilgrims 'do not sever, even temporarily, their social bonds', because in some instances Hindu pilgrims of low castes participate in pilgrimages alongside those of higher castes, without the usual social barriers which often prevent close association, such as eating together.

But Dubisch's statement does apply with particular force to the pilgrimage shrine of Kalo Dungar where the development of the site as a spiritual Hindu centre has economic, social and political ramifications not just for the local area and people but for the state, as it is slowly developed into a spiritual centre with an increasing tourism focus, and its own website, opened in 2008 (see www.kalodungar.com).

Perhaps the most interesting study on pilgrimage in terms of relevance for this research is that by Eade and Sallnow $(1991,2000)$ who 'use the term "competing discourses” to describe the various agendas and world-views that operate at a 
pilgrimage site' (Bowie 2006:242) ${ }^{8}$. Rather than a sense of unity, there is evidence, according to Eade \& Sallnow, that 'a pilgrimage shrine...provides a ritual space for the expression of a diversity of perceptions and meanings’ (1991:10), and for 'conflict between orthodoxies, sects, and confessional groups, for drives towards consensus and communitas, and for counter-movements towards separateness and division' (op.cit.2 emphasis in original). These various elements are sometimes brought by the pilgrims themselves, or in the case of Kalo Dungar and other such sites, by political bodies for political reasons to achieve political goals. Therefore the 'cultural assumptions of pilgrims and the power struggles of society are evident at pilgrimage sites' (Coleman \& Elsner 1995:200). Sallnow’s study of pilgrimage in the Andes was perhaps one of the most significant in opening up the discourse to the idea that at pilgrimage sites

...meanings collide. The mere fact of a mass gathering at a sacred site is unlikely to indicate any unanimity of meaning or motive among the participants; on the contrary, it is more likely to reveal severely discrepant or discordant understandings of the significance of the cult, even among those nominally sharing the same faith (1991:137).

Any interpretation is open to dispute, this is evident within all faiths, where branches or sects interpret the same faith quite differently, and it is most obvious within Christianity, Islam and Hinduism. Pilgrimage sites are an example of how 'interpretations change and develop according to social and historical circumstances' (Bowie 2006:255). This leads us back to past eras when there was a need for religious bodies to create syncretic pilgrimage sites and practices in order to gain a religious foothold in a region, as we have learned from Islam in India and as Sallnow suggests with the Spanish Roman Catholics in the Andes of South America. What is interesting about Sallnow's example is that even though particular shrines brought the Catholics and the local Indian population together in worship they represented a ‘theological contradiction' (op.cit.149).

For the Spaniards, they were vehicles for displacing the satanic perversions of native religiosity and for reclaiming a foreign land for their faith and their God. For the Indians, on the other hand, they

\footnotetext{
${ }^{8}$ As Bowie notes, the word 'competing' does not necessarily connote 'antagonistic contests between various groups, although these may occur' (2006:242). Kalo Dungar can be seen in the light of the antagonistic contests that can sometimes occur in competing discourses at a pilgrimage site.
} 
were the means to domesticate the foreign gods, to insert these evidently powerful divine interlopers into the matrix of the animate landscape and through them to reclaim and to re-appropriate the extra-local sacred and ritual dimension of their colonized territories. Each group perceived and misunderstood the behaviour of the other through the inverting lens of its own understandings (ibid).

As Bowie recognises, these new syncretic sites illustrated conflict in meaning, which raises the question asked earlier in the thesis about syncretic sites in India were they truly syncretic from the outset? In attempting to decide whether or not some sites can validly be defined as syncretic, I think it is important to realise that they certainly provide 'examples of cultural interchange, religious syncretism, competing discourses and dynamic readjustment to enforced changes’ (2006:257).

Coleman and Eade (2004) comment that while Turner's work on pilgrimage and the subsequent set of studies presented by Eade and Sallnow (1991, 2000) have been mostly concerned with the 'place' of pilgrimage and the 'people' of pilgrimage, attention to the aspect of movement within pilgrimage has been lacking. Morinis, to some extent, redresses this lack of attention in his categorisation of types of motivation for the pilgrim journey. According to him, 'a true typology of pilgrimage focuses on the pilgrims' journey and motivations not on the destination shrines' (1992:10). Based on the individual motivations and aspirations of the pilgrim, the pilgrimage journey can 'be sorted into a number of basic types’ (ibid). Morinis categorises six types of journey: devotional, instrumental, normative, obligatory, wandering and initiatory ${ }^{9}$. It is not my intention here to dissect all six categories but rather to look at an appropriate category in which to place the pilgrimage of Kalo Dungar. On analysis the journey to Kalo Dungar contains elements from more than one of Morinis' categories. Clearly there is the 'devotional' aspect, in which the goal is to encounter and honour the shrine divinity. Within the Hindu context this would be understood as darshan ${ }^{10}$ or seeing. For the pilgrims to Kalo Dungar, darshan of Lord Dattatreya was a major motivational

\footnotetext{
9 Devotional - to encounter and honour the 'shrine divinity, personage, or symbol'. Instrumental - whose goal is to 'accomplish finite, worldly goals'.

Normative - pilgrimage is a part of a 'ritual cycle, relating to... annual calendrical celebrations'. Obligatory - the pilgrimage as an obligation set in the scriptures of a faith. Wandering - pilgrimage with no 'predetermined goal'. Initiatory - a pilgrimage made with the goal of transforming the self (Morinis 1992:10-14).

${ }^{10}$ Darshan means 'to see', a darshan is to experience and 'see' the divine image.
} 
factor in their reason for joining the pilgrimage. But the journey to the site also represents what Morinis defines as an instrumental pilgrimage journey, one that is undertaken in order to 'accomplish finite, worldly goals' (op.cit.11), such as to cure illness, finding a marriage partner, or alleviating barrenness. However, in the context of this study, I argue that the instrumental worldly goal is political. Many pilgrims, for example the boys on cycles, undertook the pilgrimage in order to help the political worldly goal of the right-wing Hindu population in increasing the Hindu presence at Kalo Dungar and the surrounding area. The interesting aspect here is that the pilgrimage was presented under the guise of both a devotional and a normative pilgrimage. Normative pilgrimage is the third category given by Morinis, where a pilgrimage is undertaken as 'part of a ritual cycle'; the birthday of Lord Dattatreya and the calendrical celebration of it during the full moon, fit this definition (ibid). However the idea of a 'ritual cycle' could also be applied to the ritualisation process of politicising the shrine (discussed below), undertaken by the Hindu right-wing; the pilgrimage Kalo Dungar is a part of that ongoing ritual cycle.

Although politics is not given as a direct motivation in any of his categories, apart from the implication that an 'instrumental' journey might well be connected with political goals, Morinis does recognise that 'any conceivable purpose can motivate a pilgrimage’ (op.cit.19). Strong religious feeling (Morinis’ ‘devotional’ category) can be one such motivation but "“sacred” journeys have been undertaken for reasons relating more to social, political, and economic circumstances than to ostensible religious intentions' and he goes on to say that '[t]he pilgrim's goal can be the acquisition of greater wealth, political power or prestige' (ibid). In the context of Kalo Dungar, it is not so much the pilgrims' desire for personal political power and prestige that acts as a motivating force, but rather the desire of the organisers. If some pilgrims did have political motives these were not personal rather they were for the collective political purpose of the cause of Hindu nationalism.

The journey itself, and all the motivations for it (as categorised by Morinis), are one aspect of analysing movement in studies of pilgrimage. I want to suggest here that the pilgrimage site of Kalo Dungar presents a case of another aspect of movement, one in which there is a 'movement of meaning'. The changing nature of the site, and what might possibly be changes in belief about that site, whether or not 
politically contrived, perhaps adds to the already existing categories and approaches that try to further our understanding of the multiple layers of pilgrimage.

The use of ritual in creating this contestation over meaning is the next major aspect of pilgrimage that I wish to discuss further. Kalo Dungar does not only present the type of contestation described by Sallnow (1991), involving the competing discourses and interpretations of a particular shrine, but also represents the issue that Van der Veer describes, where pilgrimage is used as a ritual in the cause of religious nationalism in order to create communal antagonisms. According to Van der Veer, pilgrimages provide an opportunity for 'the construction and maintenance of boundaries between "us" and "them"' enabling the formation of 'group identities' (1996:156). In unifying one community, they also exclude those outside of that community who are then often portrayed as the threatening other. A self identity is constructed in this environment through opposition to the 'other' which is then 'demonized and violently conquered' (op.cit.157). The interviews and footage in Black Mountain provide an example of this kind of behaviour where Hindus are gathered for the pilgrimage and in the speeches at the pilgrimage site the Muslims are demonized and spoken about as if it is necessary for the Hindus to overcome them, or conquer them. As Freitag states, 'rituals have come to be linked in the construction of communal identities in public arenas' (Freitag 1989, cited in Van der Veer 2005:259). Kalo Dungar is one example to support Freitag's statement, but one could also cite the use of processions. In Chapter 3 - India's Pledge - we learned that processions have been used as a tool in promoting Hindu nationalist sentiment since the early 1920s (Van der Veer 1996, Brass 2003). Like processions, pilgrimage is a ritual that 'acts to create national identification and thus plays a role in nation-building' (Van der Veer 1996:155). Perhaps then, the process of the politicisation of Sufi dargahs is, for the VHP and the Sangh Parivar, a ritualised type of activity that plays a role in the process of Hindu nation-building. This ritualised politicisation is achieved not just through the protests or rallies that may be held, but also through 'movement of meaning', when a site is transformed from belonging to one religious orientation, or perhaps two or more, to another, different (i.e. Hindu) one. This creates communal instability in and around the site, and even nationally when a high profile religious site is targeted, whether or not the aim of changing the religious orientation of the site is completely achieved. 
In talking about my research to an Indian scholar well known for his work in the field of Indian communalism, I was asked why I was focussing on such an 'insignificant site' (i.e. Kalo Dungar) when there were far more 'important' sites to research. An example of such a site is Baba Budhangiri dargah which lies in the Baba Budhan hill range in the district of Chikmagalur, about two hundred kilometres from Bangalore in the southern state of Karnataka. This site is considered 'important' because issues of contestation were highly publicised.

Baba Budhan is a Sufi dargah which, since the late 1990s, has been a target of antisyncretic behaviour. It has been dubbed the 'Ayodhya of the South’ (Assadi 2003, Sikand 2002, 2003, 2003a) as Hindu nationalist bodies stake their claim on the site so as to 'liberate' it from the clutches of Islam in which, according to them, it has been trapped for over six centuries. There are many accounts that depict the controversy about this dargah ${ }^{11}$. Not all of these are academic texts but rather journalistic accounts of events that have taken place at the site. Apart from slight date variations, the accounts reveal the same story. The dargah of Baba Budhan is a site that is reported as being one of the oldest Sufi dargahs in the region, with, according to historical literature, both a Muslim and Hindu following and a Muslim and Hindu identity. Islam spread in Karnataka, as it did in most other states, through Sufism. As we discovered in Chapter 5, the Sufis, by 'using local motifs and idioms' (Sikand 2002:50), appealed to the local people in a religious language familiar to them and developed traditions that came to be shared by Hindus and Muslims who both came to worship these religious figures, even sharing each other's rituals of veneration. Sufis were often identified by the Muslims and Hindus differently; for Muslims they were perceived as descendants of the prophet Mohammed, for Hindus they were re-incarnations of Hindu deities (Sikand 2002, 2003).

The Saint of Baba Budhan is said to have arrived in the hills of Chikmagalur from Arabia and was known as Dada Hyat Qalandar. His real name was Shaikh Abdul Aziz Makki and he was a Sufi Saint who enjoyed close association with Prophet Mohammed. When Dada Hyat left the shrine in Chikmagalur, he left in charge a

\footnotetext{
${ }^{11}$ Assadi 2003, Menon 1998/1999, Sevam 2003, Shreedhara \& Lankesh 2004, Sikand 1999, 2000, 2002, 2003, 2003a, Souhardagiri 2002.
} 
disciple named Sayyed ${ }^{12}$ Shah Jamaluddin Maghribi, a native of Yemen, known more popularly now as Baba Budhan ${ }^{13}$ (Sikand 2003a).

There are many legends associated with Dada Hyat ${ }^{14}$ which established his reputation of having miraculous spiritual powers. As news of these powers spread, Muslim kings and Hindu rulers began to patronise the shrine, along with ordinary Hindus and those already converted to Islam. The Hindu rulers referred to it as the Sri Dattatreya Swani Baba Budhan Peetha. Hindus and converted Muslims began to pay homage at the shrine. The Hindus considered Dada Hyat a re-incarnation of Lord Dattatreya, and the shrine was also known as 'Sri Dattatreya Swani Baba Budhan Peetha' or 'the monastery of the revered Lord Dattatreya Baba Budhan' (Sikand 2002:53). This association with Lord Dattatreya has some similarities with the situation at Kalo Dungar and, according to Sikand (2002, 2003a), with many other sites, where, as mentioned in Chapter 5, Muslim Sufis adopted dual identities. There is also the possibility, as Sikand (2003a) acknowledges, that in the case of Dada Hyat, there was a corruption of words in that 'Dada' became 'Dattatreya'. What is significant here is that in the case of Baba Budhan, unlike the history of Kalo Dungar, the association with Dattatreya is not recent, but dates back much further. Writers differ in opinion as to whether there is a history of reverence to Lord Datta in Karnataka; some believe it is a recent development and that the tradition finds its roots in Maharashtra. Whatever the case may be, it is well known that in order to win the support of the local Hindu population some Pirs encouraged and even 'popularised stories of their association with Hindu deities in order to win local support and possibly as a means to preach Islam' (Sikand 2002:52).

Despite this dual identity, there was no recorded conflict around the site until the 1960s, when the Waqf board (a statutory body that administers Muslim shrines) claimed that the shrine of Baba Budhan should be administered by them due to its Islamic status and history. This was challenged by the Muzrai department (in charge of Hindu endowments in the district), but in 1975 the state government

\footnotetext{
${ }^{12}$ A name which denotes descent from a holy ancestor.

${ }^{13}$ It is believed that it was Baba Budhan who brought coffee to the region, and the hills of Baba Budhan are named after him. The running of the shrine has stayed in his family for fifteen generations.

${ }^{14}$ For further insight read Sikand 2003a.
} 
assigned the rights of the dargah to the Waqf board. A district court judgement in 1980 reversed this decision, insisting that the shrine revert back to the status it had prior to 1975, which meant that the shrine was given back to the Muzrai department. This also meant that the original Muslim caretaker was to be the sole person in charge of the dargah and that only rituals that had been carried out at the site prior to 1975 would be allowed. Trivial disputes continued through the 1980s until 1989 when the VHP stepped up their campaign by launching a committee to 'liberate' the dargah. It was during this same period whilst the Rath Yatras were being held to increase the profile of the Babri Masjid (i.e. of the Ayodhya campaign), that the VHP performed the first ever puja at the Baba Budhan shrine on Lord Dattatreya's birthday. This violated the district court order which had been upheld by both the High Court and Supreme Court. Over the next few years Lord Dattatreya's celebrations increased in length from a puja on one day, to a three-day festival, much like the Dattatreya Jayanti celebrated at Kalo Dungar. After the success of the demolition of the Babri Masjid, the campaign at Baba Budhan was stepped up even further, with Rath Yatras held across the state of Karnataka amid claims that suicide squads would be sent to the site if the campaign failed. In 1999 during another Dattatreya Jayanti, the Hindu nationalists tore down the green flags that adorned the shrine, and replaced them with saffron flags. They also succeeded in placing a statue of Lord Dattatreya in the cave shrine where the tomb of Baba Budhan and three other disciples lay. All this was obviously in breach of the Supreme Court order that a 'pre 1975 status' be upheld at the site. Rather than objecting to these violations, the Congress state government convened with the right-wing campaign, believing this would ensure that communal stability was maintained and they made no objection to the activities at the site, and to the incrementally aggressive characteristics of their performance. This is another example of the kind of 'soft' Hindutva practised by the Congress party ${ }^{15}$.

\footnotetext{
${ }^{15}$ In my experience in India it is unfortunate, but true, that legal documents like court orders do not necessarily mean that one is given any support from the state government machinery. After recently purchasing a house in India and ending up on the receiving end of unpleasant action by local villagers, despite three court orders in my favour, stating the legal ownership of the house, the local government machinery did nothing, but rather worked with the local villagers, to ensure we could not take possession of the house. In these situations the law and order machinery is completely useless and one is completely powerless to protect oneself.
} 
The case of Baba Budhan is a high profile example of how 'shared traditions [that] served to bring Hindus and Muslims together in common worship' are emerging as 'centres of inter-communal contestation and conflict' (Sikand 2003:52),

the mere fact of people from different communities worshipping at a common shrine need not necessarily promote inter-community understanding or a deeper awareness of the faith of others (op.cit.17).

Rather, at times, this 'mere fact' creates a great deal of ambiguity. Ambiguities, like anomalies are dealt with in various ways. Douglas (1966) gives five ways of dealing with ambiguity and anomaly - redefinition, physical control, avoidance, defining as dangerous, and using in ritual. Hindu nationalists deal with the problem of ambiguous sites of shared faith in all the above ways - they attempt to redefine them; take physical control over them; at times avoid them (especially those that are completely out of their control due to their mass following); define them as dangerous (in this case by defining the Muslims as dangerous and a threat to Hindu society); and use them in ritual (that is by giving a Muslim Saint a Hindu identity even if a dargah can not be redefined as a temple). There is no category of 'toleration' in Douglas' theory of dealing with ambiguity and anomaly, just as there is no room for tolerance of shared religious sites in the agenda of Hindu nationalism.

It would seem too that as state governments have become accustomed to dealing with religious communities such as Hindus and Muslims as different entities, when it comes to conflicts regarding a situation of liminality, no one is quite sure of how to deal with them. For a Congress state government it becomes apparent that it is important that they adhere to vote bank politics in order not to lose the support they need from the Hindu population. Baba Budhan is one example of this, as was the situation in Ayodhya. The VHP too, along with the Sangh Parivar, are perhaps, as Sikand suggests, unable to understand situations 'of religious syncretism and liminality, where boundaries between Hindus and Muslims are blurred' (2002: 56). These blurred boundaries directly challenge their own understanding of community, religion and identity, as well as question both the 'very basis of Hindutva as an ideology' (ibid), and their idea of 'Hindus and Muslims as two monolithic blocs permanently at war with each other' (op.cit.57). 
Other examples of right-wing politics imposing themselves on Sufi shrines are: the shrine of Pirana in Gujarat, and the site of Sai Baba of Shridi, Maharashtra, and of a less higher profile, the site of Haji Malang in Maharashtra ${ }^{16}$. The latter two have both been associated with Lord Dattatreya but, as with Kalo Dungar, they are much more recent constructs ${ }^{17}$.

Baba Budhan presents a unique case compared to all the examples mentioned above, in that in December 2002, secular democratic groups came together to forge 'an anti-fascist united front' (Selvam 2003) by using Lord Dattatreya Jayanti as an opportunity to spread communal harmony. They approached Sangh Parivar strongholds where they revealed to Sangh Parivar followers what they believed to be the 'bogus campaign' for the liberation of Baba Budhan, by trying to explain to them the fascist tendency of the Hindutva ideology. This culminated in a rally, attended by over ten thousand people, against the communal forces of Hindutva and their campaign to liberate Baba Budhan. Despite the destructive measures taken by the right-wing nationalists, it is some what surprising to me that more protests of this type do not take place. The indifference of orthodox groups regarding the syncretic traditions of the sub-continent makes it a difficult campaign to generate support for, but without it the anti-syncretic forces have the infrastructure and support to continue in their aim of eradicating the anomaly of syncretism.

\section{Conclusion}

Kalo Dungar has provided a case study which highlights the main elements of rightwing politics that affect the plural, syncretic nature of Indian society. It highlights too, the structures that underlie these politics. It has been argued that the increase in anti-syncretism is an inevitable consequence of syncretic practice as sections of the religious communities concerned object to what they see as a corruption of their

\footnotetext{
${ }^{16}$ For a history on Haji Malang, see, the Bombay Gazetteers from 1880 and the Supreme Court judgement papers for the Civil Appeal No.94, 1951, and the AIR 1954, Supreme Court 5, Vol.41, C.N.3 (from Bombay), and Assadi 2003.

${ }^{17}$ There is not space here for further discussion, but for more details on these examples and many others, see Assadi 2003, Assayag 2004, Bunsha (2004), Burman 2002, 2005b, Saheb 2003, Sikand 2003, Sila Khan \& Moir (1999), Sila Khan (2003). Bigelow 2008 gives information on places under contestation in the Punjab which have found peaceful resolutions.

Another example of a contested religious shrine is that of Rachel's tomb in Israel, currently an exclusively Jewish site. Its history suggests a more 'cosmopolitan' character (Selwyn 2006) and its ownership is contested by Palestinian Muslims.
} 
traditional religious practices. One of the consequences of these objections is HinduMuslim conflict, exacerbated by right-wing politics. Anti-syncretic behaviours, it is argued, have developed due to a number of elements. One is the issue of power and purity in religious institutions. The significance of power in imposing rigid definitions and classifications has resulted in syncretic practices being labelled as impure, because they were anomalous and ambiguous, due to their derivation from more than one source. This was set against the recent history of Indian politics, particularly the breakdown of governmental legitimacy and the crisis of secularism, brought about through the infiltration of nationalist practices which provided the opportunity for communal violence to break out. The triggering factors and dynamics of this violent behaviour and conflict were examined using Bateson's theory of schismogenesis. The theory of schismogenesis also provides a dynamic way of looking at the possibility that there can be elements of change or movement between various ways of reacting, which can be applied to Douglas' list of reactions to anomalies. It is possible that someone can begin by reacting to an anomaly in one way and then move, through processes of schismogenesis, to another reaction; just as there can be movement from a complementary to a symmetrical schismogenic behaviour. In terms of syncretic pilgrimage sites, there is evidently movement from one type of behaviour to another by pilgrims who previously might have practised at a syncretic shrine who then become involved in anti-syncretic practices targeted towards that same shrine, such as the political rally to Kalo Dungar.

All the above factors, (i.e. power, breakdown of legitimacy, crisis of secularism, communal violence), have contributed, in my opinion, to the production of fasciststyle political institutions. These institutions have used religious symbols and rituals as tools to spread their message, one of the most noteworthy being pilgrimage. There is an element of what Turner termed 'communitas' that develops at these pilgrimages, as supporters of the right-wing cause come together to demonstrate their strength (Jaffrelot 1996). The differences between them are erased (maybe only temporarily) as they are caught up in the 'anti-structure' of the moment and a collective communal consciousness (perhaps at times sub-consciousness) develops. But there are also other elements involved in pilgrimage which make Turner's approach unsatisfactory, and the critiques of 'communitas' have sharpened the analysis of events at Kalo Dungar and the background of the pilgrimage to the site, 
where it also became obvious that pilgrims embarked upon the journey there for very different reasons, as individuals and in separate groups - unrelated to one another.

Finally the flow of causation that sees traditions of syncretism evolve into the performance of anti-syncretism can be understood most succinctly in the following two diagrams. Fig.48 illustrates the important element of power in creating antisyncretic behaviour and Fig.49 illustrates the flow of causation from syncretism to anti-syncretism. 
The need for power creates syncretic practices - the syncretic practice becomes an anomaly and is taken advantage of, politically, or rejected by religious leaders. The power struggles that transpire culminate in the development of anti-syncretic practices.

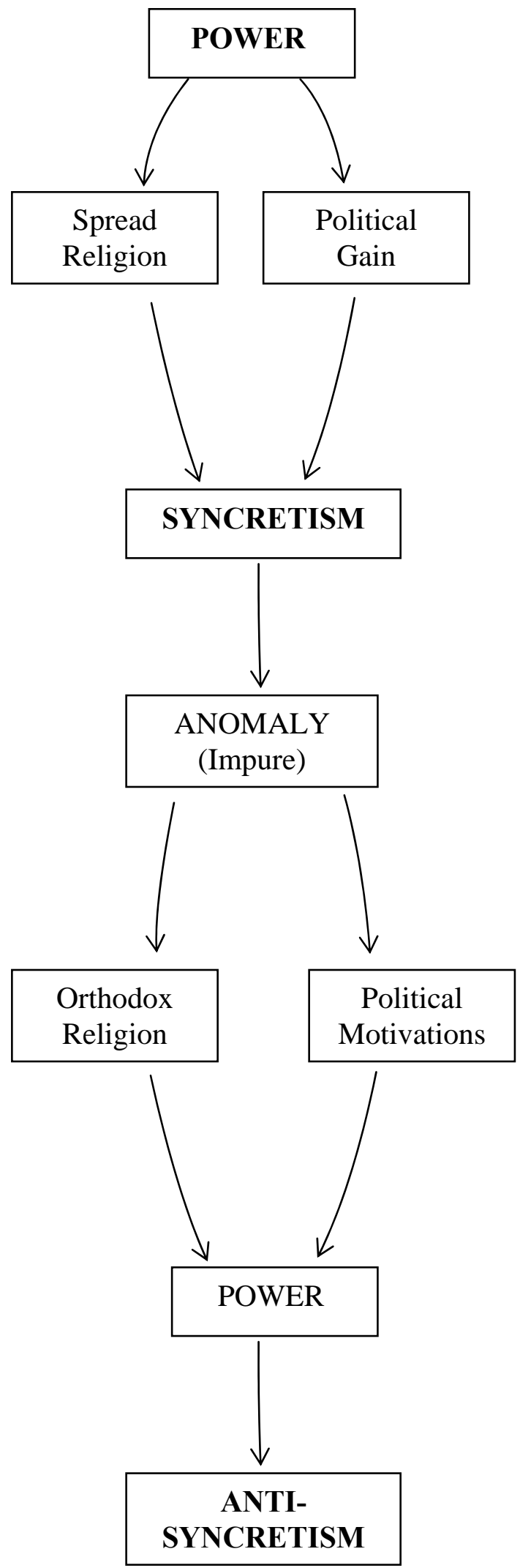

Fig. 48 - Power, syncretism, anti-syncretism 


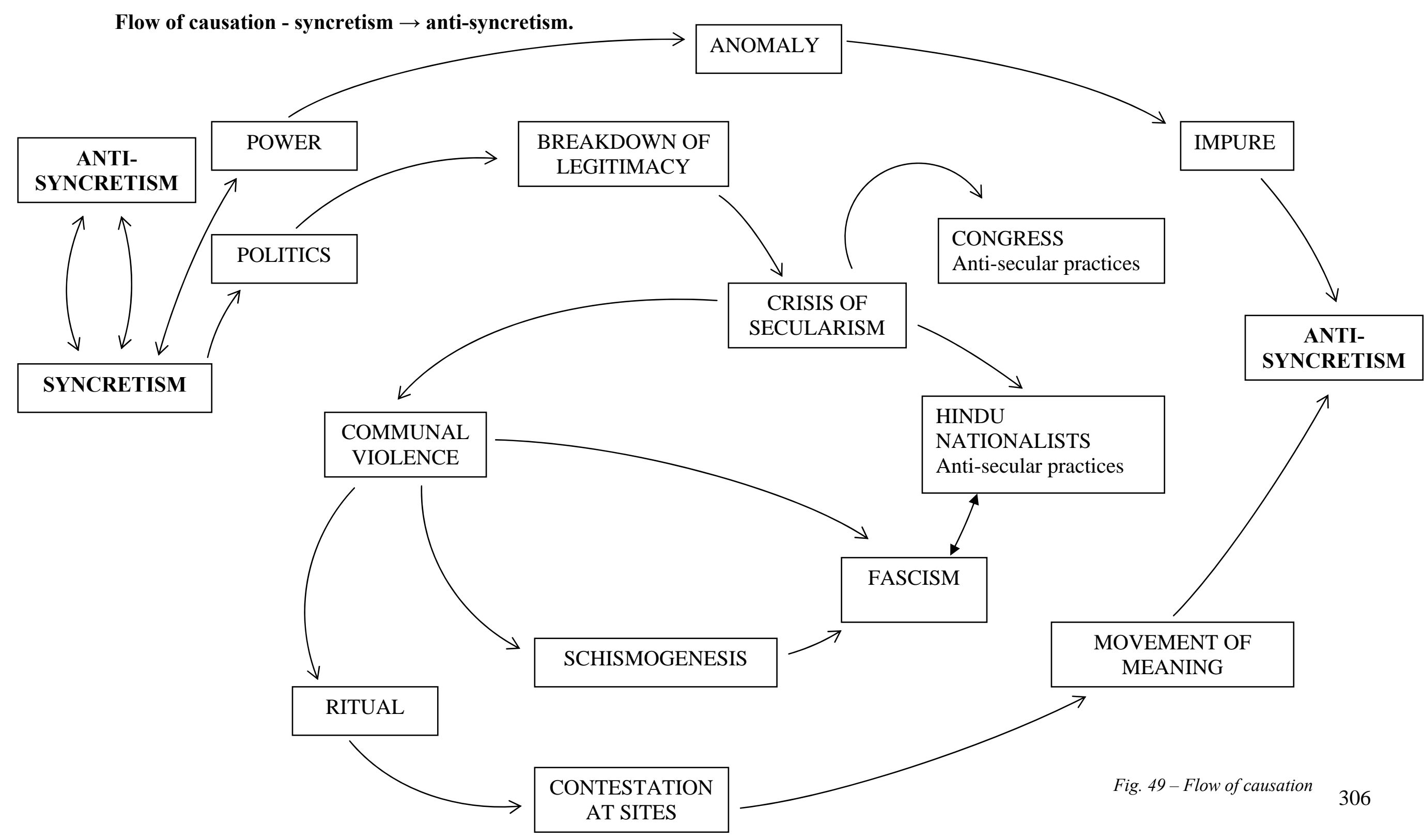




\section{Chapter 8}

\section{$\sim$ Conclusion}

My intention in this thesis has been to give a reflexive account of events which makes this research comprehensible to the 'non-indophile', who can travel the journey of discovery alongside the researcher. I also intended it to provide the wellread 'indophile' with an insight into the changing political tides of the Indian State, using the account and discussion of the events at Kalo Dungar, which many of my informants regarded as too 'low-profile' (no outright confrontations or violence), as a tool for understanding the wider picture. The reflexive account describes the steep learning curve that ensued in order to begin to make sense of the research developments. Using the methodological premise - 'ethnography as methodology'has enabled the researcher to present the thesis as a linear journey which reflects the idea that 'life can only be understood backwards but it must be lived forwards' (Soren Kierkegaard, 1813-1855). The main approach of this thesis in taking the reader along with me on the journey of this research is influenced by a number of works, most profoundly by Dubisch (1995) and Kenna (2001) who made efforts to reveal the research process to the reader.

With this methodological base in mind, this thesis has, primarily, been a journey of understanding; one that has been travelled both textually and visually. It tells a tale which began with a change in the focus of the research subject to a topic completely unforeseen and unknown to the researcher. Starting from little knowledge and understanding of India's political luggage, the journey which the investigation of this topic entailed, led to eventually gaining an integral understanding of the deep structures that make up the layers of India's political practice. Both the thesis and the film mirror this development. The journey continued chronologically, in a linear fashion, as the research material presented itself, and was primarily understood during the process of the edit to construct a film to parallel the eventual written text. During the editing process, through viewing and re-viewing almost every second of footage, one begins to understand the research data even more intimately than when living through the experience or writing it up afterwards. The premise of combining a written and a visual version of the ethnography is that if you can begin to construct 
a visual story that can be understood by an 'non-indophile' audience, then the textual account of that story must contain the same content, but with more space to elaborate directly on the issues raised.

During this process there have also been changes in my understanding of the research. After the completion of the first edit, it was obvious that a somewhat biased view of the research findings had been presented, wherein the Hindu rightwing was held primarily responsible for the breakdown of syncretic culture in the sub-continent. However, it soon became apparent that there are many contributing factors to this development. It was important that the balance of opinion, on my part, was re-addressed. The bias was no doubt generated from working with my husband (as my research assistant), who being a Muslim understood our experiences in a particular way, which affected how I understood them too, perhaps to some degree in sympathy with him. Now as I reflect, the journey has been one of understanding not just for me, but for Amin as well, as he began to understand his own cultural and political history as an Indian, and he too was able to readdress the foregone conclusions that he had reached regarding Kalo Dungar. Observing this development has been a fascinating process, and one which I believe has contributed to my own understanding of India and the politics in play at Kalo Dungar.

This shift in anthropological objectivity has been achieved not only through making the film, but also through long periods of reflection and dialogue between myself and Amin as he tried to make some kind of peace with his history, and I did too, with the history that has obviously affected him and the Muslim population so deeply. This no doubt is felt by both sides of the Hindu-Muslim divide. I agree with Misra in taking the view that 'society is only secure in its present and confident about its future if it has successfully come to terms with its past’ (2004:236); this is something, which I am not sure India and its people has yet managed to do. 'India is dominated by a certain tradition of thinking about its Muslim past and about Islam. The tradition has deep roots. Therefore it cannot easily be countered' (op.cit.237). This tradition contributes to the rhetoric of the Hindu right-wing which attempts to dehumanise the Muslim community in order for violent acts to be carried out upon it. Until India can come to terms and make peace with its past, both the Hindus' and the 
Muslims' anti-syncretic practices, like the ones we witnessed at Kalo Dungar, will continue.

the curious feature of syntheses and coming together was that these survived for as long as they were left alone; in other words, as long as there was no intervention from above. Once the intervention began either by spokesmen of dominant versions of the orthodoxy or by the elite or by the state as such - the common features of compositeness begin to dissolve...the frail nature of composite culture or syntheses was precisely in their inability to withstand the interventions from above (Alam 1999:31).

This shift in anthropological objectivity was mirrored by a second editing process the thesis edit - towards the end of the writing up of this thesis, and during the final edit of the text there was another shift in my anthropological perspective as I suddenly gained clarity in my thoughts and began to understand more completely what the research was attempting to address. It would appear from this experience that the researcher only really begins to understand their work in its completion. With that retrospective knowledge I hope that in the case study of Kalo Dungar I have been able to contribute to the discipline of anthropology in that 'the study of pilgrimage...calls for a combination of approaches, ideally drawing on a variety of disciplinary perspectives’ (Bowie 2006:237), in which one 'looks outward, making points about human behaviour through using “pilgrimage” as a case-study rather than focusing on the institution itself as a firmly bounded category of action' (Coleman 2002:363). 


\section{Chapter 9}

\section{Bibliography}

Abu Nasr Al-Sarraj. Ketab al-luma. Translated by Nicholson, R.A. (ed). 1916. London: Luzac and Co.

ACHA bulletin online. http://osu.orst.edu/groups/acha/. Article - Cow holy for both Hindus and Muslims in Kutch, Gujarat, India (From Rediff on the net 12/21/98).

Ahmad, Aijaz. 2005. 'Frontier Gandhi: reflecting on Muslim nationalism in India'. Social Scientist. Vol.33, No.1-2. Jan-Feb. pp.22-39.

Ahmed, Imtiaz. 2003. 'Takeover of state power' in: Krishna, C. (ed). Fascism in India, faces, fangs \& facts. pp.288-294. New Delhi: Manak Publications.

Alam, J. 1994. 'Post Ayodhya situation: the Left and India's crisis today'. $\underline{\text { South }}$ Asia. Vol.XVII. pp.183-90.

Alam, J. 1999. 'The composite culture and its historiography'. South Asia. Vol.XXII. pp.29-37.

Anderson, J, \& O’Dowd, L. 1999. 'Borders, border regions and territoriality: contradictory meanings, changing significance’. Regional Studies. Vol.33(7). pp. 593-604.

Ansari, S.F.D. 1992. Sufi Saints and state power: The Pirs of Sind, 1843-1947. Cambridge: Cambridge University Press.

Asch, T. 1992a. 'The Ethics of ethnographic film-making', in Crawford, P \& Turton, D. Film as ethnography. pp.196-204. Manchester: Manchester University Press.

Asch, T. 1992b. 'Some ethical considerations applied to ethnographic filmmaking: A personal view’in: Singh, K, (ed.), Visual Anthropology and India. Calcutta: Anthropological Survey of India.

Assadi. M. 2003. “"Dargah Versus Peeta”: Hindutva’s politics of appropriating syncretic culture in Karnataka'. Indian Journal of Secularism. Vol.7. No.2. pp.93107.

Assayag, J. 2004. At the confluence of two rivers: Muslims and Hindus in South India. New Delhi: Manohar.

Badone, E. 2007. 'Echoes from Kerizinen: pilgrimage, narrative, and the construction of sacred history at a Marian shrine in northwestern France'. Journal of the Anthropological Institute. Vol.13, pp.453-470. 
Banaji, J. 2003. 'The political culture of fascism' in: Krishna, C. (ed). Fascism in India, faces, fangs \& facts. pp.20-29. New Delhi: Manak Publications.

Banks, M. 2001. Visual methods in social research. London: Sage.

Banks, M \& Morphy, H. (eds). 1997. Rethinking visual anthropology. London: Yale University Press.

Bates, T.R. 1975. 'Gramsci and the theory of hegemony'. Journal of the History of Ideas. Vol. 36. No. 2. (Apr - Jun). pp.351-366.

Bateson, G. 1935. 'Culture contact and schismogenesis'. Man, Vol.25. (Dec. 1935). pp.178-183. Reprinted in: Bateson, G. 1972. Steps to an ecology of mind. pp.61-72. London: Chandler Publishing Company.

Bateson, G. 1958 (1 $1^{\text {st }}$ ed. 1936). Naven. California: Stanford University Press.

Basu et al. 1993. Khaki shorts saffron flags. New Delhi: Orient Longman.

Beckerlegge, G. 2004. 'The Rashtriya Swayamsevak Sangh’s tradition of selfless service’ in: Zavos, J, Wyatt, A, \& Hewitt, V (eds). The politics of cultural mobilization in India. pp.105-135. New Delhi: Oxford University Press.

Bhardwaj, S. 1987. 'Single religion shrines, multi-religion pilgrimages' in: Singh R \& Singh R (eds.) Trends in geography of pilgrimages. pp.107-115. Varanasi:

National Geographic Society.

Bhatt, C. 2001. Hindu nationalism origins, ideologies and modern myths. Oxford: Berg.

Bidwai, P. 2003 'A critique of hindutva', in South Asian Journal Vol. 2. www.southasiamedia.net/magazine/journal/critique_hindutva.htm - accessed on 04.11.06.

Bigelow, A. 2008. 'Converted spaces: unifying structures, structuring unity: the sharing of the Guru's mosque' received via email from Sikand, Y. ysikand@yahoo.com.

Blom Hansen, T. 1999. The saffron wave. New Delhi: Oxford University Press.

Blom Hansen, T. 2000. 'Predicaments of secularism: Muslim identities and politics in Mumbai'. Journal of the Royal Anthropological Institute. Vol.6. No.2. June. pp. 255-272.

Blom Hansen, T. 2001. Violence in urban India: identity politics, 'Mumbai' and the postcolonial city'. Delhi: Permanent Black.

Bonney, R. 2002. 'Hindu extreme right-wing groups: introduction’ in: Bonney, R. (ed). Hindu extreme right-wing groups: ideology and consequences. South Asian 
Leicester: University of Leicester, Centre for the History

of Religious and Political Pluralism.

Bonney, R \& Hawkes, G. 2004. 'Human rights in India in the South Asian context: an overview' in: Bonney, R. (ed). After Hindutva: towards the recovery of the Indian polity? Institute for the study of Indo-Pakistan relations (INPAREL), Conference proceedings 4. Leicester: University of Leicester, Centre for the History of Religious and Political Pluralism.

Bose, S \& Jalal A. (eds). 1997. Nationalism, democracy and development: state and politics in India. Delhi: Oxford University Press.

Bose, Sumantra. 1997. 'Hindu nationalism and the crisis of the Indian state: a theoretical perspective' in: Bose, S. \& Jalal A. (eds). Nationalism, democracy and development: state and politics in India. Delhi: Oxford University Press.

Bose, S \& Jalal A. 1998. Modern South Asia: history, culture, political economy. London: Routledge.

Bowman, G. 1993. 'Nationalising the Sacred: Shrines and Shifting Identities in the Israeli-Occupied Territories’. Man: Journal of the Royal Anthropological Institute. Vol.28. pp.431-460.

Bowman, G. 2000. 'Christian Ideology and the Image of a Holy Land: The Place of Jerusalem Pilgrimage in the Various Christianities' in: Eade, J.\& Sallnow, M (eds). Contesting the sacred: the anthropology of Christian pilgrimage. pp. 98-121.

Urbana: University of Illinois Press.

Bowie, F. 2006. The anthropology of religion: An introduction. $2^{\text {nd }}$ Edition. Oxford: Blackwell

Brass, P. (ed). 1996. Riots and pogroms. London: Macmillan Press Ltd.

Brass, P. 1998. 'Secularism out of its place', Contributions to Indian Sociology. Vol.32. No.2. November. pp.485-585. Delhi/Thousand Oaks/ London: Sage Publications.

Brass, P. 2003. The production of Hindu-Muslim violence in contemporary India. Seattle \& London: University of Washington Press.

Browne, E.G. 1980. 'The Sufi mysticism: Iran, Arabia and Central Asia' in: Archer, P.N. (ed). The Sufi Mystery. London: Octagon Press.

Brox, O. 2000. 'Schismogenesis in the wilderness: the re-introduction of predators in Norwegian forests'. Ethnos, Vol.65: 3. pp.387-404.

Bunsha, D. 2004. 'Communalism: the chains of Pirana'. Frontline, Vol.21, Issue 18, August $28^{\text {th }}-$ September $10^{\text {th }} 2004$.

Burgess, R. 1984. In the field: an introduction to field research. London: Routledge. 
Burgess, R. Ed. 1984a. (1 $1^{\text {st }}$ ed.1982). Field research: a sourcebook and field manual. London: Routledge.

Burman, Roy JJ. 1999. 'Hindu Muslim syncretic trends in West Bengal'. Indian Journal of Secularism. Vol.3. No.1 Apr-June.

Burman, Roy JJ. 2002. Hindu Muslim syncretic shrines and communities. New Delhi: Mittal.

Burman, Roy JJ. 2005. 'Syncretism and communal harmony in Bengal’ in: Puniyani, $\mathrm{R}$ (ed). Religion, power and violence: expression of politics in contemporary times. pp.108-123. New Delhi: Sage.

Burman, Roy. JJ. 2005b. Gujarat unknown: Hindu-Muslim syncretism and humanistic forays. New Delhi: Mittal Publication.

Burnes, Lieut. Sir Alexander. $20^{\text {th }}$ march $1827-13^{\text {th }}$ March 1828. A memoir of a map of the Eastern branch of the Indus, giving an account of the alterations produced in it by the earthquake of 1819 and the bursting of the dams in 1826; also a theory of the Runns formation \& some surmises on the route of Alexander the Great, etc. British Library shelf mark: HMNTS 1298.h.18.

Callaway, H. 1992. 'Ethnography and experience: gender implications in fieldwork and texts' in: Okely, J, \& Callaway, H. (eds). Anthropology \& Autobiography, ASA Monographs 29. pp.29-49. London: Routledge.

Campbell, J. 1880. Gazetteer of the Bombay Presidency. Volume V. Cutch, Palanpur \& Mahi Kantha. Bombay: Government Central Press.

Casolari, M. 2003. 'The fascist heritage and foreign connection of RSS-archival evidence’ in Krishna, C. (ed). Fascism in India, faces, fangs \& facts. pp.106-141. New Delhi: Manak Publications.

Chandra, B. Mukherjee, M \& Mukherjee, A. 2000. India after independence 19472000. New Delhi: Penguin.

Chatterjee, P. 2007. 'The contradictions of secularism' in: Needham A. \& Rajan, R. The crisis of secularism in India. Ranikhet: Permanent Black.

Chenoy, K.M. et al. 2003. 'Ethnic cleansing not communal riot' in: Krishna, C. (ed). Fascism in India, faces, fangs \& facts. pp.201-216. Delhi: Manak Publications.

Clammer, J. 1984. 'Approaches to ethnographic research’ in: R.F. Ellen. (ed). Ethnographic research: a guide to general conduct. London: Academic Press.

Coffey, A. 1999. The ethnographic self: fieldwork and the representation of identity. London: Sage. 
Coffey. A. 2002. 'Ethnography and self: reflections and representations' in: May, T. Qualitative Research in Action. pp.313-331. London: Sage.

Cohen, A.P. 1984. 'Informants' in: R.F. Ellen. (ed). Ethnographic research: a guide to general conduct. London: Academic Press.

Coleman, S, \& Elsner, J. 1995. Pilgrimage: past and present in the world religions. London: British Museum Press.

Coleman, S. 1997. Book review of Stewart C \& Shaw R. Syncretism/antisyncretism. Journal of the Royal Anthropological Institute. Vol.3. No.2. June. pp.402-403.

Coleman, S. 2002. 'Do you Believe in Pilgrimage?: From Communitas to Contestation and Beyond'. Anthropological Theory. Vol.2(3). pp.355-68.

Coleman, S, \& Eade, J. 2004. Reframing pilgrimage: cultures in motion. London: Routledge.

Corbridge S, \& Harriss, J. 2000. Reinventing India: liberalization, Hindu nationalism and popular democracy. London: Polity.

Coward, H.G. (ed). 1987. Modern Indian responses to religious pluralism. Delhi: Sri Satguru Publications.

Crawford, I \& Turton, D. 1992. Film as ethnography. Manchester: Manchester University Press.

Davies, C. 1999. Reflexive ethnography. London: Routledge.

Davis, R. 2005. 'The iconography of Rama's chariot' in: Ludden, D. (ed). Making India Hindu: religion, community, and the politics of democracy in India, $2^{\text {nd }}$ Edition. pp.27-54. New Delhi: Oxford Community Press.

Das, N.K. 2003. Culture, religion and philosophy: critical studies in syncretic and inter-faith harmony. New Delhi: Rawat.

De Neve, G. 2006. 'Hidden reflexivity: Assistants, informants, and the creation of anthropological knowledge' in: De Neve, G. and Unnithan-Kumar, M. (eds). Critical Journeys: The Making of Anthropologists. pp.67-90. Ashgate: Aldershot.

Devereux, L \& Hillman, R. 1995. Fields of vision: essays in film studies, visual anthropology and photography. Berkley \& London: University of California Press.

Dixit, J.N. 2002. 'A nation shamed' in: Engineer, A.A. 2003. The Gujarat carnage. New Delhi: Orient Longman.

Donnan D, \& Wilson T. 2001. Borders frontiers of identity, nation and state. Oxford: Berg. 
D’orazi Flavoni, F. 2002. Rabari: a pastoral community of Kutch. India: Brijbasi.

Douglas, M. 1966. Purity and danger: an analysis of the concepts of pollution and taboo. London: Routledge.

Douglas, M. 2002. 'Land animals, pure and impure' in: Lambeck, M. A Reader in the Anthropology of Religion. pp.194-209. London: Blackwell.

Droogers, A. 2005. 'Syncretism, power, play' in: Leopold, A.M. \& Jensen J.S. (eds). $\left(1^{\text {st }}\right.$ Ed. 2004). Syncretism in religion: a reader. pp.217-236. New York: Routledge.

Dubisch, J. 1995. In a different place: pilgrimage, gender, and politics at a Greek island shrine. Princeton, New Jersey: Princeton University Press.

Durkheim, E. 1915. The elementary forms of the religious life. London: Allen \& Unwin.

Dutton, E.C. 2007. 'Eye-glazing and the anthropology of religion: the positive and negative aspects of experiencing and not understanding an emotional phenomenon in religious studies research'. Anthropology Matters Journal. Vol.9 (1).

www.anthropologymatters.com.

Eade, J, \& Sallnow, M. 1991. Contesting the sacred: the anthropology of Christian pilgrimage. Urbana, Chicago: University of Illinois Press.

Eade, J, \& Sallnow, M. 2000. Contesting the sacred: the anthropology of Christian pilgrimage. Urbana, Chicago: University of Illinois Press.

Eaton, R. 1978. Sufi of Bijapur, 1300-1700. Social soles of Sufis in medieval India. Princeton: Princeton University Press.

Eaton. R. 1984. 'The Political and religious authority of the shrine of Baba Farid' in: Metcalf, B. (ed). Moral conduct and authority: the place of Adab in South Asian Islam. Berkeley: University of California Press.

Eaton, R. 2000. 'Temple desecration and Indo-Muslim states' in: Gilmartin, D. \& Lawrence, B.B. (eds). Beyond Hindu and Turk: rethinking and religious identities in Islamicate South Asia. Florida: University of Florida.

Eck, D.L. 1998. Darshan: seeing the divine image in India. New York: Columbia University Press.

Ellen, R.F. 1984. Ethnographic research: a guide to general conduct. ASA research methods in social anthropology, series 1. London: Academic Press.

Emerson, R. Fretz, R. \& Shaw, L. 1995. Writing ethnographic fieldnotes. Chicago: University of Chicago Press.

Engineer, A.A. 2002. 'On Sufi approach to Islam'. Islam and modern age. March 2002. Mumbai: Institute of Islamic Studies. 
Engineer, A.A. 2003a. Communal challenge \& secular response. New Delhi: Shipra.

Engineer, A.A. 2003b. The Gujarat carnage. New Delhi: Orient Longman.

Engineer, A.A. 2004. Communal riots after Independence: a comprehensive account. Centre of Study of Society and Secularism, Mumbai. New Delhi: Shipra.

Engineer, A.A. 2006. 'Communal riots 2005'. Indian Journal of Secularism. Vol. 10. No.1. April-June 2006. pp.35-42.

Engineer, A.A. 2007. 'Communal riots 2006'. Indian Journal of Secularism. Vol. 10. No.4. Jan-March 2007. pp.100-107.

Ernst, C. 1997. The Shambhala guide to Sufism. Massachusetts: Shambhala.

Evans-Pritchard, E.E. 1940. 'Nuer politics: structure and system' in: Vincent, Joan (ed). The anthropology of politics: A reader in ethnography, theory, and critique. pp.34-38. Oxford: Blackwell.

Faruqi, N A. 1999. 'Islamic Sufism in the pluralist Indian social environment'. Indian Journal of Secularism. Vol.3. No.1 pp.12-19.

Forgacs, D. (ed). 1988. An Antonio Gramsci reader. New York: Schocken Books.

Freitag, S. 1989. Collective action and community: public arenas and the emergency of communalism in North India. Berkeley: University of California Press.

Freitag, S. 2005. 'Contesting in public: colonial legacies and contemporary communalism' in: Ludden, D. (ed). Making India Hindu: religion, community, and the politics of democracy in India, $2^{\text {nd }}$ Edition. pp.211-234. New Delhi: Oxford Community Press.

Gaborieau, M. 1995. 'Muslims in the Hindu Kingdom of Nepal' in: Madan, T.N. (ed). Muslim communities of South Asia: culture, society and power. Delhi: Manohar.

Gaborieau, M. 2004. 'Introduction' in: Troll, C.W. (ed). (1 ${ }^{\text {st }}$ Ed. 1989). Muslim shrines in India. Oxford University Press: New Delhi.

Gaborieau, M. 2004b. 'A nineteenth century Indian 'Wahhabi' tract against the cult of Muslim Saints: Al-Balagh al-Mubin’ in: Troll, C.W. (ed). (1 ${ }^{\text {st }}$ Ed. 1989). Muslim shrines in India. New Delhi: Oxford University Press.

Gans, H. 1994. 'The participant observer as a human being: observations on the personal aspects of fieldwork' in: Burgess, R. ed. Field research: a sourcebook and field manual. pp.80-93. London: Routledge.

Gazetteer of India: Gujarat State, Kutch District. 1971. India: Government Publication. 
Gellner, D. 1997. 'For syncretism. The position of Buddhism in Nepal and Japan compared'. Social Anthropology. Vol.5. Pt.3. pp .277-291. European Association of Social Anthropology.

Gellner, D. 2001. 'Studying secularism, practising secularism. Anthropological imperatives'. Social Anthropology. Vol.9. Pt.3. pp. 337-340.

Geertz, C. 1968. Islam observed: religious developments in Morocco and Indonesia. London \& New Haven: Yale University Press.

Glick Schiller, N \& Fouron, G. 2002. 'Long distance nationalism defined' in: Vincent, Joan (ed). The anthropology of politics: a reader in ethnography, theory, and critique. pp. 356-365. Oxford: Blackwell.

Graham, B. 1990. Hindu nationalism and Indian politics: the origins of the Bharatiya Jana Sangh. Cambridge: Cambridge University Press.

Grimshaw, A. 2001. The ethnographer's eye: ways of seeing in anthropology. Cambridge: Cambridge University Press.

Grodzins Gold. A. 1990 (1st ed. 1989). Fruitful journeys: the ways of Rajasthani pilgrims. Berkeley, LA, London: University of California Press.

Gould, H, A. 1998. 'The Babri Masjid and the secular contract'. Contributions to Indian sociology. Vol.32. No.2. pp.507-526.

Gottschalk, P. 2000. Beyond Hindu \& Muslim: multiple identity in narratives from village India. Oxford: Oxford University Press.

Guba, E. (ed). 1990. The paradigm dialogue. London: Sage.

Gubrium, J. \& Holstein, J. (eds). 1997. The new language of qualitative methods. Oxford: Oxford University Press.

Gupta, R.K. 2004. Sufism beyond religion. Delhi: B.R. Publishing Corporation.

Hammersley, M \& Atkinson, P. 1995. Ethnography: principles in practice, $2^{\text {nd }}$ edition. London: Sage.

Hampden-Turner, C. 2004. www.ccaerasig.com/papers/05/BatesonConference.pdf accessed 03.02.07

Hardgrave, R, L, Jr. \& Kochanek, S. 1993. India: government \& politics in a developing nation, $5^{\text {th }}$ Edition. USA: Ted Buchholz, Harcourt Brace Jovanovich.

Hasan, Mushirul (ed). 1981. Communal and Pan-Islamic trends in colonial India. New Delhi: Manohar. 
Hasan, M. 1994. (1 $1^{\text {st }}$ Edition 1991). Nationalism and communal politics in India 1885-1930. New Delhi: Manohar.

Hastrup, K. 1992. 'Writing ethnography' in: Okely, J, \& Callaway, H. (eds). Anthropology \& Autobiography, ASA Monographs 29. pp.116-133. London: Routledge.

Hayes, J. 1993. Religion in Third World politics. Oxford: Oxford University Press.

Hawkins, B. 2004. Asian religions. New York: Pearson Longman.

Hawley, J. 1980. Book Review - Hedayetuallah, M. 1977. 'The Apostle of HinduMuslim unity: interaction of Hindu-Muslim ideas in the formation of the Bhakti Movement with special reference to Kabir, the Bhakta' Delhi: Motilal Banarsidas. The Journal of Asian Studies, Vol. 39. No. 2. February. pp.385-386.

Hegel GWF. 'The philosophy of history’ in: Bose, S \& Jalal A. 1998. Modern South Asia: history, culture, political economy. London: Routledge.

Heider, K. 1971. Ethnographic film. Austin: University of Texas Press.

Heider, K. 1997. Seeing anthropology: cultural anthropology through film. USA: Allyn \& Bacon.

Hendry, Joy. 1999. An introduction to social anthropology. London: Sage.

Henley, P. 2004. 'Putting film to work: observational cinema as practical ethnography’ in: Pink, S, Kurti, L \& Alfonso A. Working images: visual research and representation in ethnography. pp.109-130. London: Routledge.

Herskovits, M. 1937. 'The significance of the study of acculturation for anthropology’. American Anthropologist. Vol. 39. pp.259-264.

Herskovits, M. 1941. 'Some comments on the study of acculturation'. American Anthropologist. Vol. 43. pp.1-10.

Hickey, J. 1984. Religion and The Northern Ireland Problem. Dublin: Gill \& Macmillan Ltd.

Hockings, P. 1995. Principles of visual anthropology $2^{\text {nd }}$ edition. Berlin: Mouton De Gruyter.

Homan, R. 1991. The ethics of social research. London: Longman.

Ibrahim, F. 2004. 'No place like home: history, politics and mobility among pastoral nomadic community in Western India’. Nomadic Peoples. Vol. 8(2). pp.168-90.

Ibrahim, F. 2005. 'Defining a border, Harijan migrants and the state in Kachchh', Economic and Political Weekly. Mumbai. 
Indian Penal Code. 1860. Section 153a.

http://www.vakilno1.com/bareacts/IndianPenalCode/indianpenalcode.htm - accessed 01/08.

Ishwaran, K. 1981. 'Bhakti tradition and modernization: the case of Lingayatism' in: Lele, J. 1981. Tradition and modernity in Bhakti movements. Leiden: E.J. Brill.

Irwin, R. 2007. 'Culture shock: negotiating feelings in the field'. Anthropology Matters Journal. Vol. (9) 1. www.anthropologymatters.com.

Jaffrelot, C. 1996. The Hindu nationalist movement and Indian politics 1925 to 1990’s. London: Hurst \& Company.

Jaffrelot, C. 2004. 'From Indian territory to Hindu Bhoomi: the ethnicization of Nation-State mapping in India' in: Zavos, J, Wyatt, A, \& Hewitt, V (eds). The politics of cultural mobilization in India. pp.197-215. New Delhi: Oxford University Press.

Jadiya, U. 1997. Kachchh. Bhuj: Jadiya.

James, A. 1999. 'Learning to be friends: participant observation among English school children (the Midlands, England)’ in: Watson, C. Eds. Being there: fieldwork in anthropology. London Pluto Press.

Jethi, P. No Date. Kutch, people and their handicrafts. Bhuj-Kutch: Nayana P. Jethi.

Juergensmeyer, M. 1993. 'The rise of Hindu nationalism' in: Smart, N \& Thakur, S. (eds). Ethical \& political dilemmas of modern India. New York: St Martin's Press.

Kakar, S. 1996. Colours of violence: cultural identities, religion, and conflict. Chicago \& London: The University of Chicago Press.

Kane, E. 1985. Doing your own research. London: Marion Boyars Publishers Ltd.

Kaur, R. 2003. Performative politics \& the cultures of Hinduism: public uses of religion in Western India. Delhi: Permanent Black.

Katju, M. 2005. 'Mobilization for Hindutva' in: Puniyani, R. (ed). Religion, power and violence: expression of politics in contemporary times. pp.176-190. New Delhi: Sage.

Keay, J. 2000. A history of India. London: HarperCollins.

Keay, J. 2004. A history of India. London: Harper Perennial.

Kenna, M. 2001. Greek island life: fieldwork on Anafi. The Netherlands: Harwood.

Khan, M.I. 2004. ‘Sufism in Indian history’ in: Troll, C.W. (ed). ( $1^{\text {st }}$ Ed. 1989). Muslim shrines in India. New Delhi: Oxford University Press. 
Khilani, S. 2007. 'Nehru's faith' in: Needham A. \& Rajan, R. The crisis of secularism in India. pp.89-103. Ranikhet: Permanent Black.

Kondo, D. 1990. Crafting Selves: Power, Gender, and Discourses of Identity in a Japanese Workplace. Chicago: The University of Chicago Press.

Krishna, C. (ed). 2003. Fascism in India, faces, fangs \& facts. New Delhi: Manak Publications.

Krishna Iyer, V.R. et al. 2003. 'State complicity' in: Krishna, C. (ed). Fascism in India, faces, fangs \& facts. pp.242-277. New Delhi: Manak Publications.

Kulke, H \& Rothermund, D. 1998. History of India $3^{\text {rd }}$ Edition. London: Routledge.

Kumaraswamy, P.R. 2004. Security beyond survival. New Delhi: Sage.

Lal, Vinay. 2002. MANAS Website - Department of History, UCLA. www.sscnet.ucla.edu/southasia/History/Independent/partition.html.

Lang, A. 1887. 'Myth, ritual, \& religion’ xv.II.94 in: Oxford English Dictionary, $2^{\text {nd }}$ Edition. CD Rom Version.

Larson, J.P. 2004. Understanding religious violence: thinking outside the box of terrorism. London: Ashgate.

Lawler, S. 2002. 'Narrative in social research' in: May, T. Qualitative research in action. pp.242-258. London: Sage.

Leopold, A.M. \& Jensen J.S. (eds). 2005 ( $1^{\text {st }}$ Ed. 2004). Syncretism in religion: a reader. New York: Routledge.

Lessinger, J.M. 2003. “"Religious” violence in India: Ayodhya and the Hindu Right' in: Ferguson, B. The state identity \& violence. pp.149-176. London: Routledge.

Lewellen, T.C. 2003. Political anthropology - an introduction $3^{\text {rd }}$ edition. Westport, Conn.: Praeger.

Lewis, B. 2002. 'Introduction' in: Lewis, B. (ed). The world of Islam: faith, people, culture. pp.11-24. London: Thames \& Hudson. (First Edition printed in 1976).

Lindholm, C. 1998. 'Prophets and Pirs: charismatic Islam in the Middle East and South Asia’ in: Werbner, P. \& Basu, H. Embodying charisma: modernity, locality and the performance of emotion in Sufi cults. London: Routledge.

Linz, J. 1978. The breakdown of democratic regimes: crisis, breakdown and reequilibration. London: Johns Hopkins University Press.

Loizos, P. 1993. Innovation in ethnographic film: from innocence to selfconsciousness 1955-1985. Manchester: Manchester University Press. 
Ludden, D. (ed). 2005. Making India Hindu: religion, community, and the politics of democracy in India, $2^{\text {nd }}$ Edition. New Delhi: Oxford Community Press.

MacDougall, D. 1998. Transcultural cinema. Princeton, New Jersey: Princeton University Press.

MacDougall, D. 2001. 'Renewing ethnographic film: is digital video changing the genre?’ Anthropology Today. Vol.17 (3) pp.15-21.

MacDougall, D. 2006. The corporeal image. Princeton, New Jersey: Princeton University Press.

Madan, T.N. 2003. 'Religions of India - plurality and pluralism' in: Das, V. (ed). The Oxford India Companion to sociology and anthropology. pp.775-801. New Delhi: Oxford University Press.

Malinowski, B. 1922. Argonauts of the Western Pacific. London: Routledge.

Maroney, E. 2006. Religious syncretism. London: SCM Press.

Maso, I. 2001. 'Phenomenology and ethnography' in: Atkinson, P. et al. Handbook of ethnography. pp.136-144. London: Sage.

Mason, J. 1996. Qualitative researching. London: Sage.

May, T. 1993. Social research issues, methods and process. Buckingham: Open University Press.

Meier. F. 2002. 'The mystic path' in: Lewis, B. ed. The world of Islam: faith, people, culture. pp.117-140. London: Thames \& Hudson. (First Edition printed in 1976).

Menon, P. 1998/1999. 'A Parivar project in Karnataka’. Frontline Magazine. Vol. 15. No.26. December $19^{\text {th }} 1998$ - January $1^{\text {st }} 1999$.

Metcalf, B \& Metcalf, T. 2006. A concise history of modern India $2^{\text {nd }}$ edition. Cambridge: Cambridge University Press.

Misra, A. 2004. Identity \& religion: foundations of anti-islamisation in India. New Delhi: Sage.

Moazziz Ali Beg. 2003. 'Hinduism vs the Hindutva'. Indian Journal of Secularism, Vol.7. No.1 (April-June) pp.35-46.

Momin, S. 2002. 'In the ghetto: Guajarati's live in a segregated society' in: Engineer, A.A. (ed). 2003(b). The Gujarat Carnage. New Delhi: Orient Longman.

'Moonje Papers’ 1931, microfilm, rn 1, Nehru Memorial Museum and Library (NMML). 
Monchamp, A. 2007. 'Encountering emotions in the field: an X marks the spot'. Anthropology Matters Journal. Vol. 9 (1). www.anthropologymatters.com.

Morinis, A. (ed). 1992. Sacred journeys: the anthropology of pilgrimage. Westport, Connecticut, London: Greenwood Press.

Mornin, A.R. 1996. 'Cultural pluralism, national identity and development' in: Saraswati, B. (ed). Interface of cultural identity development. Delhi: D.K. Printworld.

Morris, B. 1998. Anthropological studies of religion. Cambridge: Cambridge University Press.

Mubarak Ali Dr. (ed). 1985. McMurdo's account of Sind. Sind: Institute of Sindhology, University of Sind, Jamshoro.

Nandy, A. 2003. 'Obituary of a culture: rise of a fascist to power' in: Krishna, C. (ed). Fascism in India, faces, fangs \& facts. pp.235-241. New Delhi: Manak Publications.

Nandy, A. 2007. 'Closing the debate of secularism: a personal statement' in: Needham A. \& Rajan, R.The crisis of secularism in India. pp.107-117. Ranikhet: Permanent Black.

Nath Jha, S. 1999. 'Syncretism, Baul-Fakirs and Indian secularism'. Indian Journal of Secularism, Vol.3. No.1 Apr-June. pp. 25-39.

Needham A. \& Rajan, R. 2007. The crisis of secularism in India. Ranikhet: Permanent Black.

Nehru Speeches, Vol.1, P.42, in: Chandra, B. Mukherjee, M \& Mukherjee, A. 2000. India after Independence 1947-2000. P.79. New Delhi: Penguin.

Nicholls, B. 1985. 'The voice of documentary' in: Nicholls, B. Ed. Movies and methods volume II: an anthology. Berkley \& London: University of California Press.

Norris, P. \& Inglehart, R. 2004. Sacred and secular: religion and politics worldwide. Cambridge: Cambridge University Press.

Noorani, A.G. 2003. 'A practising Nazi trampling on India' in, Krishna, C. (ed). Fascism in India, faces, fangs \& facts. pp.278-287. New Delhi: Manak Publications.

Nussbaum, M. C. 2007. The clash within: democracy, religious violence, and India's future. Ranikhet: Permanent Black.

Oberg, K. 1960. 'Culture shock: adjustment to new cultural environments'. Practical Anthropology. Vol.7. pp.177-182. 
Okely, J. 1992. 'Anthropology \& autobiography: participatory experience and embodied knowledge' in: Okely, J, \& Callaway, H. (eds). Anthropology \& autobiography, ASA Monographs 29. pp.1-28. London: Routledge.

Oxford English Dictionary Thesaurus and Wordpower Guide. Indian Edition. 2003. New Delhi: Oxford University Press.

Pandey, B.N. 1979. The Indian nationalist movement, 1885-1947 Selected Documents. London: MacMillan Press Ltd.

Pandey, G. 2006. Routine violence: nations, fragments, histories. California: Stanford University Press.

Pandey, G. 2006. 'The secular state' in: Routine violence: nations, fragments, histories. California: Stanford University Press.

Panhwar, M.H. 1979. Cutch Sindh relations: lecture series history of Sind. Karachi: Sind Archives.

Pant, P. 2004. 'India after elections 2004'. South Asian Journal. Vol.5. July-Sept. 2004. www.southasianmedia.net/magazine/journal/after_elections_htm - accessed 04.11.06.

Parrott W.G. \& Harré R. 1996. The emotions: social, cultural and biological dimensions. London: Sage.

Patnaik, P. 1993. 'The fascism of our times'. Social Scientist, Vol.21. No.3-4. March-April. pp.69-77.

Pertierra, A.C. 2007. 'Anthropology that warms your heart: on being a bride in the field’. Anthropology Matters Journal. Vol .9 (1). www.anthropologymatters.com.

Pina-Cabral, J. 2001. 'Three points on secularism and anthropology'. $\underline{\text { Social }}$ Anthropology. Vol.9. Pt.3. pp.329-333.

Pink, S. 2001. Doing visual ethnography. London: Sage.

Pink, S. 2004. 'Introduction: situating visual research’ in: Pink, S. Kurti, L. \& Alfonso A. Working images: visual research and representation in ethnography. pp.1-12. London: Routledge.

Pink, S. 2007. Doing visual ethnography: $2^{\text {nd }}$ edition. London: Sage.

Poole, R. 1999. Nation and identity. London: Routledge.

Punch, M. 1998. 'Politics and ethics in qualitative research' in: Denzin, K \& Lincoln, Y. Eds. The landscape of qualitative research: theories and issues. London: Sage. 
Puniyani, R. 2002. 'Hindu extreme right-wing groups: ideology and consequences', in: Bonney, R. (ed). Hindu extreme right-wing groups: ideology and consequences. South Asian history academic papers 2. Leicester: University of Leicester, Centre for the History of Religious and Political Pluralism.

Puniyani, R. 2002(b). 'Fishing for votes in the rivers of blood' in: Engineer, A.A. (ed). The Gujarat carnage. New Delhi: Orient Longman.

Puniyani, R. 2003. Communal politics: facts versus myths. New Delhi: Sage.

Puniyani, R (ed). 2005. Religion, power and violence: expression of politics in contemporary times. New Delhi: Sage.

Purewal, N. 'The Indo-Pak border: displacements, aggressions and transgressions'. Contemporary South Asia. Vol. 12(4), 2003, p 439-556.

Pye. M. 1971. 'Syncretism and ambiguity' NUMEN 18: 83-93, in: Leopold, A.M. \& Jensen J.S. (eds). 2004. Syncretism in religion: a reader. pp.59-67. London: Equinox Publishing Ltd.

Qureshi, R. 1986. Sufi music of India and Pakistan: sound, context and meaning in Qawwali. Cambridge: Cambridge University Press.

Ram-Prasad, C. 1993. 'Hindutva ideology: extracting the fundamentals'. Contemporary South Asia. Vol.2 No.3 p285-309.

Ram-Prasad, C. 2003. 'Being Hindu and/or governing India’ in: Ter Haar, G. (Ed.) The freedom to do God's Will: religious fundamentalism and social change.

London: Routledge.

Randhawa, T. 1998. Kachchh: The last frontier. New Delhi: Prakash Books.

Raymond, L.M.Lee. 1982. 'Sai Baba, salvation and syncretism: Religious change in a Hindu movement in urban Malaysia'. Contributions to Indian Sociology. Vol.16 No.1 pp.125-140.

Redfield, R, Linton, R, Herskovits, M. 1936. 'Memorandum for the study of acculturation’. American Anthropologist. Vol.38. pp.149-152.

Rizvi, S.A.A. 2002. 'Muslim India, from the coming of Islam to Independence' in: Lewis, B. (ed). The world of Islam: faith, people, culture. pp.301-320. London: Thames \& Hudson. (First Edition printed in 1976).

Robinson, R. \& Parthasarathy, D. 2005. 'After Gujarat...': making sense of reports on the post-Godhra violence and its aftermath' in: Puniyani, R, (ed). Religion, power and violence: expression of politics in contemporary times. pp.306-318. New Delhi: Sage.

Roy, Arundhati. 2003. ‘Gujarat, fascism and democracy’ in: Krishna, C. (ed). Fascism in India, faces, fangs \& facts. pp.30-44. New Delhi: Manak Publications. 
Ruby, J. 2000. Picturing culture: exploration of film \& anthropology. University of Chicago: Chicago Press.

Rushbrook Williams, L.F. 1999 (first published in 1958). The black hills: Kutch in history and legend. Printers - Ahmedabad: Sahitya Mudranalaya PVT. Ltd. First Published - London: Weidenfeld \& Nicholson.

Saheb, S.A.A. 1998. 'A festival of flags: Hindu Muslim devotion and the sacralising of localism at the shrine of Nagore-e-Sharif in Tamil Nadu' in: Werbner, P. \& Basu, H. Embodying Charisma: Modernity, Locality and the Performance of Emotion in Sufi Cults. London: Routledge.

Saheb, S.A.A. 2003. 'Sufism in South India: A study of the shrine of Nagore-eSharif in Tamil Nadu' in: Das N.K (ed). Culture, religion and philosophy: critical studies in syncretic and inter-faith harmony. pp.262-276. New Delhi: Rawat.

Saiyed, A.R. 2004. 'Saints and Dargahs in the Indian Subcontinent: a review' in: Troll, C.W. (ed). (1 ${ }^{\text {st }}$ Ed. 1989). Muslim shrines in India. New Delhi: Oxford University Press.

Sanger, J. 1996. The compleat observer? A field research guide to observation. London \& Washington D.C: Falmer Press.

Sanjek, R. 1993. 'Anthropology's Hidden Colonialism: Assistants and Their Ethnographers’. Anthropology Today. Vol. 9. No. 2 (Apr. 1993). pp.13-18.

Sarkar, J. 1998 Edition. India through the ages. Calcutta: Disha Books.

Schaeffer, J. 1995. 'Videotape: new techniques of observation and analysis in anthropology' in: Hockings, P. Ed. Principles of visual anthropology. pp.255-284. Berlin: Mouton de Gruyter.

Seal, Anil. 1971 ( $1^{\text {st }}$ Ed 1968). The emergence of Indian nationalism: competition and collaboration in the later nineteenth century. Cambridge: Cambridge University Press.

Seale, C. (ed). 1998. Researching society and culture. London: Sage.

Selvam. 2003. 'Historic rally against Hindu fascists in Chikmagalur'. Peoples March - voice of the Indian revolution. Vol.4. No.3. March 2003.

Selwyn, T. 2006. 'Rachel's Tears and the Walls of Bethlehem'. Paper given at the EASA Biennial Conference Sept. 2006.

Sen, A. 1993. 'The threats to secular India'. Social Scientist. Vol. 21 No.3-4 pp.522. 
Sen, A. 1997. 'On interpreting India's past', in: Bose, S. \& Jalal, A. (eds). 1997. Nationalism, democracy and development: state and politics in India. Oxford: Oxford University Press.

Setalva, T. 2003. 'After the Gujarat pogrom'. South Asian Journal. Vol.2. Oct-Dec 2003.

Seymour-Smith, C. 1986. Macmillan Dictionary of Anthropology. London: Macmillan.

Shreedhara, V.S. \& Lankesh, G. 2004. 'Battle over Baba'. Combat, No. 95. Jan 2004. Year 10 on, www.sabrang.com//cc/archive/2004/jan04/bbarrier.html

Sikand, Y. 1999. 'Baba Budhan Dargah controversy: ominous portents'. Islamic Voice. Vol.13-01. No.145. www.islamicvoice.com - accessed 01/02/08

Sikand, Y. 2002. 'The changing nature of shared Hindu-Muslim shrines in contemporary Karnataka, South India'. South Asia: Journal of South Asian Studies. Vol. XXV, No.1 pp.49-67.

Sikand, Y. 2003. Sacred Spaces: Exploring traditions of shared faith in India. New Delhi: Penguin.

Sikand, Y. 2003a. 'The Baba Budhan Dada Hayat Qalandar Dargah controversy: The Ayodhya of South India?’. http://nuke.humanrightskerala.com - Accessed 28/07/07.

Sikand, Y. 2006. 'The other side of Pakistani Islam'. www.islaminterfaith.org accessed 25/01/2006.

Sila Khan, D \& Moir, Z. 1999. 'Coexistence and communalism: the shrine of Pirana in Gujarat’. South Asia, Vol. XXII, Special Issue. pp.133-154.

Sila Khan, D. 2003 ( $1^{\text {st }}$ Ed. 1997). Conversations and Shifting Identities: Ramdev Pir and the Ismailis in Rajasthan. Delhi: Manohar.

Sila Khan. D. 2003b. Muslim Saints and Hindu rulers: the development of Sufi and Ismaili mysticism in the Non-Muslim states of India. London: Institute of Ismaili Studies.

Simpson, E. 2004. “"Hindutva” as a rural planning paradigm in post-earthquake Gujarat', in: Zavos, J. Wyatt, A. \& Hewitt, V. (eds). The politics of cultural mobilization in India. pp.136-165. Oxford: Oxford University Press.

Simpson, E. 2005. 'The Gujarat earthquake and the political economy of nostalgia'. Contributions to Indian Sociology. Vol.39 (2). pp.219-247. New Delhi \& London: Sage.

Simpson, E. \& Corbridge S. 2006. 'The geography of things that may become memories: the 2001 earthquake in Kachchh- Gujarat and the politics of rehabilitation 
in the pre-memorial era'. Annals of the Association of American Geographers. Vol.96 (3). pp.566-585. Oxford: Blackwell Publishing.

Simpson, E. 2006b. 'The state of Gujarat and the men without souls'. Critique of Anthropology. Vol. 26(3). pp.313-330. New Delhi \& London: Sage.

Singh, A, I. 1987. The origins of the Partition of India 1936-1947. Oxford: Oxford University Press.

Skeggs, B. 2001. 'Feminist ethnography' in: Atkinson, P. et al. Handbook of ethnography. pp.426-442. London: Sage.

Smith, L. 1990. 'Ethics, field studies, and the paradigm crisis' in: Guba, E. Ed. The paradigm dialogue. London: Sage.

Souhardgiri. 2002. 'Conference for communal amity in Baba Budhan Giri'. http://india.indymedia.org/en/2002/12/24999.shtml - accessed 19/01/08.

Spear, P. 1998 Edition. A history of India: volume two. New Delhi: Penguin.

Spodek, H. 2004. 'What has happened to the rule of law? Gujarat state 2002' in: Bonney, R. (ed). After Hindutva: towards the recovery of the Indian polity? Institute for the study of Indo-Pakistan relations (INPAREL), Conference proceedings 4. Leicester: University of Leicester, Centre for the History of Religious and Political Pluralism.

Stewart C \& Shaw, R. (Eds.) 1994. Syncretism/anti-syncretism: the politics of religious synthesis. London: Routledge.

Stern, R.W. 1993. Changing India: bourgeois revolution on the Subcontinent. Cambridge: Cambridge University Press.

Tambiah, S. 1996. Levelling crowds: ethnonationalist conflicts \& collective violence in South Asia. London: University of California Press.

Taneja, N. 2006. 'A Saffron assault abroad'. Frontline Magazine. Vol. 23 (1) January 14-27. pp.77.

Tehelka. 2007. 'India writes back’. Vol.4. Issues 44. November 2007. New Delhi: A Tarun Tejpal Publication.

Tejpal, T.J. 2007. 'Read and be afraid' in: Tehelka, 'The Truth - Gujarat 2002'. Vol.4. Issue 43. November 2007. New Delhi: A Tarun Tejpal Publication.

Teskes, R \& Nelson, B. 1974. 'Acculturation and assimilation: a clarification’. American Ethnologist. Vol.1, No.2 . pp.351-367.

Thursby, G.R. 1975. Hindu-Muslim relations in British India. E.J.Brill: Leiden, Netherlands. 
Tonkin, E. 1984. 'Participant observation' in: R.F.Ellen (ed). Ethnographic research: A guide to general conduct. London: Academic Press.

Tremblay, M. 1984. 'The key informant technique: a non-ethnographic application' in: Burgess, R. (ed). Field research: a sourcebook and field manual. pp.151-162. London: Routledge.

Troll, C.W. (ed). 2004 (1 ${ }^{\text {st }}$ Ed. 1989). Muslim shrines in India. New Delhi: Oxford University Press.

Turner, V. \& Turner, E. 1978. Image and pilgrimage in Christian culture. New York: Columbia University Press.

Vanaik, A. 1994. 'Situating threat Hindu nationalism', in Economic Weekly and Political Weekly', 9 July 1994, 1729-1948. Quoted in Puniyani, R. 2002. 'Hindu extreme right-wing groups: ideology and consequences’ in: Bonney, R. (ed). 2002. Hindu extreme right-wing groups: ideology and consequences. South Asian history academic papers 2. Leicester: University of Leicester, Centre for the History of Religious and Political Pluralism.

Van der Veer, P. 1987. ““God must be liberated!”: A Hindu liberation movement in Ayodhya'. Modern Asian Studies. Vol21. No.2. pp.283-301.

Van der Veer, P. 1994. Religious nationalism: Hindus and Muslims in India. Berkley: University of California Press.

Van der Veer, P. 1994b. 'Syncretism, multiculturalism and the discourse of tolerance' in: Stewart C. \& Shaw, R. (eds). Syncretism/anti-syncretism: the politics of religious synthesis. pp.196-211. London: Routledge.

Van der Veer, P. 1996. 'Riots and rituals: the construction of violence and public space in Hindu nationalism’ in: Brass, P. (ed.) Riots and pogroms. London: Macmillan Press Ltd.

Van der Veer, P. 1999. 'Hindus: A superior race'. Nations and Nationalism. Vol. 5 (3)1999 pp.419-430.

Van der Veer, P. 2005. 'Writing violence' in: Ludden, D. (ed). Making India Hindu: religion, community, and the politics of democracy in India, $2^{\text {nd }}$ edition. pp.250-269. New Delhi: Oxford Community Press.

Warren, M. 2004. Unravelling the enigma: Shridi Sai Baba in the light of Sufism. New Delhi: Sterling.

Watson, C. (ed). 1999. Being there: fieldwork in anthropology. London: Pluto Press.

Wax, R.H. 1971. Doing fieldwork: warnings and advice. Chicago: University of Chicago Press. 
Webb, B. 1994. 'The art of note-taking' in: Burgess, R. (ed). Field research: a sourcebook and field manual. pp.298-304. London: Routledge.

Werbner, P. \& Basu, H. 1998. Embodying charisma: modernity, locality and the performance of emotion in Sufi cults. London: Routledge.

Whyte, W. F. 1994. 'Interviewing in field research' in: Burgess, R. (ed). Field research: a sourcebook and field manual. pp.170-188. London: Routledge.

Wolcott. 1995. The art of fieldwork. London: Sage.

Wolff, K.H. 1944. 'A critique of Bateson's Naven' in: Journal of the Royal Anthropological Institute. Vol.74. No.1/2. pp.59-74.

Wolpert, S. 2004. A new history of India: seventh edition. Oxford: Oxford University Press.

Woodthorpe, K. 2007. 'My life after death: connecting the field, the findings and the feelings'. Anthropology Matters Journal. Vol. 9 (1).

www.anthropologymatters.com.

www.wikipedia.com. 2006. The free encyclopaedia.

www.expressindia.com/latest-news/Threeday-Rannotsav. Article called: Three-day Rannotsav to kick off on February 20, by D V Maheshwari. Posted online: Friday January 11, 2008 at 01:20:34. accessed 17-01-08

Yogananda, P. 1995 (first copyright 1946, $2^{\text {nd }}$ ed. 1975). Autobiography of a Yogi. Bombay: Jaico Publishing House.

Young, K. 1993. 'The Indian secular state under Hindu attack: a new perspective on the crisis of legitimation' in: Smart, N. \& Thakur, S. (eds). Ethical \& political dilemmas of modern India. New York: St Martin’s Press.

Zavos, J. Wyatt, A. \& Hewitt, V. (eds). 2004. The politics of cultural mobilization in India. Oxford: Oxford University Press.

\section{Other websites referenced in text:}

www.expressindia.com - accessed 12/07.

www.kalodungar.com - accessed 03/08.

http://www.s-a-i.info/assoc_change/poornima_10.html - accessed 01/08

http://www.astrojyoti.com/DattatreyaJayanti.htm - accessed 10/07

http://www.dattapeetham.com/india/datta/DattaLarg.html - accessed 01/08

http://www.avatara.org/dattatreya/story.html - accessed 10/07

http://www.ShreeSwami.org - accessed 10/07

http://en.wikipedia.org/wiki/Dattatreya - accessed 10/07 